\title{
TOXICOMANIA: UMA TENTATIVA DE RETORNO AO PRAZER PRIMÁRIO
}

\author{
Wesley Rossi ${ }^{1}$
}

\section{INTRODUÇÃO}

\subsection{Apresentação do tema}

O presente projeto de pesquisa tem por motivação essencial, um convite à reflexão na problemática que diz respeito a toxicomania. Através dessa modesta contribuição busca-se identificar os fenômenos existenciais, psicológicos e sociais em indivíduos que estão sob acompanhamento na instituição de atenção psicossocial, de modo a verificar os efeitos nocivos que a dependência química expressa na interação indivíduo/sociedade. Deste modo o levantamento dos dados objetivará o entendimento holístico e integral das problemáticas que englobam os fatores sociais e psicodinâmicos deste grupo de indivíduos.

\subsection{Justificativa}

O presente projeto de pesquisa tem por motivação identificar os fenômenos existenciais, psicológicos e sociais em indivíduos que estão sob acompanhamento na instituição, de modo a verificar os efeitos nocivos que a dependência química expressa na interação indivíduo/sociedade.

Desviar nosso olhar para o sujeito e não para o objeto droga, nos possibilitará esclarecer os elementos que circundam à história no sentido singular que a droga tem para este sujeito. Esta troca de papéis nos auxiliará posteriormente a construir e mapear diretrizes norteadoras que auxiliarão desde o processo de recuperação e reinserção deste sujeito na sociedade, até o processo de redução de danos, nesse sentido busca-se identificar possíveis ações que minimizem o sofrimento no uso, pois o caráter de uma escolha pressupõe a uma "jurisdição própria”, onde o exercício da escolha, também se torna um exercício da autonomia, pois esta escolha pertencerá exclusivamente ao sujeito, e uma decisão incumbirá a esse indivíduo

\footnotetext{
${ }^{1}$ Psicologia, Universidade do Contestado - UnC, Campus Concórdia.
} 
inúmeras repercussões não só em seus processos subjetivos, mas também, em toda sua rede relacional.

\section{OBJETIVOS DO ESTÁGIO}

\subsection{Objetivo geral}

- Oportunizar ao acadêmico de psicologia a vivência prática acerca da atuação profissional no CAPS (Centro de Atenção Psicossocial);

\subsection{Objetivos específicos}

- Estabelecer relação entre o Estágio Básico IV e as demais disciplinas do curso que permitam a análise e interpretação dos fenômenos observados;

- Oportunizar aos alunos a inserção na comunidade permitindo-o vivenciarem o fenômeno da observação de locais e pessoas que fazem parte da rede de atenção psicossocial;

- Promover junto aos alunos uma reflexão crítica acerca do trabalho desenvolvido pelo psicólogo e sua escolha profissional;

- Desenvolver raciocínio, interpretação de texto, habilidade de escrita, senso crítico e habilidade de síntese;

\section{REFERENCIAL TEÓRICO}

\subsection{O abuso de substâncias: Uma breve historização}

$\mathrm{Na}$ atual cena contemporânea, somos testemunhas da grande visibilidade que vem sendo alcançada pelo fenômeno do uso de drogas, apesar da problemática atual, é de compreensão pública que a utilização de substâncias químicas consiste em uma prática milenar, praticada por diversos povos e culturas, em diferentes momentos e contextos históricos. Neste movimento do desenvolvimento da história, o homem sempre reservou um lugar determinado para o uso das drogas, ainda que para funções muito específicas, desse modo, vemos que ela acompanhou a trajetória do homem por todos esses anos, porém o fato é que, em decorrência da dependência, surgem diversas consequências destrutivas, das quais, médicos, educadores, assistentes sociais e psicólogos são quase que diariamente convocados pela mídia para tratar desta temática que 
se desmembra em diversos campos, sendo considerado tanto um problema de saúde mental como também de segurança pública.

A Organização Mundial de Saúde (OMS), considera o uso abusivo de drogas como uma doença crônica e recorrente. Nesse sentido o uso de drogas torna-se um problema de saúde pública, que transpassa barreiras sociais, emocionais e políticas, preocupando a sociedade como um todo (ANDRETTA; OLIVEIRA, 2011).

Segundo a Classificação Internacional de Doenças (CID-10), a dependência química caracteriza-se pela presença de um agrupamento de sintomas cognitivos, comportamentais e fisiológicos, indicando que o indivíduo continua utilizando uma substância, apesar de problemas significativos relacionados a ela.

A partir dos dados do Centro Brasileiro de Informações sobre Drogas Psicotrópicas (Cebrid, 2010) muitos são os fatores que podem motivar o uso de drogas, como: a busca de prazer, amenizar a ansiedade, tensão, medos e até aliviar dores físicas, e é a partir deste sentido que o uso das drogas se torna uma problemática biopsicossocial.

Ao que diz respeito aos processos de tratamento dos toxicômanos, verifica-se que ao longo do desenvolvimento da história, esses usuários sempre foram tratados a partir de uma política segregadora e excludente nas instituições psiquiátricas especializadas em saúde mental, sendo que a principal meta era alcançar a abstinência. A partir da Reforma Psiquiátrica no Brasil, o Ministério da Saúde (1992), através da portaria n²24/1992 passou-se a iniciar um movimento econômico, no sentido de financiar e normatizar os serviços de saúde mental, priorizando o tratamento ambulatorial de caráter multidisciplinar, a partir dessa mudança estrutural nos serviços direcionados a este público, passou-se a regulamentar as diretrizes e normas dando subsídio para a implementação de Núcleos/Centros de Atenção Psicossocial (NAPS/CAPS). Após esse movimento estrutural, o CAPS foi redefinido, tendo também o caráter de serviço de atenção para atendimento de usuários e pacientes com transtorno decorrentes do uso de dependência substâncias químicas

\subsection{A alternância de papéis: $O$ foco no sujeito}

O processo da toxicomania se caracteriza por sua relação estrita e exclusiva do sujeito com a droga, do ponto de vista econômico a droga materializa uma espécie de encurtamento de caminho até o prazer. Este processo podemos exemplificar de uma forma análoga a um "atalho", que levará o sujeito a um mesmo destino, porém de uma forma mais rápida. A toxicomania se instala definitivamente quando ganha uma certa autonomia na função psíquica, levando a um RCMOS - Revista Científica Multidisciplinar O Saber. ISSN: 2675-9128. São Paulo, v. 08, p. 01-28, ago. 2021. 
investimento libidinal muito particular, o que por sua vez não acontece com o usuário de uso esporádico da substância.

Segundo Serretti (2012) o importante na toxicomania é a posição que o sujeito se coloca diante da substância, desse modo é lícito verificarmos qual é a posição do sujeito para com a droga, e qual é a posição da droga para o sujeito? São indagações como essas, que nos levam a explorar o campo de fixação da pulsão em um objeto, essa fixação nos conduz a um destino que acaba pervertendo o caráter contingencial da pulsão e auxilia como fator fundamental na toxicomania (SERRETTI, 2012).

A partir disso, devemos investigar quais são os fatores pré-determinantes que caracterizam o abuso de substâncias, pois as toxicomanias não podem ser explicadas somente pela substância ou objeto ao qual se busca satisfação (isso tornaria a explicação vaga e reducionista), mas sim, por qual operação inconsciente que determina a compulsão à repetição que caracteriza a adicção propriamente dita.

Nesse sentido os campos do saber precisam ser convocados a visualizar o eixo do problema a partir de uma ótica do sujeito e não para o objeto. É digno de nota a contribuição de Freud, que pouco escreveu sobre toxicomania, mas que trouxe grandes contribuições para o entendimento da forma de como o homem busca amenizar e fugir de sua angústia através de recursos cabíveis a ele. No texto $O$ mal-estar na civilização (1930) Freud teoriza sobre a intoxicação como uma das formas mais eficazes em tamponar a dor existencial sentida, o autor discorre:

\footnotetext{
"Tal como nos foi imposta, a vida resulta em demasia pesada, nos fazendo depararnos com sofrimentos, decepções, empreendimentos impossíveis. Para poder suportála, não podemos prescindir de paliativos. Existem três tipos: os entretenimentos intensos, que fazem a nossa miséria parecer menor; as satisfações substitutivas, que a reduzem; e os narcóticos, que nos tornam insensíveis a ela. Qualquer um desses remédios acaba sendo indispensável.” (FREUD, 1930, p.83)
}

A angústia e todas as formações sintomáticas desaparecem quando a estruturação toxicomaníaca exerce suas funções (SERRETTI, 2012). A intoxicação além de ser uma ferramenta efetiva para a retirada de elementos causadores de desconforto, ela também exerce uma função no campo dos afetos para aquele que a utiliza, a droga nesse sentido se estrutura sob uma condição narcísica ao sujeito.

\subsection{Narcisismo primário e autoerotismo: Uma posição de onipotência}

Partindo da teorização da segunda tópica de Freud (1923), no início da vida, o aparelho psíquico operava a partir do princípio do prazer, sem significativas interrupções. O bebê tornaRCMOS - Revista Científica Multidisciplinar O Saber. ISSN: 2675-9128. São Paulo, v. 08, p. 01-28, ago. 2021. 
se o centro das atenções, todos o agradam, fazem-no sorrir, procurando satisfazer todos seus desejos, cuidando-o e alimentando-o. Semelhante aos efeitos da intoxicação, os desejos do bebê são satisfeitos de uma maneira alucinatória, diretamente, sem obstáculos, não havendo nada para interpor-se entre desejo e a satisfação, segundo Gurfinkel (1996) o efeito desencadeado pela intoxicação, promove ao sujeito uma regressão às fases anteriores de seu desenvolvimento libidinal.

É a partir da satisfação absoluta do bebê que Freud (1915) descreve o início do psiquismo como uma fase de narcisismo primário, este processo se potencializa sobre o movimento do bebê em sugar o leite morno e adocicado do seio da mãe, ao mesmo tempo que o bebê se alimenta, ele também sente a excitação que o contato da zona erógena da boca exerce sobre o bico do seio. Este prazer primário permanece fixado e inscrito em nosso psiquismo, ele é o protótipo do sentimento de prazer.

\begin{abstract}
"Se um bebê pudesse falar, ele indubitavelmente afirmaria que o ato de sugar o seio materno é de longe o mais importante de sua vida. E nisso o bebê não se engana muito, pois nesse único ato está satisfazendo de uma só vez as duas grandes necessidades vitais. Por isso, não nos surpreendemos ao saber, por meio da psicanálise, quanta importância psíquica conserva esse ato durante toda a vida. Sugar o seio materno é o ponto de partida de toda a vida sexual, o protótipo inigualável de toda satisfação sexual ulterior, ao qual a fantasia retorna muitíssimas vezes, em épocas de necessidade. Esse sugar importa em fazer do seio materno o primeiro objeto do instinto sexual. Não posso dar-lhes uma ideia da importante relação entre esse primeiro objeto e a escolha de todos os objetos subsequentes, dos profundos efeitos que ele tem em suas transformações e substituições, até mesmo nas mais remotas regiões da nossa vida sexual." (FREUD, 1915, p.367.)
\end{abstract}

É lícito supormos a possível existência de uma organização narcisista que origina a toxicomania, o efeito desencadeado pelos agentes intoxicantes conduzem o indivíduo a uma regressão às fases anteriores de seu desenvolvimento (GURFINKEL, 1996), desse modo o sujeito para a ser regido pelo princípio do prazer. A busca por esse prazer primário, que foi inscrito no psiquismo nos primeiros anos de vida, é expressa na utilização da droga, nesse sentido, a toxicomania se expressa como uma tentativa de retorno ao prazer primário, neste movimento, o sujeito é convocado a retornar à posição que ocupava quando estava na fase do narcisismo primário. A posição simbiótica com a mãe proporcionou a este indivíduo o primeiro contato de prazer, e essa primeira experiência manteve-se registrada em seu psiquismo. A respeito da excitação oral, Freud (1905) nos alerta sobre a importância que essa fase desempenha na vida adulta:

"Nem todas as crianças praticam esse chuchar. É de se supor que cheguem a fazê-lo aquelas em quem a significação erógena da zona labial for constitucionalmente reforçada. Persistindo essa significação, tais crianças, uma vez adultas, serão ávidas apreciadoras do beijo, tenderão a beijos perversos ou, 
se forem homens, terão um poderoso motivo para beber e fumar." (FREUD, 1905, p. 171)

A tentativa de retorno a esse estado narcísico, vivenciado nos primeiros momentos de vida, torna-se a meta daquele que busca dopar-se, pois a partir disso o sujeito procura reconquistar a onipotência narcísica, não precisando assim, lidar com os limites e interrupções que a realidade externa os impõe (TOMÁS, 2008).

O uso de droga nesse sentido trata-se de uma tentativa de alteração da realidade, mas não a excluindo completamente, pois ao mesmo tempo em que ele a rechaça, ele a recria em sua fantasia. Diferentemente do psicótico, o toxicômano mantém, em geral um vínculo aparente com a realidade, segundo Serretti (2012) ver de outra maneira, não significa o repúdio radical da realidade, como é feito na psicose. A incapacidade de adaptação se caracteriza na toxicomania e na neurose, para Freud (1924) "a neurose não repudia a realidade, apenas a ignora; a psicose a repudia e tenta substitui-la".

Desse modo o funcionamento do toxicômano se aproxima muito mais ao funcionamento psíquico do neurótico, pois ambos manifestam tentativas de fuga da realidade externa, mas um elemento que caracteriza essencialmente esse funcionamento é a tentativa de mudança interna de uma realidade psíquica intolerável desse sujeito, mas o que diferencia essencialmente o toxicômano do neurótico, é que na medida em que o neurótico utiliza a fantasia para alterar sua realidade psíquica, o toxicômano utiliza-se de ferramentas materiais como forma de alteração na química de seu corpo.

É digno de nota ressaltarmos que o autoerotismo, fase que caracteriza a transição do narcisismo primário, torna-se o protótipo da toxicomania, pois diferente do sujeito que conquista sua autonomia e independência no mundo externo através de atividades saudáveis, o toxicômano busca realizar essa independência auto eroticamente através da intoxicação, para clarificarmos essa ideia, deve-se entender a toxicomania como uma atividade sexual não no sentido de ato sexual, mas sim do autoerotismo de uma posição narcisista da libido, pois o que o toxicômano busca é justamente não ter que fazer conciliações entre as instâncias psíquicas, pois ao negar à existência de conflitos psíquicos, ele busca um tratamento pelo corpo, um prazer sem palavras, que só encontrará na droga (SERRETTI, 2012). 


\subsection{A clínica da toxicomania: Perspectivas transferências}

O estereótipo clínico que foi construído no campo de atuação da toxicomania, anula em certa medida, o poder de ação da transferência, desse modo, é importante questionar-se em como se pensar as perspectivas transferências na clínica da toxicomania? Lacan (1960), em seu seminário sobre a transferência, reforça a dinâmica transferencial: "Sempre chamei a atenção de vocês que se deve partir do fato de que a transferência, em última instância, é o automatismo da repetição." (LACAN, 1960, p. 173).

É por meio da transferência que se dá o contato com o funcionamento psíquico do paciente, a psicodinâmica do paciente toxicômano é caracterizada pela repetição, a priori ocorre no toxicômano uma operacionalização de vida repetitiva. Autores como Conte (1997) e Waks (1997) teorizam sobre uma tendência presente no estabelecimento transferencial: a iniciação de vínculo baseada na disputa do lugar subjetivo que é ocupado pela droga. Segundo Da Silva (2010) esse tipo de disputa de vínculo será essencial somente nas primeiras fases do tratamento, pois permanecer nessa relação díade, poderá ser prejudicial ao desenvolvimento do tratamento.

A entrada de um terceiro na relação simbiótica do sujeito com a droga não é uma tarefa fácil, Conte (1997) ressalta que o processo de entrada de um terceiro na relação dual do toxicômano com a droga é complexo que se estabelece vagarosamente, Waks (1997) surge com uma forte contribuição para o entendimento transferência:

\footnotetext{
No começo do vínculo transferencial surge, no paciente, uma espécie de rivalidade interna entre a droga-em-si, a droga-do-analista e o analista-droga. À medida que a transferência ganha potência, a droga-do-analista constitui-se, progressivamente, em analista-droga, gradualmente ocupando o lugar da droga-em-si. O vínculo com o produto perde sua intensidade libidinal, abrindo caminho para o investimento erógeno no vínculo transferencial. (WAKS, 1997, p. 59).
}

Nesse sentido, o investimento erógeno se direciona no sentido de estabelecer um caminho de vínculo que não seja a rivalidade com a droga, mas sim, um caminho que possibilita o estabelecimento do que chamamos de relação transferencial (DA SILVA, 2010).

\footnotetext{
Mesmo que, inicialmente, o toxicômano não consiga questionar sua subjetividade e demanda ao analista o restabelecimento de um saber-fazer sobre o bom uso da droga (gozo de uma parte do corpo desertada pelo registro simbólico), aos poucos poderá acreditar que o analista tenha algo a dizer sobre seu sofrimento / falência, e passará a supor-lhe um saber, criando assim as condições necessárias para o estabelecimento da transferência. (CONTE, 1997, p. 37)"
}

A idealização que promove a suposição de que o analista/terapeuta sabe algo sobre seu sofrimento, é o que levaria o paciente toxicômano a estabelecer um vínculo transferencial, nesse sentido entende-se que é essa idealização presente que leva a este processo de vinculação, podeRCMOS - Revista Científica Multidisciplinar O Saber. ISSN: 2675-9128. São Paulo, v. 08, p. 01-28, ago. 2021. 
se pensar então, que essa suposição do saber do paciente para com o analista é um dos últimos recursos capazes de levar o paciente ao questionamento sobre seu próprio desejo (DA SILVA, 2010).

\title{
3.5 A dinâmica psicoterápica grupal: Dificuldades e ganhos.
}

\begin{abstract}
A terapia de grupo não apenas se baseia nos efeitos gerais das expectativas positivas sobre a melhora, como também se beneficia como uma fonte de esperança que é única do formato de grupo. Os grupos de terapia invariavelmente contêm indivíduos que estão em pontos diferentes ao longo de um continuum de enfrentamento e colapso. Assim, cada membro tem um contato considerável com outros - muitas vezes indivíduos com problemas semelhantes - que melhoraram como resultado da terapia. (FREUD, 1920, p.78)
\end{abstract}

A Psicoterapia de grupo nunca deve caracterizar-se por uma política julgadora, punitiva e nem mesmo paternalista, essa ferramenta terapêutica é uma intervenção profissional, onde um dos elementos fundamentais do desenvolvimento deste processo, é a escuta objetiva e analítica, embora muitas vezes os usuários no início da formação de grupos se remetem à terapia grupal como uma "roda de conversa", isso é compreensível, pois alguns usuários nunca enfrentaram um processo terapêutico, e pode confundir-se no início. Após a construção do vínculo, há uma atmosfera de confiabilidade, respeito e sigilo por tudo que é preparado e passado no processo terapêutico e na dinâmica clínica (BECHELLI, 2004).

A técnica grupal serve essencialmente como ferramenta de identificação, pois na medida em que o participante ouve histórias de vida que se assemelham à sua, dá-se a oportunidade de sentir-se importante e valorizado, pois o outro também irá ouvir a sua história, segundo Freud (1921):

[...] a psicologia de grupo interessa-se assim pelo indivíduo como membro de uma raça, de uma nação, de uma casta, de uma profissão, de uma instituição ou como parte de uma multidão de pessoas que se organizaram em grupo, numa ocasião determinada, para um intuito definido (FREUD, 1921, p. 92).

O processo grupal caracteriza-se fundamentalmente sobre a perspectiva não só da remissão do sintoma causado pela dependência, mas do processo que se desmembra também na viabilidade de proporcionar aos participantes o alívio de memórias dolorosas, experiências vivenciadas em decorrência da dependência, além disso outro fator importante é que o grupo não se limita somente pela pauta da dor, mas sim de uma pauta de esperança, onde manifestase o sorriso, graça, boas memórias e perspectivas futuras, pois esses fenômenos psíquicos 
ajudam o usuário a enfrentar o dia a dia no processo de convivência consigo mesmo e com os outros (DANTAS, 2018).

Partindo deste pressuposto, levantamos a temática da dificuldade da adesão desses pacientes no processo de tratamento, pois nesse sentido a adesão ao tratamento torna-se uma das virtudes motivacionais mais fundamentais que corroboram para o sucesso do tratamento. A Organização Mundial de Saúde (OMS) define a adesão como: “[...] o grau em que o comportamento de uma pessoa - tomar o medicamento, seguir um regime alimentar elou executar mudanças no estilo de vida - corresponde às recomendações acordadas com um prestador de cuidados de saúde. Existe um consenso universal e literário sobre o baixo índice de adesão pelos dependentes químicos, sendo que muitos iniciam o tratamento, mas poucos o mantêm, este fato é compreensível na medida em que entendemos a dependência como uma doença crônica e multicausal, pois o usuário que está em processo de recuperação enfrenta diversos obstáculos como, recaída, lapsos, ciclo de amizades, onde poucos conseguem manterse abstêmios durante o tratamento.

Em uma pesquisa desenvolvida no CAPS AD do estado do Piauí, realizada com 227 dependentes químicos em tratamento, explicitou que $56,8 \%(n=129)$ abandonaram o tratamento (MONTEIRO, 2011). Nesse sentido o problema da adesão ao tratamento reflete em uma esfera que caracteriza não só um fator motivacional, mas também um fator de saúde pública, é com esse intuito que essa temática será concatenada às análises observadas na instituição acompanhada.

\subsection{Políticas Públicas: O construto inacabado}

Um grande paradigma na construção de políticas públicas e diretrizes de tratamento para dependência química, é a organização e sistematização de processos de tratamento para este público, visto que é uma tarefa extremamente complexa que envolve diversas variáveis de cunho político, financeiro e profissional. Segundo Diehl (2018) é possível perceber que grande parte dos programas de tratamento para a dependência de substâncias químicas se constrói sob uma organização empírica, a partir do empenho e da experiência pessoal de seus profissionais, havendo assim, uma grande lacuna entre o que é eficaz e comprovado por pesquisas e o que se faz de fato na prática clínica.

Ainda segundo a autora, nas últimas décadas houve um aumento de interesse por parte de pesquisadores pela forma como o contexto organizacional dos serviços para dependentes RCMOS - Revista Científica Multidisciplinar O Saber. ISSN: 2675-9128. São Paulo, v. 08, p. 01-28, ago. 2021. 
químicos é planejado, viabilizado e executado, tanto em setores públicos quanto privados. $\mathrm{O}$ interesse que sustenta essa ideia se baseia fundamentalmente na necessidade de estabelecer métodos de tratamentos mais efetivos para dependentes químicos, já que fenômeno tem se tornado um problema de saúde pública (DIEHL, 2018).

O planejamento geral é uma etapa fundamental para a organização de um serviço efetivo para os usuários, sendo necessário considerar questões como: quais são os principais objetivos? Qual é o público-alvo que o serviço pretende alcançar? Qual é a viabilidade de aplicação? Quais são os custos envolvidos com a atividade, equipe? Após a triagem dos questionamentos internos, vem-se a seleção e organização da equipe. O trabalho com dependentes químicos exige do profissional uma série de critérios que vão além da capacidade técnica, assim sendo, o profissional deverá oferecer o serviço de acolhimento, de estar aberto, tolerar frustrações, nesse sentido uma boa seleção de profissionais torna-se essencial pois eles que estarão na linha de frente das implementações futuras (DIEHL, 2018).

É digno de nota ressaltarmos a importância que de tempos em tempos todo o serviço possa ser monitorado pelo seu desempenho, efetividade e qualidade. Faz-se necessário nesse sentido que todo serviço público de aplicação social tenha minimamente um serviço de banco de dados com um perfil geral de seus pacientes e protocolos diversos de estruturação das atividades desenvolvidas. Esse monitoramento serve como um marco norteador para avaliação dos impactos do tratamento, custos, necessidades, qualidade de vida e satisfação com o serviço oferecido, além disso, torna-se essencial que a reavaliação da estratégia principalmente quando o serviço é implantado como uma política de saúde pública (municipal, estadual ou federal), seja feita incisivamente, segundo Diehl (2018) hoje no Brasil o exemplo mais precoce que essa idealização de reavaliação poderia ser representada, é a da política pública assistencial, diretamente no CAPS (Centro de Atenção Psicossocial).

O CAPS hoje é um dos principais serviços de atendimento a pessoas com transtornos mentais graves, incluindo usuários dependentes químicos de álcool e drogas, integrando a Política Pública de Saúde Mental desde 2002. Durante todo o tempo de funcionamento há raras informações a respeito de reavaliação crítica e metodológica do modelo escolhido de tratamento e assistencialização do CAPS. Segundo a vistoria realizada pela CREMESP (2010), 230 CAPs do Estado de São Paulo foram avaliados, segue os resultados que apontam falhas no atendimento:

- 42\% não contam com retaguarda para internação psiquiátrica;

• 66,7\% não disponibilizam atendimento médico clínico; 
- 69,4\% fizeram referência a falta de profissionais;

- 45,2\% não realizam capacitação das equipes de profissionais da saúde;

• 64,3\% não fazem supervisão técnica entre os membros da equipe;

- 30\% dos CAPS III (de maior complexidade) não acataram a legislação no que se refere à atenção contínua durante 24 horas diariamente;

- em 10 dos CAPS avaliados havia apenas um único psiquiatra;

• 16,7\% não têm um responsável médico;

- 66,2\% dos CAPS não têm registro no CREMESP, o que é obrigatório.

(CREMESP, 2010)

A partir do levantamento de dados, faz-se mais que necessário que se olhe para as políticas públicas de saúde, com um olhar mais holístico e integral, onde exige uma demanda financeiro dos cofres públicos, bem como um processo efetivo de planejamento e seleção de profissionais, pois um consenso das diretrizes assistencialista irá trazer um preenchimento de lacunas e uma adequação digna para a melhoria dos serviços de dependência química, sendo possível atender centenas de pessoas desamparadas.

\section{METODOLOGIA}

\subsection{Delineamento do estágio}

Estágio de caráter qualitativo com a utilização de ferramentas analíticas e observacionais, junto ao público de 4 adultos do sexo masculino, usuários de um Centro de Atenção Psicossocial (CAPS), de um município localizado no Meio Oeste Catarinense, com duração total de 10 horas.

\subsection{Local do estágio}

As horas de estágio serão desenvolvidas em um município pertencente à região Meio Oeste de Santa Catarina. O processo observacional e analítico irá ocorrer dentro da instituição CAPS, o local foi delimitado pela Universidade do Contestado de modo a servir como inserção do acadêmico às práxis psicológicas e sociais da comunidade. O estágio será dividido em dois encontros, o primeiro no dia 06/11 e o último 13/11 contabilizando 4 horas de observação e análise. 


\subsection{Fatores de inclusão e exclusão}

Para a realização deste estágio, foram elencados os usuários que recebem atendimento junto ao CAPS, que concordaram no acompanhamento do acadêmico com o grupo, esses indivíduos se mostram capazes de compreender os objetivos alinhados com o trabalho proposto, com o foco na recuperação da autonomia, desintoxicação e construção de vínculos, estando todos os indivíduos em situação de recuperação às toxicomanias, sendo residentes do território de abrangência da instituição.

Entre os fatores de exclusão, temos as escolas maternais, jardins de infância e creches infantis, que não fazem parte do nosso campo de investigação. Também não pretendemos trabalhar com entidades que atendem crianças e adolescentes com deficiência física ou mental como a APAE, pois entende-se que merecem estudos específicos. As entidades que funcionam em regime de privação de liberdade e as que proporcionam abrigo e funcionam em regime de internato também foram excluídas, pois entendemos que elas possuem dinâmicas particulares.

\subsection{Aspectos éticos}

As observações e atuações serão realizadas com a autorização do responsável pelo Secretaria de Saúde municipal, que contém as unidades de assistência psicossocial do município, incluindo o CAPS. Todas as atividades serão resguardadas pelo sigilo, no intuito de proteger a identidade e a integridade dos participantes e da instituição.

\subsection{Descrição do Estágio}

Será realizado um contato inicial com o responsável pela Secretaria da Saúde, solicitando a autorização para que o acadêmico possa estar realizando o estágio no CAPS Com a autorização em mãos, o acadêmico se deslocará até a unidade de atendimento a fim de conhecer o histórico, a estrutura física e funcional do local, bem como as datas para a realização das horas.

Com todas essas situações definidas, será realizado a conversa primária com o psicólogo responsável pela condução do grupo e posterior a isso, o acompanhamento propriamente dito. No primeiro dia, será feita uma apresentação inicial dos acadêmicos para o psicólogo do grupo, como uma forma de estabelecer uma aproximação para conhecer as demais atividades. $\mathrm{O}$ acompanhamento observacional será aplicado no segundo encontro, após o relato das RCMOS - Revista Científica Multidisciplinar O Saber. ISSN: 2675-9128. São Paulo, v. 08, p. 01-28, ago. 2021. 
observações será desenvolvido o relatório de análise de grupo, com o intuito de levantar hipóteses a respeito dos fenômenos psicológicos e sociais que foram identificados nos encontros.

\section{CRONOGRAMA}

\begin{tabular}{|c|c|c|}
\hline Atividades & $\begin{array}{c}\text { Nov. } \\
\mathbf{2 0 2 0}\end{array}$ & $\begin{array}{c}\text { Nov. } \\
\mathbf{2 0 2 0}\end{array}$ \\
\hline Pesquisa bibliográfica & $03 / 11$ & $06 / 11$ \\
\hline Acompanhamento no CAPS & $06 / 11$ & $13 / 11$ \\
\hline $\begin{array}{c}\text { Análise e compilação dos dados } \\
\text { observados }\end{array}$ & $13 / 11$ & $17 / 11$ \\
\hline Socialização do estudo de caso & $17 / 11$ & \\
\hline Revisão e Elaboração Final & $23 / 11$ & \\
\hline Apresentação & $24 / 11$ & \\
\hline Entrega Final & $24 / 11$ & \\
\hline
\end{tabular}

\section{APRESENTAÇÃO DA INSTITUIÇÃO}

\subsection{Historização breve do CAPS}

O primeiro CAPS inaugurado no Brasil, foi no ano de 1986, em São Paulo, o centro que futuramente viria acolher usuários com transtornos mentais graves e dependentes químicos, veio a se chamar: Centro de Atenção Psicossocial Professor Luiz da Rocha Cerqueira, popularmente conhecido como CAPS do Brasil da Rua Itapeva (BRASIL, 2004). O II Congresso Nacional do MTSM (Movimento do Trabalhadores em Saúde Mental adotou como lema "Por uma sociedade sem manicômios", após essas diretrizes de conferência pública, passase a entrar em vigor no país as primeiras normas federais regulamentando a implantação de serviços de atenção diária, e as primeiras normas para fiscalização e classificações dos hospitais psiquiátricos (BRASIL, 2004). O CAPS da cidade mapeada para o desenvolvimento do Estágio Básico IV, atende pessoas com transtornos mentais graves e persistentes e usuários com necessidades desencadeadas pelo uso recorrente de drogas, em todas as faixas etárias de idade. O CAPS é norteador a partir de um Serviço de Saúde municipal e comunitário, que oferece 
atendimento diário. A instituição objetiva promover um serviço de resgate das potencialidades dos recursos comunitários à sua volta, fazendo com que os recursos humanos sejam inclusos nos cuidados psicossociais na comunidade. O CAPS iniciou suas atividades em 26 de maio de 2003 com 11 pacientes e até final do ano de 2003 foram atendidos no Programa 133 pacientes, destes 34 receberam alta a pedido, alta administrativa ou desistiram e 23 não se encaixaram como paciente do programa, encerrando o ano com 76 pacientes frequentando todas as atividades, hoje em 2020 o CAPS atende mais de 1.000 usuários.

A estrutura da instituição está localizada no centro da cidade mapeada, com um espaço que possibilita atender os usuários beneficiados com o serviço. O espaço é alugado pela prefeitura municipal, possuindo:

- 01 Recepção

- 01 Sala de Enfermagem/Psiquiátrica/Assistência Social

- 03 Consultórios Psicológicos

- 01 Sala para Terapia Ocupacional

- 04 Banheiros

- 01 Cozinha

- 01 Sala de Administração

- 01 Salão

- 01 Garagem

- 01 Horta

O espaço funciona de segunda a sexta-feira, no período matutino das 8:00h às 11:30h horas e no período vespertino da 13:00h às 17:00h horas, além da estrutura física o quadro de profissionais compõem uma equipe multidisciplinar que desenvolvem projetos terapêuticos, atividades de reabilitação psicossocial, e tratamento de saúde, orientação, acompanhamento, entre outros.

\subsection{Estrutura física}

A estrutura do CAPS é uma casa residencial no centro da cidade mapeada, com uma pequena horta e garagem: 


\begin{tabular}{|c|c|}
\hline Qt & Espaço de atendimento \\
\hline 1 & Recepção \\
\hline 2 & Salas de Espera \\
\hline 1 & Consultório médico e de enfermagem \\
\hline 3 & Salas de Psicologia \\
\hline 1 & Sala de Terapia Ocupacional \\
\hline 1 & Sala de Administração e Serviço Social \\
\hline 1 & Cozinha \\
\hline 3 & Banheiros \\
\hline 1 & Garagem \\
\hline 1 & Horta \\
\hline
\end{tabular}

\subsection{Quadro de funcionários}

\begin{tabular}{|c|c|}
\hline Qt & Funcionários \\
\hline 3 & Psicólogos \\
\hline 1 & Médico Clínico \\
\hline 2 & Médicos Psiquiatras \\
\hline 2 & Técnicas de Enfermagem \\
\hline 1 & Enfermeira \\
\hline 1 & Terapeuta Ocupacional \\
\hline 2 & Assistentes Sociais \\
\hline 1 & Coordenadora \\
\hline 1 & Auxiliar Administrativo \\
\hline 1 & Motorista \\
\hline 1 & Zelador \\
\hline
\end{tabular}




\subsection{Número de pacientes e grupos}

A instituição atende cerca de 1000 usuários, dentre internações, atendimentos e acompanhamentos, além da realização de trabalhos com um grupo de dependência química, sendo que o horário do grupo é somente no período matutino, o grupo é composto por 4 integrantes.

\subsection{Funcionamento}

A instituição funciona de segunda à sexta das $8: 00 \mathrm{~h}$ às $11: 30 \mathrm{~h}$ e da $13: 30 \mathrm{~h}$ às $17: 00 \mathrm{~h}$. Atende o grupo de dependência química todas às sextas-feiras nos períodos matutinos das 9:30h às $10: 30 \mathrm{~h}$.

\subsection{Atuação do psicólogo}

O psicólogo do CAPS acompanhado, atua com sujeitos dependentes químicos. O atendimento ocorre tanto individualmente, no sentido de acompanhamento e orientação, como no contato em grupos.

Toda sexta-feira das 9:30h até 10:30h é formado o grupo de drogadictos de forma a compartilharem vivência e trabalharem suas questões existenciais que corroboram a atmosfera do grupo para a recuperação e sobriedade.

O psicólogo aponta que os grupos sentem necessidade de diálogo, porém torna-se de difícil acesso devido à falta de adesão deles, vindo de um momento pandêmico, esse torna-se um fator determinante na composição e consistência do grupo

Os encaminhamentos dos usuários do CAPS são realizados por hospitais, postos de saúde, escolas e até mesmo pelo poder judiciário, eles se caracterizam exclusivamente pelo uso e abuso de substâncias. A orientação deste profissional é fundamental pois dá amparo e impulsiona os indivíduos e famílias a buscarem um sentido existencial pelo qual possam permanecer sóbrios e alcançar a recuperação. 


\section{APRESENTAÇÃO E ANÁLISE: ESTUdO DE CASO}

\subsection{Grupo de dependência química: Resistências, adesão ao tratamento e suas adversidades}

O construto analítico será baseado nas observações realizadas nos períodos de 06/11 e 13/11, com o intuito de levantar hipóteses diagnósticas não só do grupo de dependentes químicos, mas também do contexto integral em que o CAPS está inserido.

O CAPS é um serviço de atenção psicossocial para atendimento de pacientes com transtornos decorrentes do uso e dependência de substâncias psicoativas. Conforme a confirmação fixada pelo Ministério da Saúde (2006), esse serviço oferece atendimento diário aos pacientes que fazem uso prejudicial de álcool e outras drogas, permitindo o planejamento terapêutico. Segundo o psicólogo da instituição, os encaminhamentos são feitos por hospitais, postos de saúde, escolas ou até mesmo pelo poder judiciário. Ao chegar os prontuários dos pacientes é realizado o primeiro contato via telefone, que é efetuado pelo próprio psicólogo, aqui encontramos diversas variáveis que irão refletir no processo de adesão de tratamento, tais como resistência, comprometimento, e percepção de necessidade de ajuda.

Discorreremos agora sobre um dos empecilhos fundamentais do tratamento de dependentes químicos, que são as resistências e a falta de adesão. É de entendimento comum que a resistência nos dependentes químicos torna-se um fator determinante e explicitamente visível, pois este elemento está presente na maior parte dos procedimentos que envolvam mudanças fundamentais na vida do indivíduo, de acordo com Fontanella e Turato (2002), visualiza-se que a maioria dos usuários adia a procura por tratamento simplesmente por não pensarem nessa possibilidade, negando a própria condição, isso é concatenado pela falta de percepção de necessidade de ajuda que esse próprio paciente dispõe. Durante o acompanhamento com o psicólogo, ele informou que a estrutura do primeiro contato, muitas vezes pode comprometer o restante do tratamento, no caso das internações mediada pelo poder judicial, o profissional se apresenta na residência do usuário juntamente com a polícia, nesse sentido vemos que o primeiro contato poderá ter repercussões significativas durante todo o tratamento, durante a fala do psicólogo foi expressado: "imagine que o sujeito que está te tratando, é o mesmo sujeito que foi na sua casa com a polícia, para depois te levar a um tratamento", nota-se que nessa passagem do psicólogo identifica-se um erro na estrutura do primeiro contato, podendo ser refletido em algumas hipóteses como: falta de profissionais, falta 
de financiamento e políticas públicas para contratar os profissionais, falta de conhecimento do processo terapêutico, pois nesse sentido a percepção do primeiro contato estará influenciando intrinsecamente o decorrer do tratamento, é lícito levantarmos uma hipótese resolutiva no sentido de que no primeiro contato, o mesmo seja realizado por um profissional que não terá vínculo direto com o tratamento do usuário, pois segundo a percepção do psicólogo, este processo do primeiro contato pode "abalar" o andamento da adesão ao tratamento.

Já no que diz respeito às resistências, poderemos citar aqui o determinante que corrobora para a superação destes mecanismos resistências. É digno de nota ressaltar a contribuição de Occhini (2006), o autor assinala algumas estratégias de ação para conquistar essa superação, como a capacidade do profissional para tomar a resistência como uma oportunidade de abertura à percepção do problema, auxiliando assim o usuário compreender sua problemática, nesse sentido além de promover essa interação, o psicólogo pode ainda alcançar uma dimensão no usuário que é a da sensibilização, ajudando também no fortalecimento de vínculo. Desse modo vale ressaltar um fragmento discursivo do psicólogo, quando ele fala: "nossa trabalho é responsabilizá-los", torna-se necessário ressaltar a importante diferença entre responsabilizar e culpar, pois esse é um trabalho fundamental dos profissionais que ali estão, responsabilizar o sujeito por suas escolhas e também pelas consequência delas, no sentido de que o sujeito responsabilizando-se, ele também cria novas possibilidades de ação, promovendo assim sua autonomia em prol de sua vida.

Além de todo esse processo, cabe aqui destacar a importância da adesão do grupo de tratamento que vem a posteriori dos pleitos citados. O processo grupal caracteriza-se fundamentalmente sobre a perspectiva não só da remissão do sintoma causado pela dependência, mas do processo que se desmembra também na viabilidade de proporcionar aos participantes o alívio de memórias dolorosas e experiências vivenciadas em decorrência da dependência, além disso, outro fator importante é que o grupo não se limita somente pela pauta da dor, mas sim de uma pauta de esperança, onde manifesta-se o sorriso, graça, boas memórias e perspectivas futuras, pois esses fenômenos psíquicos ajudam o usuário a enfrentar o dia a dia no processo de convivência consigo mesmo e com os outros. (DANTAS, 2018)

Partindo deste pressuposto, levantamos a temática da dificuldade da adesão desses pacientes no processo de tratamento, pois nesse sentido a adesão ao tratamento torna-se uma das virtudes motivacionais mais fundamentais que corroboram para o sucesso do tratamento. A Organização Mundial de Saúde (OMS) define a adesão como: “[...] o grau em que o comportamento de uma pessoa - tomar o medicamento, seguir um regime alimentar elou RCMOS - Revista Científica Multidisciplinar O Saber. ISSN: 2675-9128. São Paulo, v. 08, p. 01-28, ago. 2021. 
executar mudanças no estilo de vida - corresponde às recomendações acordadas com um prestador de cuidados de saúde.

Existe um consenso universal e literário sobre o baixo índice de adesão pelos dependentes químicos, sendo que muitos iniciam o tratamento, mas poucos o mantêm, este fato é compreensível na medida em que entendemos a dependência como uma doença crônica e multicausal, pois o usuário que está em processo de recuperação enfrenta diversos obstáculos como, recaída, lapsos, ciclo de amizades, onde poucos conseguem manter-se abstêmios durante o tratamento.

Nesse sentido concatena-se as ideias citadas ao processo de adesão do tratamento, pois ambos dos dias observados, foram corroborados pela ausência e falta de adesão dos usuários, fazendo com que o trabalho de aplicação das ferramentas de intervenção fiquem com imensas lacunas, dificultando não só o progresso do usuário, mas também da própria política do CAPS. Dentro deste contexto, o processo analítico foi imensamente dificultado pela falta de matériaprima (observações do grupo) que veio em decorrência da falta de adesão ao tratamento, independentemente de qualquer empecilho, não poderemos deixar de citar aqui, o empenho e dedicação dos profissionais do CAPS, que mesmo com todas as lacunas sociais, burocráticas, e subjetivas dessa atmosfera que engloba a política pública de saúde para dependentes químicos, mesmo assim, ainda conseguem prestar suas práxis técnicas, sem deixar de lado, a priori, sua sensibilização e humanização no acompanhamento e tratamento desses usuários, fazendo com que o CAPS seja uma referência no que diz respeito à recuperação destes usuários.

Durante a conversa com o psicólogo, foi mencionado sobre o processo do acolhimento, recurso este que é preconizado pela política de humanização de nosso sistema de saúde (SUS), o acolhimento além de ser uma ação prática, ela é um processo ativo que auxilia incisivamente o processo da construção de uma relação de confiança e comprometimento desses profissionais para com o usuário. Para além do cenário clínico, acolher é abrir portas, aceitar, redimir-se, fornecer, dar crédito. Esse ato implica em uma ação inclusiva, que promove a este usuário um corpo estrutural na qual ele se sente parte de um todo, condição esta que não existia antes na situação de dependência e das demais comorbidades que este usuário enfrentava, em última análise o processo de acolhimento torna-se uma das diretrizes de maior relevância para esse sistema de tratamento e recuperação desses usuário, pois acolher torna-se a base primária de todo um movimento que deverá ser feito durante o processo que este usuário estiver inserido no CAPS, ou seja, o acolhimento é um modo de lidar com todas as vicissitudes do usuários de modo a conseguir procurar através do serviço de saúde, uma forma de atender seus pedidos, 
exigindo assim do profissional uma postura capaz de acolher, escutar e dar respostas suficientemente adequadas, responsabilizando-o, orientando-o de forma a dar consistência em sua recuperação, objetivando o seu progresso. Os encaminhamentos dos usuários do CAPS são realizados por hospitais, postos de saúde, escolas e até mesmo pelo poder judiciário, eles se caracterizam exclusivamente pelo uso e abuso de substâncias, porém essa utilização se configura de maneira distinta entre eles, mas se traçarmos um denominador comum majoritário nesses usuários, indiscutivelmente será o uso do álcool. Segundo Arthur Guerra (2010), teórico referência no Brasil sobre a utilização de álcool, afirma que o álcool é uma droga que o sujeito pode consumir durante a vida toda, todos os dias, sem ter complicações, porém $12 \%$ a $15 \%$ desses que se empenham no uso, adotam o quadro de dependência, a dependência ao alcoolismo. Nesse sentido torna-se importante levantarmos a questão do porquê do uso do álcool ou das demais drogas?

Compreender o porquê do uso de álcool, é entendermos ele como sintoma, um sintoma que muitas vezes denuncia problemas que todos nós enfrentamos, problemas sociais, familiares e subjetivos. Quando se procura refletir sobre os motivos que podem levar um sujeito a consumir algum tipo de droga, torna-se importante ressaltar que não são pequenos motivos ou uma causa isolada, existe um conjunto de fatores que ao atuarem no contexto no qual está inserido esse sujeito, acaba predispondo-o à utilização da substância. Uma das modestas hipóteses propostas no levantamento deste trabalho, torna-se a busca de sentido e significado da vida deste usuário, pois o sujeito não encontrando sentido no contexto vivencial, ele buscará através da substância, uma experiência que irá oferecer o seu suposto significado e sentido de vida, além disso, outra hipótese acerca da problemática, seria a romantização do uso do álcool, essa romantização vem da propaganda globalizada e glamourizada que não raramente encontramos nos mais variados canais abertos, além da herança hedonista, que existe a partir de um imperativo de gozo a estes sujeitos, quase obrigando-os a terem prazer, e caso não o tiverem, são seres incompletos. Essa sintomatologia social que se constrói a base do princípio do prazer, dificilmente consegue lidar com a frustração ou interdição de suas vontades, o uso do álcool nesse sentido torna-se uma ferramenta de onipotência narcísica que promove ao sujeito uma condição de retorno ao prazer, e em última análise, de permanência ao prazer (pelo menos até enquanto durar o efeito). Por fim, poderemos enfatizar que o recurso das drogas é entendido como uma resposta possível do sujeito ao mal-estar que é inerente ao ser humano tanto subjetivamente quanto socialmente, podendo ser uma medida paliativa extremamente útil, porém com prazo de validade, pois o sofrimento é uma sensação, e só existe na medida em que 
é sentida, e o sujeito, ao usar algum tipo de substância, provoca diretamente em seu organismo sensações prazerosas, alterando suas condições de sensibilidade, tornando-os insensíveis à própria desgraça.

\subsection{Atuações do CAPS no cuidado do paciente}

Nos centros de atendimento do CAPS o profissional além de realizar atendimentos em grupo, também realiza atendimentos individuais, porém tem como principal atendimento os grupos, trabalhando no sentido de incluir e reinserir esses usuários na sociedade, trabalhando com a fenomenologia existencial que é manifestada nos encontros.

A construção teórica no que diz respeito ao profissional, teve uma base psicanalítica, porém na prática dos atendimentos o psicólogo optou pela abordagem comportamental (TCC). O profissional apontou questões que são denominadores comum entre os profissionais da instituição, como a falta de material, mudanças de diretrizes, carência de recursos financeiros, além de múltiplas problemáticas que vão além do alcance da equipe, como pobreza, violência, desemprego, apontam também dificuldades de ordem estrutural relacionado ao espaço físico, pois logo a instituição terá que mudar de local, essa mudança irá repercutir na percepção de espaço nesses usuários e profissionais devido à uma quebra da ideia que antes era direcionada a uma dimensão de residência, para uma dimensão agora, institucionalizada. Dentre as principais atuações do profissional estão, o trabalho clínico, seja ele individual ou em grupo, triagens, acolhimentos, acompanhamento em internações compulsórias, coordenação de atividades, atuações em grupos operativos e terapêuticos.

Desse modo, vemos que a prática clínica tem uma condição hegemônica no atendimento dentro do CAPS, apesar de não ser a única técnica, ela aparece como destaque devido a sua efetividade e relação positiva com os usuários, além de ser uma prática norteadora para o serviço deste profissional.

\section{CONSIDERAÇÕES FINAIS}

A partir do construto teórico realizado até aqui, objetivou-se levantar dados qualitativos a respeito da temática do atendimento realizado dentro do CAPS. Foi construída uma breve historização do uso de abuso de substâncias, a importância da alternância de papéis, pois deslocar o sujeito do eixo das drogas é visualizá-lo a partir de uma ótica holística, propomos também levantar hipóteses acerca do entendimento de narcisismo, sendo que a droga, 
semelhante a masturbação, torna-se um culto ao próprio corpo, uma tentativa de retorno ao prazer primário que fora vivenciado em seus anos mais primitivos, e que por meio da droga, tenta retornar à essa posição onipotente, além dos processos transferências e de políticas públicas que estão intrinsecamente ligados à essa problemática social.

Nesse sentido, buscou-se através das observações realizadas, concatenar a teoria com a prática, levantando hipóteses acerca do sintoma social que é a toxicomania, buscando evidenciar lacunas no sistema público de saúde, que não raro, repercutem nas mais variadas entidades que recebem estas diretrizes públicas. Deste modo faz-se necessário continuarmos na luta da desconstrução do estigma da doença mental e da toxicomania, pois a luta que vem sendo travada contra os fenômenos sociais e existenciais, ainda não parou, estamos em constante labuta para melhorarmos o serviço público, e oferecer acolhimento e suporte para esses usuários e famílias, de modo a reintegrá-los na sociedade buscando uma melhor qualidade de vida para ambos os lados, o entendimento disso carece de investimentos públicos, pois ainda trabalhamos a partir de uma política imediatista que precisa de resultados no mesmo momento de suas ações, essa alternância de ideias, fará com que possamos pensar a longo prazo, investindo, psicoeducando e trabalhando para o melhor desempenho desses profissionais, que em última análise irá repercutir no desenvolvimento e reintegração destes usuários, aqui finalizo com um trecho da música de nosso querido poeta e músico Belchior (1946-2017) que acredito que se alinha com o que viemos construindo ao longo deste projeto a respeito da toxicomania, o nome da música é Alucinação que diz assim: "Eu não estou interessado, em nenhuma teoria, nem nessas coisas do oriente, romances astrais, a minha alucinação, é suportar o dia-a-dia, e meu delírio, é a experiência, com coisas reais".

\section{REFERÊNCIAS}

ANDRADE, Arthur Guerra de et al. I levantamento nacional sobre o uso de álcool, tabaco e outras drogas entre universitários das 27 capitais brasileiras. Brasília: Secretaria Nacional de Políticas sobre Drogas, v. 1, p. 284, 2010.

Andretta, I., Oliveira, M. S. A entrevista motivacional em adolescentes usuários de droga que cometeram ato infracional. Psicologia: Reflexão e Crítica, 24, v. 2, p. 218-226, 2011.

BRASIL, M. da S. et al. Ministério da Saúde. Portaria MS, v. 2914, p. 12, 2004.

CREMESP constata falhas no atendimento dos Centros de Atenção Psicossocial. Jornal Cremesp. 2010, v. 269, p.8-9. 
CONTE, M. Da necessidade à demanda. Pulsional Revista de Psicanálise, 10 (103), 33-41, 1997.

CONTE, M. A clínica psicanalítica com toxicômanos: o corte \& costura no enquadre institucional. Santa Cruz do Sul: EDUNISC, 2003.

DANTAS, M. L. N. B.; DANTAS, J. S. SILVA, G. de S. A psicoterapia de grupo no atendimento a dependentes químicos-relato de experiência em um projeto social. Revista Ciência (In) Cena, v. 1, n. 7, p. 105-120, 2018.

DA SILVA, Mariana Benatto Pereira; CREMASCO, M. V. F. O analista e a toxicomania. Revista Mal-estar E Subjetividade, v. 10, n. 3, p. 913-929, 2010.

DOS SANTOS, ÉLEM GUIMARÃES. O grupo como estratégia terapêutica nos Centros de Atenção Psicossocial Álcool e Drogas do Espírito Santo. 2010.

FERREIRA, A. C. Z. et al. Fatores que interferem na adesão ao tratamento de dependência química: percepção de profissionais de saúde. Revista Mineira de Enfermagem, v. 19, n. 2, p. $150-164,2015$.

FREUD, Sigmund. The ego and the id. The Standard Edition of the Complete Psychological Works of Sigmund Freud, Volume XIX (1923-1925): The Ego and the Id and Other Works. 1961. p. 1-66.

O mal-estar na civilização. Edição Standard Brasileira das obras psicológicas completas de Sigmund Freud, v. XXI, (p. 67-148). (J. Salomão, dir. da Trad.). RJ: Imago Ed. (Trabalho original publicado em 1930), 1996.

(1996) Além do princípio de prazer. Edição Standard Brasileira das obras psicológicas completas de Sigmund Freud, v. XVIII, 1(p.105-154). (J. Salomão, dir. da Trad.). RJ: Imago Ed. (Trabalho original publicado em 1920)

GRECO, CRISTINA PINI. O grupo de acolhimento: um dispositivo para facilitar a adesão ao tratamento. 2009.

GURFINKEL, D. A pulsão e seu objeto-droga: estudo psicanalítico sobre a toxicomania. Petrópolis: Vozes, 1996.

LACAN, J. O Seminário: Livro 8: A transferência. Rio de Janeiro: Zahar. (Originalmente publicado em 1960-1), 1980.

Ministério da Saúde (Brasil). A Política do Ministério da Saúde para a atenção integral a usuários de álcool e outras drogas. Brasília (DF); Editora MS; 2003

Secretaria Nacional de Políticas sobre Drogas, Centro Brasileiro de Informações sobre Drogas Psicotrópicas. (Org.).VI Levantamento Nacional sobre o Consumo de Drogas Psicotrópicas entre Estudantes do Ensino Fundamental e Médio das Redes Pública e Privada de Ensino nas 27 Capitais Brasileiras. São Paulo, SP: Secretaria Nacional de Políticas sobre Drogas, 2010. 
OCCHINI, M. F.; TEIXEIRA, M. G. Atendimento a pacientes dependentes de drogas: atuação conjunta do psicólogo e do psiquiatra. Estudos de Psicologia (Natal), v. 11, n. 2, p. 229-236, 2006.

SERRETTI, M. A. T. Toxicomania: um estudo psicanalítico. Mosaico: estudos em psicologia, v. 5, n. $2,2012$.

TOMÁS, M. A. Intoxicação: um retorno à onipotência narcísica. Mosaico: estudos em psicologia, v. 2, n. 1, 2008.

ZIMERMAN, D. E.; OSÒRIO, L. C. (Col.). Como trabalhamos com grupos. Porto Alegre: Artes Médicas, 1997.

WAKS, C. E. M. O lixo clínico: A clínica psicanalítica da toxicomania. Pulsional Revista de Psicanálise, 10 (103), 55-61, 1997. 


\section{ANEXOS}

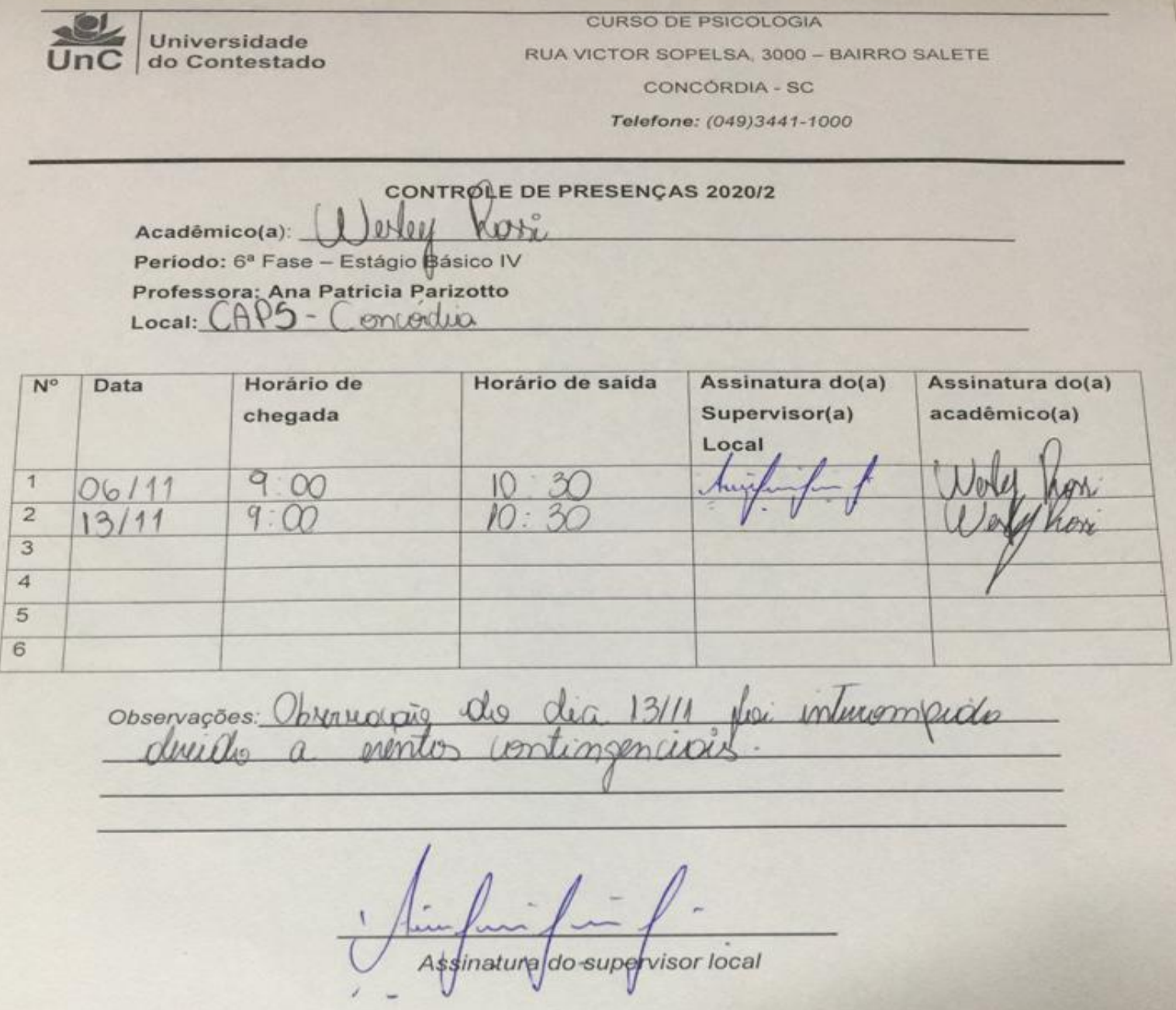

RCMOS - Revista Científica Multidisciplinar O Saber. ISSN: 2675-9128. São Paulo, v. 08, p. 01-28, ago. 2021. 


\title{
Avaliação Neuropsicológica em Pacientes com AVC
}

\author{
Neuropsychological Assessment In Stroke Patients
}

Lis Fiorini ${ }^{1}$

\section{Resumo}

O Acidente Vascular Cerebral (AVC) é a doença que mais mata no Brasil e a que mais causa incapacidade no mundo e acontece quando os vasos que levam sangue ao cérebro entopem ou se rompem, causando assim a paralisia da área afetada. Por esse acidente acontecer no cérebro, muitos pacientes ficam com sequelas para o resto da vida, dessa forma a avaliação neuropsicológica foi criada a fim de determinar o quanto essas lesões estão prejudicando o paciente. O objetivo geral deste estudo foi dissertar cerca da avaliação neuropsicológica em pacientes com AVC. O método de pesquisa utilizado foi a revisão de literatura, onde buscouse em bancos de dados confiáveis estudos já publicados sobre a temática com o objetivo de fazer uma compilação de informações e discussão entre os autores. Dessa forma, conclui-se que mais estudos devem ser feitos para determinar com exatidão quais as lesões, seus graus e assim conseguir dar ao paciente uma melhor qualidade de vida.

Palavras-chave: AVC. Avaliação Neuropsicológica; Déficit Cognitivo.

\begin{abstract}
Cerebral Vascular Accident (CVA) is the disease that kills the most in Brazil and the one that causes the most disability in the world. It happens when the vessels that carry blood to the brain clog or rupture, thus causing paralysis in the affected area. Because this accident happens in the brain, many patients are left with sequelae for the rest of their lives, so the neuropsychological assessment was created in order to determine how much these injuries are harming the patient. The general objective of this study was to discuss the neuropsychological assessment in stroke patients. The research method used was the literature review, which searched in reliable databases for studies already published on the subject in order to compile information and discuss among authors. Thus, it is concluded that more studies should be carried out to accurately determine which injuries, their degrees, and thus be able to provide the patient with a better quality of life.
\end{abstract}

Keywords: CVA. Neuropsychological Assessment. Cognitive Deficit.

\section{Introdução}

O acidente vascular cerebral é a segunda principal causa de morte e uma causa comum de deficiência física e cognitiva em pacientes nos países desenvolvidos (LOPEZ et. al., 2006; DONNAN et. al., 2008). A importância do tratamento do AVC após a alta é cada vez mais

\footnotetext{
${ }^{1}$ Psicóloga, Neuropsicóloga especialista pela Faculdade de Medicina Universidade de São Paulo - FMUSP São Paulo (SP), Brasil.

RCMOS - Revista Científica Multidisciplinar O Saber. ISSN: 2675-9128. São Paulo, v. 8, p. 01-19, ago. 2021. (cc) BY-NC-SA
} 
reconhecida por ser capaz de reduzir a carga do AVC e garantir a independência. Os médicos são desafiados a avaliar os pacientes que precisam de atendimento, em particular ao considerar que a população acima de 65 anos é o grupo que mais cresce nos países ocidentais (KINSELLA, 2001), e a idade é um importante fator de risco para AVC e demência consequente (PENDLEBURY; ROTHWELL, 2009).

O comprometimento cognitivo que surge após o AVC é um fator cada vez mais reconhecido para a incapacidade de longo prazo. A prevalência de comprometimento cognitivo varia entre os estudos, dependendo dos métodos de avaliação, definições ou características da amostra. Freqüentemente, instrumentos de triagem como o Miniexame do Estado Mental (MEEM) (FOLSTEIN; FOLSTEIN; MCHUGH, 1975) ou a Avaliação Cognitiva de Montreal (MoCa) (NASREDDINE et. al., 2005) são aplicados, embora pareçam inadequados para identificar déficits cognitivos sutis ou específicos (NYS et. al., 2005). A avaliação neuropsicológica revela que os déficits no funcionamento executivo, atenção, velocidade de processamento mental, percepção visual e capacidade de construção são doenças comuns em pacientes subagudos e crônicos (LESNIAK et. al., 2008; NYS et. al., 2005a; STEPHENS et. al., 2004; HOCHSTENBACH; DEN OTTER; MULDER, 2003; SACHDEV et. al., 2009).

O risco de declínio cognitivo contínuo e demência após o AVC é frequentemente declarado. No entanto, vários autores enfatizaram as múltiplas tendências evolutivas nas mudanças cognitivas em pacientes com AVC crônico (DEL SER et. al., 2005; BALLARD et. $a l ., 2003)$. Eles encontraram uma conversão anual para demência em 8-13\% no primeiro ano após o AVC. Além disso, os resultados indicaram que uma grande proporção de pacientes (50\%) demonstrou melhora no funcionamento cognitivo (BALLARD et. al., 2003) ou prejuízo estável (78\%) (DEL SER et. al., 2005). Dois estudos longitudinais recentes demonstraram que o AVC aumenta o risco de declínio persistente e cognitivo, em particular no funcionamento executivo (BARKER-COLLO et. al., 2010; LEVINE et. al., 2015). Um fator variável com o tempo que pode influenciar o desempenho cognitivo ao longo do tempo é o nível de sintomas depressivos.

A depressão pós-AVC (PSD) é relatada como ocorrendo com taxas de prevalência entre 5 e $64 \%$, com essa variação dependendo da população do estudo, do tempo de avaliação após o AVC e dos instrumentos de avaliação (HOSKING; MARSH; FRIEDMAN, 2000; AYERBE et. al., 2013). O PSD é conhecido por estar relacionado à mortalidade, redução do resultado funcional e qualidade de vida (PAN et. al., 2011; CHEMERINSKI; ROBINSON; RCMOS - Revista Científica Multidisciplinar O Saber. ISSN: 2675-9128. São Paulo, v. 8, p. 01-19, ago. 2021. (cc) BY-NC-SA 
KOSIER, 2001; STURM et. al., 2004), e pode estar ligado a vários fatores e mecanismos psicológicos. Com relação às variáveis demográficas e sua associação com a depressão em pacientes com AVC, parece não haver um padrão claro. A maioria dos estudos parece revelar que a idade avançada não está associada à depressão no AVC, embora nem todos possam apoiar esses achados (CHEMERINSKI; ROBINSON; KOSIER, 2001; BARKER-COLLO, 2007). Além disso, e em algum contraste com a população em geral, as pacientes com AVC do sexo feminino não parecem mais afetadas pela depressão do que os homens (HOSKING; MARSH; FRIEDMAN, 2000). Descobriu-se que o PSD está relacionado ao comprometimento cognitivo, como atenção, memória, percepção e construção visual e linguagem (KAUHANEN et. al., 1999; NYS et. al., 2005b). No entanto, a direção se o comprometimento cognitivo leva à depressão ou se o PSD leva ao comprometimento ainda está sendo debatido (HACKETT et. al., 2005; MURATA; KIMURA; ROBINSON, 2000).

Em ambientes clínicos, autorrelatos sobre a função cognitiva são comuns no tratamento do derrame, e foi demonstrado que os pacientes frequentemente relatam redução do ritmo mental, déficits de memória e dificuldades de concentração (DUITS et. al., 2008; HOCHSTENBACH; PRIGATANO; MULDER, 2005). No entanto, nem sempre foi possível confirmar essas queixas com dados empíricos (VAN RIJISBERGEN et. al., 2014). Foi demonstrado que as queixas cognitivas subjetivas (CEC) estão associadas a fatores como satisfação com a rede social, dificuldades emocionais autorrelatadas e escores de sintomas de depressão e neuroticismo (TOOMELA et. al., 2004; PASSIER et. al., 2010; LAMB et. al., 2013). Van Rijsbergen et. al. (2014) concluíram em sua revisão a ocorrência frequente de CCE após o AVC. Mesmo que eles não pudessem determinar um padrão claro relacionando o CCE ao desempenho cognitivo objetivo ou aos sintomas depressivos, eles enfatizaram que os pacientes com CCE devem ser monitorados por médicos, pois isso pode ser indicativo de declínio cognitivo.

A Escala de Impacto do AVC (SIS) foi desenvolvida para levar em consideração a perspectiva dos pacientes e cuidadores sobre o impacto do AVC na saúde e no estado funcional. Inclui uma escala separada na função de memória e pensamento. Até agora, poucos estudos combinaram medidas de desempenho cognitivo e funcionamento autorrelatado na subescala SIS de memória e pensamento (mtSIS).

Com isso este artigo se justifica por trazer uma importante implicação para a área da saúde uma vez que se pretende sanar diversas dúvidas relacionadas com o quanto um AVC pode prejudicar cognitivamente.

RCMOS - Revista Científica Multidisciplinar O Saber. ISSN: 2675-9128. São Paulo, v. 8, p. 01-19, ago. 2021. (c) EY-NC-SA 
Este estudo tem por objetivo geral dissertar acerca da avaliação neuropsicológica em pacientes com AVC e por objetivos específicos: a) Conceituar Acidente Vascular Cerebral (AVC); b) Determinar seus graus e c) Compreender quais os déficits cognitivos que o AVC pode causar em suas vítimas. Assim, há a pergunta norteadora: Qual a importância da avaliação neuropsicológica em pacientes com AVC?

\section{Fundamentação Teórica}

\subsection{Acidente Vascular Cerebral - AVC}

Uma das principais causas de morte e de incapacitação física no mundo todo é o acidente vascular cerebral (AVC). Nos Estados Unidos da América, em média 5000 mil pessoas tem um AVC por ano (OLIVEIRA; ANDRADE, 2001).

Deste número, 150 mil morrem de AVC por ano. Há mais de três milhões de sobreviventes ao AVC nos EUA; e os custos por ano decorrem da perda de produtividade com esses pacientes, passando assim os 18 bilhões de dólares. Por ano, cerca de 50 mil norteamericanos sofrem ataques isquêmicos transitórios (AITs), dentre esse número, quase um terço desenvolve um AVC como consequência.

O Ataque Isquêmico Transitório (AIT) é definido com um episódio rápido de perda da função do cérebro, por conta da isquemia, podendo ser localizada em uma porção do sistema nervoso central, suprida por certo sistema vascular (carotídeo direito ou esquerdo, ou vertebrobasilar), e o qual não tem mais nenhuma outra causa.

Já por arbitrariedade, os déficits duram menos de 24 horas. OS AITs normalmente duram pouco tempo (média de 2 a 15 minutos). Assim, se há a presença de episódios abruptos, durando poucos segundo, muito capaz que não sejam AITs (OLIVEIRA; ANDRADE, 2001).

Porém há condições poucos comuns que fogem a essa. Essa diferença é fundamental para a prevenção secundária eficiente. Estudos cooperativos mostram que em pacientes sintomáticos que possuem mais de $70 \%$ de estenose da carótida, a endarterectomia funciona muito bem para reduzir o risco de um AVC ipsilateral subsequente.

Na fase aguda dos AVCIs, o tratamento é feito com o uso de anticoagulantes, com restrição, pois podem baixar demais a pressão arterial, cuidados clínicos gerais e em casos raros, o uso de agentes fibrinolíticos. Os AVCs hemorrágicos (AVCHs) representam uma RCMOS - Revista Científica Multidisciplinar O Saber. ISSN: 2675-9128. São Paulo, v. 8, p. 01-19, ago. 2021. (c)) EY-NC-SA 
parcela de aproximadamente $10 \%$ dos AVCs, tendo tendência a acontecer mais precocemente do que os infartos. Ter hipertensão arterial e idade avançada é fatores principais de risco para o AVCH (OLIVEIRA; ANDRADE, 2001). Considerações sobre etiopatogenia dos AVCHs e condutas de tratamento para esses pacientes são apresentadas. Um estudo cooperativo de AITs determinou uma duração média de 14 minutos para os AITs de origem carotídea e 8 minutos para os de origem vertebrobasilar. Dois terços dos episódios isquêmicos são revertidos de forma espontânea, o que acontece dentro de 1 hora.

Quando isso acontece, é usado o termo "infarto cerebral com sinais transitórios", quando o problema encontrado bate com a sintomatologia neurológica apresentada. Um estudo foi realizado em Lausanne, na Suíça, e detectou 5 pacientes com AITs no meio de 75 pacientes com oclusão da artéria carótida interna.

Esses pacientes passaram por uma tomografia computadorizada do crânio (TC) que mostrava pequenos infartos profundamente localizados, quase não sendo possível distinguilos dos infartos lacunares.

Os autores acreditam que os infartos cerebrais com sinais transitórios tenham a ver com a necrose cerebral incompleta, relacionando o suprimento da rede colateral bem desenvolvido, ou ainda a frequentes isquemias na região de um antigo e silencioso infarto. $\mathrm{O}$ New York Hospital do Cornell Medical Central fez um estudo e no período de 1980 a 1986, tiveram 382 pacientes registrados com AITs, sendo que 50\% apresentaram uma melhora completa dos sintomas em menos de 30 minutos e 59\% na primeira hora (OLIVEIRA; ANDRADE, 2001).

Os eventos mais longos de AIT normalmente mostram uma alteração na TC ou na ressonância magnética $(\mathrm{RM})$ do crânio, ainda mais quando são utilizadas as mais recentes técnicas para adquirir imagens (técnicas de perfusão e difusão). Nicolaides et. al. estudaram 149 pacientes com AITs hemisféricos; onde $48 \%$ tinham um infarto à TC e $35 \%$ tinham um infarto no hemisfério que correspondia aos sintomas apresentados.

Os autores, no mesmo estudo, juntaram o resultado de dezessete trabalhos sobre a frequência com que os pacientes com AITs hemisféricos tinham infartos em TC.

De 738 pacientes estudados, 154 (20\%) tinham infartos à TC. Em questão de diagnósticos de infartos cerebrais, a RM é mais sensível do que a TC (OLIVEIRA; ANDRADE, 2001).

A partir desse estudo pode-se tirar a conclusão de que: 1) os AITs e os AVCIs são parte de um mesmo processo patológico, sendo causados pela isquemia cerebral; 2) se um RCMOS - Revista Científica Multidisciplinar O Saber. ISSN: 2675-9128. São Paulo, v. 8, p. 01-19, ago. 2021. (c) EY-NC-SA 
médico observar um paciente que apresente déficits clínicos por conta de uma isquemia e os sintomas durar mais de uma hora, é muito provável que se trate de um infarto cerebral. Dessa forma é necessário que haja um rigor maior no tratamento e na investigação dos AITs. Para se diagnosticar um AITs, depende-se da habilidade ao coletar o histórico dos eventos e sua interpretação, menos se o médico assistir a esse evento. Dormência e formigamento são sintomas comuns, que nem sempre indicam que é um AIT.

Pacientes com AITs tem uma chance maior de ter um infarto cerebral do que o restante da população saudável. O risco de se ter um AVC após um AIT é de 24\% a 29\% nos próximos cinco anos. Esse risco é de geralmente 4 a $8 \%$ durante o primeiro mês e de $12 \%$ durante o primeiro ano. O risco de pacientes com AIT desenvolverem um AVC é aumentado de treze a dezesseis vezes durante o primeiro ano e aproximadamente sete vezes durante os cinco anos seguintes. Subgrupos diferentes apresentam prognósticos diferentes.

Pacientes que tenham AITs hemisféricos e estenosa de carótida maior que $70 \%$ possuem um prognóstico perigoso, tendo uma taxa de desenvolver um AVC maior que 40\% em dois anos. Já pacientes jovens e pacientes com sintomas de déficit visual monocular tem um prognóstico bem melhor (OLIVEIRA; ANDRADE, 2001).

Os maiores fatores de risco para que haja eventos cardioembólicos na gênese dos AITs são: fibrilação ventricular, estenose mitral, próteses valvares cardíacas, infarto do miocárdio recente, trombo ventricular esquerdo (principalmente móvel ou pediculado), mixoma atrial, endocardite infecciosa, cardiomiopatias dilatadas e endocardite marântica; outros fatores de risco não tão importantes são: prolapso de válvula mitral, calcificação do anel mitral intensa, forâmen oval patente, aneurisma do septo atrial, estenose aórtica calcificada, anormalidades da contralidade do ventrículo esquerdo e placas ateromatosas no arco aórtico.

Todos os métodos de tratamentos devem ser utilizados para que somados possam permitir um diagnóstico adequado quanto ao grau de estenose, presença e característica das placas, presença de úlceras, dissecções ou displasia fibromuscular.

As características desta placa podem mudar de uma significativa os eventos isquêmicos consequentes. Placas ecoluscentes e heterogêneas tem um conteúdo lipídico alto, ou uma hemorragia intraplaca, que pode acabar produzindo ulceração da placa, levando a um maior potencial embolígeno (OLIVEIRA; ANDRADE, 2001).

Ao se estudar pacientes assintomáticos com a doença carotídea, cerca de só $20 \%$ a $30 \%$ deles possuíam placas ecoluscentes, em contraste com pacientes sintomáticos, onde as placas ecoluscentes equivaliam a 70\%. A característica mais marcante da placa na avaliação RCMOS - Revista Científica Multidisciplinar O Saber. ISSN: 2675-9128. São Paulo, v. 8, p. 01-19, ago. 2021. (c) EY-NC-SA 
do risco de novos eventos é a porcentagem de estenose na porção proximal da artéria carótida interna. Isso vale tanto para pacientes sintomáticos quanto para pacientes assintomáticos. Os AITs são pacientes de emergência. São para o infarto cerebral o que a angina instável é para o infarto agudo do miocárdio. Há várias controvérsias sobre qual é a conduta melhor para controlar os AITs mais recentes. Alguns autores são a favor de usar heparina intravenosa imediata para pacientes com um risco alto de novos AITs, ou com AITs de gravidade ou com uma maior frequência (OLIVEIRA; ANDRADE, 2001).

Porém, nenhum estudo maior foi feito para poder comparar a ação da heparina aos antiagregantes plaquetários. Deve-se levar em consideração a provável ou conhecida etiologia dos episódios. O ácido acetilsalicílico e a ticlopidina são aliados na prevenção de um AVC após um AIT.

Em uma análise do benefício relativo, os efeitos colaterais e os custos da droga, o ácido acetilsalicílico é considerado como uma droga de escolha para que se possa iniciar o tratamento antitrombótico.

A dose permitida de ácido acetilsalicílico é controversa, pois aceita-se que $325 \mathrm{mg}$ por dia seja o ideal para a adequada proteção com efeitos colaterais mínimos. O clopidogrel também pode ser usado com sucesso, porém o custo é muito maior.

O uso de "estatinas" no controle das placas carotídeas precisa de um estudo mais aprofundado; mas, no entanto, dados preliminares mostram que esse tipo de droga tem um papel muito importante para que se previnam as úlceras e no controle do crescimento das placas ateromatosas. Os efeitos antioxidantes desses remédios por sobre as placas coronárias já são muito conhecidos (OLIVEIRA; ANDRADE, 2001).

Os AVCIs serão classificados de acordo com o mecanismo etiológico envolvido, em: aterotrombóticos, cardioembólicos, lacunares, hemodinâmicos e venosos. Diferenciar essas características é essencial para a prevenção secundária efíciente.

$\mathrm{O}$ infarto cerebral aterotrombótico acontece quando a aterosclerose é envolvida em determinados sítios das artérias intra e extracranianas, o que leva à oclusão ou a um de seus ramos. São conhecidos dois principais mecanismos que leva a aterosclerose para o infarto.

Se houver uma placa aterosclerótica com obstrução da luz arterial ou fragmentação da placa ou um tombo sobreposto a ela, com embolia artério-arterial, então se pode ter uma trombose. Históricos de AITs e de sopro carotídeo são mais normais em pacientes com infarto aterotrombótico do que em outros tipos de AVCs. O diagnóstico clínico é baseado no achado de estenose ou oclusão arterial por conta da aterosclerose em ou mais sítios. O infarto pode RCMOS - Revista Científica Multidisciplinar O Saber. ISSN: 2675-9128. São Paulo, v. 8, p. 01-19, ago. 2021. (c)) EY-NC-SA 
ser de origem bem pequena e quase impossível de ser distinguido daqueles com origem cardioembólica. Tem sido mostrado, por meio de estudos anatomopatológico que a distribuição de lesões ateroscleróticas não acontece por acaso ao longo da rede arterial cerebral (OLIVEIRA; ANDRADE, 2001). O sistema arterial carotídeo é afetado em primeiro grau na bifurcação da carótida, depois no sifão carotídeo, e logo após no segmento M1 da artéria cerebral média. Já no sistema vertebrobasilar, os mais acometidos são o primeiro e o quarto segmento das artérias vertebrais e o primeiro segmento da artéria basilar.

Os fatores que desencadeiam essas lesões a tornarem-se sintomáticas não são muito conhecidos, mas o que se sabe é que as estenoses superiores a 70\% estão lineadas e associadas com o aumento de risco de infarto cerebral distal. Estudos coorporativos mostram que em pacientes sintomáticos com mais de $70 \%$ de estenose de carótida, a endarterectomia é muito efetiva ao reduzir o risco de um AVC ipsilateral subsequente.

No entanto, deve-se conhecer e indicar uma equipe de cirurgiões vasculares, se o risco de cirurgia for inferior a 3\%. As indicações para se fazer uma endarterectomia dependem de risco cirúrgico, tanto para pacientes que possuem a doença aterosclerótica carotídea assintomática quanto para as sintomáticas.

Essas indicações devem levar em consideração o grau em que a estenose se encontra e o tipo de placa. Ter úlceras na placa, mostrada pela angiografia tem sido um importante marcador para o risco de se ter um AVC subsequente (OLIVEIRA; ANDRADE, 2001).

O tamanho e a extensão da lesão têm se relacionado muito com a evolução neurológica. Usando a angiografia convencional, o tamanho da úlcera pode ser dado se for multiplicado o comprimento pela largura da úlcera em milímetros. Dessa forma, úlceras que medem < $10 \mathrm{~mm} 2$ são nomeadas úlceras "A", úlceras que variam de $10 \mathrm{~mm} 2$ a $40 \mathrm{~mm} 2$ são nomeadas de úlceras "B", e úlcera que passam de $40 \mathrm{~mm} 2$ são nomeadas de úlcera "C".

O fato de se ter uma úlcera "C", mesmo que não tenha uma estenosa carotídea junto, identifica um grupo de pacientes que sofrem o risco de ter um AVC de 7,5\% ao ano. Caso as úlceras sejam do tipo "A", não há relação com o aumento no risco de se ter um AVC.

No entanto, as úlceras "B" passam por muitas controvérsias, uma vez que alguns autores as relacionam com um risco de $\mathrm{AVC}$ de $4,5 \%$ ao ano, enquanto outros não encontram qualquer relação (OLIVEIRA; ANDRADE, 2001).

A embolia artério-arterial a partir de placas aórticas foi avaliada mais recentemente. Mais ou menos $40 \%$ dos infartos cerebrais tem a causa desconhecida, ou limitada à estenose 
carotídea menor do que $70 \%$, ou ainda a pequenos defeitos cardíacos, que nem sequer são aceitos como uma causa definitiva.

Com o advento do ecocardiograma transesofágico placas no arco aórtico começaram a ser detectadas com mais facilidade. Várias pesquisas recentes têm estabelecido uma relação estatística entre as placas ateroscleróticas no arco aórtico e o AVC (OLIVEIRA; ANDRADE, 2001). Em pacientes que possuem uma placa maior do que $5 \mathrm{~mm}$, quando são comparadas com um grupo-controle, é encontrado um risco de desenvolverem AVCIs, infarto do miocárdio ou ainda embolia periférica de $33 \%$ em 2 anos; porém se só os eventos retinianos e os AVCIs forem analisados, o risco é de $16 \%$ em 2 anos, uma vez que esse risco é de $7 \%$ no grupo-controle sem ateromas. Placas ateroscleróticas $\geq 4 \mathrm{~mm}$ de espessura na aorta ascendente e arco aórtico proximal foram achadas em $14,4 \%$ dos pacientes com infarto cerebral e em $2 \%$ do grupo-controle $(\mathrm{p}<0,001)$.

Foram encontradas uma grande associação entre placas que tem de $1 \mathrm{~mm}$ a $3,9 \mathrm{~mm}$ de espessura e estenose carotídea, mas com placas maiores do que $4 \mathrm{~mm}$ de espessura, o risco de se ter um AVCI aumenta de 5 para mais do que 13 vezes. Esse grande aumento foi percebido somente para placas maiores do que $4 \mathrm{~mm}$ de espessura, se localizando perto do óstio da artéria subclávia esquerda, e não placas distais ao óstio. Pode-se acreditar que placas com mais de $4 \mathrm{~mm}$ de espessura tenham em sua composição material trombótico superposto a placas ulceradas.

Dessa forma, as placas aórticas que tenham mais de $4 \mathrm{~mm}$ de espessura são um fator grande de risco para que ocorram os infartos cerebrais, com uma possível relação etiológica em alguns pacientes. O modo para se abordar esses pacientes de uma forma terapêutica ainda não está determinado.

Há inúmeros relatos de casos de trombólise ou retirada de forma cirúrgica os ateromas encontrados por ecocardiograma transesofágico. Uma alternativa é a anticoagulação, mesmo que ainda há quem duvide que seja completamente seguro, uma vez que o anticoagulante pode ajudar a causar a microembolização de cristais de colesterol para a remoção do trombo por sobre uma placa ulcerada (OLIVEIRA; ANDRADE, 2001).

O objetivo dos anticoagulantes e antiagregantes plaquetários para que previnam os infartos cerebrais por conta dos trombos de placas no arco aórtico, ainda necessita de mais estudo. Os infartos de zonas limítrofes, que também são chamados de infartos das zonas divisórias das águas (watershed áreas), secundários a um mecanismo aerodinâmico, são bem mais difíceis de acontecer. Podem acontecer devido a associação com a estenose crítica das RCMOS - Revista Científica Multidisciplinar O Saber. ISSN: 2675-9128. São Paulo, v. 8, p. 01-19, ago. 2021. (cc) BY-NC-SA 
artérias carótidas, ou ainda a distúrbios hemodinâmicos, hipotensão ou bradiarritmia. Sua prevalência real ainda não foi estimada, porém quanto mais pacientes que passaram por longos períodos de hipotensão são investigados, como por exemplo, quando passam por uma grande cirurgia, porém podem-se encontrar exemplos desse tipo de AVC (OLIVEIRA; ANDRADE, 2001).

A forma para se controlar a pressão arterial ainda não está estabelecida ao certo. Um leve ou um moderado aumento da pressão arterial é visto com frequência em pacientes que sofreram AVCs, de um modo transitório, e parecendo ser um tipo de mecanismo compensatório por causa da perda da autorregulação do cérebro, tendo uma duração de poucos dias, e geralmente não sendo necessário aplicar nenhum tipo de tratamento.

Alguns eventos acabam por ajudar a aumentar a pressão arterial, como por exemplo, o estresse, a dor, a repleção vesical, o aumento da pressão intracraniana uma resposta fisiológica à hipóxia; a pressão abaixa de forma espontânea ao serem corrigidas tais alterações.

Entretanto, pode-se considerar a perda da autorregulação do fluxo sanguíneo cerebral, que acontece na região em que a isquemia chegou, e agravar a lesão com uma eventual redução da pressão arterial, diminuindo a perfusão.

Pacientes com hipertensão crônica tem a autorregulação do fluxo sanguíneo cerebral regulado com níveis pressóricos maiores, e uma redução repentina pode causar um dano maior ao cérebro (OLIVEIRA; ANDRADE, 2001).

Nos casos em que a hipertensão é mais grave, a redução da pressão arterial deve ser feita de forma lenta e cuidadosa. O uso de medicamento anti-hipertensivo é indicado para quando a pressão arterial média estiver mais alta do que $130 \mathrm{mmHg}$ ou quando a pressão arterial sistólica estiver mais alta do que $220 \mathrm{mmHg}$. Quando a pressão arterial for associada com a transformação hemorrágica, ao infarto do miocárdio, dissecção de aorta torácica ou insuficiência renal secundária, deve-se apelar para os fármacos parentais, como enalapril ou labetalol.

Para que a hipertensão arterial associada com a hipertensão intracraniana seja controlada, não se deve usar drogam que aumentam a vasodilatação cerebral (nitroprussiato de sódio) e nem as que provocam uma queda rápida da pressão arterial, como por exemplo, os bloqueadores de cálcio via sublingual. Para a maior parte dos pacientes, betabloqueadores ou inibidores da enzina conversora da angiotensina é o suficiente. Diuréticos também devem ser 
evitados pelo fato de causarem hipovolemia e agravar de forma séria o quadro neurológico (OLIVEIRA; ANDRADE, 2001).

A hipotensão arterial é uma coisa bem difícil de ser ver, enquanto a hipovolemia é muito mais comum. A prioridade de tratamento na fase inicial do AVC é corrigir a hipovolemia e normalizar o débito cardíaco. Enquanto a hipertensão arterial é tratada, já se deve saber se o paciente pode ou não usar o trombolítico, caso a resposta seja positiva, então fármacos distintos serão receitados como tratamento.

Pesquisas para o tratamento do AVCI usando agentes trombolíticos ou fibrinolíticos foram iniciadas quando estes medicamentos começaram a ser usados para tratar o infarto agudo do miocárdio. Após estudos importantes, o uso de agentes trombolíticos para AVCI tornou-se possível e muito mais seguro. Porém esse estudo também mostrou o fracasso ao se usar trombolíticos para casos isolados de infarto cerebral, abrindo outros estudos controlados com estreptocinase e om rt-PA.

Por esses estudos, limites e condições para o tratamento trombolítico mais seguro foram estabelecidos. O estudo NINDS obteve o melhor resultado, e os seus métodos foram usados como base que a Academia Americana de Neurologia e a American Heart Association mostrassem critérios e procedimentos essenciais para que o tratamento fosse mais seguro e eficaz (OLIVEIRA; ANDRADE, 2001).

É importante ficar atento para o número considerável de hemorragias intracerebrais obtidas em todos os estudos multicêntricos, tanto com a droga-teste como com o placebo, o que mostra que é preciso melhorar o método de seleção dos pacientes.

Conhecer e conferir os critérios deste protocolo é pré-requisitos muito importantes para que esse tratamento seja seguro. A trombólise só pode ser realizada quando um médico especializado em AVC e capacitado a interpretar um TC de crânio der o diagnóstico final (OLIVEIRA; ANDRADE, 2001).

Estudos que medem a capacidade de interpretação da TC de crânio de médicos da emergência, neurologistas e radiologistas mostrou que até mesmo esses últimos não eram capacitados o suficiente para localizar uma hemorragia intraparenquimatosa, o que atrapalha a seleção adequada de pacientes para a trombólise. É muito importante que haja um treinamento específico para médicos na área de doenças vasculares cerebrais, para que o diagnóstico seja aperfeiçoado.

Nos locais onde o tratamento do AVC é realizado com agentes trombolíticos, seja em qualquer lugar do mundo, o que limita muito a equipe treinada para dar uma avaliação correta RCMOS - Revista Científica Multidisciplinar O Saber. ISSN: 2675-9128. São Paulo, v. 8, p. 01-19, ago. 2021. (c)) EY-NC-SA 
e iniciar o tratamento com segurança, é a demora do paciente em processo de AVC chegar ao hospital. Normalmente não é recomendado que se abaixe a pressão arterial (PA) de pacientes que estejam em fase aguda de AVCI, porém vários estudos já mostraram que a PA elevada, acima de certos níveis, está associada de uma forma muito forte com a transformação hemorrágica e a resultados negativos quando usado o tratamento trombolítico, então nesse caso o indicado é que a PA seja abaixada apenas a um nível adequado para que se possa iniciar o tratamento trombolítico (OLIVEIRA; ANDRADE, 2001).

Depois da infusão de RT-PA, a pressão arterial precisa ser mantida abaixo nos níveis indicados por no mínimo 24 horas. A injeção intra-arterial de trombolíticos é uma alternativa eficaz no tratamento de AVCI na fase aguda, sendo vantajosa, pois permite uma maior concentração local do agente e uma menor concentração sistêmica dele. Sem se esquecer da outra vantagem, que é uma seleção de pacientes mais seguras, tendo a demonstração do ramo ocluído da artéria através da angiografia.

Com esse estudo percebemos que o fator tempo é muito importante e muito limitado para a indicação do trombolítico, tornando-se mais crítico, uma vez que para um estudo angiográfico ser feito, pois todos os trâmites normais de uma internação, avaliações clínicas e neurológicas necessárias costumam levar um tempo maior do que a tolerância máxima para a indicação do tratamento.

Os AVCH tomam um lugar de $10 \%$ na quantidade total de AVCs, e geralmente acontecem mais rápido do que os infartos. São muito mais frequentes do que a hemorragia subaracnoidea e bem mais agressiva d que o infarto cerebral. Alguns estudos mostram uma mortalidade de $30 \%$ a $50 \%$ no primeiro mês, onde metade dessas mortes acontece nos primeiros dois dias (OLIVEIRA; ANDRADE, 2001).

Depois de um mês, $10 \%$ mostram uma vida independentes, e após seis meses, esse número sobe para 20\%. Hipertensão arterial e idade avançada são os principais fatores de risco para um AVCH. Há uma pequena preferência por homens negros jovens e de meia idade. Também há essa preferência com os asiáticos, se comparar com os ocidentais.

Fatores de alimentação também afetam a taxa de AVCH. Homens japoneses, residentes no Japão, mostram uma incidência maior para o AVCH do que os que se mudaram para os EUA. Negros dos EUA também mostram um risco bem maior do que os brancos.

Os AVCHs quando atribuídos com a hipertensão acontecem de forma característica nos núcleos da base, tálamo, ponte e cerebelo. Essas áreas são supridas por vasos de pequeno calibre, ramos diretos para vasos mais largos, dessa forma, mais vulneráveis para os efeitos da 
pressão. Essas áreas são também os sítios de infartos lacunares, pois essa mesma doença vascular secundária à hipertensão arterial sendo responsável por ambos (OLIVEIRA; ANDRADE, 2001).

Um risco maior de mortalidade por AVC está relacionado com os níveis baixos de colesterol $(<160 \mathrm{mg} / \mathrm{dl})$. A razão para esse fato acontecer é desconhecida. Outros tipos de estudos, ulteriores, foram relacionados com uma maior incidência de AVCH a níveis baixos de colesterol e de hipertensão arterial diastólica. O consumo de álcool e a ocorrência de AVCH estão relacionados de uma forma mais complexa.

Novos estudos sugerem um comportamento parecido com um AVCI, tendo efeito protetor para um consumo diário de até $60 \mathrm{~g} / \mathrm{dia}$. As mudanças principais para fisiopatológicas para a gênese de AVCH ocorrerem em artérias pequenas e arteríolas por um efeito da hipertensão arterial. Porém, outras causas foram achadas durante AVCs hemorrágicos.

Outras causas não tão frequentes são as malformações arteriovenosas, aneurismas, distúrbios de coagulação e uso de anticoagulantes ou trombolíticos, transformações hemorrágicas de infartos e sangramento de tumores, ou ainda por uso abusivo de drogas (OLIVEIRA; ANDRADE, 2001).

Uma causa que os médicos dificilmente percebem é o uso crônico de antiagregantes plaquetários, em especial a aspirina, o que facilita um AVC hemorrágico em um paciente que seja medicado de forma preventiva, ainda mais se tentar evitar um AVCI ou um evento isquêmico em algum outro órgão. $O$ número de pacientes que usam consideravelmente a aspirina, servindo muitas vezes para prevenir de forma primária eventos isquêmicos cardiocirculatórios.

É possível que sejam detectadas malformações arteriovenosas, aneurismas e tumores. De forma usual se tenta determinar que a causa do sangramento seja por conta de sua localização, seguindo a ideia que sangramentos profundos capsulonucleares, atribuem-se a alterações microvasculares secundárias para uma hipertensão arterial, uma vez que sangramentos lobares são causados por angiopatia amiloide, como já se tem a chance de mencioná-las anteriormente. Um diagnóstico de forma presumida, mas não comprovada, mostra um risco maior para se recorrer ao paciente (OLIVEIRA; ANDRADE, 2001).

Ao analisar as angiografias em pacientes que sofreram $\mathrm{AVCH}$ foram encontradas alterações em $84 \%$ deles (32/38). Em uma parcela de 19\% dos pacientes foram detectadas malformações arteriovenosas insuspeitas, e, em 5\%, aneurismas. Foi mostrado, através de um estudo prospectivo, que a angiografia cerebral tem uma chance mínima para conseguir RCMOS - Revista Científica Multidisciplinar O Saber. ISSN: 2675-9128. São Paulo, v. 8, p. 01-19, ago. 2021. (c)) EY-NC-SA 
distinguir alterações em pacientes que sofreram AVCH e que tenha mais de 45 anos de idade, com sangramento talâmico putaminal ou na fossa posterior, e histórico de hipertensão.

\subsection{Avaliação Neuropsicológica em Pacientes com AVC}

A escolha do Teste da Figura Complexa de Rey (RCFT) pode ter contribuído para achados que indicam um alto comprometimento no domínio da memória visual. O teste requer habilidades visuomotoras durante a condição de cópia (a pontuação usada para representar o domínio visuoconstrutivo) e, posteriormente, reproduzir / memorizar um desenho de linha complexo (domínio da memória visual). Assim, a falha pode surgir de deficiência construtiva, deficiência visual ou memória espacial ou uma interação de ambos, ou mesmo outros fatores (LEZAK; HOWIESON; LORING, 2004). Por meio dessa complexidade, o RCFT pode, portanto, explorar habilidades ligeiramente diferentes de um teste de memória visual em que os itens devem ser apenas lembrados.

Barker-Collo et. al. (2010) incluindo o RCFT em um estudo de acompanhamento de 5 anos descobriu que os escores de memória visual estavam dentro de 1 DP dos dados normativos, enquanto a função de cópia média do grupo estava claramente prejudicada sendo> 2 DP abaixo dos dados normativos. Eles sugerem que a pontuação de cópia prejudicada está relacionada às funções executivas que são necessárias ao copiar a figura. Conforme sugerido por Barker-Collo et. al. (2010) contribuiu para o comprometimento da memória visual.

Os achados que mostram prejuízo no funcionamento executivo e na velocidade de processamento estão, em geral, de acordo com achados anteriores (NYS et. al., 2005a; STEPHENS et. al., 2004; SACHDEV et. al., 2009). Em particular, é notável a descoberta de que o comprometimento executivo ocorreu com mais frequência na faixa etária mais velha.

Enfatizou-se que disfunção executiva e velocidade de processamento reduzida frequentemente ocorrem em indivíduos com comprometimento cognitivo vascular (NORDLUND et. al., 2007) que podem apresentar declínio cognitivo adicional e progressão para demência (SACHDEV et. al., 2009). Podemos apenas especular que isso se aplica a alguns dos pacientes.

Ainda assim, ele destaca a necessidade de estudos longitudinais, incluindo avaliação cognitiva abrangente em pacientes com AVC. Essa importância é ainda mais enfatizada e 
ampliada pelos resultados que mostram correlações significativas entre os sintomas de depressão, função executiva, velocidade de processamento e produção da linguagem.

A proporção de pacientes que relataram sintomas de depressão e ansiedade (13-14\%, respectivamente) foi consideravelmente menor em comparação com os relatados por Ayerbe et. al. (2011) (28\% depressão e 33\% ansiedade) ou Kauhanen et. al. (1999) (42\%) e mais semelhantes aos de Astrom et. al. (1993) (depressão de 16\%). No entanto, Ayerbe et. al. (2011) descobriram que o comprometimento cognitivo (com base no MMSE) previu depressão ao longo de um acompanhamento de 5 anos e mostrou que a prevalência de depressão até dobra nesses indivíduos.

A produção da linguagem apresentou a relação inversa mais forte com a depressão. Ou seja, a produção reduzida de palavras indicava mais sintomas de depressão. Apesar de exigirem conhecimento e processamento semântico, esses testes, em particular a fluência das letras, mostram atingir muito funcionamento executivo, uma vez que estratégias de recuperação devem ser iniciadas, as respostas dadas devem ser mantidas em mente para evitar repetições (memória de trabalho) e semanticamente palavras fechadas devem ser evitadas (LUO; LUK; BIALYSTOK, 2010).

Foi demonstrado anteriormente que a disfunção executiva está intimamente associada às atividades da vida diária (POHJASVAARA et. al., 2002) e ao declínio cognitivo acelerado (LEVINE et. al., 2015). A ligação clara entre depressão e funcionamento executivo enfatiza a importância do acompanhamento desses pacientes para evitar que terminem em um círculo vicioso.

As análises mostrando que a subescala mtSIS se correlacionou significativamente com os domínios cognitivos da linguagem, função executiva e memória são novas e dignas de nota. Até onde sabemos, nenhum estudo anterior combinou o mtSIS com a avaliação neuropsicológica.

A princípio, deve-se reconhecer que o funcionamento autorrelatado com base no mtSIS foi bastante positivo, conforme indicado por uma mediana alta. Isso parece estar em algum contraste com estudos anteriores que demonstraram queixas cognitivas em mais de $50 \%$ dos pacientes com AVC (HOCHSTENBACH; PRIGATANO; MULDER, 2005).

Duncan et. al. (2003) descobriram que os itens eram muito fáceis de responder e só detectariam dificuldades em pacientes com AVC gravemente prejudicados. Existem correlações positivas significativas entre o mtSIS e o funcionamento executivo e a produção da linguagem, embora 4 das 7 questões do mtSIS se relacionem com a função de memória. RCMOS - Revista Científica Multidisciplinar O Saber. ISSN: 2675-9128. São Paulo, v. 8, p. 01-19, ago. 2021. (c) EY-NC-SA 
Isso indica que os pacientes que relatam bom funcionamento cognitivo também têm um desempenho igualmente bom.

No entanto, a sensibilidade e especificidade para o mtSIS em relação a todos os domínios cognitivos foram criticamente baixas. Embora a falta de evidência empírica entre função cognitiva objetiva e autorrelatada não seja um fenômeno novo, isso indica que os médicos devem ser cautelosos ao usar o mtSIS para identificar pacientes com comprometimento cognitivo.

Assim, o comprometimento pode não ter sido tão proeminente quanto necessário para ser mencionado. Na verdade, há uma correlação significativa entre os escores do mtSIS e o número de domínios prejudicados. Isso pode implicar que um certo "limite" de deficiência deve ser ultrapassado antes que afete as atividades diárias de rotina com frequência suficiente para ser observado e relatado pelo paciente. No entanto, o problema da sensibilidade foi comentado por Duncan et. al. (2003) mesmo em um grupo mais heterogêneo de pacientes. Em sua revisão sobre queixas cognitivas subjetivas, van Rijsbergen et. al. (2014) sublinharam a necessidade urgente de obter mais informações sobre as queixas pós-AVC e as suas razões subjacentes multifacetadas.

As análises revelaram que um viés de referência adicional é possível, uma vez que o estudo inclui indivíduos com AVC bastante leve (conforme indicado pelo NIHSS) e indivíduos que são capazes de se submeter a avaliação neuropsicológica. Assim, pacientes com AVC mais grave e comprometimento cognitivo mais grave e / ou depressão estão subrepresentados.

\section{Considerações Finais}

O comprometimento cognitivo em pacientes com AVC crônico ocorre com frequência e persistência no primeiro ano após o AVC. É importante fornecer uma avaliação neuropsicológica mais abrangente, além de medidas de triagem para detectar déficits cognitivos, bem como sua interação com os sintomas depressivos.

Os resultados sublinham o fato de que os pacientes com AVC devem ser monitorados e que os dados longitudinais são necessários. Fornecer uma avaliação mais abrangente para pacientes com AVC permite que os médicos ofereçam tratamento adequado e definam os indivíduos que precisam de atendimento adicional. Os médicos devem estar cientes de possíveis comprometimentos, mesmo que os pacientes não os relatem.

RCMOS - Revista Científica Multidisciplinar O Saber. ISSN: 2675-9128. São Paulo, v. 8, p. 01-19, ago. 2021. (c)) EY-NC-SA 


\section{Referências}

ASTROM, M.; ADOLFSSON, R.; ASPLUND, K. Major depression in stroke patients. A 3year longitudinal study. Stroke. 1993, v. 24, p. 976-982.

AYERBE, L., et. al. Natural history, predictors, and associations of depression 5 years after stroke: the South London Stroke Register. Stroke. 2011; 42:1907-1911.

AYERBE, L., et. al. The natural history of depression up to 15 years after stroke: the South London Stroke Register. Stroke. 2013; 44:1105-1110.

BALLARD, C., et. al. Prospective follow-up study between 3 and 15 months after stroke: improvements and decline in cognitive function among dementia-free stroke survivors $>75$ years of age. Stroke. 2003; 34:2440-2444.

BARKER-COLLO, S. L. Depression and anxiety 3 months post stroke: prevalence and correlates. Arch Clin Neuropsychol. 2007, v. 22, p. 519-531.

BARKER-COLlO, S., et. al. Auckland Stroke Outcomes Study. Part 2. Cognition and functional outcomes 5 years poststroke. Neurology. 2010, v. 75, p.1608-1616.

CHEMERINSKI, E.; ROBINSON, R. G.; KOSIER, J. T. Improved recovery in activities of daily living associated with remission of poststroke depression. Stroke. 2001; 32:113-117.

DEL SER, T., et. al. Evolution of cognitive impairment after stroke and risk factors for delayed progression. Stroke. 2005; 36:2670-2675.

DONNAN, G. A., et. al. Stroke. Lancet. 2008, v. 371, p. 1612-1623.

DUITS, A., et. al. Cognitive complaints in the early phase after stroke are not indicative of cognitive impairment. J Neurol Neurosurg Psychiatry. 2008; 79:143-146.

DUNCAN, P. W., et. al. Glycine Antagonist in Neuroprotection Americans Investigators Rasch analysis of a new stroke-specific outcome scale: the Stroke Impact Scale. Arch Phys Med Rehabil. 2003; 84:950-963.

FOLSTEIN, M. F.; FOLSTEIN, S. E.; MCHUGH, P. R. "Mini-mental state." A practical method for grading the cognitive state of patients for the clinician. J Psychiatr Res. 1975; 12:189-198.

HACKETT, M. L., et. al. Frequency of depression after stroke: a systematic review of observational studies. Stroke. 2005; 36:1330-1340.

HOCHSTENBACH, J. B.; DEN OTTER, R.; MULDER, T. W. Cognitive recovery after stroke: a 2-year follow-up. Arch Phys Med Rehabil. 2003, v. 84, p. 499-1504. 
HOCHSTENBACH, J.; PRIGATANO, G.; MULDER, T. Patients' and relatives' reports of disturbances 9 months after stroke: subjective changes in physical functioning, cognition, emotion, and behavior. Arch Phys Med Rehabil. 2005; 86:1587-1593.

HOSKING, S.; MARSH, N.; FRIEDMAN, P. Depression at 3-months poststroke in the elderly: predictors and indicators of prevalence. Aging Neuropsychol Cogn. 2000; 7:205216.

KAUHANEN, M., et. al. Poststroke depression correlates with cognitive impairment and neurological deficits. Stroke. 1999; 30:1875-1880.

KINSELLA, K. Urban and rural dimensions of global population aging: an overview. $\boldsymbol{J}$ Rural Health. 2001; 17:314-322.

LAMB, F., et. al. Predictors of subjective cognitive complaint in postacute older adult stroke patients. Arch Physical Med Rehabil. 2013; 94:1747-1752.

LESNIAK, M., et. al. Frequency and prognostic value of cognitive disorders in stroke patients. Dement Geriatr Cogn Disord. 2008; 26:356-363.

LEVINE, D. A., et. al. Trajectory of cognitive decline after incident stroke. JAMA. 2015; v. 314, p. $41-51$.

LEZAK, M. D.; HOWIESON, D. B.; LORING, D. W. Neuropsychological Assessment. ed 4. Oxford: Oxford University Press; 2004.

LOPEZ, A. D., et. al. Global and regional burden of disease and risk factors, 2001: systematic analysis of population health data. Lancet. 2006; 367:1747-1757.

LUO, L.; LUK, G.; BIALYSTOK, E. Effect of language proficiency and executive control on verbal fluency performance in bilinguals. Cognition. 2010; 114:29-41.

MURATA, Y.; KIMURA, M.; ROBINSON, R. G. Does cognitive impairment cause poststroke depression? Am J Geriatr Psychiatry. 2000; 8:310-317.

NASREDDINE, Z. S., et. al. The Montreal Cognitive Assessment, MoCA: a brief screening tool for mild cognitive impairment. J Am Geriatr Soc. 2005; 53:695-699.

NORDLUND, A., et. al. Cognitive profiles of mild cognitive impairment with and without vascular disease. Neuropsychology. 2007, v. 21, p. 706-712.

NYS, G. M., et. al. Restrictions of the Mini-Mental State Examination in acute stroke. Arch Clin Neuropsychol. 2005a; 20:623-629.

NYS, G. M., et. al. The prognostic value of domain-specific cognitive abilities in acute firstever stroke. Neurology. 2005b; 64:821-827.

PAN, A., et. al. Depression and risk of stroke morbidity and mortality: a meta-analysis and systematic review. JAMA. 2011; 306:1241-1249.

RCMOS - Revista Científica Multidisciplinar O Saber. ISSN: 2675-9128. São Paulo, v. 8, p. 01-19, ago. 2021. (c)) EY-NC-SA 
PASSIER, P. E., et. al. Prevalence and determinants of cognitive complaints after aneurysmal subarachnoid hemorrhage. Cerebrovasc Dis. 2010; 29:557-563.

PENDLEBURY, S. T.; ROTHWELL, P. M. Risk of recurrent stroke, other vascular events and dementia after transient ischaemic attack and stroke. Cerebrovasc Dis. 2009, v. 27 (suppl 3), p. 1-11.

POHJASVAARA, T., et. al. Post-stroke depression, executive dysfunction and functional outcome. Eur J Neurol. 2002; 9:269-275.

SACHDEV, P. S., et. al. The determinants and longitudinal course of post-stroke mild cognitive impairment. J Int Neuropsychol Soc. 2009; 15:915-923.

STEPHENS, S., et. al. Neuropsychological characteristics of mild vascular cognitive impairment and dementia after stroke. Int J Geriatr Psychiatry. 2004; 19:1053-1057.

STURM, J. W., et. al. Quality of life after stroke: the North East Melbourne Stroke Incidence Study (NEMESIS). Stroke. 2004; 35:2340-2345.

TOOMELA, A., et. al. Possible interpretation of subjective complaints in patients with spontaneous subarachnoid haemorrhage. J Rehabil Med. 2004; 36:63-69.

VAN RIJSBERGEN, M. W., et. al. Subjective cognitive complaints after stroke: a systematic review. J Stroke Cerebrovasc Dis. 2014, v. 23, p. 408-420. 


\title{
O DOMÍNIO DAS TECNOLOGIAS DE INFORMAÇÃO E COMUNICAÇÃO COMO CONTRIBUTOS PARA PRÁTICA DO COORDENADOR PEDAGÓGICO
}

\author{
Amanda Andrade Sancho ${ }^{1}$ \\ Markélen Dutra ${ }^{2}$
}

\begin{abstract}
RESUMO
Diante da sociedade atual, este artigo almeja proporcionar uma reflexão teórica quanto à incorporação pedagógica das Tecnologias de Informação e Comunicação (TICs) na prática do Coordenador Pedagógico enfatizando os contributos das mesmas quando utilizadas adequadamente e de acordo com as demandas da instituição e propósito do PPP. Para tal, usouse método com tipologia qualitativa reflexiva, nessa perspectiva, foi embasado em autores renomados que contribuem para o melhor entendimento referente à prática pedagógica, tecnologia educacional e cultura do uso pedagógico dos recursos tecnológicos. Os enfoques teóricos abordados apresentaram as potencialidades das TICs na prática pedagógica deste profissional da educação, bem como os desafios para incorporação pedagógica e a relevância da cultura do uso pedagógico em prol da melhoria do funcionamento no cotidiano escolar, outrossim, como apoio na execução das tarefas do profissional referido. Além do mais, observou-se que perante a sociedade contemporânea, a cultura digital, obter recursos tecnológicos não é suficiente para proporcionar transformações. É imprescindível a escola estar sujeita ao novo, a mudanças que são inevitáveis e utilizá-las de forma a viabilizar alterações favoráveis no processo educativo. Logo, mediante aos resultados das análises dos dados coletados, tornou-se nítido o quão é significativo o Coordenador Pedagógico dominar tais recursos, visto que, enquanto articulado, formador do docente e participante ativo dos processos educacionais, percebeu-se que as TICs tendem a contribuir na prática pedagógica do mesmo devido proporcionar agilidade e eficácia. Assim, se faz necessário buscar compreender acerca dessas ferramentas tecnológicas para usufruir de suas potencialidades e propiciar a incorporação pedagógica e efetiva.
\end{abstract}

Palavras-chave: Coordenador Pedagógico. TICs. Prática Pedagógica.

\begin{abstract}
Given the current society, this article aims to provide a theoretical reflection on the pedagogical incorporation of Information and Communication Technologies (ICTs) in the practice of the Pedagogical Coordinator emphasizing their contributions when used properly and in accordance with the demands of the institution and purpose of the PPP. To this end, a method with reflective qualitative typology was used. In this perspective, it was based on renowned authors who contribute to a better understanding of the pedagogical practice, educational technology and culture of the pedagogical use of technological resources. The theoretical approaches presented presented the potentialities of ICTs in the pedagogical practice of this education professional, as well as the challenges for pedagogical incorporation and the relevance of the culture of pedagogical use in order to improve the functioning in school daily life, as well as support in the execution of tasks. referred professional. Moreover, it was observed that in contemporary society, digital culture, obtaining technological resources is not
\end{abstract}

\footnotetext{
${ }^{1}$ Amanda Andrade Sancho, Graduada em Pedagogia (Faculdade IBRA), Especialisação em Gestão Escolar Integrada (Faculdade IBRA), Neuropsicopedagogia (Faculdade IBRA), cursando Especialização em Novas Tecnologias Educacionais (Faculdade IBRA). E-mail: sancho.amanda.a@gmail.com

${ }^{2}$ Markélen Dutra, Especialização em Tecnologia da Educação, Pedagogia Empresarial, MBA em Gestão Estratégica de Pessoas. E-mail: profa.markelen@gmail.com.
}

RCMOS - Revista Científica Multidisciplinar O Saber. ISSN: 2675-9128. São Paulo, v. 08, p. 01-13, ago. 2021. (cc) BY-NC-SA 
enough to provide transformations. It is essential that the school be subject to the new, changes that are inevitable and use them in a way that enables favorable changes in the educational process. Thus, through the results of the analysis of the collected data, it became clear how significant it is for the Pedagogical Coordinator to master such resources, since, while articulated, teacher trainer and active participant in educational processes, ICTs tend to be contribute in the pedagogical practice of the same due to provide agility and effectiveness. Thus, it is necessary to seek to understand about these technological tools to take advantage of their potential and provide the pedagogical and effective incorporation.

Key words: Pedagogical Coordinator. ICTs. Pedagogical Practice.

\section{INTRODUÇÃO}

Nas instituições as quais realizei estágio supervisionado do curso de pedagogia, foi possível perceber que, mediante ao período em que acompanhei o Coordenador Pedagógico as múltiplas funções deste profissional, tais como: articular com a comunidade escolar, auxiliar o docente no planejamento pedagógico, promover a organização dos processos educacionais, além de proporcionar o atendimento aos pais ou responsáveis e educandos. Tornou-se nítido, então, a necessária busca por recursos que pudessem contribuir de forma eficaz para essa prática pedagógica. Dado o exposto e diante da sociedade contemporânea em que vivemos, cada vez mais tecnológica, os avanços das tecnologias de informação e comunicação (TICs) surgem como recursos que tendem a facilitar na execução das tarefas pedagógicas. Nessa perspectiva, essas tecnologias contribuem de forma significativa no ofício do Coordenador Pedagógico, pois auxiliam na formação continuada do docente através de Ambientes Virtuais de Aprendizagem (AVA) e Educação a Distância (EAD) e facilitam nos processos de ensino, por meio de aplicativos, programas, softwares e internet. Além dos contributos dessas ferramentas tecnológicas disponíveis nas instituições, há também implicações quanto à sua introdução nos processos e dificuldades na utilização adequada pelos profissionais.

A presente pesquisa remeteu-se às transformações e avanços tecnológicos vivenciados pelo setor educacional, que por vez, refere-se ao surgimento de diversos recursos tecnológicos, disponíveis nas instituições educacionais atualmente, como o uso de computadores, softwares, simuladores, lousa digital, projetores multimídia, aplicativos de celulares e os atuais recursos da internet. As TICs, por meio da utilização dos recursos computacionais, viabilizam e otimizam processos e são relevantes na elaboração ou adaptação de documentos importantes, os quais podemos elencar: o Projeto Político Pedagógico (PPP), o regimento escolar, o calendário escolar, relatórios de turmas e boletim de notas. É inegável os benefícios que esses recursos proporcionam, tanto nas tarefas pedagógicas, quanto nas administrativas e financeiras. Igualmente, as tecnologias da comunicação podem, também, viabilizar a articulação da 
comunidade com a escola, visto que, por meio dos recursos tecnológicos de comunicação, educandos, famílias e os diferentes profissionais, todos os que colaboram com a instituição têm uma maior possibilidade de articulação/comunicação, pois tais recursos tecnológicos são amplamente utilizados por todos. Nesse sentido, e em virtude dessas contribuições que estão ao dispor do Coordenador Pedagógico, o artigo em questão pretende pesquisar as contribuições das TICs, disponíveis nas instituições, e de que forma esses recursos são utilizados pelo Coordenador Pedagógico na sua prática diária, ou seja, até que ponto o domínio dessas tecnologias oportuniza eficiência e praticidade na prática desse profissional. Assim, a relevância das ferramentas tecnológicas na prática do mesmo evidencia como é imprescindível a compreensão de suas funcionalidades.

Este artigo visa, então, enfatizar a importância do domínio das TICs disponíveis nas instituições e os contributos das mesmas na prática do Coordenador Pedagógico, uma vez que o mesmo é um articulador e mediador das práticas pedagógicas. Desta forma, esse profissional obtendo formação continuada adequada aos conhecimentos tecnológicos e usufruindo dos benefícios que essas dispõem - como ferramenta didático-pedagógica a ser incorporada adequadamente - tendem a contribuir significativamente no fazer pedagógico da instituição.

Por meio de uma revisão bibliográfica acerca das produções acadêmicas que versam sobre a utilização e a importância das tecnologias de informação e comunicação na prática do Coordenador Pedagógico, este artigo está organizado em 3 capítulos: o primeiro aborda os benefícios das TICs na prática deste profissional, o qual almeja-se promover a compreensão de suas potencialidades; o segundo refere às dificuldades quanto a incorporação pedagógica das TICs, com intuito de instigar a busca por métodos de superar os desafios que emergem e impedem a introdução eficazmente dos recursos tecnológicos; já o terceiro retrata o potencial das TICs mediante a cultura do uso pedagógico, contemplando as capacidades de algumas ferramentas tecnológicas e seus rendimentos na execução das tarefas.

\section{OS BENEFÍCIOS DAS TICS NA PRÁTICA DO COORDENADOR PEDAGÓGICO}

Cada instituição escolar constrói sua identidade por meio de sua cultura, suas práticas e com o trabalho daqueles que atuam diretamente em sua organização: os gestores, professores, auxiliares de apoio e também os alunos e seus responsáveis. A boa condução dos processos de atendimento e mediação, bem como a comunicação interna e externa são fatores essenciais nesse processo. O Coordenador Pedagógico é, geralmente, o protagonista desse trabalho de articulação com a comunidade escolar (profissionais diversos da instituição, 
educandos e famílias), pois, está diretamente incumbido de apoiar o planejamento pedagógico do docente e participar ativamente na elaboração e/ou adaptação de diversos documentos oriundos da instituição, tais como: regimento escolar, calendário escolar, relatórios e planejamentos, além de ser o responsável pela articulação da comunidade escolar para a constituição e/ou adaptação do PPP, uma vez que quando esse documento é constituído em articulação com todos os envolvidos no processo de ensino e em conformidade com as leis vigentes, tende a viabilizar o ensino qualitativo e o desenvolvimento satisfatório da instituição. Silva M. (2012, p. 58) elucida sobre a função do Coordenador Pedagógico para a constituição do PPP:

[...] o coordenador pedagógico é aquele que durante o ano articula equipe pedagógica em torno do melhor cumprimento do que foi estabelecido pelo projeto políticopedagógico, coordenando seus diversos desdobramentos: planejamento, acompanhamento e avaliação.

Nesse sentido, percebe-se como o trabalho deste profissional alcança uma função de destaque no contexto escolar. Sua função mediadora o torna capaz de fortalecer a parceria dos pais e a escola, articular as propostas curriculares e diretrizes educacionais com os planejamentos dos professores. Este profissional da educação, além de ser incumbido das funções referente às tarefas pedagógicas, ele participa de funções acerca do administrativo, financeiro e é encarregado por orientar os docentes a respeito do planejamento pedagógico, organização curricular, metodologias adequadas e por oportunizar a formação permanente (MONTEIRO, et.al, 2012). É relevante ainda mencionar que, além das funções abordadas acima, o mesmo é responsável por buscar novos métodos de criar ou reforçar vínculos entre professores/alunos, alunos/alunos e entre escola e família. Constata-se, desta forma, que, sob a perspectiva evidenciada, é essencial que esse profissional domine as TICs e saiba utilizá-las como suporte em sua prática cotidiana, em virtude que estes recursos tecnológicos além de contribuírem para otimizar o ofício do Coordenador Pedagógico, também oportunizam o funcionamento eficiente da instituição.

Mediante o grande volume de demandas de diversas origens e as múltiplas funções atribuídas e desempenhadas por esse profissional na instituição escolar, as TICs tendem a potencializar os processos educacionais e agilizar as demandas quando incorporadas pedagogicamente à prática da coordenação e ao fazer pedagógico. Conforme alerta Monteiro et al. (2012, p. 32) sobre a rotina de trabalho do Coordenador Pedagógico: "É comum observarmos [...] sendo engolido pelo cotidiano, dedicando boa parte do seu tempo à resolução de problemas emergenciais. [...] seu papel principal é ajudar na formação dos professores e na gestão pedagógica da escola [...]”" 
Neste aspecto, emerge a necessidade deste profissional adquirir conhecimentos acerca das TICs, em prol do desenvolvimento satisfatório da instituição, uma vez que é imprescindível para ele conhecer, compreender suas funcionalidades, saber aplicá-las e, por conseguinte, integrá-las como ferramenta do trabalho pedagógico de forma adequada (KENSKI, 2007).

Por intermédio da sociedade contemporânea, ou seja, diante da cultura digital que nos remete aos avanços na tecnologia de informação e comunicação, se faz cada vez mais urgente que os recursos tecnológicos disponíveis na instituição sejam utilizados como ferramenta de trabalho, objetivando a melhoria na educação.

De acordo com Miranda (2007, p. 43), “o termo Tecnologias da Informação e Comunicação (TIC) refere-se à conjugação da tecnologia computacional ou informática com a tecnologia das telecomunicações [...]”. Assim, essas tecnologias, quando utilizadas nos processos de ensino e aprendizagem, podem ser consideradas como tecnologias educativas, pois, viabilizam novas informações e saberes a todo instante, oportunizando, assim, a construção constante do conhecimento.

Recorrendo aos recursos tecnológicos que podem estar disponíveis na instituição, tais como: televisão, telefone, dispositivo móvel, projetores multimídia, softwares, computador e internet, Kenski (2007, p.46) afirma que

para que as TICs possam trazer alterações no processo educativo, [...] elas precisam
ser compreendidas e incorporadas pedagogicamente. Isso significa que é preciso
respeitar as especificidades do ensino e da própria tecnologia para poder garantir que
o seu uso, realmente, faça diferença. Não basta usar a televisão ou o computador, é
preciso saber usar de forma pedagogicamente correta a tecnologia escolhida.

Constata-se que embora a instituição tenha recursos tecnológicos disponíveis, as mesmas só irão beneficiar no processo educativo caso sejam compreendidas como ferramenta pedagógica, a serviço da prática e processos escolares. Candau (1979, p.66), salienta, ainda, que

para que a Tecnologia Educacional seja um instrumento de busca da relevância é necessário que continuamente se coloque questões relativas ao para quem, ao para que e ao porquê de sua contribuição à análise e solução dos problemas educacionais [...].

Em virtude do que foi mencionado, torna-se essencial compreender as tecnologias e buscar o entendimento sobre a forma que estes recursos podem contribuir nas demandas da instituição. Logo, o Coordenador Pedagógico ciente das demandas educacionais, e conhecedor dessas tecnologias, tende a dominar as TICs, e, a partir de então, ser um disseminador, um incentivador, aquele que, além de usar efetiva e eficazmente os recursos da tecnologia, também motiva e estimula o uso das mesmas nos planejamentos pedagógicos dos professores, oportunizando a introdução e a utilização de forma adequada. Assim, as TICs incorporadas na 
prática do Coordenador Pedagógico servem não só de apoio, mas também beneficiam o funcionamento favorável da instituição.

\section{AS DIFICULDADES ACERCA DA INCORPORAÇÃO PEDAGÓGICA DAS TICs}

As TICs viabilizam a comunicação e tendem a contribuir significativamente no processo educativo, logo torna-se nítido a importância dos recursos tecnológicos na instituição. Todavia, a incorporação pedagógica e ativa desses recursos implicam em dificuldades e desafios, tais como: equipamentos obsoletos, falta de recursos para manutenção técnica, planejamento insuficiente para uso pedagógico das ferramentas tecnológicas; a escola inflexível e arcaica que prioriza a educação formal em detrimento da formação integral do aluno; e, ainda, situações imprevistas no cotidiano escolar. Esses são obstáculos a serem vencidos, conforme enfatiza Sancho (2006, p. 19)

[...] muitas pessoas interessadas em educação viram nas tecnologias digitais de informação e comunicação o novo determinante, a nova oportunidade para repensar e melhorar a educação. Contudo, [...] a história recente da educação está cheia de promessas rompidas; de expectativas não-cumpridas, geradas ante cada nova onda de produção tecnológica (do livro de bolso ao vídeo ou ao próprio computador). Devemos considerar as problemáticas associadas ao fracasso na incorporação às aulas de cada um destes meios e como podemos ajudar a planejar melhor sua integração nos processos de ensino e aprendizagem.

Assim sendo, em busca da melhoria na educação, os envolvidos no setor educacional, devem assimilar sobre as possibilidades e potencialidades da implementação das TICs, e, consequentemente, fazer um planejamento que conduz a incorporação adequada dos recursos tecnológicos às aulas e ao desenvolvimento favorável do processo de ensino e aprendizagem.

De acordo com Moran (2012, p. 48) “o vídeo e outras tecnologias tanto podem ser utilizados para organizar como para desorganizar o conhecimento. Depende de como e quando os utilizamos." Percebe-se, então, que a utilização inadequada é outra dificuldade quanto à incorporação pedagógica das TICs. Uma vez que a mesma é um dos fios condutores para a construção do conhecimento e desenvolvimento de habilidades. Em contrapartida, caso seja utilizada apenas como um fim em si mesma pode desconstruir e interferir negativamente nos processos educacionais, pois não agregará valor pedagógico as atividades desenvolvidas.

Além desses fatores negativos mencionados, outro fator dificultador é a própria escola, enquanto instituição convencional, ainda resistente à mudança. As escolas, como qualquer âmbito social, também possuem um conjunto de cultura organizacional, e em função dessa cultura que em grande parte é constituída de normas e regras, tende a ser rígida e inflexível perante as transformações. À vista disso, Bolívar (1997) citado por Novais (2003) menciona 
que as instituições embora se dediquem ao processo de aprendizagem, são resistentes ao ato de aprender. Em relação a cultura organizacional em detrimento da melhoria de ensino e das necessidades de mudanças educacionais de qualidade, Lück (2014, p. 129) esclarece:

\begin{abstract}
Verifica-se com facilidade que a escola despende grandes esforços no sentido da preservação de uma cultura estabelecida, de seu modo de ser e de fazer contumaz, em detrimento da melhoria da qualidade de ensino, segundo as necessidades de uma época em que a rapidez da mudança é a tônica. A respeito, é fundamental o alerta no sentido de que a escola não pode deixar de absorver as lições da história que demonstram não haver nada tão inevitável na sociedade quanto a mudança. Essa mesma história identifica que as organizações e os grupos sociais que não conseguem se renovar estão fadados a ficarem anacrônicas rapidamente e perdem sua vitalidade e até mesmo sua razão de ser.
\end{abstract}

Desta forma, evidencia-se que é relevante a escolar ser flexível, inovadora perante as mudanças que emergem na sociedade contemporânea e não aderir uma postura estagnada, inerte perante tais transformações. Visto que as mesmas refletem na qualidade de ensino, tanto quanto, no desenvolvimento da instituição e no acúmulo de demandas.

Em virtude das demandas institucionais no cotidiano escolar, o Coordenador Pedagógico enfrenta obstáculos para cumprir efetivamente seu planejamento, dificultando, assim, o alcance dos objetivos institucionais e pedagógicos. Muitas vezes ele precisa delegar funções e distribuir tarefas encarregando outros profissionais de suas funções, devido não só de situações imprevistas que são comuns no ambiente escolar, mas também do acúmulo de trabalho e da falta de um planejamento diário. Esses são fatores que alavancam a busca por meios cabíveis para viabilizar a incorporação pedagógica das TICs. De acordo com Almeida (2005) citado por Oliveira (2017, p. 153) muitas vezes essas demandas impedem o Coordenador Pedagógico de desempenhar suas reais funções:

A predominância das situações não previstas, existentes no cotidiano do coordenador pedagógico, demonstra que ele passa a ter dificuldades em planejar sua rotina de trabalho. [...] e assumem a responsabilidade pelo não-cumprimento de seu planejamento ou pelo desvio das tarefas inerentes à sua função que são deixadas de lado por causa das emergências que surgem no cotidiano escolar. [...] As situações inesperadas são resolvidas no desenrolar do dia, caracterizando o coordenador pedagógico como um "apagador de incêndio".

Dado o exposto, percebe-se que perante os avanços da tecnologia, obter recursos tecnológicos e midiáticos não são suficientes para ofertar contributos no processo educativo, o que se configura um dos grandes desafios acerca da incorporação pedagógica das TICs. Assim, é pertinente que os envolvidos no processo permaneçam em constante formação, visto que as mudanças nessa área são rápidas e inevitáveis. Por isso, a necessidade de formação continuada, se configura em um fator imprescindível para evitar o fracasso nesta empreitada rumo ao efetivo uso dos recursos tecnológicos. O planejamento é outro fator fundamental para oportunizar a RCMOS - Revista Científica Multidisciplinar O Saber. ISSN: 2675-9128. São Paulo, v. 08, p. 01-13, ago. 2021. (c) BY-NC-SA 
incorporação pedagógica desses recursos, no qual contempla as potencialidades e as fragilidades dessa incorporação nos processos da instituição escolar. Em virtude do que foi mencionado, evidencia-se que o Coordenador Pedagógico em prol do melhor cumprimento de suas funções (enquanto mediador da comunidade escolar, organizador dos processos educacionais e mediador docente/dicente.), ao dominar e compreender as funcionalidades das TICs, proporciona a melhoria na qualidade de ensino, igualmente, o desenvolvimento favorável da instituição em sua totalidade. É relevante, sobretudo, que este profissional da educação instigue e cultive na comunidade escolar uma cultura do uso pedagógico das ferramentas tecnológicas, possibilitando, desta forma, a superação dos desafios mencionados.

\section{O POTENCIAL DAS TICs MEDIANTE A CULTURA DO USO PEDAGÓGICO}

Anteriormente abordou-se os benefícios que as TICs oportunizam e as dificuldades que emergem de sua não utilização ou uso inadequado, se configurando em obstáculos, que por vez, inviabilizam a incorporação pedagógica e permanente das mesmas na instituição. É possível que o Coordenador Pedagógico já utilize em seu cotidiano social muitos dos recursos que ele poderia também utilizar na prática pedagógica, como por exemplo: aplicativos de celulares, softwares, internet, wikis, chats. Deu-se enfoque para alguns desses recursos, mas também para aqueles utilizados para estudos como os Ambientes Virtuais de Aprendizagem (AVA) utilizados normalmente para cursos de Educação à Distância (EAD). Esses recursos já estão inseridos no cotidiano de tal forma que é impossível pensar em executar tarefas diárias, se comunicar ou estudar sem utilizá-los. Pretende-se então, evidenciar o potencial que os recursos tecnológicos possibilitam quando o seu uso passa a ser uma prática habitual a ponto de se tornar uma cultura, ou seja, estar tão enraizada no cotidiano e inerente à execução das tarefas do Coordenador Pedagógico que ele nem perceba ou nem faça esforço para utilizá-la. Mediante essa cultura do uso pedagógico das TICs, é possível que esse profissional incentive também outros profissionais, inserindo esses recursos e ferramentas tecnológicas no planejamento pedagógico e usufruindo de suas contribuições para o cunho científico e didático-pedagógico.

Nesse seguimento, atendendo as demandas de tarefas destinadas a este profissional, Oliveira (2012) ressalta que é viável o uso de aplicativos, softwares, tais como: os processadores de textos e planilhas eletrônicas, devido suas potencialidades. Em relação aos processos educacionais, os processadores de textos, oportunizam a elaboração e/ou adaptação dos documentos oriundos da instituição, visto que é permitido modificar o arquivo quantas vezes almejar. No que diz respeito à planilha eletrônica, é possível organizar informações e dados, RCMOS - Revista Científica Multidisciplinar O Saber. ISSN: 2675-9128. São Paulo, v. 08, p. 01-13, ago. 2021. $(\mathrm{cc}) \mathrm{EY}-\mathrm{NC}-\mathrm{SA}$ 
em tabelas e gráficos, além de beneficiarem na construção/produção de relatórios, as mesmas possibilitam, também, a realização de cálculo rápido, bem como, expor assuntos como funções, médias, entre outros; podendo fazer representação gráfica, que conseguinte, propicia o melhor entendimento dessas informações (OLIVEIRA, 2012). Além desses benefícios, segundo Silva T. (2012, p. 123) as TICs “[...] em particular a internet, hoje permitem uma maior pluralidade [...] de conteúdo e opiniões [...]", logo, possibilitando novas informações a todo instante, que, propicia a construção do conhecimento crítico, devido ao acesso a informações diversas. Os recursos mencionados são exemplos claros de ferramentas tecnológicas que podem beneficiar o Coordenador Pedagógico na execução de tarefas do seu afazer diário que ele levaria horas, dias ou até meses para realizá-las. Ao que se refere as potencialidades das TICs como facilitador da articulação entre escola e comunidade escolar, Silva T. (2012, p. 123) afirma que

[...] com tecnologias e ambientes digitais como computadores pessoais, dispositivos móveis, internet, web, mensageiros instantâneos, chats, fóruns e wikis, os cidadãos comuns conseguem mais possibilidades de se expressar, expandindo temporalmente e espacialmente seu alcance.

Assim, a possibilidade de comunicação entre todos é muito maior, uma vez que através da cultura digital, educandos, famílias e profissionais diversos da instituição fazem uso desses recursos tecnológicos para se comunicar. Percebe-se então, o quão é importante o uso pedagógico destas ferramentas tecnológicas, pois superam os empecilhos do tempo e espaço geográfico, facilitando a articulação e comunicação entre escola e comunidade escolar. De acordo com o Ministério da Educação, Brasil (2007, p.11), os AVAs são:

[...] programas que permitem o armazenamento, a administração e a disponibilização de conteúdos no formato Web. Dentre esses, destacam-se: aulas virtuais, objetos de aprendizagem, simuladores, fóruns, salas de bate-papo, conexões a materiais externos, atividades interativas, tarefas virtuais (Webquest), modeladores, animações, textos colaborativos (wiki).

Nesse sentido, o Coordenador Pedagógico enquanto mediador, deve nortear e incentivar o processo de formação continuada do docente em serviço. $O$ Ambiente Virtual de Aprendizagem (AVA) pode ser uma importante ferramenta nesse processo, visto que oportuniza a capacitação mediante a Educação à Distância (EAD), ou seja, os conteúdos podem ser postados e acessados de qualquer lugar com acesso à internet. O Moodle é uma plataforma EAD que pode ser configurado em um AVA tanto para uso de formação continuada dos professores, como para o uso didático-pedagógico (professor/aluno). O Ministério da Educação (MEC) também oportuniza diversos cursos EAD para formação continuada dos professores e coordenadores, bem como sugestões de novas práticas e planos de aula dos diferentes componentes curriculares. Sendo assim, o docente ao obter novos saberes, metodologias, 
conteúdos através dos AVAs, se sente estimulado a utilizar os recursos tecnológicos, que por vez, auxiliam em sua prática. A seguir, apresenta-se um mapa conceitual, a fim de demonstrar, de forma concreta, o fluxo da incorporação das TICs nas instituições de forma a ser incorporada na cultura escolar e os seus contributos para prática pedagógica do Coordenador Pedagógico.

Figura 1 - Mapa conceitual da representação gráfica da concepção da cultura a ser implementada com o uso pedagógico das TICs no ensino.

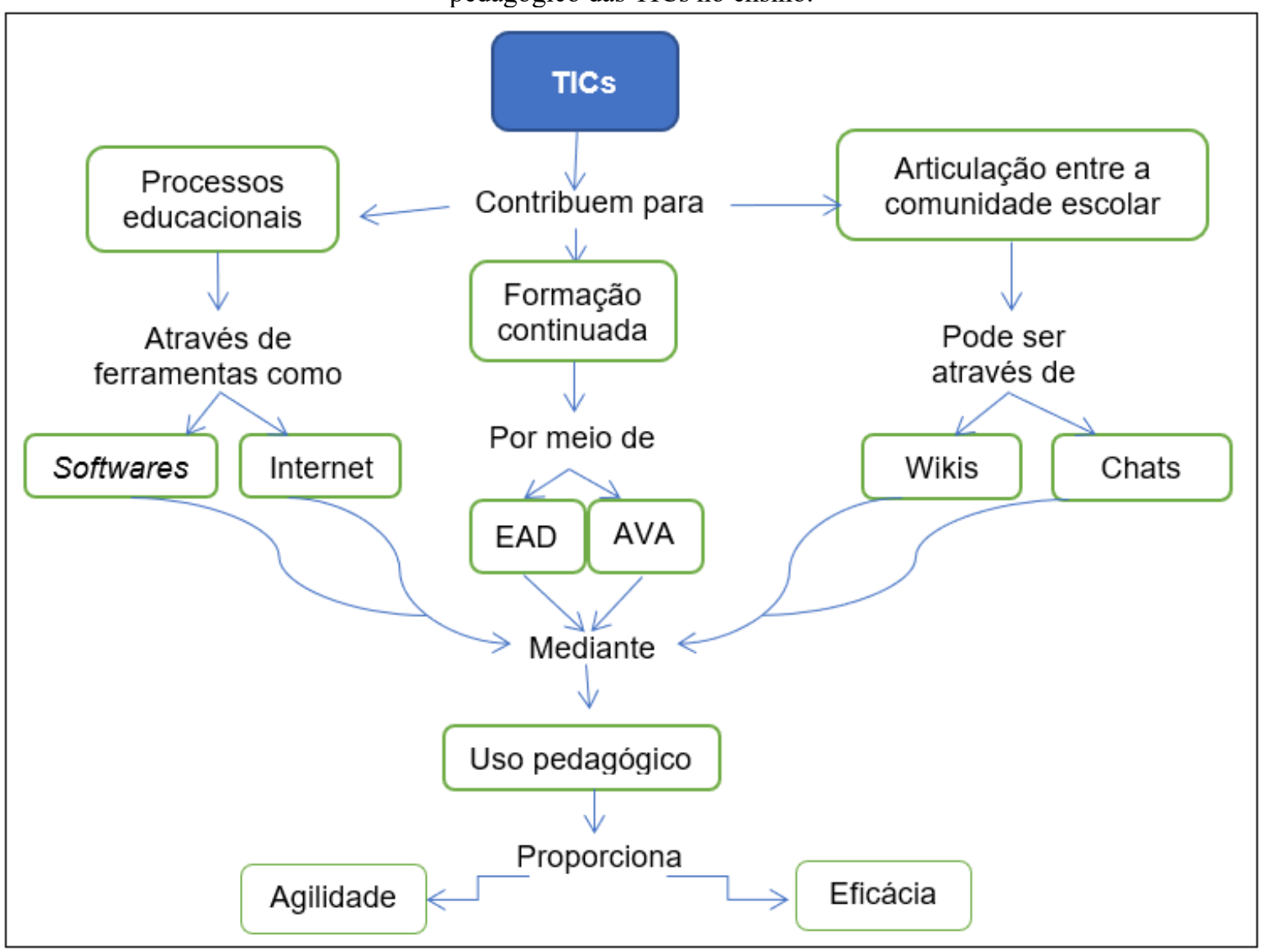

Mediante a análise do mapa, percebe-se que os recursos tecnológicos quando utilizados adequadamente e de forma pedagógica, conforme as demandas da instituição, resultam na agilidade e eficácia dos processos. Desse modo, é imprescindível a cultura do uso pedagógico para os recursos tecnológicos no âmbito escolar.

Diante do enfoque, evidencia-se os contributos desses recursos na prática pedagógica deste profissional da educação, perante a utilização do computador. Compreende-se, então, que é de suma importância que o Coordenador Pedagógico instigue a comunidade escolar à cultura do uso/manuseio pedagógico dos recursos tecnológicos, além disso, constata-se as potencialidades desses recursos na execução das tarefas do cotidiano escolar. Nesse sentido, as 
TICs tendem a contribuir na prática do profissional referido, assim como, predispõe o bom desenvolvimento/funcionamento da instituição.

\section{METODOLOGIA}

A pesquisa consistiu em revisão bibliográfica e fundamentação teórica. Optou-se pela análise de conteúdo de natureza explicativa, uma vez que, após tornar explícito as potencialidades e obstáculos em virtude da incorporação pedagógica desses recursos tecnológicos, almejou-se evidenciar os contributos das TICs através da utilização adequada e condizente com o propósito do PPP.

A coleta de dados ocorreu no período de abril de 2019 a novembro de 2019, através de pesquisas por meio de livros, artigos e internet. No qual enfocou-se em elementos como, Coordenador Pedagógico, TICs e prática pedagógica. Também, foi fundamentado em autores como, Kenski (2007), Lück (2014), Miranda (2007), Moran (2012) e Oliveira (2017).

Na perspectiva de sua natureza e acerca dos fins, a pesquisa realizada, classifica-se como uma abordagem qualitativa reflexiva. Visto que, através de análises cautelosas e embasamentos norteados pelo conhecimento científico, em que viabilizou a construção deste artigo, contemplando os benefícios e desafios sobre a incorporação pedagógica e o potencial das TICs mediante a cultura do uso pedagógico. Do mesmo modo, permitiu a relacionar estes com as funções pertinentes ao Coordenador Pedagógico e as capacidades dos recursos tecnológicos na prática pedagógica do mesmo. Assim, oportunizando o melhor entendimento quanto à temática, pois este conduz a uma reflexão a respeito da relevância do domínio das TICs e dos contributos das mesmas na prática do Coordenador Pedagógico.

\section{CONSIDERAÇÕES FINAIS}

À vista dos resultados das análises dos dados coletados da pesquisa, constata-se que o Coordenador Pedagógico possui funções múltiplas, tais como, articulador, formador do docente e referente aos processos educacionais. Logo, torna-se nítido os contributos das TICs quando utilizadas com propósito educacional e de forma pedagógica, visto que tendem a proporcionar eficiência e praticidade na execução das tarefas. Nessa perspectiva, compreende-se que essas tecnologias podem beneficiar tanto a prática pedagógica do referido profissional como na melhoria dos processos de desenvolvimento da instituição.

Ao que refere à incorporação pedagógica dos recursos tecnológicos na prática pedagógica, tanto quanto, na instituição, há implicações e dificuldades, devido à falta de uma 
utilização pedagógica ou não uso dos recursos; aos imprevistos emergenciais no cotidiano escolar, que por vez, impossibilita o Coordenador Pedagógico de cumprir suas funções efetivamente; e diante da escola convencional que preza pela sua cultura organizacional, em detrimento da atualização das metodologias e recursos, se configurando resistente à mudança. Assim, constata-se que é imprescindível que a escola esteja aberta às inovações tecnológicas, tanto nas práticas articuladoras da coordenação pedagógica, bem como no trabalho do coletivo de professores, na formação continuada e planejamento, pois esses se configuram em subsídios que podem propiciar a superação dos desafios supracitados, e possibilitar a perpetuação da cultura do uso pedagógico das ferramentas tecnológicas.

Por fim, acerca do potencial das TICs perante a cultura do uso pedagógico, elucidou-se o quão é significativo que o Coordenador Pedagógico incentive e implemente o uso dos recursos tecnológicos para mediar e articular pedagogicamente com a comunidade escolar. Além disso, com relação aos contributos do domínio das tecnologias de informação e comunicação na prática do Coordenador Pedagógico e nos processos educacionais, evidenciou-se que se faz necessário que ele busque métodos de viabilizar o uso pedagógico das TICs na formação continuada do docente e na articulação entre escola e comunidade escolar.

Em virtude do que foi abordado ficou claro que possuir recursos tecnológicos não é suficiente para proporcionar melhoria na prática do Coordenador Pedagógico, é de suma importância que o profissional da educação compreenda as funcionalidades, implicações e a relevância desses recursos, para então conduzir a efetiva incorporação pedagógica das TICs. Ante ao exposto, conclui-se que o Coordenador Pedagógico, devido suas funções, precisa dominar as TICs não só para usufruir de seus contributos em sua prática pedagógica, mas também para potencializar a incorporação/uso pedagógico dos recursos tecnológicos, que por conseguinte, propicia progresso e melhoria no ensino nos processos pedagógicos.

Compreende-se então, que, embora haja referências bibliográficas de todos os recursos e aplicativos citados, as produções em relação as redes sociais, e aplicativos de comunicação instantâneas, tais como facebook, instagram e whatsApp e as bibliografias encontradas e correlacionando as práticas do Coordenador Pedagógico são insuficientes.

\section{REFERÊNCIAS}

BRASIL, Ministério da Educação. Referenciais para elaboração de material didático para EaD no Ensino Profissional e Tecnológico. Brasília, DF, 2007. Disponível em: http://ltcead.nutes.ufrj.br/vivencias/recursos/45ref_materialdidatico.pdf. Acesso em: 27/09/2019. 
CANDAU, Vera Maria Ferrão. Tecnologia educacional: concepções e desafios. Caderno de Pesquisa, $\quad$ n. $28, \quad 1979 . \quad$ Disponível em: http://publicacoes.fcc.org.br/ojs/index.php/cp/article/view/1696/1682. Acesso em: 01/06/2019.

KENSKI, Vani Moreira. Educação e tecnologias: o novo ritmo da inovação. $3^{\mathrm{a}}$ ed. Campinas, SP: Papirus, 2007. ISBN 978-85-308-0828-0.

LÜCK, Heloisa. Liderança em gestão escolar. v. 4, Série Cadernos de Gestão. 9. ed. Petrópolis, RJ: Vozes, 2014. ISBN 978-85-326-3620-1.

MIRANDA, Guilhermina Lobato. Limites e possibilidades das TIC na educação. Revista de Ciências da Educação, n.3, Maio/Ago 2007, ISSN 16494990. Disponível em: $<$ http://ticsproeja.pbworks.com/f/limites+e+possibilidades.pdf $>$. Acesso em: 05/06/2019.

MONTEIRO, Elisabete; et al.. Coordenador Pedagógico: função, rotina e prática. $1^{\text {a }}$ Edição 2012. ISBN 978-85-65956-00-0. Disponível em: < http://institutochapada.org.br/livros/Livro\%20Coordenador\%20Pedag\%C3\%B3gico.pdf $>$. Acesso em: 05/06/2019.

MORAN, José Manuel. Bases para uma educação inovadora. In: MORAN, José Manoel (org.). A educação que desejamos: novos desafios e como chegar lá. $5^{\mathrm{a}}$ ed. Campinas, SP: Papirus, 2012. ISBN 978-85-308-0835-8.

NOVAIS, Vera Lúcia Duarte de. A cultura escolar e a inserção das TICs: dificuldades e oportunidades. Workshop em Informática na Educação (wie), 2003. São Paulo. Disponível em: $<$ https://www.br-ie.org/pub/index.php/wie/article/view/769/755>. Acesso em: 09/09/2019.

OLIVEIRA, J. Cordeiro de. O Cotidiano Escolar do Coordenador Pedagógico: Diversidades, Tensões e Possibilidades. v. 26, n. 1, p. 143-160, jan./jun. 2017. E-ISSN 23163100. Disponível em: < file:///C:/Users/'rtk5156o23y7.i08/Downloads/6138-20120-1PB\%20(10).pdf. Acesso em: 26/09/2019.

OLIVEIRA, R. de. Informática na Educação. In: OLIVEIRA, Ramon de (org.). Informática Educativa. 17. ed. Campinas, SP: Papirus, 2012. ISBN 978-85-308-0453-4.

SANCHO, Juana María. De tecnologias da informação e comunicação a recursos educativos. In: SANCHO, Juana María; Hernandez, Fernando et al. (org.). Tecnologias para transformar a educação. Porto Alegre: Artmed, 2006, p. 19. ISBN 978-85-363-0709-1.

SILVA, Moacyr da. O trabalho articulador do coordenador pedagógico: a integração curricular. In: PLACCO, Vera Maria Nigro de Souza; ALMEIDA, Laurinda Ramalho de. (org). O coordenador pedagógico e os desafios da educação. $5^{\text {a }}$ ed. São Paulo: Ed. Loyada, 2012. ISBN 978-85-15-03597-7.

SILVA, Tarcízio. Comunicação Publicitária em Aplicativos de Análise de Informações Sociais: Persuasão Sociotécnica nos Sites de Redes Sociais. Comunicação \& Mercado/UNIGRAN Dourados - MS, v. 01, n. 03, p. 120-134, jul-dez 2012. ISSN 2316-3992. Disponível em: https://www.unigran.br/dourados/mercado/paginas/arquivos/edicoes/3/12.pdf $>$. Acesso em: 25/09/2019. 


\title{
Atendimento pedagógico domiciliar: inclusão além dos muros da escola Atendimento pedagógico domiciliar: inclusão além dos muros da escola
}

\section{Bruna Letícia Santos de Oliveira ${ }^{1}$}

\begin{abstract}
Resumo
O presente artigo justifica-se através da necessidade de entender o funcionamento do Atendimento pedagógico domiciliar, considerando seu funcionamento, organização, legislação, formação do professor e impacto sobre a dinâmica familiar. O Artigo tem como objetivo abordar os aspectos ligados as demandas que o APD (atendimento pedagógico domiciliar) tem, diante dos alunos, professores e sua importância em uma perspectiva inclusiva, colocando aspectos históricos e legislativos de uma modalidade de ensino que muitas vezes é desconhecida por parte de muitos educadores. O Atendimento domiciliar tratase de uma modalidade de ensino que tem por encargo a manutenção do processo educacional do aluno que por razões de saúde, estão impossibilitados de frequentar a escola regularmente. Esta pesquisa de caráter bibliográfico, documental e prático baseado nas metodologias utilizadas no trabalho docente realizado com uma aluna no ano de 2019. Utiliza-se artigos e livros que abordam o funcionamento desta dinâmica de atendimento e aspectos históricos e legislativos sobre o tema.
\end{abstract}

Palavras-chave: Educação inclusiva; Educação Domiciliar; Educação; lúdico

\section{Abstract / Resumen}

This article is justified if, through the need for meaning, the functioning of home pedagogical assistance, considering its functioning, organization, teacher training and impact on family dynamics. The article aims to address the connected aspects such as demands that the APD (home pedagogical assistance) has before students, teachers and its importance in an inclusive perspective, placing historical and legislative aspects of a teaching modality that is often unknown by many educators. Home care is a teaching modality that is responsible for maintaining the educational process of the student who, due to health reasons, are unable to attend school regularly. This bibliographic, documentary and practical research based on the methodologies used with a student in the year 2019. Articles and books that address the functioning of this service dynamics and historical and legislative aspects on the topic are used.

Keywords: Inclusive education; home education; Education; ludic

\section{Introdução}

O Atendimento Pedagógico Domiciliar é um modelo de atendimento educacional que vem ganhando espaço em nosso país. Este suporte está dirigido para crianças e adolescentes enfermos que não podem sair de suas casas. Esses estudantes apresentam doenças distintas, uns apresentam doenças crônicas, outros apontam disfunções degenerativas e há também

\footnotetext{
${ }^{1}$ bruna.leticia95@gmail.com
} 
casos nos quais os alunos foram sujeitos a tratamentos ou mesmo sofreram circunstâncias que os inabilitaram de frequentar conjunturas sociais e as escolas regulares. Durante muito tempo, os responsáveis destas crianças e adolescentes demandavam desenvolver ferramentas particulares ou contratar docentes para proporcionar atendimento educacional convencional a seus filhos que por ventura se enquadravam nesse perfil. Atualmente, diversos estados e municípios do Brasil têm conseguido proporcionar e assegurar o direito a educação para essas crianças e adolescentes que são atendidos individualmente em suas residências através do Atendimento Pedagógico Domiciliar. Eles são atendidos por docentes que atuam nas redes públicas de educação, esses professores ensinam a esses educandos os conteúdos da grade curricular regular que eles estudariam em suas receptivas instituições escolares, alem de abordar as habilidades de acordo com suas demandas individuais.

Em contrapartida temos o AEE- atendimento educacional especializado, que é caracterizado por ser oferecido no contraturno de uma maneira que possibilite a suplementação das necessidades do aluno na educação regular. Essa modalidade é regulamentada pela lei de diretrizes e bases da educação 9394/96 além da Resolução CNE/CEB n², de 2001 (CNE/CEB/BRASIL, 2001). Os documentos trazem uma concepção mais ampla, assumindo o Atendimento Educacional Especializado como complemento ao ensino regular (BRASIL. SEESP/MEC, 2002.). coloca que:

Elaborar estratégias e orientações para possibilitar o acompanhamento pedagógico-
educacional do processo de desenvolvimento e construção do conhecimento de
crianças, jovens e adultos matriculados ou não nos sistemas de ensino regular, no
âmbito da educação básica e que encontram-se impossibilitados de frequentar
escola, temporária ou permanentemente e, garantir a manutenção do vínculo com as
escolas por meio de um currículo flexibilizado e/ou adaptado, favorecendo seu
ingresso, retorno ou adequada integração ao seu grupo escolar correspondente, como
parte do direito de atenção integral. (BRASIL. SEESP/MEC, 2002, p. 05)

Portanto, o processo educacional pode ser realizado em outros ambientes que não sejam espaço escolar, dentre eles as Classes hospitalares e Ambientes domiciliares (BRASIL, 2002). Ambos os serviços são destinados a viabilizar um atendimento para alunos que por motivos diversos são impossibilitados de frequentar as aulas regularmente. Desta forma, o atendimento pedagógico domiciliar, vai muito além dos alunos frequentadores na sala de recursos, mas todos que por algum motivo necessitam ausentar-se da escola por razoes de saúde sendo elas temporárias ou não.

Entende-se que este trabalho tem como objetivo realizar uma pesquisa bibliografia e documental sobre o tema, apresentando aspectos históricos e legislativos, além de discorrer sobre o atendimento domiciliar de alunos que se enquadram nessa modalidade e ratificar as 
políticas inclusivas e ações que existem para garantir que todos que tenham alguma deficiência o acesso à escola e não sejam privados do seu desenvolvimento pedagógico e cognitivo.

\section{Materiais e métodos}

Este artigo é a junção do relato da prática pedagógica ocorrida durante o ano de 2019 no município de Caraguatatuba, além de uma breve revisão de artigos relacionados ao tema que contribuíram para a construção de uma visão pautada no funcionamento dessa modalidade de ensino. A literatura foi selecionada a partir da sua relevância para apontar aspectos históricos, legislativas e funcionais sobre o tema. Os artigos foram coletados através de bases de dados eletrônicos nacionais tais como: Scientific Eletronic Library Online (SciELO) e google scholar.Os artigos foram pesquisados através de palavras chaves ligadas ao tema para apontar as possíveis contribuições para se discutir a formação docente e a composição do atendimento pedagógico domiciliar, (APD).

\subsection{História e legislação: da educação especial à educação inclusiva}

Embora se fala sobre educação especial devesse entender que no Brasil houve diversas legislações e acontecimentos ligados as políticas educacionais inclusivas. De acordo com Aranha (2005), o primeiro acontecimento relevante para Educação Especial no Brasil, deu-se em 1835 posto que o Deputado Cornélio Ferreira apresentou à Assembleia o Projeto de Lei que estipulava a formação do cargo de Professor de Primeiras Letras para o ensino de surdosmudos e de cegos. Em 1857 Mazzotta (2003) afirma que D. Pedro II fundou no Rio de Janeiro Imperial Instituto dos Surdos-Mudos, condigno aos esforços de Ernesto Hüet e seu irmão, três anos após A formação do Instituto Benjamin Constant para cegos. Em 1910, três cegos que frequentaram o Instituto, entraram para a Faculdade de Direito de São Paulo e em 1943 através do Decreto $\mathrm{n}^{\circ} .165$ o Instituto recebe o direito de ministrar os ensinos primários e secundários De acordo com Battisti (2007) o deficiente começa a ser observado como sujeito, com direitos educacionais iguais aos demais. Exclusivamente a partir do Século XX. Assim, para Mittler (2003):

A Inclusão implica uma reforma radical nas reformas em termos de currículo, avaliação, pedagogia e formas de agrupamentos dos alunos em sala de aula. Ela é baseada em um sistema de valores que todos se sintam bem-vindos e celebra a diversidade que tem como base o gênero, a nacionalidade, a raça, a linguagem de 
origem, o background social, o nível de aquisição educacional ou a deficiência. (MITTLER,2003, p34).

Atualmente, tivemos grandes evoluções já citados, segundo Battisti (2007, p.132) as leis que consolidam e resguardam o portador de necessidades especiais são: a LDB, Lei n9394 de 1996 e as Diretrizes Nacionais para Educação Especial na Educação Básica (Decreto $n^{\text {o }} 3956$ de 2001). De acordo com Neri (2003), a LDB concede as escolas especiais, mas não dá autonomia para que o aluno ou os pais sejam capazes determinar a modalidade que desejam enviar seus filhos. Vale evidenciar que a lei endossa às pessoas com necessidades especiais tem direto a docentes com formação pertinente para enxergar as diferenças, carregando consigo praxe de ensino que favoreçam a divergência e as características de cada aluno. (MANTOAN, 2003).

Além de assegurar, segundo o Decreto $N^{o} 7.611$ de 2011, ajuda técnico e financeiro às redes de ensino público. Ornamentando o atendimento educacional especializado, com investimentos sólidos na formação dos educadores e gestores, adaptando espaços de maneira arquitetônica e implantando das salas de recursos multifuncionais (dotadas de insumos visuais e materiais pedagógicos e educacionais indicados).

\section{APD aspectos legislativos}

A Lei de Diretrizes e Bases da Educação Nacional/LDB 9394/1996 no seu artigo $5^{\circ}$ coloca que ao Poder Público cabe gerar formas alternativas de acesso aos inúmeros níveis a educação, acarretando a organização para garantir o processo de aprendizagem (artigo 23) (BRASIL, 1996). Elementos diversos de saúde podem transcorrer impossibilitando a presença do educando em espaço escolar. De acordo com a Resolução no 02, de 11 de setembro de 2001, artigo 13, do Conselho Nacional de Educação concede que os sistemas de ensino, diante da ação integrada com os sistemas de saúde, necessitam regular o atendimento educacional especializado a educandos impossibilitados de comparecer as aulas em compreensão de tratamento de saúde (BRASIL, 2001).

Desta forma o atendimento pedagógico domiciliar concede a inclusão social de educandos que externam alguma enfermidade por longos períodos, e necessitam ausentar-se do espaço escolar. O perfil de ação agregada entre saúde e educação no relativo ao Atendimento Educacional Domiciliar é apontada na resolução do CNE/CEB n 02, de 11/09/2001 que reforça que: 
frequentar as aulas em razão de tratamento de saúde que implique internação hospitalar, atendimento ambulatorial ou permanência prolongada em domicílio.

Diante da legislação indicada, cabe enfatizar que ainda que haja direito, o apoio pedagógico domiciliar diversas vezes não é oferecido e assim é fundamental que profissionais da educação, familiares, educandos juntamente com os órgãos públicos evidenciem proposto ações que consigam preservar a obrigatoriedade da oferta e cumprimento deste direito. A relevância do atendimento pedagógico Domiciliar está no fato de atender ao direito dos educandos em tratamento de saúde, oferecendo a sucessão de seus estudos, sem ter perdas em seu avanço pedagógico, cognitivo e social.

Os educandos retirados de sua rotina, necessitam de atividades que os remeta à realidade diária que ele vivia antes do afastamento por razões de saúde. O Atendimento Pedagógico Domiciliar é a inclusão da atmosfera escolar, no ambiente domiciliar que por meio do comparecimento do docente que por sua vez, tem o papel de oportunizar a escolarização. Os estudantes desta modalidade de atendimento que recebem os professores em seus domicílios enfrentam alguns fatores que vão além de limitações pedagógicas, cabendo assim ao professor ter a sensibilidade necessária para entender as demandas desses estudantes.

Cabe, portanto, ao professor, neste contexto rever sua postura anterior da realidade formal da educação e ampliar sua visão de maneira multifacetada, para possibilidades e os desafios que ali se apresentam (MATOS e MUGGIATI, 2011). Considerando que todos têm direito a educação em sua integralidade, o modelo de atendimento pedagógico domiciliar deve ser entendido como uma experiência educacional completa para esses alunos. A questão que se levanta a partir dos problemas é como se dá a construção de lugares de não aprendizagem no âmbito escolar e a influência do diagnóstico médico. (FONSECA e MATTOS 2013)

Conglobar essas ideias as práxis diárias é fazer desse modelo educacional parte da rotina destes alunos e incluí-los de forma integral dentro do currículo educacional, impossibilitando perdas em sua formação.

O professor durante o processo precisa considerar diversas possibilidades para que tenha um local minimamente adequado para o trabalho escolar com esses alunos. De acordo com Silva, Pacheco e Pinheiro (2014) o professor precisa "adequar a sua práxis a gradações e particularidades de um espaço que a priori não é seu". Pois uma vez que o professor entra na residência de um aluno e presencia situações familiares é um dos aspectos singulares do atendimento pedagógico domiciliar, que o docente viverá durante o seu trabalho. Cardoso 
(2006) afirma que o educador nesse processo é um importante mediador, cujas estratégias de ensino estão apoiadas pela utilização de recursos específicos, facilitadores no Atendimento.

\subsection{O Papel Do Professor No Atendimento Domiciliar}

O docente que atua no atendimento pedagógico domiciliar precisa estar ciente que suas atribuições e responsabilidades são as mesmas que o ambiente escolar consequentemente desenvolver e reconduzir o procedimento do atendimento do aluno; notificar de encontros, reuniões e cursos de qualificações e formação continuada; efetuar relatório e portfólio sobre o desenvolvimento no intervalo em que o aluno esteve em Atendimento; realizar o plano de trabalho, a partir da Proposta Pedagógica. Neste contexto, cabe destacar que o Atendimento Pedagógico Domiciliar, requer:

Discernimento para atuar com planos e programas abertos, móveis, mutantes constantemente reorientados pela situação especial e individual de cada criança ou adolescente sob atendimento (CECIM; FONSECA, 1998, p 26).

Desta maneira compreende-se que deve constituir parcela importante do perfil profissional do docente que atua no Atendimento Domiciliar, a assistência na medida em que a relação do ser humano com o mundo não é, por consequente, uma vinculação direta, mas uma relação mediada por outras pessoas e pelas produções humanas, que depende das atividades efetiva em que ele se envolve e não se limitam aos encontros físicos.

No âmbito que se refere às práticas pedagógicas junto aos educandos acompanhados em atendimento domiciliar, é essencial evidenciar o quanto se aproxima das práticas junto aos alunos com deficiência em razão das adequações necessárias.

$\mathrm{O}$ atendimento requer de o docente reconsiderar a sua prática e flexibilizá-la a partir do âmbito vivido onde o tempo necessita ser otimizado, a aprendizagem deve intercorrer de modo positivo, a família precisa ser parceira neste processo e o agravo educacional devido à ausência da atmosfera escolar minimizado.

É indispensável possuir uma forte articulação entre o docente que realiza o atendimento e a escola de referência do estudante, visto que há uma proposta pedagógica direcionada para o desenvolvimento deste educando visto que a condição de saúde do educando pode se modificar e num imprevisível retorno para a escola logo desta forma também retorna para o atendimento educacional especializado em ambiente regular. Por isso, é essencial que o professor do atendimento pedagógico domiciliar atue conforme estivesse em 
uma sala de aula regular, no sentido de expandir uma união com os professores da turma em que o educando está matriculado.

\section{Resultados e discussões}

Como citado anteriormente o artigo baseia-se nas experiências vivenciadas por uma professora da escola pública do município de Caraguatatuba, em relação ao atendimento educacional especializado realizado com um aluno da rede pública municipal de Caraguatatuba-SP partindo que os atendimentos acorriam em sua residência, todo o plano de ação foi transformado em um portifólio e adaptado de acordo com as demandas do aluno. $\mathrm{O}$ trabalho executado durante o ano de 2019, foi dividido em duas partes principais, a primeira estava ligada a criação do vínculo segundo Dias (2018):

Quando existe uma relação afetiva entre professor-aluno, o último sente-se seguro e confiante ao realizar as atividades propostas, como também a relacionar-se com outros colegas. Isso ajuda na construção da autoestima e contribui diretamente para a aprendizagem e, consequentemente, para o desenvolvimento dele.

O vínculo, parte de uma importante etapa das relações humanas e principalmente nas ralações educacionais, envolvendo professor e aluno. Entendendo isso durante os primeiros meses muito além do conteúdo, a construção de um vínculo com o aluno fez-se essencial para o bom desenvolvimento do trabalho pedagógico, juntamente com a compreensão das demandas e limitações do educando.

Em um segundo momento, o foco foi as adaptações dos conteúdos, entendendo que o aluno que se faz apto a essa modalidade de atendimento, tem limitações e necessidades que cabe ao professor entender e suprir.

Uma das estratégias adotadas durante as aulas é o trabalho com portifólios que ajuda o professor a observar o progresso do aluno em diferentes competências trabalhadas. Diante desta prática o professor media a construção do conhecimento de seu aluno, trabalhou-se com o aluno a teoria da Zona de Desenvolvimento Proximal, utilizando-se do conhecimento já existente do aluno para que ele seja capaz de formular novos conceitos e assim avançar em suas aprendizagens mesmo fora do ambiente educacional regular.

Durante as aulas, o planejamento das atividades foi pensado para ir além do ambiente escolar, entendendo que a aprendizagem deve ser efetiva em um ambiente não convencional. Trazer a escola para dentro da casa do aluno é um objetivo claro, que foi proporcionado através não só de atividades, mas de objetos e brinquedos pedagógicos que acompanhavam as atividades para um momento lúdico. Durante os atendimentos pode-se notar a receptividade 
por parte da família em relação ao docente, criando assim expectativas sempre positivas sobre o descendimento do Educando, Glat e Pletsch, (2004) colocam sobre as dinâmicas pedagógicas em relação as dinâmicas familiares e como devem ser tratadas diante deste modelo de educação.

Durante o ano, a relação entre o docente e o aluno tornara-se naturais, entendendo que a partir destes processos iniciais executados, o aluno internalizou a dinâmica das aulas e o funcionamento da rotina em ambiente domiciliar, tornando assim o ambiente domiciliar, uma extensão do espaço escolar.

\section{Considerações Finais}

Este trabalho permitiu abranger fatos ligados ao processo de escolarização de crianças que se fazem apta ao atendimento pedagógico domiciliar. Para compreender melhor os aspectos sobre o tema, além de informações históricas e legislações ligadas a inclusão e educação especial.

Utilizou-se uma serie de referências bibliográficas e documentais, utilizando-se de artigos que permitiram compreender a importância dos atendimentos domiciliares é um importante auxílio para suprir as demandas desses alunos que se encontram em tratamento médico e assim impossibilitados de frequentar o ambiente escolar. Salientou-se neste artigo através do relato da prática docente ocorrida em 2019 com um aluno que por motivos de saúde foi impossibilitado de frequentar a escola, através do relato pode-se notar a importância do trabalho em equipe dos professores juntamente com a família, para garantir a esses educandos a possibilidade ampla de seu desenvolvimento social, pedagógico e cognitivo, assim buscando de forma efetiva de contribuir com esses alunos.

Nesse contexto, cabe ainda referir que durante a realização da pesquisa, foram feitas diversas buscas bibliográficas em diversas bases de dados, nacionais, e com múltiplos descritores. Pode-se concluir que essa modalidade de atendimento apesar de ser respaldada pela legislação, não é explorada amplamente na literatura, no entanto a pesquisa fornece um conhecimento relevante no âmbito da educação especial e inclusiva no campo do atendimento pedagógico domiciliar e de sua prática diária. 


\section{Referências}

BATTISTI, C. M. Inclusão: História e Legislação. Disponível em http://ceedo.com.br/agora/agora4/inclusaohistoriaelegislacao CleusaMolinariBattisti.pdf.

Acesso em: abr. 2019. p. $131-134$

BRASIL. Conselho Nacional de Educação. Câmara de Educação Básica. Resolução Conselho Nacional de Educação / Câmara de Educação Básica n. 2, de 11 set. 2001: Institui diretrizes nacionais para a Educação Especial na Educação Básica. Diário Oficial da União, Brasília, 14 de setembro de 2001.

BRASIL. Decreto n. 7.611, de 17 de novembro de 2011. Dispõe sobre a educação especial, o atendimento educacional especializado e dá outras providências. Diário Oficial da União, Brasília, 18 de novembro de 2011.

BRASIL. Ministério da Educação e Cultura. Lei de diretrizes e bases da Educação Nacional, n. 9394. Brasília: MEC, 1996.

BRASIL. Secretaria de Educação Continuada, Alfabetização, Diversidade e Inclusão. Classe hospitalar e atendimento pedagógico domiciliar: estratégias e orientações. Brasília, DF: Mec/Seesp, 2002.

BRASIL. Secretaria de Educação Continuada, Alfabetização, Diversidade e Inclusão. Política Nacional de educação especial na perspectiva da educação inclusiva. Brasília: Mec/Seesp, 2008.

CARDOSO, M. Aspectos Históricos da Educação Especial: da exclusão à Inclusão - Uma Longa Caminhada. In: STOBÄUS, C.D.; MOSQUERA, J. J. M. (org.). Educação Especial: em direção à Educação Inclusiva. Porto Alegre: Edipucrs, 2006. p.15-26.

CECCIM, R. B.; FONSECA, E. S. Classes hospitalares no Brasil. Rio de Janeiro: Secretaria Municipal da Saúde: Secretaria Municipal da Educação, 1998. Reunião de trabalho realizada na classe hospitalar do Hospital Municipal Jesus, em 04 ago. 1998.

DIAS, Beatriz Simão. O relacionamento professor-aluno na educação infantil: observações de vínculos corriqueiros em sala de aula com crianças de 1 a 2 anos participantes de uma creche do DF. 2018.

FONSECA, A. S. S.; Mattos, M. G. O lugar da aprendizagem e a patologização da infância. XIII Encontro Latino-Americano de Pós-graduação, 2013, São José dos Campos. Ciência, Inovação \& Tradição, 2013.

GLAT, R. e PLETSCH, M. D. Orientação familiar como estratégia facilitadora do desenvolvimento e inclusão de pessoas com necessidades especiais. Santa Maria. Revista 


\title{
INTELIGÊNCIA EMOCIONAL NAS ORGANIZAÇÕES: ATIVO OU PASSIVO NA PERSPECTIVA DOS ADMINISTRADORES?
}

\author{
Geisse Martins ${ }^{1}$
}

\begin{abstract}
Resumo
O presente trabalho tem como objetivo analisar e investigar como os administradores gerenciam a inteligência emocional dentro das organizações. Sendo as emoções parte fundamental dentro das empresas e objeto de atenção e análise dos administradores contemporâneos, nos últimos 50 anos, ganham destaque e figuram no planejamento estratégico como vantagem competitiva. A metodologia, utilizada foi a revisão teórica bibliográfica, com abordagem qualitativa, a partir da qual procurou-se compreender esse fato social contemporâneo, na tentativa de responder uma questão inquietante sobre como os administradores em tempos atuais compreendem o capital emocional, seja como um ativo ou despesas. Dentro de um contexto mundial, em que há mudanças rápidas e consideráveis em todos os níveis e em várias dimensões, sociais, econômicas e sobretudo tecnológicas, essas transformações agudas exigem cada vez mais das pessoas que atuam dentro das organizações de habilidades e competências não apenas técnicas, mais ainda de habilidades emocionais. Para além do equilíbrio emocional, os administradores estão sendo convidados a reverem conceitos e desconstruírem velhos paradigmas no que concerne às emoções. Esses administradores agora se dedicam ao estudo e à aplicação de teorias e conceitos que estruturam novos ambientes de trabalho, de forma a promoverem o bem-estar dos colaboradores, ao mesmo tempo que os impelem a gerenciar as emoções em favor mútuo, para os colaboradores e para as empresas e seus respectivos mercados.
\end{abstract}

Palavras-chave: Gerenciamento. Inteligência emocional. Emoções. Bem-estar. Vantagens sociais.

\begin{abstract}
This work aims to analyze and investigate how administrators manage emotional intelligence within organizations. As emotions are a fundamental part of companies and an object of attention and analysis by contemporary managers, in the last 50 years, they have gained prominence and figure in strategic planning as a competitive advantage. The methodology used was a theoretical literature review, with a qualitative approach, from which we sought to understand this contemporary social fact, in an attempt to answer a disturbing question about how administrators in current times understand emotional capital, whether as an asset or expenses. Within a global context, in which there are rapid and considerable changes at all levels and in various dimensions, social, economic and above all technological, these acute transformations increasingly demand from people who work within organizations, not just technical skills and competences. even more so of emotional skills. In addition to emotional balance, administrators are being asked to review concepts and deconstruct old paradigms when it comes to emotions. These managers are now dedicated to the study and application of theories and concepts that structure new work environments in order to promote the well-being of employees, while urging them to manage emotions in mutual favor, for employees and also for companies and their respective markets.
\end{abstract}

Keywords: Management. Emotional intelligence. Emotions. Welfare. Social advantages.

\footnotetext{
${ }^{1}$ Graduado em Pedagogia e Telecomunicações, possui MBA em Gestão Estratégica e especialização em: Neurociência e Aprendizagem, Psicopedagogia, Coordenação/Supervisão Escolar, Inspeção Escolar com ênfase em Educação Especial Inclusiva e Pedagogia Empresarial. Mestre em Tecnologias Emergentes em Educação, mestrando em Administração pela Must University e doutorando em Educação pela Eikon University. E-mail: geisse@geisse.com.br
} 


\title{
1 INTRODUÇÃO
}

A inteligência humana está intrinsecamente entrelaçada aos tempos e aos movimentos do trabalho. Desde a simples confecção de ferramentas até a construção de sofisticados equipamentos eletroeletrônicos, a inteligência humana se faz presente. Mais recentemente, dentro do conceito da quarta Revolução Industrial - de que o avanço no campo das ciências, suportadas pelas novas tecnologias da informação e da comunicação, que potencializam a inteligência de modo geral dentro das organizações, mas sobretudo a inteligência emocional faz-se necessária, dentro destes contextos de mudanças radicais e adaptações cotidianas, que os mercados das empresas (internos e externos) se imponham para as pessoas dentro organizações. Conforme o entendimento de Schwab (2016):

\begin{abstract}
Atualmente, enfrentamos uma grande diversidade de desafios fascinantes; entre eles, o mais intenso e importante é o entendimento e a modelagem da nova revolução tecnológica, a qual implica nada menos que a transformação de toda a humanidade. Estamos no início de uma revolução que alterará profundamente a maneira como vivemos, trabalhamos e nos relacionamos. Em sua escala, escopo e complexidade, a quarta revolução industrial é algo que considero diferente de tudo aquilo que já foi experimentado pela humanidade (Schwab, 2016, p. 15).
\end{abstract}

A inteligência humana e suas derivações, ao longo da história, sempre foi e ainda é objeto de estudos. Especificamente a inteligência emocional, nos últimos 50 anos, vem ganhando destaque no campo de pesquisas dentro das organizações, já que os ambientes laborativos, cada vez mais, aumentam o seu nível de complexidade e os conceitos mais elementares sobre inteligência geral já não dão suporte ao universo circunscrito das organizações.

Nessa direção e sentido, e dentro do contexto da inteligência emocional nas organizações, um termo que advém da Física - resiliência ${ }^{2}$ - que no contexto do comportamento humano é a capacidade de pessoas suportarem pressão, adaptarem-se e utilizarem a capacidade interior que soma habilidades e competências técnicas a habilidades sociais, emocionais, é agora parte integrante da estrutura edificante dos profissionais nas organizações. Por conseguinte, as habilidades emocionais (saber lidar com as emoções) são cada vez mais valorizadas nos ambientes organizacionais e têm lugar de destaque nas competências dos profissionais de modo geral, independentemente das funções que desempenham em seus respectivos postos de trabalho. Sem óbices, dentro das organizações, quando das decisões de investimento em inteligência emocional, algumas incertezas se impõem. Muitos executivos,

\footnotetext{
${ }^{2}$ Resiliência: propriedade que alguns corpos apresentam de retornar à forma original após terem sido submetidos a uma deformação elástica
} 
administradores, gestores e proprietários, e até mesmo a contabilidade, não conseguem chegar a um denominador comum acerca deste investimento. Dentre inúmeras questões, uma insurge inquietante: Investimentos em inteligência emocional nas organizações são compreendidos como ativos ou como despesas? Assim como pesquisa e desenvolvimento (P\&D), por que investimentos em inteligência emocional ainda são tímidos dentro das organizações?

No afã de discorrer sobre a inteligência emocional dentro das organizações, seu impacto e sua relevância como um investimento que esse artigo, à lume das considerações, afirmações e proposituras de autores e especialistas no assunto, procura elucidar essas questões inquietantes. A metodologia deste trabalho apresenta abordagem qualitativa e para a análise utilizou-se a técnica de observação e revisão teórica bibliográfica. Conforme argumenta Minayo (2001):

\begin{abstract}
A pesquisa qualitativa responde a questões muito particulares. Ela se preocupa, nas ciências sociais, com um nível de realidade que não pode ser quantificado. Ou seja, ela trabalha com o universo de significados, motivos, aspirações, crenças, valores e atitudes, o que corresponde a um espaço mais profundo das relações, dos processos e dos fenômenos que não podem ser reduzidos à operacionalização de variáveis (Minayo, 2001, p. 22).
\end{abstract}

Sendo assim, trazer à baila um estudo de observação e um olhar direcionado para dentro das organizações no que tange emoção das pessoas é um fato social de relevância atual no campo da administração contemporânea.

\title{
2 DESENVOLVIMENTO
}

Dentro das empresas contemporâneas, especificamente no que concerne à gestão de pessoas, idealizar, desenvolver, distribuir bens, produtos e serviços apenas de forma racional, sistematizada e com foco deliberadamente em questões financeiras já não mais são suficientes para a sobrevivência em seus respectivos mercados. Líderes e liderados dentro das organizações precisam atuar com habilidades e competências que transcendam habilidades técnicas. $\mathrm{Na}$ inteligência de Pezzi, Eckert, Pezzi e Zanotto (2020):

\begin{abstract}
A Inteligência Emocional (IE) gera maior qualidade de vida às pessoas que passam a controlar melhor seus sentimentos e isso afeta diretamente o bem-estar no ambiente de trabalho, pois estas passam a se relacionar de maneira mais agradável e tendem a reduzir conflitos desnecessários e focarem no objetivo da empresa (Pezzi, Eckert, Pezzi, \& Zanotto, 2020, p. 3).
\end{abstract}

Nessa direção e sentido, gigantes do setor de tecnologia, como Google e Microsoft, possuem investimentos no que se refere à inteligência emocional de seus colaboradores diretos 
e até mesmo indiretos. Essas organizações, geralmente, sabem que os resultados ao concretizar benefícios (emocionais) que possam atingir a vida pessoal e profissional dos colaboradores representam valor agregado não somente à marca, mas também tem impacto direto nas relações comerciais de seus produtos e serviços.

Na perspectiva das organizações, os principais benefícios da inteligência emocional são a integralização de equipes, que passam a apresentar mais comprometimento em suas atividades, e tarefas, na medida em que podem lidar com as adversidades advindas do trabalho e de suas vidas pessoais. Colaboradores que foram expostos ao conhecimento acerca de resiliência, capacidade de trabalhar em equipe, enfrentar dificuldades em situações de conflito e manter o equilíbrio emocional tendem a responder mais assertivamente às demandas que se apresentam nos locais de trabalho cotidianamente. Dentre as habilidades que as organizações esperam dos seus colaboradores, têm-se:

- autoconsciência;

- liderança de emoções positivas;

- automotivação;

- empatia;

- relações interpessoais positivas.

Por isso, muitas empresas desenvolvem suas atividades focando na interpretação e utilização da inteligência emocional como fator produtivo. É inevitável pensar em resiliência sem abordar o tópico "automotivação". Apenas profissionais com amplo controle de suas emoções, aliado a uma boa relação com toda a organização, desde a presidência, gerência, até as áreas operacionais, desenvolvem a capacidade de automotivação e o foco na solução do problema.

Importante ressaltar que os conceitos fundantes de inteligência emocional foram propostos por Saloney e Mayer na década de $1990^{3}$, em seu artigo teórico e seminal que versava sobre "a capacidade do indivíduo monitorar os sentimentos e as emoções dos outros e os seus, de discriminá-los e de utilizar essa informação para guiar o próprio pensamento e as ações”. Nessa década, também pode se destacar os trabalhos de Jonh Caippo e Gary Berntson acerca da também seminal "Neurociência Social", de acordo com Goleman (2011). A posteriori, compreender o que são as emoções e sua importância dentro das organizações figurou e ainda figura como um desafio para os administradores. Para além de simplesmente entender como as

\footnotetext{
${ }^{3}$ Mayer, J., \& Salovey, P. (1997). What is emotional intelligence? New York: Basic Books. Recuperado em 03 julho $2021 \mathrm{de} \mathrm{http://citeseerx.ist.psu.edu/viewdoc/download?doi=10.1.1.385.4383 \& rep=rep1 \& type=pdf.}$ 
emoções no ambiente de trabalho, aos administradores, dentro de seus planejamentos, há uma preocupação constante. Os investimentos em formação continuada dos colaboradores no que se refere à inteligência emocional. Não basta apenas compreender esse fenômeno social das relações interpessoais e das emoções dentro das organizações, é preciso também estabelecer planejamento, organização e controle de ações efetivas e afirmativas dentro deste escopo.

Por conseguinte, nesse planejamento há de figurar o investimento que potencialize as capacidades dos colabores (diretos e indiretos) ao que se refere à inteligência emocional, de tal sorte que se, no passado, esse tema estava restrito aos círculos acadêmicos e figurava mais intensamente com aspectos filosóficos, agora é uma realidade dentro das empresas e deve receber aporte do setor financeiro, sendo gerenciado pelos departamentos que lidam com a gestão de pessoas.

Um bom exemplo dessa nova dinâmica é o exemplo da Google e da Tecfil, que implantaram em suas estruturas internas o diretor de felicidade. Na gigante de tecnologia, o nome do cargo foi denominado como Chief Culture Officer (CCO). Esse cargo visa, fundamentalmente, a atuar no gerenciamento do bem-estar dos colaboradores bem como os bons resultados nos ambientes profissionais.

Há 15 anos como gerente de RH da Tecfil, Ana Paula de Oliveira diz que não existem segredos em estruturar um plano de felicidade corporativo. "O primeiro passo é conhecer e entender o perfil dos colaboradores, interesses, objetivos, sonhos etc., e construir uma jornada que faça sentido", declarou. A Tecfil, fabricante de filtros automotivos, tem 1.500 funcionários (Varella, 2017).

Com efeito, os administradores se depararam com o desafio de não somente gerenciar esse aspecto transdisciplinar, mas também determinar se o investimento em gestão do conhecimento em inteligência emocional é encarado como um ativo ou como uma despesa.

Sem hesitar, a administração contemporânea tem agora em sua estrutura de formação não somente estruturas das ciências econômicas, mas também da ciência de pessoas, do comportamento humano e com ênfase das ciências sociais. Isto porque o que se entende por economia emocional influencia diretamente os negócios de uma organização. A Figura 1 mostra os principais elementos que devem estar presentes na inteligência emocional. 
Figura 1 - Principais aspectos que envolvem a inteligência emocional

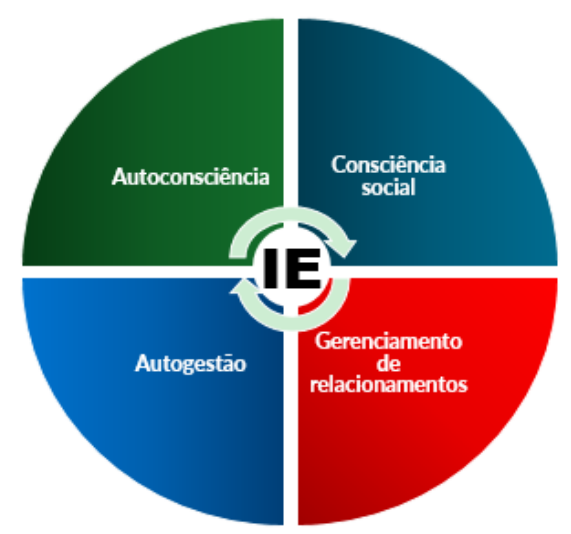

Fonte: Adaptado de Goleman, 2012, p. 10

Esse diagrama proposto por Goleman ilustra e vai ao encontro dos grandes questionamentos que agora suscitam e frequentam não somente os círculos acadêmicos, mas também permeiam as fileiras dentro das organizações. Questões do tipo: Há uma entidade definida como inteligência das organizações que difere do quociente de inteligência anteriormente usado como parâmetro de medida? Há também a dinâmica do radar ético do cérebro e das emoções, além de uma dinâmica neural da criatividade que existe e está presente não somente dentro das pessoas, mas como uma fragrância dentro das organizações.

As dúvidas em relação aos retornos esperados com investimentos em inteligência emocional nas organizações por parte dos administradores perpassam pelo fato de que essa nova perspectiva não constava da sua formação no passado recente. A administração clássica, que por décadas arrimou os conhecimentos dos administradores, não tinham a felicidade como um poderoso ativo dentro das organizações. Isto de certa forma torna céticos alguns administradores que ainda apoiam seus planejamentos em estruturas voltadas apenas para o objetivo e como numa espécie de miopia impede que vejam que a felicidade dentro dos ambientes laborativos pode ser encarada como ferramenta de estratégias importantes.

Deve-se ter a percepção de que, como em qualquer investimento, há variáveis que precisam ser entendidas e estudadas com rigor e que o administrador e/ou gestor precisam considerar esse aspecto em seu dashboard. Alguns pontos importantes desse investimento precisam de atenção dos administradores, como:

- compreender o que é esforço emocional;

- entender a teoria dos eventos afetivos;

- compreender como as emoções e sentimentos impactam as atividades organizacionais; 
- perceber a importância das emoções para a liderança;

- compreender o conceito de inteligência emocional;

- reconhecer a importância da inteligência emocional;

- compreender o que significa identificar emoções e;

- reconhecer a importância de identificar emoções nos ambientes laborativos.

Estudar e compreender todos esses aspectos pode ser determinante para que os administradores efetivamente percebam que a gestão estratégica da inteligência emocional (com ênfase na felicidade) nos ambientes laborativos das organizações tem a possibilidade de trazer impactos positivos na produtividade com consequentes resultados também positivos nos negócios.

Segundo Elcio Paulo Teixeira, CEO da Heach Recursos Humanos, diversas pesquisas apontam um ganho mínimo de 12\% de produtividade (para empresas que promovem algumas ações regulares de felicidade) e de até $40 \%$ (para empresas que possuem ações bem estruturadas de gestão da felicidade) (Varella, 2017). De acordo com o site Startee, em seu artigo intitulado "Employee Experience e a felicidade como ferramenta de produtividade":

Nos últimos cinco anos, cresceram as questões relacionadas à produtividade, bemestar, excesso de trabalho e esgotamento, segundo a Deloitte. Em um cenário de transformação digital, $84 \%$ dos entrevistados dizem que precisam repensar sua experiência na força de trabalho com o intuito de melhorar a produtividade. No entanto, por mais importante que seja, apenas $9 \%$ dos entrevistados acreditam que estão prontos para resolver esse problema, tornando-o uma prioridade para organizações em todo o mundo (Prado, 2020). Na mesma direção e sentido, têm-se as considerações de Madalena Carey, fundadora da Happiness Business School:

[...] felicidade no trabalho é como as pessoas se sentem. É saímos da cultura do dar para fazer os colaboradores sentirem e deixá-los serem quem são. Se pensarmos na adaptação hedônica, claramente, não adianta acharmos que faremos os colaboradores felizes somente com o aumento de seus salários, bônus, benefícios. Afinal, quando eles conquistarem isso, com certeza, continuarão na busca incessante do mito da felicidade de que só somos felizes quando obtemos algo (Rivetti, 2021).

Portanto, pode-se afirmar com certa segurança que a inteligência emocional dentro das organizações é considerada, cada vez, mais como uma ferramenta estratégica da empresa, apoiada nas ações de gestão de pessoas, do que apenas uma disciplina isolada no campo das ciências sociais.

Para além das percepções tradicionais da administração que, com uma lente voltada apenas para objetivos práticos e econômicos que visam apenas aos lucros e aos resultados financeiros como foco principal da função social das empresas, na contemporaneidade, a inteligência emocional nas organizações firma-se como um ativo importante e sinaliza para a administração a importância de se garantir o bem-estar dos seus colaboradores. 
Dentre as habilidades e competências que serão um diferencial dentro das organizações de futuro está a habilidade emocional associada ao uso de novas formas de trabalho e tecnologias que, nesse momento, se firmam para um futuro dentro das organizações. Nesse sentido e direção, Schwab (2016) orienta que:

\begin{abstract}
[...] organizações bem-sucedidas passarão cada vez mais de estruturas hierárquicas para modelos mais colaborativos e em rede. A motivação será cada vez mais intrínseca, impulsionada pelo desejo colaborativo dos empregados e pela gestão para a maestria (mastery), independência e significado. Isso sugere que as empresas irão tornar-se cada vez mais organizadas em torno de equipes distribuídas, trabalhadores remotos e coletivos dinâmicos, com uma troca contínua de dados e conhecimentos sobre as coisas ou tarefas em andamento (Schwab, 2016, p. 65).
\end{abstract}

Desse modo, pode-se afirmar que uma atenção especial em relação às emoções, com ênfase na inteligência emocional, além de promover bem-estar aos colaboradores de modo geral também propicia uma cultura colaborativa em que os sentimentos passam a ser compreendidos como cento de importância dentro das organizações.

\title{
4 CONSIDERAÇÕES FINAIS
}

As organizações que focam no futuro e seus administradores, que sobrevivem em ambientes cada vez mais mutantes e de cenários incertos, sabem que a inteligência humana está intrinsicamente ligada aos tempos e aos movimentos das novas realidades de trabalho. E para se manterem no mercado precisam aprimorar suas capacidades em inovar. Há agora uma tendência em crer que para suportar tempos e movimentos ainda mais incertos faz-se necessário romper com antigos paradigmas da administração clássica e da administração por objetivos, esse modo de pensamento é em certo ponto positivo, uma vez que rompe com antigos modelos de administração que eram centrados apenas no lucro e nos objetivos, relegando pessoas e sentimentos a um segundo plano. De certo que, o pensamento baseado na equação "homens $\mathrm{x}$ máquinas x tempos/movimentos" já não dá suporte para um posicionamento estratégico no futuro. Uma variável (a resiliência das pessoas) que já existia e que, por vezes, passava despercebida dentro das organizações é agora a mola propulsora da disrupção e que junto à criatividade vem fazendo a diferença aos olhos dos administradores.

Sem óbices, a emoção é agora o cerne do olhar científico dos gestores e administradores contemporâneos. A inteligência emocional, que no passado recente era considerado um passivo, é agora um importante ativo e vem sendo considerado com um potencial investimento. 
Equipes são integralizadas com o poder deste investimento e mercados vêm sendo desbravados a partir da inteligência emocional das pessoas que formam as fileiras dentro das organizações que se destacam em vários setores da economia. Empresas do setor de tecnologia da informação, geralmente, sempre se destacam em relação à valorização da inteligência emocional, que é parte integrante do processo de valoração destas organizações.

Com efeito, a administração na contemporaneidade tem a emoção e a inteligência emocional como um diferencial competitivo e como parte fundamental do planejamento estratégico das organizações. Os departamentos de gestão de pessoas possuem planejamento, organização e controle deste investimento e procuram com ações determinísticas potencializar esse poderoso ativo. Isso impele na cultura organizacional práticas que visam a favorecer não somente ambientes que promovam experiências de bem-estar, mas também em que a felicidade seja um sentimento a ser buscado e conservado junto às pessoas que dão corpo às organizações.

Portanto, pode-se concluir que se no passado as questões relacionadas às emoções estavam direcionadas para áreas transdisciplinares dentro das organizações e que eram encaradas pelos administradores, advindos de uma formação da administração clássica, como um passivo, na contemporaneidade, não mais. Agora, dentro das organizações, as emoções, a inteligência emocional e a felicidade figuram como ordem primeira dentro do planejamento estratégico das organizações, recebem não somente atenção, mas também aporte de recursos financeiros para se firmarem com alternativa importante para que as organizações e as pessoas que as compõem possam enfrentar os desafios do futuro que hão de advir.

\section{REFERÊNCIAS}

Goleman, D. (2011). Inteligência social: o poder das relações humanas. Trad. Ana Beatriz Rodrigues. Rio de Janeiro: Elsevier.

Goleman, D. (2012). O cérebro e a inteligência emocional: novas perspectivas. Rio de Janeiro: Objetiva.

Minayo, M. C. de S. (2001). Pesquisa Social: Teoria, método e criatividade. (18a ed.) Petrópolis: Vozes.

Pezzi, S. dos S., Eckert, A., Pezzi, G. dos S., Zanotto, M. P. (2020, novembro) Importância da Inteligência Emocional na atuação da Liderança no Ambiente Organizacional. Anais da Mostra de Iniciação Científica, Pós-Graduação, Pesquisa e Extensão Programa de Pós-Graduação em Administração, Caxias do Sul, RS, Brasil, 20. 
Prado, L. (2020). Employee Experience e a felicidade como ferramenta de produtividade. Recuperado em 01 julho, 2021, de https://www.startse.com/noticia/nova-economia/employeeexperience-e-a-felicidade-como-ferramenta-de-produtividade

Quessa, B., Fischer, J.; Pugens, J. (2017, novembro). A importância da Resiliência na Administração. Anais do Encontro Científico e Tecnológico, Campos de Toledo, PR, Brasil, 2017, 13.

Rivetti, R. (2021). Afinal, o que é felicidade corporativa e por que é tão essencial que entendamos isso? Recuperado em 02 jul. 2021, de https://www.reconnecthappiness atwork.com/post/afinal-o-que-\%C3\%A9-felicidade-corporativa-e-por-que-\%C3\%A9-

$\mathrm{t} \% \mathrm{C} 3 \% \mathrm{~A} 30-$ essencial-que-entendamos-isso.

Schwab, K. (2016). A quarta revolução industrial. Trad. Daniel Moreira Miranda. São Paulo: Edipro.

Varella, C. (2017). Felicidade no ambiente corporativo. Recuperado em 01 julho, 2021, de https:/economia.uol.com.br/reportagens-especiais/diretor-de-felicidade-nova-profissaoganha-relevancia-no-brasil/\#page3 


\title{
ANÁLISE DAS CONSEQUÊNCIAS CAUSADAS PELO USO EXCESSIVO DO CLONAZEPAM EM CLIENTES DE UMA FARMACIA NO MUNICIPIO DE SANTANA DO IPANEMA-AL
}

\author{
ANALYSIS OF THE CONSEQUENCES CAUSED BY THE EXCESSIVE USE \\ OF CLONAZEPAM IN CLIENTS OF A PHARMACY IN THE MUNICIPALITY \\ OF SANTANA DO IPANEMA-AL
}

\author{
Geovana Alves da Silva \\ Loane Marzia Lopes Costa \\ Isac da Silva Macêdo \\ Maria Tamires Santos da Silva
}

\section{RESUMO}

O consumo de psicotrópicos vem crescendo gradativamente nos últimos anos, dentre estes fármacos um dos mais procurados nas farmácias do Brasil é o clonazepam o qual pertence ao grupo doa benzodiazepínicos, tendo em vista que é um dos mais receitados por clínicos e psiquiatras. Este medicamento vem sendo ingerido pela população cada vez mais cedo. Vale ressaltar que o a uso desta substância a longo prazo pode causar dependência química além de outros fatores que prejudicam a saúde do paciente caso o quadro de tratamento se estenda por um período maior a oito meses que é o recomendado pela maioria dos médicos. o presente estudo teve como objetivo analisar as consequências causadas pelo uso excessivo do clonazepam a longo prazo, por clientes de uma farmácia do município de Santana do IpanemaAL. Dentre os principais motivos para a utilização do medicamento foram relatados que o clonazepam auxiliava no tratamento da ansiedade transtornos do humor e depressão além de demonstrar que grande maioria dos clientes da farmácia consome o medicamento mensalmente por um período além do recomendado.

Palavras-chave: Benzodiazepínico; Dependência; Efeitos; Complicações

\begin{abstract}
The consumption of psychotropic drugs has been growing gradually in recent years, among these drugs one of the most sought after in pharmacies in BrazBil is clonazepam, considering that it is one of the most prescribed by clinicians and psychiatrists. This medicine has been and ingested by the population earlier and earlier. It is noteworthy that the use of this substance in the long term can cause chemical dependency and other factors that harm the patient's health if the treatment is extended for a period longer than eight months, which is recommended by most physicians. The present study aimed to analyze the consequences caused by the excessive use of clonazepam in the long term, by customers of a pharmacy in the city of Santana do IpanemaAL. Among the main reasons for using the drug, clonazepam was reported to help treat anxiety, mood disorders and depression, in addition to demonstrating that the vast majority of pharmacy customers consume the drug monthly for a period beyond the recommended period.
\end{abstract}

Keywords: Benzodiazepine; Dependency; Effects; complications

\section{INTRODUÇÃO}

Nos últimos anos o consumo de psicotrópicos vem crescendo gradativamente. Dentre estes, o fármaco clonazepam é o mais procurado nas drogarias do Brasil. (MANGINI, 2014). 
De acordo com a Agência Nacional de Vigilância Sanitária (Anvisa), somente em 2010 o consumo brasileiro do princípio do Rivotril que é o medicamento referência do clonazepam, atingiu cerca de 10 milhões de caixas. O crescimento significativo em pouco tempo, desperta as suspeitas de uso excessivo e desnecessário por parte dos especialistas (FIRMINO et al., 2011).

De acordo com Cruz, (2016), "O Clonazepam pertence à classe farmacológica dos benzodiazepínicos”. Benzodiazepínicos são uma categoria de medicamentos indicados para casos de ansiedade, transtornos de humor, insônia e outras condições relacionadas ao Sistema Nervoso Central (SNC). Segundo Schweizer; Rickels, (1998), a o consumo exagerado dos benzodiazepínicos (BZD), por um período que ultrapasse seis meses de tratamento pode ocasionar nos pacientes quadros clínicos de dependência química, física ou psicológica.

O uso prolongado de benzodiazepínicos, classe ao que o clonazepam pertence, está associado à muitos efeitos adversos, incluindo sedação, amnésia, deterioração cognitiva e ataxia, além de um maior número, de quedas (RICHARDSON; BENNETT; KENNY, 2015).

\begin{abstract}
Apesar desses medicamentos constarem na literatura como um dos mais seguros, eles escondem graves problemas no seu manejo, pois as dificuldades inerentes a um quadro de dependência não prevalecem sobre os benefícios e, muitas vezes, passam despercebidas, devido à complexidade das situações envolvidas no tratamento dos pacientes. (RANG, et al, 2007).
\end{abstract}

De acordo com Brasil, (2011), o Conselho Internacional de Controle de Narcóticos (INCB), em um relatório feito no ano de 2011, relata um abuso sistemático de preparações farmacêuticas que contém clonazepam como também a ocorrência do abuso da prescrição desse medicamento junto com a facilidade da compra de prescrições deste fármaco em muitos, onde no Brasil, os dados relativos à comercialização do clonazepam apontam para um consumo superior a doze milhões de unidades desse medicamento, entre os anos de 2008 e 2009.

Conforme Martin et al. (2013) Tanto os médicos como os pacientes encontram dificuldades para propor protocolos que levem o paciente a reduzir o uso do medicamento até atingir sua suspensão total, levando em conta que muitos pacientes minimizam ou negam sentir os efeitos colaterais do medicamento. Nesse sentido o papel do farmacêutico é definido como um aliado do paciente durante sua reabilitação do desuso do fármaco, Brito et al. (2010) reitera que:

No desenvolvimento dessa prática, entre suas inúmeras competências, o profissional farmacêutico se encarrega de avaliar, prevenir, reduzir ou minimizar o impacto da interação medicamentosa terapêutica, prevenindo o aparecimento de novos problemas à saúde do paciente, além de reduzir custos para o sistema de saúde. Dessa forma, satisfaz uma necessidade social através do atendimento das necessidades individuais dos pacientes (BRITO et al., 2010). 
A molécula clonazepam movimentou em 2015, no Brasil, cerca de R \$ 220 milhões, representando $0,3 \%$ do mercado farmacêutico total. Os medicamentos genéricos representam $40 \%$ (IMS Health, 2015).

Como já se sabe, o uso de clonazepam diminui a capacidade cognitiva e altera a capacidade psicomotora. Seus efeitos colaterais estão relacionados com a depressão do sistema nervoso central, os mais comuns são: depressão, sonolência, tontura, diminuição da concentração, cefaleia, falta de coordenação muscular, diminuição da libido, dificuldade de ereção, conduta social inconveniente, hipotensão, depressão respiratória, náuseas, alteração do apetite, visão borrada, confusão, euforia, despersonalização, pesadelos (Laranjeira e Castro,1999; Lab. Roche 2016).

Deste modo, o objetivo desta pesquisa foi analisar as consequências causadas pelo uso excessivo do clonazepam a longo prazo, por clientes de uma farmácia do município de Santana do Ipanema-AL, como também alertar sobre as consequências do abuso e o uso inadequado deste fármaco.

\section{FUNDAMENTAÇÃO TEÓRICA}

Benzodiazepínicos constituem o grupo de psicotrópicos mais utilizados na prática clínica, de acordo com Azevedo et al., (2016) quatro atividades principais estão presentes: ansiolítica, anticonvulsivante, hipnótica e relaxante muscular, embora de modo mais amplo esse tipo de medicamento é mais utilizado em transtornos de ansiedade, epilepsia e insônia. Abaixo, o Quadro 1 mostra para quais patologias o clonazepam é mais indicado:

Quadro 1 - Grupo de doenças em que o fármaco clonazepam é mais procurado para auxiliar no tratamento.

\begin{tabular}{|l|}
\hline Transtornos de ansiedade \\
-Como ansiolítico em geral. \\
-Distúrbio do pânico com ou sem agorafobia. \\
-Fobia social. \\
\hline Transtornos do humor \\
-Transtorno afetivo bipolar: tratamento da mania. \\
-Depressão maior: como adjuvante de antidepressivos (depressão ansiosa e \\
na fase inicial de tratamento). \\
\hline $\begin{array}{l}\text { Emprego em síndromes psicóticas } \\
\text { - Tratamento da acatisia. }\end{array}$ \\
\hline Tratamento da síndrome das pernas inquietas \\
\hline $\begin{array}{l}\text { Tratamento da vertigem e sintomas relacionados à perturbação do equilíbrio: } \\
\text { como náuseas, vômitos, pré-síncopes ou síncopes, quedas, zumbidos, } \\
\text { hipoacusia, hipersensibilidade a sons, hiperacusia, plenitude aural, distúrbio da } \\
\text { atenção auditiva, diplacusia. }\end{array}$ \\
\hline Tratamento da síndrome da boca ardente \\
\hline
\end{tabular}

Fonte: Milagres (2015)

RCMOS - Revista Científica Multidisciplinar O Saber. ISSN: 2675-9128. São Paulo, v. 08, p. 01-15, ago. 2021. (cc) EY-NC-SA 
Direcionando o estudo para o Clonazepam, este medicamento possui a característica de agir no sistema nervoso central, podendo ele inibir algumas funções do corpo. Sobre sua ação, o Clonazepam potencializa a ação do neurotransmissor Ácido Gama-Aminobutírico (GABA), o principal mediador químico inibitório e depressor do sistema nervoso central. Quanto ao seu tempo de ação para o fármaco iniciar o efeito, o Clonazepam, em média, pode levar até $1 \mathrm{~h}$, a depender de sua forma farmacêutica, se comprimido, gota, ou sublingual, o tempo de duração no organismo. Pode variar entre 12 (doze) a 40 (quarenta) horas, a depender do metabolismo (ZORZANELLI et al., 2019).

No Brasil, a importação de clonazepam é regulamentada pela Resolução RDC n⿳011 de 6/3/2013 (Brasil. Resolução - RDC No 11, 2013). A produção, transformação, fabricação, fracionamento, manipulação, embalagem, distribuição, transporte, reembalagem, venda de medicamentos que contenham o clonazepam são regulamentados pela Port. No 344 , de 12/5/1998. O clonazepam pertence à Lista "B1" - Lista das Substâncias Psicotrópicas sujeitas a Notificação de Receita "B" de cor azul, com validade para 30 dias, válida apenas no estado emitente, quantidade máxima por receita equivale a 60 dias de tratamento (Brasil. Portaria n³44, 1998). O sentimento vago de solidão, desagradável é referente ao que se diz respeito da ansiedade, caracterizado pela apreensão e medo, fazendo parte um grande desconforto, sensação de perigo e estranheza as pessoas em volta. Castillo et al., (2020), em suas contribuições apresenta a ansiedade reconhecido como patológico quando são exagerados, desproporcionais em relação ao estímulo, ou qualitativamente diversos do que se observa como norma naquela faixa etária e interferem com a qualidade de vida, o conforto emocional ou o desempenho diário do indivíduo.

No que corresponde a suas formas, o Clonazepam está presente nas farmácias e estabelecimentos autorizados, em diferentes formas: em solução oral (gotas), havendo a necessidade de atenção sobre a posologia e cuidados ao ingerir, deve-se gotejar com o frasco na vertical e bater levemente no fundo para iniciar o gotejamento. No uso do medicamento pela via sublingual, deve ser colocado sob a língua para dissolver o medicamento na saliva e, em seguida, ser absorvido o fármaco. Assim, os medicamentos pela via sublingual ao fazer uso do comprimido em contato direto com a língua devem permanecer ao mínimo por três minutos, sem mastigar ou ser deglutido, por fim, por meio de comprimidos de via oral, estes devem ser deglutidos com um pouco de líquido não alcoólico, como consta Moreira (2018). 


\section{MÉTODOS}

A metodologia utilizada para alcançar os objetivos deste trabalho foi a qualiquantitativa, ou seja, foram utilizados tanto métodos qualitativos quanto quantitativos, para uma análise mais explanada do tema.

Trata-se de uma pesquisa aplicada de caráter exploratório, segundo Gil (2002), permite evidenciar o problema uma vez que existe um contato maior com o tema, podendo incluir levantamento bibliográfico ou entrevistas. Sendo capaz de assumir a condição de pesquisa bibliográfica e estudo de caso.

\subsection{PÚBLICO ESTUDADO}

Participaram desta pesquisa os clientes de uma farmácia (cuja identificação foi preservada) do município de Santana do Ipanema localizado no Sertão Alagoano, que faziam uso mensal e contínuo do fármaco clonazepam. As informações foram colhidas no período de novembro e dezembro de 2019, na própria farmácia com devida autorização dos proprietários.

\subsection{COLETA DE DADOS}

Para obter os resultados alcançados, foi produzido um questionário semiestruturado contanto com seis perguntas de múltipla escolha, este questionário foi aplicado na própria farmácia quando o cliente realizava a compra do medicamento e se voluntariava para responder as questões abordadas. A identidade dos entrevistados foi mantida em anonimato. Vale ressaltar que o questionário foi aplicado na farmácia em dezembro de 2019, as medidas contra a propagação da Covid-19 ainda não tinham sido tomadas.

\section{RESULTADOS E DISCUSSÕES}

Os resultados obtidos através do questionário foram organizados em gráficos para uma melhor compreensão. 
Gráfico1 - Tempo de consumo do fármaco clonazepam pelo grupo pesquisado.

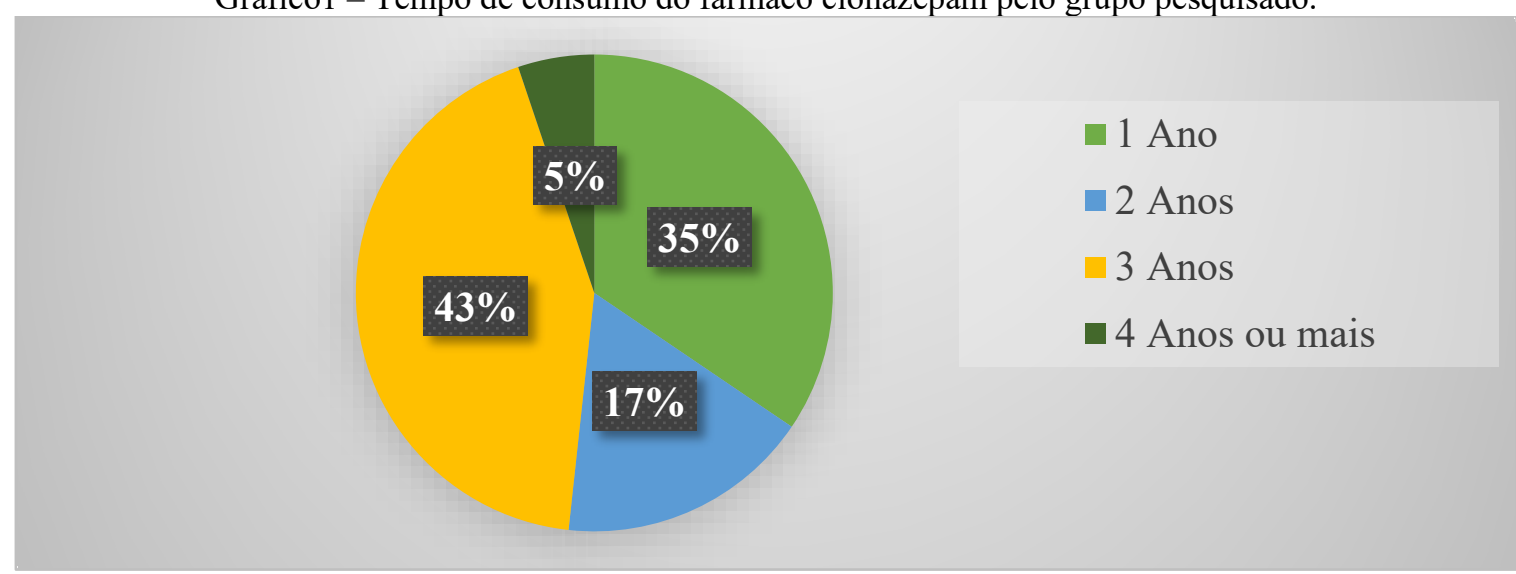

Fonte: Autores 2021.

Das 30 pessoas que participaram da pesquisa, $43 \%$ afirmaram fazer o uso do clonazepam a 3 anos, enquanto $35 \%$ usavam por 1 ano, $17 \%$ a 2 anos e $5 \% 4$ anos ou mais. Esses dados são alarmantes e evidenciam um grau de dependência do fármaco em questão. De acordo com Rang (2007), a utilização de medicamentos benzodiazepínicos como o clonazepam por um período que ultrapasse os seis meses de tratamento que normalmente são prescritos pelos médicos, podem levar o paciente a dependência química, física e ou psicológica, podendo acarretar aos pacientes, novos problemas de saúde e prejudicar a sua qualidade de vida. Nastasy (2008) comenta que a melhor estratégia de suspender o uso do clonazepam, está relacionada com a diminuição gradual da medicação, mesmo que o paciente esteja usando doses terapêuticas. É importante que o indivíduo que faz uso do medicamento, esteja ciente da importância de interromper o uso do clonazepam. O acompanhamento psicológico nesse momento de desmame do clonazepam é fundamental. Houve questionamentos ao público pesquisado, sobre os principais sintomas sentidos por eles ao ficar alguns dias sem a medicação, diante de tal questionamento responderam:

Gráfico 2- principais consequências relatadas pelo grupo pesquisado ao ficar sem ingerir o fármaco.

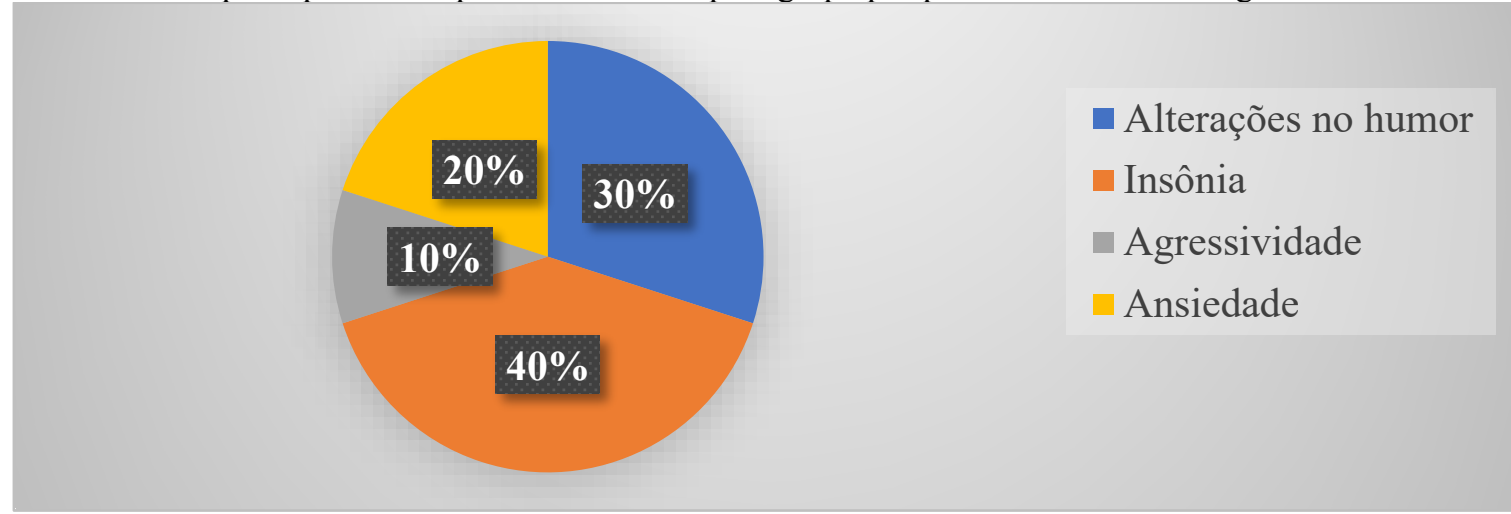

Fonte: Autores 2021. 
As maiorias dos entrevistados responderam que ao ficar sem tomar o clonazepam por algumas semanas $40 \%$ afirmaram ter insônia durante esse período, 30\% sofreram alterações no humor, $20 \%$ relataram um aumento no nível de ansiedade e 10\% disseram ficar mais agressivos.

Gilman (2012) relata em seu estudo que ao interromper o uso do clonazepam os pacientes passam por um tipo de crise de abstinência, com sintomas como agitação, sintomas de ansiedade, tremores, cefaleia, insônia, dificuldade de concentração, entre outros. Isso mostra que o abuso e o uso prolongado do fármaco em questão podem causar ao paciente uma serie de complicações, pois ao interromper o tratamento e ao sentir alguns dos sintomas descritos acima o paciente sentem-se inseguros e volta tomar o medicamento. Quando questionados por quais motivos utilizavam aquele medicamento os consumidores apontaram que:

Gráfico 3- Principais motivos relatados que levaram ao uso do fármaco.

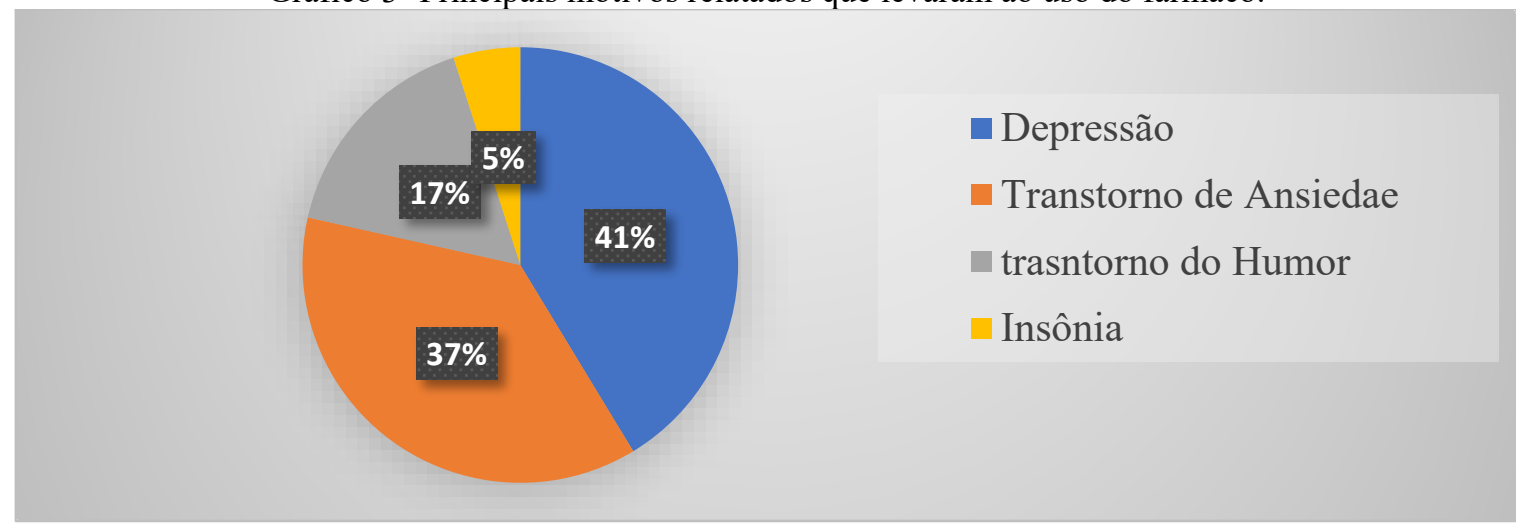

Fonte: Autores 2021.

Entre os principais motivos para o uso do medicamento $41 \%$ dos entrevistados afirmaram que começaram a utilizar o medicamento para tratar sintomas da depressão, 37\% para o transtorno de ansiedade, $17 \%$ transtornos de humor e 5\% para o tratamento da insônia.

Semelhante pesquisa realizada por Cruz (2016) 47,34\% dos pacientes utilizavam o clonazepam para o tratamento da depressão, $42,11 \%$ para controle da ansiedade entre outros motivos, esses dados corroboram com apresente pesquisa que também destacou que os principais motivos para o uso do clonazepam foram depressão e ansiedade. Quando questionados sobre a possibilidade de deixar de utilizar o clonazepam o grupo pesquisado se posicionou da seguinte maneira: 
Gráfico 4- Dependência dos consumidores em relação ao fármaco.

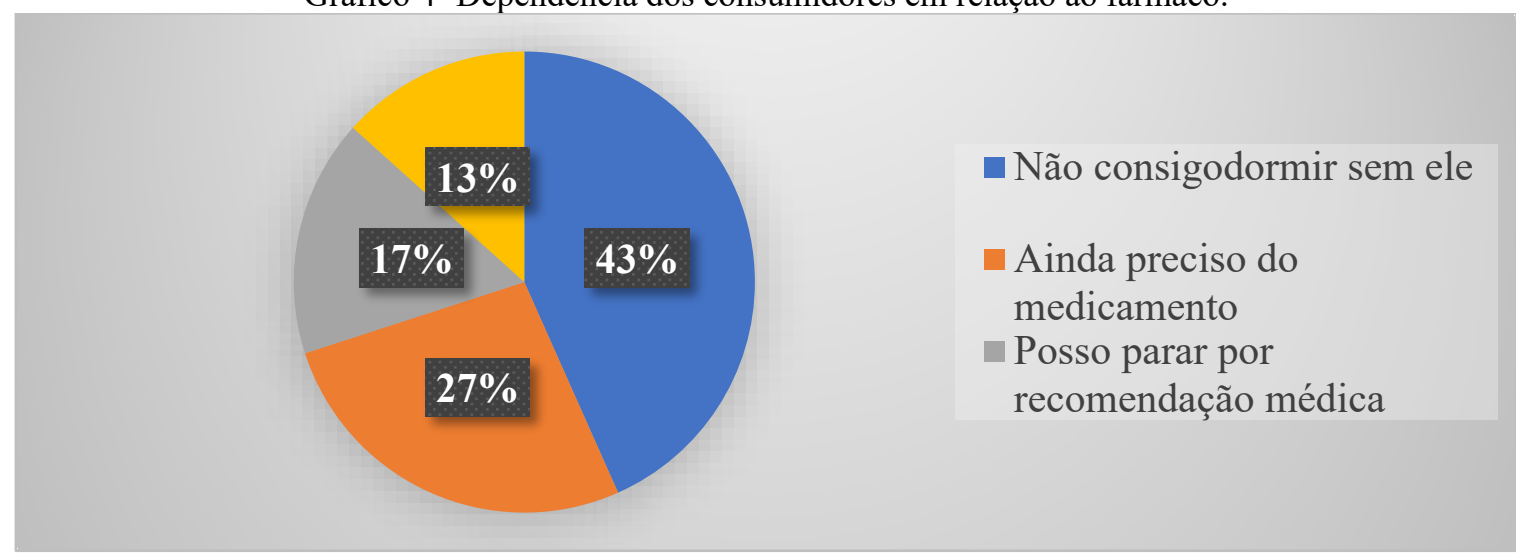

Fonte: Autores 2021.

Levando em consideração o longo período de uso do medicamento (Gráfico 1), há uma confirmação de um grau de dependência dos pacientes com o fármaco para justificar a continuidade do seu uso, $43 \%$ dos entrevistados afirmam que não conseguem dormir sem tomar o medicamento, $27 \%$ não apontaram um motivo especifico para continuidade do tratamento, apenas afirmaram que necessitam do remédio para se sentirem bem, 17\% afirmaram que interromperia o uso caso o médico recomendasse, e 13\% não souberam opinar a respeito disso.

Os médicos, farmacêuticos e laboratórios têm responsabilidade na promoção do uso racional de medicação. De acordo com a Organização Mundial de Saúde (OMS, 2016), há uso racional de medicamentos quando o paciente recebe o medicamento apropriado às suas necessidades clínicas, na dose correta, por um tempo adequado e ao menor custo possível para o paciente e ou sua comunidade. Questionados sobre a sessão e benefícios que o clonazepam traz quando é ingerido apontaram:

Gráfico 5- Benefícios alcançados com o uso do clonazepam.

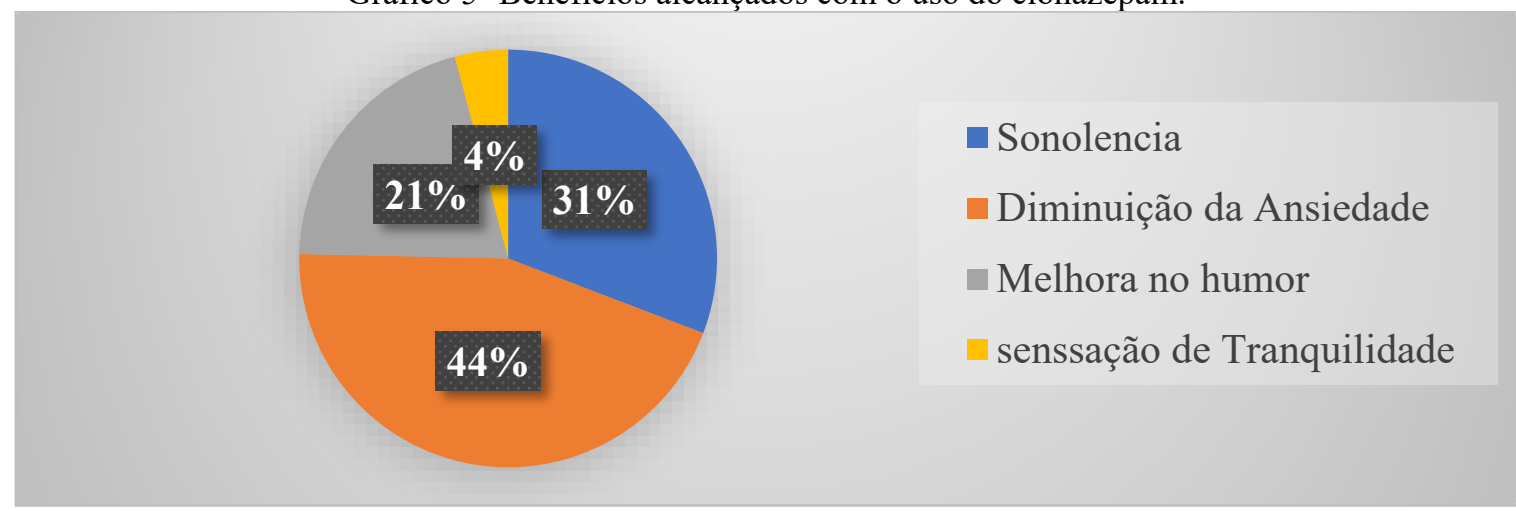

Fonte: Autores 2021 .

Ao ingerir o clonazepam $44 \%$ do público entrevistado, afirmou uma diminuição a ansiedade, $31 \%$ sentiam-se sonolentos (lembrando que o clonazepam é indicado na maioria dos 
casos para ingestão à noite) $21 \%$ relataram uma melhora no humor alguns minutos depois de tomar a medicação, e 4\% relataram uma sensação de tranquilidade.

Cruz (2016), demostra em seus estudos dados que corroboram com a presente pesquisa pois também são relatados após a ingestão do clonazepam sensação de tranquilidade, sono, relaxamento e uma sensação agradável. Questionados quanto à idade que o entrevistado iniciou a tomar o clonazepam obteve os seguintes resultados:

Gráfico 6- Idade do público entrevistado que faz uso do clonazepam.

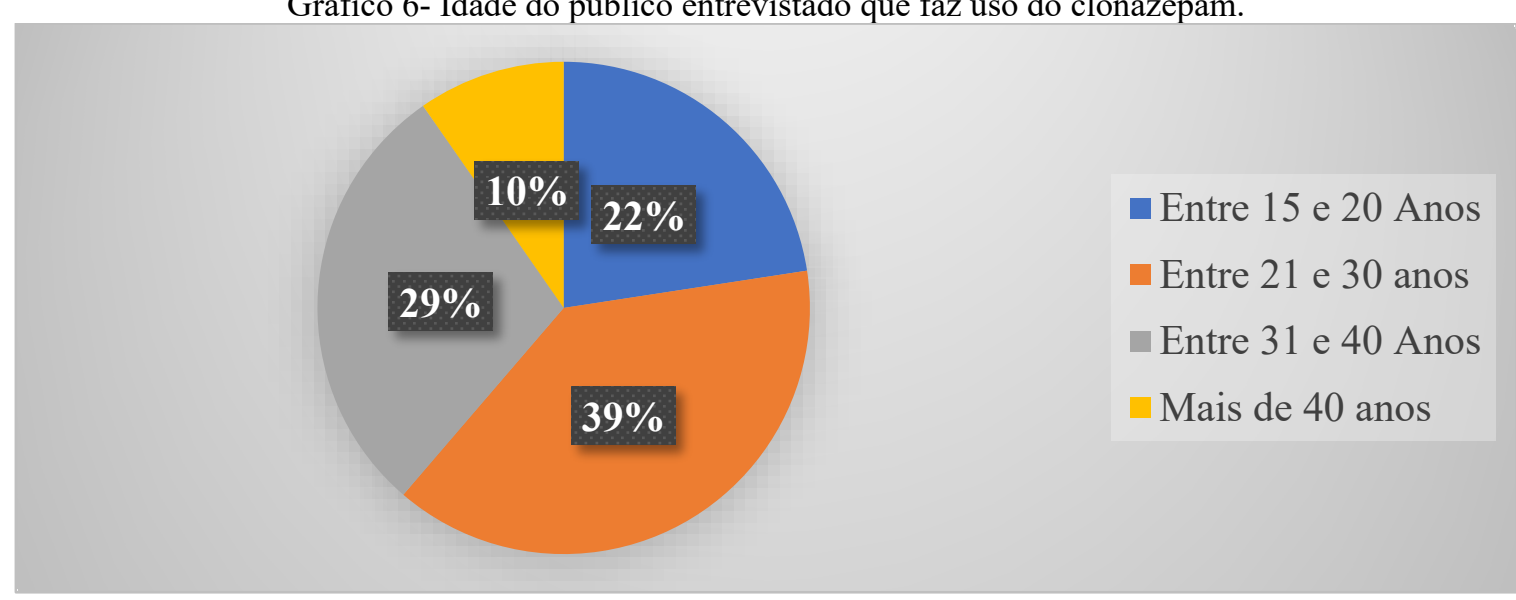

Fonte: Autores 2021.

O gráfico 6 aponta que, 39\% dos pacientes que participaram da pesquisa e fazem uso do clonazepam tem entre 21 e 30 anos, $29 \%$ possuem idades entre 31 e 40 anos, $22 \%$ entre 15 e 20 anos, e 10\% mais de 40 anos. Esses dados demonstram que o início do uso do medicamento tem se tornado cada vez mais precoce.

Tais dados diferem de uma pesquisa realizada por Felipe em 2016, que mostrava que a maioria das pessoas que faziam o uso do clonazepam tinha entre 40 e 60 anos. O que demostra que ao longo dos anos esse medicamento vem sendo utilizado pela população cada vez mais cedo.

Vale ressaltar que dentro do público entrevistado $69,23 \%$ eram do sexo feminino e $30,77 \%$ do sexo masculino corroborando com a pesquisa realizada por Souza (2013). Onde os pacientes entrevistados eram em sua maioria do sexo feminino $(73,68 \%)$, Isto reforça que são as mulheres as maiores usuárias de medicamentos psicoativos, e que mais sofrem de transtorno psiquiátricos, que mais buscam alívio ao estresse, que vivem mais que os homens e por isto psicologicamente sofrem mais com os efeitos da idade, também são as quem mais procuram ajuda médica, quem tem mais facilidade de falar sobre seus problemas e angústias, quem mais aceita o uso de medicamentos psicotrópicos (LARANJEIRA; CASTRO, 1999; ALVARENGA et al,2007; NORDON et al, 2009; SOUZA, 2013). 


\section{CONSIDERAÇÕES FINAIS}

Benzodiazepínicos constituem o grupo de psicotrópicos mais utilizados na prática clínica, embora a automedicação não é recomendada, sendo de extrema responsabilidade dos responsáveis cabíveis, assim torna necessária a importância de divulgar os efeitos do medicamento para a população.

O uso do medicamento é presente na vida dos usuários, por no mínimo 3 anos, enquanto a segunda maior porcentagem (35\%) represente os usuários mais recentes com pelo menos 1 ano do uso do medicamento, com idade a partir dos 21 anos. Dos que fazem uso do medicamento, as principais consequências em ordem de maior representatividade, está a insônia, seguida de alterações no humor, ansiedade e agressividade.

Relacionado aos motivos que levou o uso do fármaco, $41 \%$ dos entrevistados, apresentam sintomas de depressão e $37 \%$ usam para transtornos de ansiedade e humor, assim como para o tratamento da insônia. Por fim, a maioria dos frequentadores da farmácia depende do uso do medicamento, pelos motivos de ter dificuldade para dormir, embora apresente benefícios como diminuição da ansiedade, sonolência e melhoria no humor.

\section{REFERÊNCIAS}

ALVARENGA JM, Filho AIL, Firmo JOA, Costa MMFL, Uchoa E. Prevalence and sociodemographic characteristics associated with benzodiazepines use among community dwelling older adults: The Bambuí Health and Aging Study (BHAS). Revista Brasileira de Psiquiatria 2007; 30(1)7-11.

AZEVEDO, AJP; ARAUJO, AA; FERREIRA, MAF. Consumo de ansiolíticos benzodiazepínicos: uma correlação entre dados do $\mathrm{SNgPc}$ e indicadores sociodemográficos nas capitais brasileiras. Ciência \& Saúde Coletiva, 21(1):83-90, 2016.

Brasil. Portaria $\mathrm{n}^{\mathrm{0}} 344$, de 12 de maio de 1998 - Aprova o Regulamento Técnico sobre Substâncias e medicamentos sujeitos a controle especial - Secretaria de Vigilância Sanitária do Ministério da Saúde, Brasil.

CASTILLO, ARGL; RECONDO, R; ASBAHR, FR; MANFRO, GG. T. Transtornos de ansiedade. Rev Bras Psiquiatr 22(Supl II):20-3, 2000.

CRUZ, N. Lourenco de Matos. Clonazepam, um campeão de vendas no Brasil. Por quê? 2016. Disponível em: https://core.ac.uk/download/pdf/160027736.pdf Acesso em: 18 de jan. de 2020 FELIPE, Karen Caroline de. Abordagem Do Uso De Clonazepam Dispensado Pela Drogaria Municipal De Ariquemes-Rondônia. 2016. Disponível em: http://repositorio.faema.edu.br/handle/123456789/1121 Acesso em: 18 de jan. de 2020 
FIRMINO KF, ABREU MHNG, PERINI E. MAGALHAES SMS. Fatores associados ao uso de benzodiazepínicos no serviço municipal de saúde da cidade de Coronel Fabriciano, Minas Gerais, Brasil 2011 27(6): p1223-1232. Disponível em: https://www.scielo.br/j/csp/a/Hkfn7HNQNcPsTx3bXvRgStv/abstract/?lang=pt\&format=html Acesso em: 23 de jan. de 2020

GIL, A. C. Como elaborar projetos de pesquisa. 4.ed. São Paulo: Atlas S.A, 2002. Disponível em:

http://www.uece.br/nucleodelinguasitaperi/dmdocuments/gil como elaborar projeto de pes quisa.pdf Acesso em: 25 jan. 2020

GOODMAN J.G, Gilman A.G. As Bases Farmacológicas da Terapêutica. $12^{\circ}$ edição. Rio de Janeiro: McGraw-Hill; 2012. p. 458-468.

LARANJEIRA R \& Castro LA. Potencial de abuso de benzodiazepínicos. In: Bernik MA. Benzodiazepínicos, quatro décadas de experiências. 1ed. São Paulo: Edusp; 1999. P.187-198. Disponível em: https://books.google.com.br/books?hl=pt-BR\&lr=\&id=4MABMI1eLwC\&oi $=$ fnd\&pg $=$ PA $187 \& d q=$ LARANJEIRA $+\mathrm{R}+\% 26+$ Castro + LA.+ Potencial + de + abuso + de +benzodiazep $\% \mathrm{C} 3 \%$ ADnicos. + In:+Bernik + MA. + Benzodiazep $\% \mathrm{C} 3 \%$ ADnicos,+ quatro $+\mathrm{d} \% \mathrm{C}$ 3\%A9cadas + de + experi\%C3\%AAncias. +1 ed. + S\%C3\%A3o+Paulo:+Edusp $\% 3 \mathrm{~B}+1999 .+\mathrm{P} .187$ 198.\&ots $=$ EAmEPD4ZZx\&sig=KKXQ6if7maC5pNF795wjTjUhDjo\&redir esc $=\mathrm{y} \# \mathrm{v}=$ onepag e\&q\&f=false Acesso em: 03 de fev. de 2020.

MANGINI JR, Z.s Antonio; CAPONI, S. Noemi Cucurullo. Condicionantes relacionados ao uso crônico de clonazepam no Brasil: uma história de vida. Cadernos de Pesquisa Interdisciplinar em Ciências Humanas, v. 15, n. 106, p. 117-139, 2014. Disponível em: https://periodicos.ufsc.br/index.php/cadernosdepesquisa/article/view/1984-

8951.2014v15n106p117 Acesso em: 14 fev. 2020

MILAGRES, Christiane Reis. Sentidos atribuídos ao rivotril na mídia: um estudo de reportagens veiculadas nos sites das revistas Superinteressante e Trip. CES Revista, v. 27, n. 1, p. 313-332, 2015.

MOREIRA, P; BORJA, A. Benzodiazepínicos: uso e abuso em pacientes idosos. Pesquisa e [Extensão $\quad$ Oswaldo $\quad$ Cruz]. $2018 . \quad$ Disponível em: http://revista.oswaldocruz.br/Content/pdf/Edicao_19 Acesso em: $14 \mathrm{de} \mathrm{fev.} \mathrm{de} 2020$

Nastasy, H.; Ribeiro, M.; Marques, A.C.P.R. Abuso e Dependência dos Benzodiazepínicos. Associação Brasileira de Psiquiatria/Projeto Diretrizes - Associação Médica Brasileira e Conselho Federal de Medicina, 2008. Disponível em: http://www.abp.org.br/portal/educacao/diretrizes Acesso em: 20 fev. 2020

NORDON DG, AKAMINE K, Novo NF, HUBNER CVK. Características do uso de benzodiazepínicos por mulheres que buscavam tratamento na atenção primária. Rev Psiquiatr. RS 2009; 31(3):152-8.

OMS - Organizacion Mundial de la Salud - Tratamiento farmacológico de los transtornos mentales em la atención primaria de salud. Washington, D.C. OPS. 2010 - ISBN: 978-9275-33113-2. 
http://www.who.int/mental_health/management/psychotropic book_spanish.pdf Acesso em: 20 de fev. de 2020

RANG, H. P. et al. Fármacos antiinflamatórios e imunossupressores. Rang \& Dale Farmacologia. 6th ed. Rio de Janeiro, RJ: Elsevier, 2007.

RICHARDSON, Kathryn et al. Use of medications with anticholinergic activity and selfreported injurious falls in older community-dwelling adults. Journal of the American Geriatrics Society, v. 63, n. 8, p. 1561-1569, 2015. Disponível em: https://agsjournals.onlinelibrary.wiley.com/doi/abs/10.1111/jgs.13543 Acesso em: 23 de fev. de 2020

SCHWEIZER E, RICKELS K. Benzodiazepine dependence and withdrawal: a review of the syndrome and its clinical management. Acta Psychiatric Scand 1998; (98 - Suppl.393): 95-101. Disponível em: https://onlinelibrary.wiley.com/doi/abs/10.1111/j.1600-0447.1998.tb05973.x Acesso em: 14 de fev. de 2020

Souza A.R.L, Opaleye E.S, Noto A.R. Contextos e padrões do uso indevido de benzodiazepínicos entre mulheres. Ciênc. saúde coletiva vol.18 no.4 Rio de Janeiro Apr. 2013. Disponível em: http://dx.doi.org/10.1590/S1413-81232013000400026

ZORZANELLI, RT; GIORDANI, F; GUARALDO, L; MATOS, G; BRITO JUNIOR, AG; OLIVEIRA, MG; SOUZA, RM; MATOS, RQM; ROZENFELD, S. Consumo do benzodiazepínico clonazepam (Rivotril@) no estado do Rio de Janeiro, Brasil, 2009-2013: estudo ecológico. Ciênc. saúde coletiva v.24 no.8.2019. 


\title{
GESTÃO ESTRATÉGICA COMO AÇÃO QUE VIABILIZA O SUCESSO NO EMPREENDIMENTO
}

\section{RESUMO}

Maxmiliano da Silva Soares

Trata-se de uma pesquisa qualitativa, descritiva e de cunho bibliográfico, pautada na revisão de literatura sobre o assunto escolhido, cuja problemática que impulsionou a investigação foi: - Quais as ações necessárias dentro da gestão estratégica que viabilizam o sucesso de uma organização? O Objetivo principal deste trabalho é traçar uma investigação teórica com base na revisão de literatura a respeito da gestão estratégica como ação para viabilidade de um empreendimento, cujo tema parte da motivação desta autoria em conhecer mais sobre este assunto, uma vez que teóricos afirmam que o empreendimento compreende um espaço para a aplicação de estratégias e planejamentos bem elaborados para atingir êxito. No presente esboço, ainda é possível identificar e entender que a gestão estratégica como uma ação com a qual se viabiliza o sucesso no empreendimento. Os objetivos específicos do referido trabalho consistem em apresentar as vantagens nas quais a gestão estratégica permite o sucesso de uma organização empresarial; compreender como a gestão estratégica se faz necessário e sua importância no contexto empresarial; além de discutir as consequências da ausência da gestão estratégica dentro da organização. Finalmente, conclui-se que a gestão estratégica é extremamente importante para o trabalho empresarial, pois ele é fator decisivo para o sucesso empresarial.

PALAVRAS-CHAVE: Gestão. Estratégica. Sucesso. Empreendimento. Empresarial

\begin{abstract}
It is a qualitative, descriptive, and bibliographic research, based on the literature review on the chosen subject, whose problem that drove the investigation was: - What are the necessary actions within the strategic management that make the success of an organization feasible? The main objective of this work is to outline a theoretical investigation based on the literature review regarding strategic management as an action for the viability of an enterprise, whose theme starts from the motivation of this authorship to know more about this subject, since theorists affirm that the The enterprise comprises a space for the application of well-designed strategies and plans to achieve success. In the present outline, it is still possible to identify and understand that strategic management as an action with which success in the enterprise is made possible. The specific objectives of this work are to present the advantages in which strategic management allows the success of a business organization; understand how strategic management is necessary and its importance in the business context; in addition to discussing the consequences of the absence of strategic management within the organization. Finally, it is concluded that strategic management is extremely important for business work, as it is a decisive factor for business success.
\end{abstract}

KEYWORDS: Management. Strategic. Success. Enterprise. Business

\section{INTRODUÇÃO}

Com as constantes transformações que o mercado tem passado tornando-se necessário que as empresas estejam sempre em busca de novos modelos gerenciais e de novas 
tecnologias para se manterem competitivas no mercado, aprimorando sempre a qualidade de seus produtos e serviços. Desse modo, é imprescindível utilizar-se de um diferencial na gestão das organizações, por isso, a escolha do objeto desta pesquisa.

Neste contexto, a problemática que mobilizou este estudo foi a seguinte: - Quais as ações necessárias dentro da gestão estratégica que viabilizam o sucesso de uma organização?

A gestão estratégica é uma ferramenta administrativa que pode auxiliar as organizações a se avaliarem e avaliar o mercado em que atua, para ajudar na busca pela competitividade, além de auxiliar na determinação de suas metas, objetivos e quais suas estratégias para alcançá-los.

A empresa, ao se relacionar com o mercado defronta-se com a incerteza gerada pelos elementos incontroláveis e imprevisíveis do ambiente, gerando assim as ameaças ambientais e oportunidades disponíveis para a empresa. Assim, é preciso definir as estratégias a serem utilizadas para lidar com o ambiente complexo, dinâmico, mutável e imprevisível.

O objetivo deste trabalho é defender a gestão estratégica enquanto ação que viabiliza o sucesso de um empreendimento. Neste sentido, a escolha se fez na oportunidade de conhecimento a respeito de um assunto cuja identificação pessoal harmoniza com as pretensões futuras de desempenho profissional. A importância da gestão estratégica nos empreendimentos é um assunto bastante tratado nas pesquisas acadêmicas e descrever neste nicho é uma oportunidade de oferecer, ainda mais, mais uma produção acadêmica a respeito do assunto, ampliando sua oferta de consultas e pesquisas.

A pesquisa é qualitativa, descritiva e de cunho bibliográfico, pautada nos ensinos técnicos e suas revisões no assunto escolhido. A relevância desta pesquisa indica a possibilidade de oferecer um precioso conjunto de ideias que podem servir de argumentação teórica em outros trabalhos a respeito desse mesmo assunto.

A importância da gestão estratégica não se observa apenas no mundo dos negócios como todos pensam, mas pode contribuir também em outros sentidos, como por exemplo, ensinando a pessoa a agir de forma diferente, ou seja, pode ajudar na contribuição para além da formalidade da ciência, bem como com a personalidade do fazer em todas as tarefas do dia a dia. 


\section{DESENVOLVIMENTO}

\subsection{CONCEITOS DE ESTRATÉGIAS}

Em conformidade aos estudos de Christensen e Rocha (1995), o termo estratégia tem origem e fundamento na teoria militar, o que significa a utilização dela no combate a fim de se atingir a vitória na guerra.

Partindo desta discussão sobre planejamento, podemos afirmar que ela envolve uma gama de ações e atividades, as quais precisam ser pensadas sumariamente, sendo necessário estabelecer, antes de tudo, uma programação para todas essas ações e atividades, quer comercial ou não, mas, ao final, o que importa é o sucesso pretendido.

De fato, o planejamento é fundamental na administração de uma organização empresarial. Chiavenato (2010) entender o quanto a estratégia é importante num empreendimento organizacional, ao defender a ideia de que ela carece nos negócios.

Sobre o aspecto administrativo, este artigo ainda questiona a necessidade de uma empresa ou uma organização poder conduzir sua estratégia até o fim para obter de resultados práticos, e ainda discute a importância que tal planejamento se verifica no âmbito das associações informais e setores não governamentais da sociedade civil onde também pode ser este aplicado.

\subsubsection{A gestão estratégica}

Observar o planejamento de forma ordenada, a fim de conceber no caminho certo para os quais uma empresa ou organização poder conduzir cálculos para sua apropriação no plano administrativo e funcional, é entendido por Chiavenato (2010), no primado de um gerenciamento eficaz.

Assim, é preciso antes fazer a avaliação do potencial de lucro futuro, afim de que se possa realocar o capital da empresa. Em suma, coloca-se adiante, uma criteriosa alocação de recursos, indicadas no portfólio do negócio, pois esta é uma das ideias mais básicas da gestão estratégica.

Por conseguinte, é preciso estar em constante avaliação, com vistas ao potencial de lucro futuro para cada tipo de negócio, pois a empresa não poderá agir, simplesmente, com 
base no planejamento anual, como também, fazendo planejamento para longo prazo usando a base nas vendas passadas.

Para Drucker (2007), gestão estratégica é entendido também como uma estratégia propriamente dita, em que, para cada tipologia de negócio a empresa teria que utilizar de uma estratégia para alcance dos objetivos para longo prazo, uma vez que, não há uma estratégia única para todos os concorrentes.

Portanto, a fim de entender melhor sobre a gestão estratégica, faz-se necessário exame da estrutura organizacional da organização, no qual, normalmente, se divide em três níveis: alta administração, unidade negocial da empresa e produto.

Cabe acrescentar que, cada produto, cada unidade, e tarefa do negócio da empresa irão desenvolver-se num plano de marketing a fim de que se possam atingir os objetivos do produto no mercado. Adiante, é possível identificar o papel do planejamento nas corporações, suas categorias e a argumentação da literatura no sentido prático de sua viabilidade técnica.

\subsection{GESTÃO ESTRATÉGICA NAS CORPORAÇÕES}

A gestão estratégica nas corporações abrange 4 linhas de ação. A primeira desenvolvese uma clara ideia da missão da empresa, o que ocorre em termos de objetivos da história, do segmento de mercado, o que ocorre na produção vertical e área geográfica. Isso tudo, quando bem definido, permite, finalmente que, aos empregados um senso compartilhado de direção, oportunidade, significância e realização. Outra importante atividade é aquela consiste finalmente que, em definir as unidades de negócios. O negócio é, portanto, bem definido pelos grupos de clientes, portanto, também pelas necessidades dos clientes e tecnologias empregadas. As unidades de negócio se beneficiam de planejamento específico, enfrentam concorrentes próprios e são geridas como centros de lucro.

Gestão estratégica, portanto, significa o ponto de largada para uma administração estratégica de organizações, independentemente do tamanho ou de seu tipo. Este método de planejamento possui como objeto principal a adoção de medidas de importância decisiva aos resultados e na condução de atividades proativas no gerenciamento de tais organizações. (GAJ, 2002). A realização de uma gestão estratégica em um empreendimento se depreende em responder questões como:

a) Onde se almeja chegar?

b) O que se deve fazer?

c) Como fazer? Quando fazer?

RCMOS - Revista Científica Multidisciplinar O Saber. ISSN: 2675-9128. São Paulo, v. 08, p. 01-15, ago. 2021. (cc) BY-NC-SA 


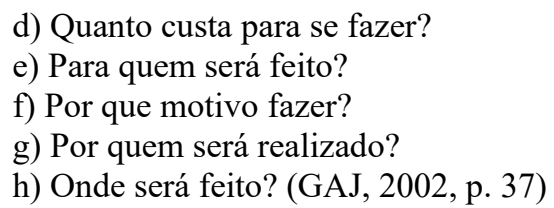

Contudo, todo esse conjunto de questionamentos deve ser apreciado nos momentos de planejamentos estratégicos para os empreendimentos, sobretudo, para àqueles que possuem vários limitantes e estes são percebidos incialmente se impõe que na estrutura em que o capitalismo constitua enquanto essência observará uma relação de classes em que a economia e o social se unem a fim de definir de uma forma explicativa o sistema de relações entre elas.

Quando a gestão deve ser vista enquanto ação que viabilize o sucesso num empreendimento se estabelece, a sociedade brasileira vivia um momento de retenção econômica, o que ocorreu devido ao condicionamento do país advindo de uma economia de agricultura para uma economia industrial, e logo em seguida tomando empréstimos internacionais no lume de seu desenvolvimento.

\subsection{GESTÃO ESTRATÉGICA PARA OS NEGÓCIOS}

Becker reafirma que um negócio, quando iniciado sem gestão estratégica tende ao fracasso. E iminente a uma perda de sentido final os projetos que não usam da gestão estratégica numa perspectiva construtiva. Portanto, as unidades de negócio realizam a sua gestão estratégica, no qual as fases adiante podem ser uteis:

\footnotetext{
a) Definir missão,

b) Observação de ambientes externo e interno,

c) Metas,

d) Elaborar estratégias do negócio,

e) Formular programas de ação,

f) Feedback interno e externo

g) Controles. (ALMEIDA JUNIOR,1999, p.23).
}

Todas essas fases mantêm a unidade de um negócio constantemente ligada ao ambiente, como também atenta às novas ameaças e oportunidades. Deste modo, a gestão estratégica fornece um contexto para preparação dos planos de mercado aos produtos e serviços específicos.

Adiante Gaj (2002, p.189) inclui que, esta metodologia, sobretudo à carência de uma declaração de visão da referida empresa embasada em sua realidade, que expresse nos verdadeiros sentimentos as intenções de seus recursos humanos, já que as declarações 
fantasiosas de nada podem contribuir a uma visão da empresa, a não ser sobre o fato de tornála mais capaz de ser desmentida, ou de até, ridicularizada ao longo com as práticas cotidianas.

\subsection{GESTÃO ESTRATÉGICA PARA O NÍVEL FUNCIONAL}

No nível funcional consolidam-se os requisitos funcionais demandados através da estratégia corporativa, e se constitui no arsenal de armas competitivas que serão transformadas nas competências distintivas da empresa.

As estratégias funcionais podem ser aplicadas às funções de cada tipo de negócio, ou de cada tipologia nas unidades em que se atua em determinado ramo de negócios, entre eles o marketing, a produção, as finanças, e engenharia de recursos humanos, áreas de pesquisa e desenvolvimento, de logística, de vendas e/ou de serviços etc.

O nível funcional objetiva manutenção do bom desempenho para as corporações e interatividade em meio a cada negócio estratégico da organização. Igualmente, chama-se de objetivo funcional, o conjunto de metas relacionadas à área funcional a serem atingidas com a finalidade de se concretizarem os objetivos da empresa, ou seja, da organização como um todo. (GRACIOSO,1996)

Torna-se, por diante, importante ao nível funcional, não somente em atingir tais objetivos e metas correlatas, mas com o desempenho geral da organização, pois esse nível compreende grande compatibilidade para metas e para objetivos entre seus negócios.

\subsection{AS FASES DA GESTÃO ESTRATÉGICA NA PRÁTICA FUNCIONAL}

A partir destas fases, a empresa é situada em um ambiente que oferece oportunidades e riscos e, estas informações deverão ser coletadas em quantidade e qualidade adequadas, proporcionando uma boa tomada de decisão em grande parte de seus executivos (FISHMANN, 2002).

A administração estratégica se identifica, de forma total, de uma forma de acrescentar novos componentes à observação e ação sequenciada e habitual e comum. Assim se fazendo, o objetivo é calcular uma ocorrência, colocar em pauta na elaboração de projetos de transformações bem fundamentadas em processos metódicos de orientação, e conduzir e dirigir e chefiar os passos de implementação. Em resumo, é o controle gerencial de todos os meios de uma organização para aferir ou alcançar anseios e perseguições dos anseios. Com o RCMOS - Revista Científica Multidisciplinar O Saber. ISSN: 2675-9128. São Paulo, v. 08, p. 01-15, ago. 2021. (cc) EY-NC-SA 
concorrido mercado em que todos ficam hoje em dia, trabalhar com metodologias é indispensável à sobrevivência do negócio.

Nessa assimilação, como para aferir seu lugar e prestar serviço ajustadamente, o constante excelente aperfeiçoamento é bastante preciso. Ou seja, é por meio da administração estratégica que os dados com relação a alta competição da corporação empresarial, meios acessíveis, ameaças, oportunidade e, com relação a outras acabam se fazendo erguidas com o objetivo de pensar estrategicamente em demais planejamentos para as ações futuras.

Assim, um plano comercial sem estratégia é um processo fadado ao fracasso. Isto porque não podem fugir da realidade do planejamento e observado em um compasso de etapas sem estrutura do escopo de planejar que tenha subsídio em uma ação diminuta de racionalidade técnica. A gestão estratégica numa perspectiva atinge certa racionalidade técnica, é o que observa Motta (1984) em suas conclusões.

Acima de tudo, a gestão estratégica informa sob a tutela do trabalho administrativo e funcional um denominador comum com o público atingido que espera do mesmo uma ação ordenada e eficiente no atendimento de suas necessidades.

A administração estratégica é o campo em que é efetivado o processo metódico de orientação estratégico da corporação empresarial possuindo enquanto bases sua a finalidade maior, visão e valores.

O desenvolvimento de uma metodologia competitiva se identifica, de forma total, de uma fórmula ampla de que modos a corporação empresarial competirá e que poderão ser as perseguições dos anseios e políticas estabelecidas para aferir ou alcançar o objetivo.

Motta (1984) descreve que a gestão estratégica parte do sentido operacional administrativo. Chiavenato (2010) concorda com ele, mas discorda no sentido de que a economia e a administração se entrelaçam de uma forma menos crítica e mais disposta ao âmbito do operacional (atender clientes) e suas necessidades deixando as observações da macroeconomia e suas expressões sociais para outro momento.

No estratégico, o parágrafo anterior se desloca a perguntar como, porque e qual o momento melhor de atender a clientela e suas expectativas. Portanto, na aplicação de uma gestão estratégica, observar-se-á, antes de tudo, as disposições legais e condicionar tal gestão estratégica em suas bases legais, pois a definição da missão, objetivos, dentre outros elementos pertinentes devem atender a tais requisitos legais para se obter sucesso numa determinada organização empresarial. Entende-se que as corporações que não têm administração estratégica ficam fadadas à derrota. Em conformidade com um inquérito RCMOS - Revista Científica Multidisciplinar O Saber. ISSN: 2675-9128. São Paulo, v. 08, p. 01-15, ago. 2021. (c) BY-NC-SA 
realizada pelo Sebrae, envolve de $25 \%$ das corporações falham e encerram no Brasil. Por outro lado, um levantamento praticado, acertadamente, pelo IBGE expôs que em média, 72\% das corporações sobrevivem nos 2 primeiros anos.

Para tanto, essas pessoas terminam trabalhando com bases no achismo, ou por terem alguma pessoa seguinte que esteja tendo êxito com o empreendimento. Aliás, a ausência de um processo metódico de orientação estratégico atento em uma administração de alto desempenho faz com que muitas corporações fechem as portas precocemente.

Por outro lado, a administração estratégica é de extrema importância ao desenvolvimento do empreendimento. Por isto, abordaremos neste artigo tudo o que o usuário necessita saber com relação a planejamento: o significado, que áreas se aplica, como necessita ser usada, com relação a outras opiniões ou dicas que irão te melhor acrescentar a conduzir e dirigir a empresa

De acordo com o SEBRAE (2018), Porque refletir com estratégia é essencial para quem quer aferir ou alcançar o êxito empresarial, sobrevivendo às transformações seguidas do mercado.

Muitas corporações se originam e aumentam de um modo desordenado, devendo até resistir por certo tempo no mercado. Mas, em tempos de tantas transformações nos qualidades específicas políticos, econômicos, sociais e científicos, num mercado exaustivamente concorrente, resistir com resultados distintos e notados, cobra muita organização, manejo estratégico e inovação.

Se a corporação empresarial está iniciando, dar definição de a metodologias que irá trilhar no mercado fará grande desigualdade pontual, dado que, ao saber de que se identifica, de forma total, as potências e as insuficiências para ação, falhas acabam se fazendo evitadas, conquistando resultados mais consistentes com a sua razão de existir (SEBRAE, 2018)

Se a corporação empresarial já está no mercado, é essencial repensar a forma de ação. No ambiente de seguidas transformações, é capaz de ser preciso tornar assíduos processos de recomposição para sobrevivência e alta competição. Ademais, as reestruturações acabam se fazendo na forma da organização, financeira, todavia seja, igual a, dos produtos e serviços apresentados no mercado.

Ainda de acordo com o Sebrae (2018), as estratégias de Crescimento: metodologias empresariais para evoluírem os lucros, as comercializações, ou a bem-vinda contribuição do mercado, acrescentando desenvolvimentos aumentativos oportunos o valor da empresa. Estratégias de estabilidade: quando existem operações em muitos setores, a corporação RCMOS - Revista Científica Multidisciplinar O Saber. ISSN: 2675-9128. São Paulo, v. 08, p. 01-15, ago. 2021. (c) BY-NC-SA 
empresarial é capaz de desejar concentrar suas operações, seus empenhos administrativos, nas corporações reais, sem evoluírem suas unidades. Estratégias de redução: quando os resultados ficam abaixo do esperado, ou a sobrevivência está desafiadora, a diminuição é capaz de ser uma metodologia de melhora da situação negativa, devendo ser, de reviravolta transformações para melhoria; desinvestimento ou liquidação se for o caso (SEBRAE, 2018).

Para colocar em pauta na elaboração de as metodologias entendidos, às corporações, é importante percorrer um roteiro, estruturar o conceito de um modo estratégico, ensinando a corporação empresarial rumo ao futuro.

Para tanto, é usada a técnica de Planejamento Estratégico. Nela, o dono de um empreendimento e os diretores administrativos analisam o ambiente em que promovem, identificam suas crenças e valores para ação no mercado, estabelecendo a finalidade maior da corporação empresarial, sua razão de estar no mercado, o que irá entregar e como deverá ser identificada em definido e ajustado prazo.

\section{CONSIDERAÇÕES FINAIS}

O presente trabalho se propôs a investigar a gestão em um patamar estratégico, enquanto ação que viabiliza o sucesso num empreendimento dissecou a respeito da necessidade dele na condução do sucesso de um empreendimento, bem como deu ênfase a sua importância e relevância para as organizações empresariais, bem como para toda a sociedade.

Conclui-se que o sucesso da partida viabilize os fins lucrativos não somente no sentido econômico, mas na cultura organizacional e no plano político organizacional dispostas no âmbito da discriminação industrial e empresarial. A estratégia de ações é observada no âmbito da discriminação industrial e privada no sentido amplo das conquistas ansiadas pelo nível organizacional do comércio.

Para tanto, o nível gerencial de comércio também observa a melhor maneira para atender as necessidades do amplo organizacional superior e subordinado a este. Observa a melhor forma de uma empresa ou organização poder conduzir cálculos para sua apropriação no plano de estratégia política de suas ações de comando. (ANSOFF, 1987). Embora tendo sido planejada estrategicamente, a ação operacional é a última fase de um processo de operação, pois a gestão permite à continuidade deste para a avaliação de resultados, fase depois de cumprida a ação planejada realizada através dos meios estratégicos. Para se alcançar um efeito desejado, a gestão estratégica necessita do apoio e comprometimento de RCMOS - Revista Científica Multidisciplinar O Saber. ISSN: 2675-9128. São Paulo, v. 08, p. 01-15, ago. 2021. (c) BY-NC-SA 
todos do corpo funcional da empresa por ocasião da implementação das várias ações estratégicas dele decorrentes. Baseado nessa premissa, os atores das diversas fases do processo são os próprios integrantes da organização. Desse modo e diante do exposto, defendemos a ideia de que esse modelo de gestão é imprescindível para o sucesso de uma organização empresarial e, para tanto, faz-se necessário considerar todas as fases para a sua criação e implementação.

\section{REFERÊNCIAS}

ANSOFF, H. Igor, DECLERK, Roger P., HAYES, Robert L. (Org.) Da gestão estratégica à administração estratégica. São Paulo: Editora Atlas, 1987.

DUCKER, A. A importância do planejar para o comércio. São Paulo. Ed.3. Nobel, 2007.

CHRISTENSEN, Carl. ROCHA, A. da. Marketing: Teoria e Prática no Brasil - Editora: Atlas Ano: 1995.

CHIAVENATO, Idalberto. Gestão de pessoas: o novo papel dos recursos humanos nas organizações 3. ed. Rio de Janeiro: Elsevier, 2010.

FISHMANN, Adalberto Martinho I.R. Gestão estratégica na prática. São Paulo: Editora Atlas, 1990.

GAJ, Luis. O estrategista: do pensamento à ação estratégica na organização. São Paulo: Editora Makron Books, 2002.

GIL, Antonio Carlos. Como elaborar projetos de pesquisa. 5. ed. São Paulo: Atlas, 2008.

GRACIOSO, Francisco. Gestão estratégica orientado para o mercado. $3^{\mathrm{a}}$ ed. São Paulo: Editora Atlas, 1996.

HINDLE, Tim. Tudo sobre administração. São Paulo: Editora Nobel, 2002.

JÚNIOR, Aldery Silveira Guilherme. Gestão estratégica como instrumento de mudança organizacional. 2. ed. São Paulo: Editora Atlas, 1999.

KOTLER, Philip. Administração de marketing: análise, planejamento, implementação e controle. 2. ed. São Paulo: Editora Atlas, 1992.

LEVY, A. R. Estratégia em ação. São Paulo: Editora Atlas, 1986.

MARCONI, M. de A. LAKATOS, E. M; Fundamentos de metodologia científica. 5. ed. São Paulo: Atlas, 2003. 
MATOS, F. G., CHIAVENATO, I. Visão e ação estratégica. São Paulo: Editora Makron Books, 1999.

MOTTA, P. R. Dimensões gerenciais do planejamento organizacional estratégico. In: VASCONCELLOS FILHO, P.; MACHADO, A. M. V. (Org.). Gestão estratégica, formulação, implantação e controle. Belo Horizonte: Editora Moderna ,1984, Capítulo 2, p.132-133.

SEBRAE. 2018. O que são estratégias empresariais. 2018, disponível em https://www.sebrae.com.br/sites/PortalSebrae/artigos/o-que-sao-estrategiasempresariais,e4df6d461ed47510VgnVCM1000004c00210aRCRD acesso em 29 dez. 2020.

SILVA, R. O. Teorias da administração. São Paulo: Editora Pioneira Thomsom Learning, 2001. 


\title{
GESTÃO DE CONFLITOS COMO TRANSFORMAR FRAQUEZA EM FORÇA ORGANIZACIONAL.
}

\author{
Maxmiliano da Silva Soares
}

\section{RESUMO}

Introdução: o tema deste artigo é considerado como um vasto campo de investigações e procedimentos metodológicos de pesquisa, a gestão de conflitos é postulada enquanto terreno fértil de pesquisas e conduz-se a amplas perspectivas pela em vislumbre de sua potencialidade. Justificativa: Fato posto, que pode ser verificado em categorias e subáreas das ciências humanas e ciências sociais. Isto posto, trata-se de espaço aberto a todos na construção do conhecimento, e desloca-se nas fronteiras de elaboração desta sapiência que se faz necessariamente interdisciplinar. Problematização: Nesse artigo, portanto, discute-se como se pode transformar fraqueza em força organizacional através da revisão de literatura. Objetivos: Os objetivos específicos se dedicam a dizer se esta resposta pode ser obtida através da revisão literária, descrever de que forma ocorre e analisar sua contribuição como um todo. Hipóteses: seria a bibliografia se faz capaz de responder tal questão? Existem elementos interpessoais que interferem neste sentido transformador? Esta síntese requer uma argumentação focada nos conceitos da administração geral? Metodologia: realiza uma breve exposição do conceito de força organizacional, o qual decorre a partir de autores fundamentais, realizando-se uma revisão de literatura. Ao desfecho, conclusão: Conclui-se ao apontar anseios, limites e possibilidades no uso deste tipo de força para vencer as fraquezas em uma organização através da gestão de conflitos.

Palavras-chave: Gestão de conflitos. Fraqueza organizacional, força organizacional.

\begin{abstract}
Introduction: the topic of this article is considered as a vast field of research and methodological procedures of research, once the research data were submitted to research and research conducted by a group of researchers in its potentiality. Rationale: Post facto, which can be verified in categories and subareas of the human sciences and social techniques. This, then, is an open space in the construction of knowledge, and it moves within the boundaries of the interdisciplinary consciousness. Problematization: In this context, it is discussed how one can transform weakness in organizational security through literature review. Objectives: The specific objectives are dedicated to being able to present themselves through the literary review, the description of the results and their contribution as a whole. Hypotheses: Would it be a bibliography capable of answering such a question? Are there interpersonal elements that interfere in this transformative sense? Does this question require an argument in the concepts of general administration? Methodology: it comprises a great exposition of the organizational concept, which stems from an initiative of fundamental authors, carrying out a literature review. When finishing, conclusion: Conclude to the yearning, have limits and possibilities of not using this kind of force to overcome as weaknesses in an organization through conflict management.
\end{abstract}

Keywords: Conflict management. Organizational weakness, organizational strength.

\section{APRESENTAÇÃO}

Historicamente, a gestão de conflitos se dedicou à descrição dos sistemas administrativos observando o desenvolvimento em vários países do globo. Esta tarefa foi 
desenvolvida através de pesquisadores ligados a campos da organização administrativa ou às áreas de estudos de administração pública. As pesquisas varrem o mundo procurando e coletando informações e a partir destas aplicam-se em seus sistemas de ensino de origem.

Eis o ponto de maior intensidade deste debate teórico, pois que a gestão de conflitos pode transformar fraquezas em força organizacional. Neste artigo, pretende-se percorrer esta trajetória para construção do campo da gestão de conflitos, ao evidenciar sua história e seus demais avanços que intercorrem no debate em função de melhorias sociais, econômicas e da gestão ocorridas nas últimas décadas.

O objetivo geral deste estudo é indica como as fraquezas podem ser transformadas em força organizacional a partir da gestão de conflitos. Os objetivos específicos se dedicam a dizer se esta resposta pode ser obtida através da revisão literária, descrever de que forma ocorre e analisar sua contribuição como um todo.

O questionamento a se responder é como transformar fraqueza em fortaleza a partir da gestão de conflitos? E a suas hipóteses com a máxima clareza na leitura informativa apontam que a gestão é a principal responsável por essa possibilidade.

A metodologia é bibliográfica pautada em autores a partir de uma pesquisa nas bases Scielo, Google Acadêmico pelos termos "conflitos"; AND “organização" AND "lideranças". O trabalho é subdividido em tópicos a partir dos objetivos específicos, e norteado pela resposta ao problema de pesquisa.

\section{DESENVOLVIMENTO}

\subsection{A GESTÃO DE CONFLITOS E SUAS EXPRESSÕES.}

Neste sentido, a gestão de conflito é descrita como um processo inerente às relações humanas, fazendo parte de cada pessoa envolvida. Ademais, o termo conflito está ligado ao desacordo, discórdia, controvérsia, divergência ou antagonismo. Conforme Robbins (2002, p. 185), temos que,

"[...] o conflito ocorre quando uma das partes percebe que a outra parte afeta, ou pode afetar, negativamente, alguma coisa que a primeira considera importante". Os conflitos são praticamente inevitáveis e podem ocorrer em diferentes ambientes: familiar, social e de trabalho.

Envolve, contudo, questionamentos relacionados ao convívio de indivíduos com suas personalidades, valores, culturas, e diversos interesses diferentes. Nas organizações públicas ou privadas, esta situação pode ser acentuada por diversas questões de ordem políticas ou em 
virtude da diferenciação de vínculos e das relações interpessoais de trabalho. Adiante, tem-se, na visão de Schermerhorn, Hunt e Osborn (1998) ocorrerá conflito sempre que os desacordos houve em numa situação social com ou com relação a questões muito importantes, ou sempre em que apareçam antagonismos emocionais capazes de criar um atrito entre indivíduos ou grupos de indivíduos.

Continuamente, o conceito sobre conflito têm sido significa mente modificado, isto ocorreu em virtude de mudanças dos tempos, e de uma considerável evolução das teorias organizacionais. Parafraseando Robbins (2002 apud OLIVEIRA, 2006) destacam-se três abordagens principais: a tradicional, relações humanas e interacionista.

$\mathrm{Na}$ visão tradicional entende-se que todo conflito não seja bom e que, deva ser evitado. O conflito, nesta visão é visto como a disfunção resultante das falhas de comunicação, entre elas, a falta de confiança entre os indivíduos de um grupo e um fracasso dos gestores no atendimento das necessidades e dos anseios de seus funcionários. A visão tradicional prevaleceu durante as décadas de 1930 e 1940.

[...]Neste caso, competição só pode ser frutífera se ela for aberta (todos ganham), visto que, nas competições fechadas, tem-se uma pessoa ganhando da outra, o que pode levar aos conflitos destrutivos. Assim, os conflitos podem ser categorizados em três tipos básicos: discussão, competição e conflito propriamente falado. Os dois primeiros podem ser considerados benéficos ou frutíferos, já o terceiro é perigoso. (MARTINELLI, 2002, p. 17)

Martinelli (2002) intui que nas contribuições de diferentes pontos de vista, se podem levar a uma melhor o problema a uma melhor solução, visto que sugere a existência de lideranças compartilhadas, com familiaridade entre integrantes daquele grupo, levando tal grupo a apresentar consensualmente não só os fatos, mas suas impressões pessoas a respeito de cada situação.

O autor acrescenta que muitos dos conflitos, que surgem dentro e fora das organizações, não são nem do tipo discussão nem competição. As razões para isso são a falta de confiança, perspectivas diferentes e enfoques individuais no seu tratamento, podendo transformar-se em conflitos destrutivos.

Segundo Nascimento (2002) os conflitos podem ser ainda do tipo interpessoal, que ocorrem entre duas ou mais pessoas, e podem acontecer por vários motivos: diferenças de idade, sexo, valores, crenças, por falta de recursos materiais, financeiros, por diferenças de papéis. Eles podem ser divididos em dois tipos:

a) Hierarquia: colocam em xeque as relações com a autoridade existente. Ocorrem quando a pessoa é responsável por algum grupo, não encontrando apoio junto aos seus subordinados e vice-versa.

RCMOS - Revista Científica Multidisciplinar O Saber. ISSN: 2675-9128. São Paulo, v. 08, p. 01-11, ago. 2021. (cc) EY-NC-SA 
b) cunho-Pessoais: são os que dizem respeito ao indivíduo, à sua maneira de ser, agir, falar e tomar decisões. As rixas pessoais fazem com que as pessoas não se entendam e, portanto, não se falem. Em geral esses conflitos surgem a partir de pequenas coisas ou situações nunca abordadas entre os interessados. O resultado é um confronto tácito que reduz em muito a eficiência das relações. (NASCIMENTO, 2002.p.29).

Os conflitos, tanto hierárquicos quanto pessoais não podem ser considerados comuns quando se tornam uma rotina constante, é claro que devem existir alguns conflitos, mas que estes possam contribuir para a melhora do processo como um todo.

Entretanto deve-se considerar que o conflito com clientes, compradores etc., deve ser inexistente, na medida do possível evitado ao máximo, pois o cliente é quem mantém a empresa ou o vendedor.

\subsection{As Consequências dos conflitos para as organizações}

De acordo com Chiavenato (2008, p. 210) apresenta-se outro rol de categorias para os conflitos, relacionadas ao nível da gravidade em que cada um destes ocorre. Para o referido autor, os conflitos são categorizados em:

a) Conflito é percebido: os componentes envolvidos percebem e compreendem que o problema essencial existe porque sentem que seus anseios acabam se fazendo diferenciados tipos de dos anseios dos demais no qual existem muitas oportunidades e, para obstrução ou bloqueio. É o invocado por problema essencial latente, que as divisões percebem que existem eventualmente.

b) Conflito é experienciado: quando o problema essencial causa sentimentos de hostilidade, raiva, medo, descrédito entre uma parte e outra. É o invocado por problema essencial velado, quando é disfarçado, oculto e não declarado no exterior com clareza.

c) Conflito manifestado: quando o problema essencial é descrito através de um comportamento de obstrução ativa ou passiva por pelo menos uma das frações. É o invocado por problema essencial aberto, que se declara sem dissimulação.

Assim se fazendo, conflitos acabam se fazendo percebidos ou facilmente amplamente identificados em especial, na observação das frações que o acabam envolvendo, ou permanecerem nele ocultas, sem que possa ocorrer nem ao menos um tipo de manifestação a seu respeito. Além disto, o autor ainda incrementa que, das categorizações de conflitos, caberia o grandioso evidência também sob as suas causas, assim que estas ocorram dentro das unidades organizacionais. Seguindo na visão interacionista, Martinelli (2002, p. 15) discute que existem duas maneiras de se afrontar os instantes de conflitos:

[...] uma negativista, que encara o problema essencial como algo tão apenas, prejudicial, que necessita ser evitado a todo custo, ou não se devendo evitá-lo, pelo menos ter seus resultados minimizados. A $2^{\mathrm{a}}$ escolha é a de afrontar o problema essencial de maneiro esperançosa, caçando observar aquilo que é capaz de buscar de proveitoso, em sentido de diferenças de opiniões e visualizações, igual a, de muitas 
oportunidades e, de abstração de conteúdos e enriquecimento, individuais e culturais. Diante de tal sobreposição Chiavenato (2004 apud AAL JUNIOR; HAMMERSCHMIDT; PAMPOLLINI JÚNIOR, 2010, p. 7).

Destaca-se nesta compreensão, que o excelente produto do problema essencial poderia ser positivo, caso este, incentivasse os grupos os seus integrantes a encontrarem meios melhor bastante eficazes e transformadores ao desenvolvimento de suas operações, e, de forma mais importante, nas bem diversificadas muitas oportunidades e, e nas que se enfrentam diversos intensos conflitos.

Todavia, é capaz de o problema essencial também ser proveitoso quando se motivam os grupos a praticarem relações de interatividades, de do qual sentido seja, o de resolver o problema essencial, e como excelente produto, os integrantes tornam-se menos dispersos, comumente nos instantes em que podem ocorrer como meio de se invocar a atenção para áreas discussões de uma instituição.

\section{COMO TRANSFORMAR FRAQUEZA EM FORÇA ORGANIZACIONAL.}

A percorrer, destaca-se a experiência ou aptidão de transformação das fraquezas em força da Organização por meio da orientação dos conflitos em uma instituição. O texto usa diversos escritores cargos em grande evidência a acerca desse tema discutido e as argumentações atentam uma dada criticidade a fim de esclarecer o assunto ou matéria discutida com o objetivo de seja, melhor entendido.

Neste ponto de observação, Chiavenato (2004) informa mesmo que os conflitos também podem invocar resultados negativos, aos que se causam certas causas que conseguem impedir o melhor desenvolvimento de uma instituição qualquer ou corporação empresarial, já que os agentes envolvidos e grupos organizados podem chegar a fazer sentimentos hostis, como os de frustrações e de inquietudes em frente dos seus empenhos além dos exercidos corretamente bloqueados num momento de problema essencial.

Assim se fazendo, os conflitos devem prestar serviço de motivação a fim de que se consiga a chamada força da organização, que é capaz de ser entendida nas unidades organizacionais que fazem dos instantes de problema essencial a oportunidade e de transformarem suas qualidades específicas, e conferência de equívocos simples, e, mesmo depois de um instante tenso, este fica na memória de todos com o objetivo de não ocorra novamente. Agindo-se desta forma, o problema essencial impede ou dificulta na ampla eficiência da instituição além dos agentes envolvidos, já que as perseguições dos anseios 
ficam de lado, e a maior parte das energias originadas por meio do problema essencial se dispersa nele mesmo, e logo, consegue-se permear por ações ou atitudes de ações inseridas que não acabam se fazendo substituídas através de comportamentos egoístas, que chocam de forma direta na natureza dos relacionamentos.

Notoriamente, os conflitos podem ocorrer num ambiente da organização, ou podem ocorrer no trato com públicos-alvo, se tornarem que fazem bem ou não. No momento em que, um problema essencial se acaba originando desde uma forma moderada, melhora-se o desempenho de uma ação, e, por outro lado, se podem ocorrer de um modo bastante diminuído, podem tornar-se condicionantes de um desempenho limitado.

Por conseguinte, cabe-se grande evidência à importância de a Gestão de Conflitos em propiciar na inevitável mediação dos mesmos no ambiente dos grupos ou de unidades organizacionais. Adiante, descrever-se-á a respeito desta importância. De acordo com Schiefer, Teixeira e Monteiro (2006, p. 233), tem-se que:

\begin{abstract}
"[...] baseia-se na experiência de combinar grupos com convenientes, valores, meios e intenções eventualmente contraditórios ou antagônicos". No contexto das unidades organizacionais públicas, fica certo e claro a carência e a real importância de os diretores públicos conhecerem as formas mais corretas e cumplices à inevitável mediação e administração dos conflitos, enxergando a peculiaridade da parte de Recursos Humanos nessas organizações.
\end{abstract}

Nogueira (2010, p. 9) ilustra de forma apontada e destacada, que, a acerca desse aporte de Recursos Humanos nas unidades organizacionais públicas a administração de conflitos completa, de modo excelente, a equipe de atribuição administrativa que se acha com a responsabilidade pelo pessoal, e traduz seus empenhos nos processos de própria escolha de pessoal, de treino e da remuneração, no qual não de forma fácil constrói qualquer outra ação no sentido das algumas associações coletivas.

Igualmente, o dever do agente na inevitável mediação de conflitos tem grande real importância, de um modo que se é cabível a este conduzir e dirigir e se facilmente identificar as situações de um problema essencial que venha a ocorrer na organização. Ele necessita ser

[...]capaz de estudar convenientes, entender com relação a conflitos e esmiuçar estrategicamente algumas associações de poder, de tal forma que as situações realmente consigam ser colocadas dentro de medidas de manejo estratégico, certas qualidades técnicas acabam se fazendo requeridas aos diretores para lidarem com estas situações. (MORGAN, 1996, p. 30 apud CAVALCANTI, 2006, p. 9).

Geralmente, os diretores podem causar certas mediações a fim de modificarem assimilações e/ou comportamentos e as bases de um modo que realmente consigam dar oferece apoio na redefinição ou na nova orientação dos conflitos para estas sirvam a meios e objetividades, construtivos. 
Assim se fazendo, a experiência ou aptidão psicológico emotivo, de cada gestor impede ou dificulta neste processo, comumente, a sua experiência ou aptidão em coordenar e administrar situações conflitantes. Esta expertise é redefinida e ajustada através dessas preferíveis competências individuais e por meio da sua influência com os membros de uma equipe de trabalho.

Assim se fazendo, não existe fórmula básica para decidir conflitos. Deve-se, antes de tudo, buscar por meio da devida expertise e aptidões da operacionalidade (em sua dinâmica) do problema essencial e de suas incidências, a fim de aferir ou alcançar um diagnóstico mais condizente aceito, dentro de outras oportunidades e, de redefinida e ajustada situação na qual se é capaz de transformar esta oposição em força da organização. (MOSCOVICI, 2000 apud AAL JUNIOR; HAMMERSCHMIDT; PAMPOLLINI JÚNIOR, 2010, p. 4). Dubrin (2006, p. 183) comenta que a melhor forma de se decidir uma ocorrência conflitante a fim de transformá-la em proveitosa poderia ser que,

\begin{abstract}
“[...]os conflitos acabam se fazendo bastante diminuídos, ou preparados, quando um ou mais membros de uma unidade da Organização substituem de lugar com membros de outra unidade." O autor comenta mesmo que "a substituição de pessoal tem bom funcionamento melhor quando os colaboradores têm a aptidão técnica a se dar bem no remodelado ambiente." Na visão de Chiavenato (2008), para pelejar com as situações de problema essencial consegue-se empregar um dos seguintes estilos: de evitação, de acomodação, concorrente, dever e colaboração.
\end{abstract}

Deve-se entender com relação a que, depois de iniciado o problema essencial, é cabível utilizar-se de metodologias e ações bem adotadas, com o objetivo de se enfim consiga transformar aquele momento num sentido motivacional ao grupo, e então, é cabível a obstrução de pelo menos um dos membros que tome a vanguarda só desfecho e incentive o grupo a refletir que a aquele momento se identifica, de forma total, de uma oportunidade e de esmiuçar estrategicamente os relacionamentos. (CAETANO; VELA, 2002; RAHIM, 1991 apud MCINTYRE, 2007, p. 298)

Assim se fazendo, quando é falado em transformar fraqueza em força da organização, está-se referindo a uma experiência ou aptidão que todas as unidades organizacionais concretizam perfeitamente desenvolvimento de através de sua integração, dado que, se o grupo não está juntado e não busca antes decidir sua desigualdade pontual deverá ser praticamente impossível que haja esta transformação.

Um mercado em constante evolução, as atualizações cada vez mais rápidas e as diferenciados tipos de carências dos trabalhadores, tornam improvável para líderes e empreendedores estabelecerem uma ampla dimensão de cultura empresarial robusta. Isso porque este significado irá bastante além da listagem de valores que a corporação empresarial 
ostenta. Sua verídica essência acaba se fazendo os pensamentos e ações inconscientes que determinam as decisões e comportamentos dos envolvidos no dia a dia do empreendimento.

Um mercado em constante evolução, as atualizações cada vez mais rápidas e as diferenciados tipos de carências dos trabalhadores, tornam improvável para líderes e empreendedores estabelecerem uma ampla dimensão de cultura empresarial robusta. Isso porque este significado irá bastante além da listagem de valores que a corporação empresarial ostenta. Sua verídica essência acaba se fazendo os pensamentos e ações inconscientes que determinam as decisões e comportamentos dos envolvidos no dia a dia do empreendimento.

Sem indagações, a ampla dimensão de cultura da Organização é essencial a fim de que haja um excelente ambiente de trabalho, em que os colaboradores acham claramente sua obrigação e se acham livres a se facilmente identificar expressamente suas sugestões ou concepções. Para tanto, muitas companhias aumentaram sem se devotar mais a este assunto e, apenas quando os problemas impulsionados por meio da sua ausência chegaram, se viram forçados a transformar a atitude (conduta e comportamento), até diante disso corrente.

Investir em educação corporativa se identifica, de forma total, de uma das maneiras mais bem bastante eficazes de fazer com que os colaboradores se sintam caros por meio da corporação empresarial. Ao fazer experiência de dar força a ampla dimensão de cultura empresarial, expor com o amparo de capacitações e treinos para associar e harmonizar a equipe na nova realidade alarga, de forma considerável, as chances de êxito.

Sem indagações, a ampla dimensão de cultura da Organização é essencial a fim de que haja um excelente ambiente de trabalho, em que os colaboradores acham claramente sua obrigação e se acham livres a se facilmente identificar expressamente suas sugestões ou concepções.

O desenvolvimento tem relação às experiências da organização que pretendem a continuar mantendo a ampla dimensão de cultura viva: trajetórias (relatos), rituais (atividades), símbolos (objetos, ações com conceitos especiais), linguagem (símbolos verbais), entre outros Meios. Ademais, as lideranças, devido ao seu domínio de persuasão, auxiliam e colaboram invencivelmente com a distribuição da dimensão de cultura.

Outra forma de continuar mantendo a ampla dimensão de cultura é a socialização (ou aculturação). O significado é capaz de ser certo e definido como o processo pelo qual os agentes envolvidos abstraem conhecimento a forma de ser, de fazer e de "proceder" na organização. Para tanto, muitas companhias aumentaram sem se devotar mais a este assunto e, 
apenas quando os problemas impulsionados por meio da sua ausência chegaram, se viram forçados a transformar a atitude (conduta e comportamento), até diante disso corrente.

\section{CONSIDERAÇÕES FINAIS}

Considera-se bastante proveitoso o desenvolvimento do presente texto, dado que, o conjunto de defesas usadas por meio da bibliografia invocada se fez cabível quanto o desfecho do problema estabelecido.

O mais improvável é justamente entender o que incentiva essas pessoas e o que as mesmas buscam no maior prazo se devotando ao seu simples projeto, perfilar isto, a remuneração e a um sistema que privilegie o mérito; e demonstrar a esta pessoa que ensinar os mais novos vale a pena e é melhor resposta para este relacionamento dar certo.

Considera-se que muitas pessoas que não têm gozo e satisfação em repartir seu conhecimento não devem durar bastante em unidades organizacionais que buscam este mix.

Em nossa opinião, é importante entender bastante do empreendimento e o que a corporação empresarial é capaz de dar em sentido de muitas oportunidades, e de desenvolvimento; afinal, pessoas excelentes desejam, na maioria das vezes, crescer.

$\mathrm{Na}$ nossa visão, os profissionais das corporações incumbentes (tradicionais e não inovadoras) ficam ensinando aos insurgentes (disruptivas) e assistindo as transformações acontecerem.

Pois, não necessita ser tão improvável convencê-las a aceitar um desejo e encantá-las com o panorama seguinte até em que as mesmas podem e desejam retornar, o que desejam engrandecer na comunidade aos seus públicos-alvo e como criarão valor. Sonhos poderosos encantam pessoas boas.

Os anseios específicos tinham sido trabalhados com o passar do planejamento e elaboração, cargos em grande evidência em instantes durante esta descrição, se fazendo oportunos na o esclarecimento da questão preeminente. Ademais, as suposições se somaram ao anseio, enxergando apoio na orientação da transcrição de estas sugestões ou concepções, com um azimute a se perseguir no desenvolvimento deste texto.

Ao final ficou certo e claro que a papelada se faz apto de oferecer resposta a tal questão, no qual realmente existem componentes individuais que interferem neste sentido transformador no qual este resumo solicita uma defesa, atenta nos entendimentos conceituais da administração geral. Ao final, indica-se este trabalho com o objetivo de sirva de subsídio a investigações teóricas e averiguações a acerca desse frequente tema, de em que a significância 
bastante importa, além disso, nas algumas associações comerciais, todavia seja, Da mesma forma, interpessoal seja, no trabalho, no atendimento ou na própria intimidade familiar.

\section{REFERENCIAS}

CHIAVENATO, I. Gestão de Pessoas: o novo papel dos recursos humanos nas organizações. 3. ed. Rio de Janeiro: Elsevier, 2008.

ChIAVEnato, I. Teoria Geral da Administração. 6. ed. Rio de Janeiro: Elsevier, 2004.

DI PIETRO, M. S. Z. Direito Administrativo. São Paulo: Atlas, 2003.

DUBRIN, A. J. Fundamento do Comportamento Organizacional. 1. ed. São Paulo: Pioneira Thomson, 2006. 144 Coleção Gestão da Saúde Pública - v. 8. A Importância da Gestão de Conflitos nas Relações de Trabalho: um estudo de caso na Secretaria de Saúde de Biguaçu/SC

FARIAS, L. O; VAITSMAN, J. Interação e conflito entre categorias profissionais em organizações hospitalares públicas. 2002. Disponível em: http://www.scielo.br/pdf/\%0D/csp/v18n5/10995.pdf. Acesso em: 30 nov. 2020.

GIL, A. C. Métodos e Técnicas de Pesquisa Social 5. ed. São Paulo: Atlas, 2006.

MARTINELLI, P. D. Negociação Empresarial: enfoque sistêmico e visão estratégica. 1. ed. São Paulo: Manole, 2002.

MCINTYRE. S. L. Como as pessoas gerem o conflito nas organizações: estratégias individuais negociais. 2007. Disponível em: http://www.scielo.oces. mctes.pt/pdf/aps/v25n2/v25n2a09.pdf. Acesso em: 27 nov. 2020.

MINAYO, M. C. S. Teoria, método e criatividade. 11. ed. Petrópolis: Vozes; 1999.

NASCIMENTO, E. M.; EL SAYED, K. M. Administração de Conflitos. 2002. Disponível em: http://www.someeducacional.com.br/apz/gestao_ conflitos/4.pdf. Acesso em: 29 nov. 2020 .

NOGUEIRA; A. J. F. M. Relações de trabalho no setor público. 2010. Disponível em: http://www.pucsp.br/eitt/downloads/III_Ciclo_Arnaldo_Nogueira.pdf $>$. Acesso em: 30 nov. 2020.

OLIVEIRA, J. M. Gestão de Conflitos Organizacionais. 2006. Disponível em: http://www.administradores.com.br/_resources/files/_modules/academics/academics_131_20 $100311150634052 b . p d f$. Acesso em: 30 nov. 2020.

PIRES, C. S.; MACÊDO, K. B. Cultura organizacional em organizações públicas no Brasil. 2006. Disponível em: http://www.scielo.br/pdf/rap/ v40n1/v40n1a05.pdf. Acesso em: 30 nov. 2020. 
QUEIROZ, D. T. et al. Observação Participante na Pesquisa Qualitativa: Conceitos e Aplicações na Área da Saúde. 2007. Disponível em: http://www. facenf.uerj.br/v15n2/v15n2a19.pdf. Acesso em: 30 nov. 2020.

ROBBINS, S. P. Administração: mudanças e perspectivas. São Paulo: Saraiva, 2002.

SCHERMERHORN, J. R.; HUNT JR., J. G.; OSBORN, R. N. Fundamentos de comportamento organizacional. 2. ed. Porto Alegre: Bookman, 1998.

SCHIEFER, U.; TEIXEIRA, P. J.; MONTEIRO, S. MAPA - Manual de Facilitação para a Gestão de Eventos e Processos Participantes. Estoril: Princípia, 2006.

SILVA, E. L.; MENEZES, E. M. Metodologia da pesquisa e elaboração de dissertação. Florianópolis: UFSC, 2005. 


\title{
O PAPEL DA LIDERANÇA SITUACIONAL E SUA INFLUÊNCIA NA GESTÃO DE DILEMAS, ESTRATÉGIAS E POSSIBILIDADES NAS ORGANIZAÇÕES
}

\author{
MAXMILIANO DA SILVA SOARES
}

\section{RESUMO}

Trata-se de uma atribuição organizacional do líder e como ele influência na gestão de conflitos, seus dilemas, estratégias e possibilidades no âmbito situacional. Na escolha do tema, iremos relacionar como o comportamento do líder é capaz de influenciar as decisões do grupo em conflito, do qual afeta diretamente o resultado esperado pela organização. Justificando, sabe-se que para que a equipe entregue os resultados almejados pela organização, é fator dominante que o líder seja dotado de habilidades, conhecimentos e atitudes, que estimule o comprometimento e engajamento da equipe. Foi realizada uma pesquisa bibliográfica nas bases acadêmicas. A análise das respostas permitiu comprovar que funcionários motivados ao consenso, sendo de grande importância para uma empresa. Sem dúvida, o líder tem um papel imprescindível e fundamental neste caso, pois tem o poder de influenciar os funcionários tanto positivamente quanto negativamente. O sucesso da solução de conflitos em uma empresa depende do empenho das pessoas e o líder tem que saber desenvolver as habilidades para lidar com sua equipe, aprender a tomar as decisões em diversas situações, conquistar o espaço e o respeito de sua equipe pela resolução dos conflitos. Palavras-Chaves: liderança, influência, dilemas, estratégias e solução de conflitos.

\begin{abstract}
It addresses an organizational attribution of the leader and how he influences conflict management, its dilemmas, strategies, and possibilities. In choosing the theme, we will relate how the behavior of the leader is able to influence the decisions of the group in conflict, which directly affects the outcome expected by the organization. Justifying, it is known that for the team to deliver the results desired by the organization, it is a dominant factor that the leader is endowed with skills, knowledge and attitudes, which stimulates the commitment and engagement of the team. A bibliographic research was carried out on the academic bases. The analysis of the answers allowed to prove that employees motivated to the consensus, being of great importance for a company. Undoubtedly, the leader has an essential and fundamental role in this case as it has the power to influence employees both positively and negatively. The success of conflict resolution in a business depends on people's commitment and the leader must be able to develop the skills to deal with his team, learn to make decisions in different situations, earn space and respect his team for solving conflicts.
\end{abstract}

Keywords: leadership, influence, dilemmas, strategies, and conflict resolution

\section{INTRODUÇÃO}

Liderança é uma a arte de conduzir pessoas, atrair seguidores e influenciar as atitudes e comportamentos dos seus seguidores, cuja pergunta inicial se coloca em identificar qual o papel da liderança nesse sentido. Portanto o objetivo geral dessa discussão é fomentar o líder enquanto conciliador de conflitos na administração. Para atingi-lo, faz-se necessário 
apresentar conceitos gerais de liderança e líder; apresentar dilemas e conflitos, estratégias e possibilidades do líder neste sentido (NASCIMENTO; SAYED, 2002).

Neste artigo, relaciona-se como o comportamento do líder é capaz de influenciar na solução de conflitos de sua equipe, e de que maneira afeta diretamente o resultado esperado pela instituição ou organização.

Sabemos que, para que a equipe entregue os resultados almejados pela instituição ou organização, é fator dominante que o líder seja dotado de habilidades, conhecimentos e atitudes, que estimule o comprometimento e engajamento de sua equipe.

Justifica-se que o verdadeiro líder atrai seguidores, não dá ordens, mas faz com que as pessoas queiram trabalhar com ele, permanecer na equipe e serem engajadas. Neste artigo será realizada pesquisa para relacionar como o líder influencia atitudes e comportamentos, do qual faz com que as os liderados tenham um certo mindset para que façam certas tarefas, cumpram processos, normas, regras, participem, estejam alinhadas aos seus valores como líder e os valores da instituição ou organização.

A metodologia foi realizada através da revisão de literatura com base em artigos, revistas, e publicações a respeito desse assunto, sendo, portanto, de caráter qualitativa e descritiva.

\section{DESENVOLVIMENTO}

\subsection{A LIDERANÇA E SUAS CATEGORIAS}

Liderança é a arte de conduzir pessoas, atrair seguidores e influenciar as atitudes e comportamentos dos seus seguidores. Quando o líder conduz pessoas, ele dá foco, direção e metas. O verdadeiro líder atrai seguidores, não dá ordens, mas faz com que as pessoas queiram trabalhar com ele, permanecer na equipe e serem engajadas. E quando ele atua na influência de atitudes e comportamentos, faz com que as pessoas tenham uma certa influência para motivar certas tarefas, e que cumpram processos, regras, normas gerais e participem dos valores da empresa.

O desempenho e o sucesso da equipe de vendas vão depender diretamente da postura do líder, pois quando ele lidera de forma inadequada, o engajamento e o retorno da equipe diminuem muito. Nesse sentido, a psicóloga Angela Duckworth e autora do livro Garra - O 
poder da paixão e da perseverança ao longo de seus estudos encontrou vários líderes, que faziam com que a persistência e a paixão por objetivos de longo prazo fossem maiores que a média, em um nível incomum. Ela criou uma matriz que mostra os níveis de apoio e exigência que o líder pode ocupar em relação à equipe.

\subsubsection{Líder Negligente}

Este tipo de líder possui baixo apoio e baixa exigência. O líder que está nesse nível é ausente. Ele não dá apoio nem exige, portanto vai ter baixo engajamento, baixos resultados.

\subsubsection{Líder Permissivo}

Este tipo de liderança possui alto apoio e baixa exigência. O líder que está nesse nível é o "paizão" ou a "mãezona" da equipe. É aquele que apoia e raramente dá bronca, "passa a mão na cabeça", tenta sempre ajudar e solucionar os problemas. Quando necessário, ele até descumpre normas e regras para ajudar. Esse tipo de líder tem um alto engajamento por causa da sua postura, no entanto, os resultados são baixos. Quando são estipuladas metas altas e ambiciosas, o funcionário da empresa não terá apoio.

\subsubsection{Autoritário:}

Este tipo de líder possui baixo apoio e alta exigência. O líder neste nível é o oposto do permissivo, é o mandão. Sabe aquela história de que "eu não quero saber se o pato é macho ou fêmea, eu quero o ovo?" É esse o líder autoritário. Ele manda sem explicar o porquê, quer resultado e vai exigir muito da equipe, mas dando pouco apoio.

\subsubsection{Líder democrático}

Este tipo é o que possui alto apoio e alta exigência. Este é o nível do líder de verdade. $\mathrm{O}$ que tem muita exigência, principalmente em relação ao desenvolvimento, comprometimento e entrega de resultados, mas também apoia muito para que a equipe seja engajada. 


\subsection{A DIFERENÇA ENTRE CHEFIA E LIDERANÇA}

Existe uma diferença entre ser chefe e ser líder. O chefe comanda e o líder é aquele que incentiva e envolve a equipe para o sucesso. Bernardinho (2006) ressalta que a lição de liderança não é uma obra autobibliográfica, e sim "uma história de líderes e liderança construída a partir de observações, teorias e conceitos, assimilados ao longo da trajetória ao lado de grandes equipes". Ele em seu livro ensina algumas lições sobre planejamento e liderança que podem muito bem ser usadas dentro de uma empresa:

\footnotetext{
- O planejamento deve visar metas factíveis. Ambiciosas, mas realizáveis. Se não for assim, as frustrações virão inevitavelmente.

- Não importa o tamanho do seu talento. Se você é incapaz de fazer parte de um grupo de uma comunidade e se dá mais importância ao 'eu' do que ao 'nós', você está fadado ao fracasso.

- A missão do líder e sua contribuição de buscar o máximo de cada um muitas vezes contrariam interesses, mas ele deve seguir suas convicções sem buscar popularidade, e sim o melhor para sua equipe.

- É fundamental que o líder monitore intensamente sua relação com os funcionários das empresas em momentos de sucesso. (BERNARDINHO, 2006. P.14)
}

Não basta que o líder esteja comprometido com seus liderados, é preciso que a instituição ou organização comungue dessa postura. Caso contrário, todos os seus esforços podem naufragar.

\subsection{O PAPEL DO LÍDER FRENTE AO DESEMPENHO}

Chiavenato (2008) afirma que somente pode alcançar metas e ultrapassar objetivos através das pessoas com que trabalha. O líder deve repensar o modelo de gestão que possui e a cultura corporativa da empresa e focar nas pessoas como parceiros do negócio e não como simples subordinados ou trabalhadores.

De acordo com Chiavenato (2008) o conceito de liderança pode variar de autores e dentro das organizações podem ter alguns significados diferentes, "constata-se que a maior parte dos autores conceitua liderança como processo de influência de um indivíduo sobre outro indivíduo ou grupo, com vistas à realização de objetivos em uma situação dada".

As organizações são constituídas por pessoas, com sentimentos e motivos racionais diferentes, sujeitos a força do ambiente que influenciam a motivação, os relacionamentos e a liderança, entre outras dinâmicas que motivam o comportamento do ser humano e do grupo onde ele se situa. Assim, as instituições podem complementar sua política motivacional a RCMOS - Revista Científica Multidisciplinar O Saber. ISSN: 2675-9128. São Paulo, v. 08, p. 01-12, ago. 2021. $(\mathrm{Cc})$ BY-NC-SA 
partir da liderança motivacional, permitindo que os funcionários das empresas possam escolher seus monitores dentro da instituição.

Contudo, a má liderança tem sido um grande problema em todas as atividades da vida de uma pessoa, até mesmo em suas relações pessoais, e prejudicam enormemente o clima organizacional de uma empresa. Combater o tanto quanto possível a pressão exagerada no ambiente de trabalho é necessária (KOUSES; POSNER, 2001).

\subsection{A ESCOLHA DO LÍDER PELA ORGANIZAÇÃO.}

A prática de liderar sempre foi uma oportunidade de se conhecer, estudar e aprender outras atividades e pode ser encarada como promoção e punição, dependendo do caso, se retornam funcionário das empresas nas fases iniciais do seu ingresso a fim de que aprimorem as bases de seus conhecimentos técnicos, para depois retornarem ao local onde se encontram na atualidade (KOUSES; POSNER, 2001).

Algumas pessoas são colocadas para ser líder apenas por afinidade da chefia com ele, sem saber se ele tem a vocação natural para ser uma verdadeira liderança, e esta é uma forma errada. A figura 1 mostra o jeito errado de se escolher a pessoa que irá realizar a liderança:

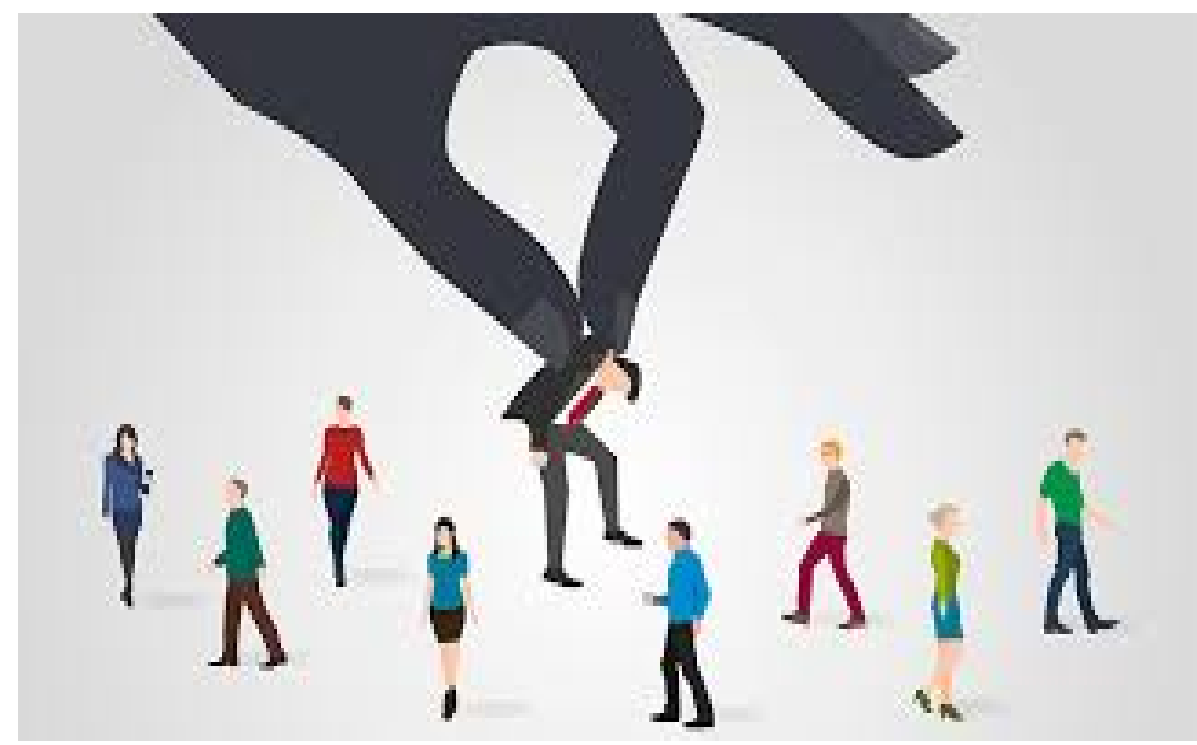

Figura 1 - a colocação errada de um líder. FONTE: OLIVEIRA (2017)

A escolha errada de um líder está selecionada com a evasão de bons funcionários das empresas de uma instituição ou organização. As motivações a fim de o desligamento devem ser diversas; os atores funcionais podem requerer e seu desligamento por não contentamento RCMOS - Revista Científica Multidisciplinar O Saber. ISSN: 2675-9128. São Paulo, v. 08, p. 01-12, ago. 2021. (cc) BY-NC-SA 
com líderes ou colegas. Kouzes e Posner (2001) indicam que a política motivacional dentro de qualquer que seja o empreendimento empresarial pode vivenciar a ausência de motivação, ou perseguição de líderes má intencionados, e deixa-se de ter uma melhor sobreposição profissional.

Assim, conforme a organização de seu pessoal, a capacidade de motivar se impõe neste lapso quanto ao líder, promovendo uma certa instigação pela desistência voluntária de empregados menos capacitados com sentido de se limpar o seu quadro funcional, enquanto estratégia.

$\mathrm{Na}$ atualidade, com o grande acúmulo das Instituições em meras atividades práticas de RH, ou seja, de Recursos Humanos, mais precisamente na atividade de gerir pessoas, são, portanto havidos os gestores pela necessidade de uma frequente avaliação da sua liderança, em virtude das principais razões ou motivos que promovem ou conduzem um bom funcionário da Organização a se evadir, e da mesma forma, identificar nessa evasão, quais os elementos que promovem ou conduzem essa vacância (KOUSES; POSNER, 2001).

Com um mercado de trabalho excludente e entendido hoje, no aspecto de ser totalmente competitivo, e da mesma forma com aumentativa perseguição por permanentes índices de qualidade, os empregados com um certo grau de qualidade profissional são os mais bem-vindos. O que se torna difícil na manutenção de um funcionário perfeito da empresa é a liderança que não se torna alinhada ao mesmo (idem).

Kouses e Posner (2001) entendem que o agente de Recursos humanos que recruta pode dar crédito a uma personalidade forte e que possua um bom treinamento profissional técnica, ou não possuindo as habilidades consideradas imprescindíveis, sendo depois estas exigidas através do treinamento, a fim de possa não desempenhar bem uma boa liderança.

Após a escolha do líder, pode ser notório que o escolhido não possuía um perfil corretamente disposto a fim de ter diante da situação de liderar pessoas, pois a atribuição na qual foi escolhido, pode ter sido apenas na ocorrência de fato e não de méritos. Ainda existe também dilemas com o treinamento, o funcionário da empresa não receber uma excelente capacitação para saber como liderar.

\subsection{O PAPEL DO LÍDER NA MOTIVAÇÃO FUNCIONAL}

Continuamente, consegue-se não motivar e até desmotivar, pois Chiavenato (2008) indica que na Gestão das Pessoas, a maioria delas, quando em uma organização ou espaço RCMOS - Revista Científica Multidisciplinar O Saber. ISSN: 2675-9128. São Paulo, v. 08, p. 01-12, ago. 2021. (cc) EY-NC-SA 
coletivo de trabalho, tendem a ser desmotivadas rapidamente, e principalmente quando não lhe fazem propostos um bom ambiente de produção amigável, e ao desempenho das suas tarefas, desde as mais fáceis, o que se torna bastante complicado quando os líderes são malvistos.

De acordo com Chiavenato (2008, p. 88), princípios de liderança pode variar de autores e dentro das organizações podem ter alguns significados diferentes, "constata-se que a maior parte dos autores conceitua liderança como processo de influência de um indivíduo sobre outro indivíduo ou grupo, com vistas à realização de objetivos em uma situação dada".

As organizações são constituídas por pessoas, com sentimentos e motivos racionais diferentes, sujeitos a força do ambiente que influenciam a motivação ao trabalho, aos novos relacionamentos e a sinergia com os que ocupam a liderança.

Adiante, percebe-se que, entre outras dinâmicas que motivam o comportamento do ser humano e do grupo onde ele se situa. Existem, contudo, vários estilos de liderança e seus princípios aplicados, como a liderança afetiva, a autoritária, a democrática, a liberal, a coaching, a diretiva, a modeladora, a participativa, a visionária, entre outras.

Adiante, são discutidos como são vistos como os princípios da liderança podem ser invocados diante dos dilemas, estratégias e as possibilidades de que a liderança carece conhecer, estudar e implementar para uma melhora dos ambientes de trabalho coletivo, cujos dilemas sempre se apresentam requerendo respostas imediatas.

\subsection{DILEMAS DA LIDERANÇA NA GESTÃO DE CONFLITOS.}

Sabemos que, para que a equipe entregue os resultados almejados pela instituição ou organização, é fator dominante que o líder seja dotado de habilidades, princípios, conhecimentos e atitudes, que estimule o comprometimento e engajamento de sua equipe na solução de dilemas impostos em todos os tipos de instituição ou organização.

Diante dos princípios se colocam alguns dilemas como a alta rotatividade devido a um líder e a gestão de conflitos. A grande rotatividade de colaborados de uma dada empresa em qualquer tipo de segmento, é considerado um aspecto que precisa ser levado em pertinência pelas grandes e pequenas instituições empresariais na determinação de suas estratégias. Atribuir perda a um bom talento e sempre prejudicial, pois perde-se lucratividade, produtividade e histórico. Kouzes (2001) indica que a dinâmica do local de trabalho pode 
vivenciar a ausência de motivação, ou na pior das hipóteses, a perseguição de líderes má intencionados, e deixa-se de ter uma melhor sobreposição ao lado profissional.

Mas, as instituições mostram a consciência de que nenhum dos e insubstituível, por mais gastos que possa gerar a fim de a empreendimento empresarial e um fato real e que necessita ser resolvido

Kouses (2001) entende que o recrutador pode dar crédito a uma personalidade que possua um bom treinamento profissional técnica, ou não possuindo as competências exigidas através do cargo e possa não desempenhar bem uma boa liderança.

Continuamente, consegue-se desmotivar, (as pessoas tendem a se desmotivar muito rapidamente) principalmente quando não the fazem propostos um bom ambiente de produção amigável, e desempenhar as suas tarefas fáceis se torna bastante complicado quando os líderes são malvistos.

Conforme Nogueira (2010), a liderança envolve questionamentos relacionados ao convívio de atores funcionais com suas personalidades, valores, culturas, e diversos interesses diferentes. Nas organizações de vendas, esta situação pode ser acentuada por diversas questões de ordem técnica ou pessoais, ou em virtude da diferenciação de vínculos e das relações interpessoais de trabalho geram conflitos diversos.

É nítido que o papel do Recursos Humanos que pode estar atenção às seguidas transformações do clima organizacional promovido pelo líder, e da mesma forma da realidade das pessoas que compõe a instituição ou organização (OLIVEIRA, 2017)

Continuamente, os dilemas observados com relação ao nível maior de contentamento de pessoal com o líder devem ter seu começo ainda no momento do recrutamento e escolha deste líder.

Portanto, é preciso investigar e descobrir as causas dos dilemas, tendo feito isto, planejar a solução através de algumas estratégias que podem ser colocadas para a resolução dos mesmos. Adiante, a próxima seção apresenta e analisa algumas estratégias que podem ser invocadas nesse sentido.

\subsection{ESTRATÉGIAS PARA RESOLUÇÃO DE DILEMAS NA LIDERANÇA E GESTÃO DE EQUIPES.}

Adiante, estratégias podem ser impostas ao se descobrirem os conflitos e neste sentido, tem-se, na visão de que ocorrerá conflito sempre que os desacordos houverem em numa RCMOS - Revista Científica Multidisciplinar O Saber. ISSN: 2675-9128. São Paulo, v. 08, p. 01-12, ago. 2021. (c)) EY-NG-SA 
situação social ou econômica com ou com relação a questões muito importantes como o clima organizacional.

$\mathrm{Na}$ visão tradicional entende-se que todo conflito não seja bom e que, deva ser evitado. O conflito, nesta visão é visto como a disfunção resultante das falhas de comunicação, entre elas, a falta de confiança entre os atores funcionais de um grupo e um fracasso dos gestores no atendimento das necessidades e dos anseios de seus funcionários. Uma das estratégias que pode ser utilizada pode ser a boa competição,

[...]Neste caso, competição só pode ser frutífera se ela for aberta (todos ganham), visto que, nas competições fechadas, tem-se uma pessoa ganhando da outra, o que pode levar aos conflitos destrutivos. Assim, os conflitos podem ser categorizados em três tipos básicos: discussões, competições e conflito propriamente falado. Os dois primeiros podem ser considerados benéficos ou frutíferos, já o terceiro é perigoso. (MARTINELLI, 2002, p. 17).

Segundo Martinelli (2002) os conflitos podem ser atenuados com aumento do relacionamento interpessoal, ao contrário, não havendo mutualidade ocorrem algumas questões envolvendo diferenças de idade, sexo, valores, crenças, por falta de recursos materiais, financeiros, por diferenças de papéis

De acordo com Chiavenato (2008, p. 210) apresenta-se outro rol de orientações para a resolução dos conflitos, relacionadas ao nível da gravidade em que cada um destes ocorre. Para o referido autor, os conflitos são categorizados em:

a) O Conflito experienciado: quando o conflito provoca sentimentos de hostilidade, raiva, medo, descrédito entre uma parte e outra. É o chamado conflito velado, quando é dissimulado, oculto e não manifestado externamente com clareza. Conflito é manifestado: quando o conflito é expresso através de um comportamento de interferência ativa ou passiva por pelo menos uma das partes. É o chamado conflito aberto, que se manifesta sem dissimulação.

Entende-se que os conflitos podem ser percebidos ou identificados pelo líder claramente na observação das partes que o envolvem, ou permanecerem nele ocultas, sem que ocorra nenhum tipo de manifestação a seu respeito. A solução é identificar, convocar as partes e discutir em consenso. Enfim, resolvendo-se os conflitos abrem-se algumas portas que podem ser chamadas de oportunidades, as quais seguem de forma evidente adiante na próxima seção deste esboço.

\subsection{METODOLOGIA}

Os dados foram organizados através da pesquisa em que se faz um estudo de cunho bibliográfico, utilizando materiais disponíveis, como livros, apostilas, artigos e textos RCMOS - Revista Científica Multidisciplinar O Saber. ISSN: 2675-9128. São Paulo, v. 08, p. 01-12, ago. 2021. $(\mathrm{Cc})$ BY-NC-SA 
publicados em sites que abordam o assunto, como se verifica adiante os instrumentos utilizados para este fim podem ser melhor evidenciados adiante no quadro 1.

\begin{tabular}{|c|c|}
\hline INSTRUMENTO UTILIZADO & DADO A SER OBTIDO \\
\hline Leitura exploratória & $\begin{array}{c}\text { Todo material foi estudado, lido e relido de forma pausada e } \\
\text { reflexiva. }\end{array}$ \\
\hline Leitura focalizada & $\begin{array}{c}\text { Os parágrafos e capítulos que interessavam ao trabalho foram } \\
\text { focalizados na releitura. }\end{array}$ \\
\hline Registro de anotações & $\begin{array}{c}\text { Realizou-se grifos e marcações nos textos registravam o que } \\
\text { realmente seria transcrito ao trabalho. }\end{array}$ \\
\hline Análise de comparação & $\begin{array}{c}\text { Logo depois de se transcrever o material, comparou-se as } \\
\text { opiniões dos autores a respeito do problema. }\end{array}$ \\
\hline $\begin{array}{c}\text { Dedução da resposta ao problema de } \\
\text { pesquisa. }\end{array}$ & $\begin{array}{c}\text { Analisando-se todas as opiniões dos autores, coube tecer } \\
\text { considerações hipotéticas julgando a resposta para o problema } \\
\text { de pesquisa. }\end{array}$ \\
\hline $\begin{array}{c}\text { Comprovação da dedução escolhida. } \\
\text { Realizou-se uma breve explanação que ocorreu através da } \\
\text { triangulação de dados primários (comentários) das pesquisas } \\
\text { bibliográficas (secundários). }\end{array}$ \\
\hline
\end{tabular}

QUADRO 01- DESCRIÇÃO DOS INSTRUMENTOS.

Fonte: Elaboração própria a partir de Markoni e Lakatus (2013)

Desta forma, buscou-se apoiar a pesquisa através da argumentação dos autores escolhidos e emitir resultados, as quais seguem adiante.

\subsection{APRESENTAÇÃO E ANÁLISE DOS RESULTADOS}

A fim de se entender as possibilidades que podem ser aproveitadas após a resolução de dilemas na liderança e gestão de equipes, pressupõe-se que o verdadeiro líder que resolve os problemas da equipe atrai seguidores, não dá ordens, mas faz com que as pessoas queiram trabalhar com ele, permanecer na equipe e serem engajadas.

Afirmar-se-á que somente se poderá alcançar metas e ultrapassar objetivos através das pessoas com que trabalha após se resolverem os conflitos. O líder deve repensar o modelo de gestão de conflitos que possui, e a cultura corporativa da empresa e focar nas pessoas como parceiros, almejando um maior sentido de equipe. Já um indivíduo que atua como" chefe", após estar com a equipe unida, tem-se a possibilidade de desenvolver as potencialidades individuais do funcionário da empresa. Ele impõe e cobra resultados, muitas vezes pressionando, assediando e encorajando os seus liderados a mostrarem os seus potenciais. Em todas as organizações e quem se requer um trabalho de produção em equipe, faz-se necessário 
levar em consideração o elemento humano é o que participa da produção através das uniões de particularidades de que cada um possui e pode oferecer ao outro.

$\mathrm{O}$ associativismo no trabalho permite que a rotatividade se realize de uma forma natural, pois quando os funcionários das empresas vencerem as barreiras limiares de suas tarefas e partem para ajudar outros colegas noutras atividades estão facilitando seus deslocamentos até estas.

Deve-se compreender que, após iniciado o conflito, cabe utilizar-se de estratégias e ações bem adotadas, a fim de que se possa transformar aquele momento em um sentido motivacional para o grupo, e neste momento, cabe a interferência de pelo menos um dos membros que tome a vanguarda da solução e incentive o grupo a pensar que a aquele momento é uma oportunidade de discutir as relações (CHIAVENATO, 2008).

Após a escolha do líder, pode ser notório que o escolhido não possuía um perfil corretamente disposto a fim de ter diante da situação de liderar pessoas, pois a atribuição na qual foi escolhido, pode ter sido apenas na ocorrência de fato e não de méritos. Ainda existe também dilemas com o treinamento, o funcionário da empresa não receber uma excelente capacitação correta pra liderar (KOUSES, 2001).

Portanto, quando se diz que quando se fala em o líder poder transformar conflitos em possibilidades, está-se referindo a uma capacidade que todas as organizações podem desenvolver através de sua integração, uma vez que, se o grupo não está unido e não procura antes resolver suas diferenças será praticamente impossível que haja esta transformação.

\section{CONSIDERAÇÕES FINAIS}

Diante das argumentações, cabe colocar que fica claro que os conflitos existem em toas as organizações, afinal é o elemento humano que opera nessa coletividade e todo ser humano possui limitações e potencialidades. Descobrir as limitações e emancipar as possibilidades deve ser uma das maiores qualidades de um verdadeiro líder.

Fica claro que, após desencobertos os dramas, conflitos dilemas impostos, pode-se traçar um plano estratégico a fim de resolve-los. Neste sentido, reunir a equipe e motivar o consenso pode ser uma ideia bastante proveitosa. Em seguida, pode-se tomar as providencias e resolver os problemas do grupo. Finalmente, após descobertos e resolvidos os problemas conflitantes a equipe estará realmente unida e poderá desenvolver suas possibilidades. Fica 
O papel da liderança situacional e sua influência na gestão de dilemas, estratégias e possibilidades nas organizações

claro que o papel do líder se faz em tornar possível a transformação de tais problemas em força organizacional, e neste sentido, aplicar os princípios da liderança se faz uma de suas maiores necessidades.

\section{REFERÊNCIAS}

BERNARDINHO. Transformando suor em ouro. Rio de Janeiro: Sextante, 2006.

BLANCHARD, Kenneth; ZIGARMI, Patrícia e ZIGARMI, Drea. Liderança e gerente minuto. Rio de Janeiro: Record, 1986.

CHIAVENATO, I. Gestão de Pessoas: o novo papel dos recursos humanos nas organizações. 3. ed. Rio de Janeiro: Elsevier, 2008.

CHIAVENATO, I. Gerenciando pessoas. 4. ed. São Paulo: Prentice Hall, 2002.

DUCKWOTH, Angela. Garra - O poder da paixão e da perseverança. 1.ed. 2016.

KOUZES, James ME e POSNER, Barry Z. O Desafio da Liderança. Rio de Janeiro: Campus, 2001. 10. ed.

LAKATOS, E. Maria; MARCONI, M. de Andrade. Fundamentos de metodologia científica: Técnicas de pesquisa. 8 Ed. - São Paulo: Atlas, 2013.

MARTINELLI, P. D. Negociação Empresarial: enfoque sistêmico e visão estratégica. 1. ed. São Paulo: Manole, 2002.

NASCIMENTO, E. M.; EL SAYED, K. M. Administração de Conflitos. 2002. Disponível em: http://www.someeducacional.com.br/apz/gestao_conflitos/4.pdf $>$. Acesso em: 30 de nov, de 2020 .

NOGUEIRA; A. J. F. M. Relações de trabalho no setor público. 2010. Disponível em: http://www.pucsp.br/eitt/downloads/III_Ciclo_Arnaldo_Nogueira.pdf $>$. Acesso em: $30 \mathrm{de}$ setembro de 2018.

OLIVEIRA, Thais Fátima L. Entenda da rotatividade de pessoal. 2017, disponível em https://www.rhportal.com.br/artigos-rh/rotatividade-de-pessoal-turnover-2/ acesso em 17-122020.

SCHIEFER, U.; TEIXEIRA, P. J.; MONTEIRO, S. MAPA - Manual de Facilitação para a Gestão de Eventos e Processos Participantes. Estoril: Princípia, 2006. 


\title{
Viabilidade econômica de uma pequena indústria para abate de rãs
}

\author{
SHIDOSHI, Christian José ${ }^{1}$; \\ SANTOS, Claudio Luciano dos ${ }^{2}$
}

\section{Resumo}

O Brasil por possuir condições climáticas ideais para a criação de rã em cativeiro tem visto crescer a atividadenos últimos anos. A ranicultura no país ainda tem muito a se desenvolver, mas já é uma atividade altamente lucrativa, quando executadas por pessoas capacitadas e treinadas para tal. Com o crescimento da busca por alimentos saudáveis, vem crescendo o interesse pela carne de rã por ser importante fonte proteica. A rã possui alta versatilidade no uso culinário, podendo ser usada na elaboração de vários pratos ou até mesmo em simples porções, agradando os mais sofisticados paladares. Quanto à comercialização a carne de rã possui alta aceitabilidade por ser um produto de qualidade e alto poder nutritivo, além de ter mercado para todos os seus rejeitos. A falta de um abatedouro do gênero na região foi um dos motivos que motivou o estudo. Com sua implantação seria possível o fortalecimento da cadeia produtiva na região. Uma grande vantagem da atividade é o aproveitamento total da matériaprima. O projeto permitiu visualizar o retorno rápido que a atividade proporciona quando feita observando as normas de qualidade e de regulamentação do setor e a lucratividade alta, tendo em vista o investimento relativamente baixo.

Palavras-chave: Agroindústria, lucratividade, Processamento, rana catesbeiana.

\begin{abstract}
The Brazil has a climate ideal for frog breeding in captivity has seen growing activity in recent years. The frog culture in the country still has a lot to develop, but it is a highly profitable activity when performed by qualified personnel and trained to do so. With the growth of the search for healthy foods has been growing interest in the frog meat due to be important protein source. The frog has high versatility in culinary use and can be used in the preparation of various dishes or even simple parts, pleasing the most sophisticated palates. As for marketing the frog meat has high acceptability for being a quality product and high nutritional value, in addition to market for all their waste.

The lack of an abattoir of its kind in the region was one of the reasons that motivated the study. With its implementation would be possible to strengthen the supply chain in the region. One of the great advantages of the activity is the total utilization of raw material, its refuse and waste, with a large gap activity. The project enabled to view quick return to activity when done watching provides quality standards and industry regulations and high profitability, given the relatively low investment.
\end{abstract}

Keywords: Agribusiness, profitability, processing, rana catesbeiana

\section{INTRODUÇÃO}

Na busca por uma alimentação mais saudável, a partir da década de 1980, o consumo

\footnotetext{
${ }^{1}$ Graduado em Agronegócio pela Faculdade de Tecnologia de Rio Preto - Fatec. São J.do Rio Preto - SP. Pósgraduado em Engenharia de Produção pela Faculdade Play - Praia Grande - SP.

${ }^{2}$ Graduado em Agronegócio pela Faculdade de Tecnologia de Rio Preto - Fatec. São J.do Rio Preto - SP.
}

RCMOS - Revista Científica Multidisciplinar O Saber. ISSN: 2675-9128. São Paulo, v. 08, p. 01-22, ago. 
de carnes consideradas brancas aumentou consideravelmente. Essa tendência proporcionou um aumento considerável à aqüicultura. Em 2008 a produção mundial atingiu 73 milhões de toneladas (LOPEIRA-BARREIRO et al., 2010).

No período entre 2003 e 2009 a produção aquícola brasileira teve um crescimento de $25 \%$, acima do mundial que foi $10 \%$ no mesmo período (OSTRENKY et al., 2008). Este cenário possibilitou um grande crescimento na criação de rã no Brasil, destacando-se pela qualidade da carne e excelente fonte de proteína.

De acordo com a FAO (2010), a produção mundial da carne de rã, durante o período de 1999-2008, foi em torno de 44.000 toneladas anuais, atingindo em 2008, 85.000 toneladas.

O Brasil produz cerca de 600 toneladas anuais de rã. Os estados com maior produção são: São Paulo, Minas Gerais e Pará (KOHLER, 2010).

Praticamente toda a produção brasileira é absorvida pelo mercado interno, mas o Brasil possui condições de conquistar grande espaço no mercado externo, porém, necessita prepararse para tal. Quanto aos subprodutos podemos dizer que praticamente o ranicultor ganha dinheiro praticamente só com a venda da carne. As vísceras e a pele são quaseque em sua totalidade descartadas. Existe tecnologia para curtimento da pele, mas não há indústria que faça isso em escala comercial (LIMA; CRUZ, 1999).

A implantação de uma indústria de abate e processamento de qualquer animal exige investimentos relativamente elevados, e uma equipe habilitada para seguir as mesmas normas higiênico-sanitárias que são adotadas internacionalmente, com base no código alimentar da Food and Agriculture Organization (FAO) (CODEX ALIMENTARIUS,1984). Para Negrini (2001), a demanda potencial pela carne de rã é três vezes maior do que a oferta, tornando-se, assim, um atrativo para a instalação de novas empresas.

\section{REVISÃO BIBLIOGRÁFICA}

A ranicultura no Brasil teve início na década de 30, quando Tom Cyrril Harrison trouxe do Canadá os primeiros 300 exemplares de Rana catesbeiana, popularmente conhecido como rã-touro americana. Em 1935 foi implantado o primeiro ranário comercial no Brasil, o Ranário Aurora, situado no município de Itaguaí, Estado do Rio de Janeiro, nas proximidades da rodovia Presidente Dutra. A partir de 1975 outros empreendimentos foram construídos, mas geralmente funcionando de forma empírica (FERREIRA, 2002).

Segundo Vizzoto (1975), a ranicultura foi introduzida no Brasil em 1935, importados

RCMOS - Revista Científica Multidisciplinar O Saber. ISSN: 2675-9128. São Paulo, v. 08, p. 01-22, ago. 2021. 
da América do Norte os primeiros casais da espécie rã-touro. Devido sua grande adaptabilidade, a rã-touro tornou-se a espécie cultivada no Brasil, surgindo vários sistemas de cultivo.

É considerado um animal exótico, pois é originária dos EUA (nordeste) e Canadá (sudeste), onde vive em temperaturas muito baixas durante vários meses do ano. Quando foi introduzida no Brasil, adaptou-se perfeitamente às condições climáticas do país, o que favoreceu seu desempenho em relação à reprodução e engorda, passando a atingir rapidamente maturidade sexual e peso de abate (sete meses e um ano em média, respectivamente) (LIMA \& AGOSTINHO, 1988).

O consumo da carne de rã é um hábito tão saudável quanto antigo, já citado por Heródoto (filósofo grego, nos anos de 484-425 a.C.) em seus escritos, como fina iguaria que os gregos serviam aos nobres em comemorações da mais distinta e elevada sociedade (LIMA et al, 2004).

O hábito de consumir rã no Brasil era prática das famílias de baixa renda. Os animais eram capturados na natureza para complementar sua alimentação. Mais tarde, alguns restaurantes passaram a oferecer o produto como aperitivo, o que estimulou a caça com objetivos comerciais. Como a caça proporcionava um fornecimento da carne de maneira irregular, foi preciso esperar pelo desenvolvimento da criação comercial para que o fornecimento se tornasse mais sistemático e alguns restaurantes oferecessem pratos requintados à base de sua carne (LIMA; AGOSTINHO, 1988).

A canalização da produção da carne de rã para comercialização abrirá um grande nicho, uma vez que ela poderáser conhecida e popular, já que, sendo introduzida no mercado, será facilmente encontrada, despertando a curiosidade nos consumidores em experimentá-la ou mesmo consumi-la com certa regularidade (CARRARO, 2008).

O preço dos produtos oriundos da Ranicultura, no mercado internacional, é bastante variável em função de diversos fatores, entre os quais merecem destaque o tamanho do produto, a época do ano e a sua origem. Os originários da criação em cativeiro, geralmente têm preço mais elevado, em razão de seus próprios custos de produção e também por possuírem maior qualidade e regularidade na oferta (BELTRÃO, 2008).

O desenvolvimento da rã-touro no Brasil é superior ao de seu país de origem (EUA). Esta afirmativa apóia-se no desempenho da mesma para as condições brasileiras que, em média, não ultrapassa quatro meses de duração para as fases de girino e engorda (FERREIRA; FONTANELLO, 2011).

A carne de rã in natura (congelada ou fresca) sempre foi o principal produto da 
ranicultura. Os demais produtos ainda se encontram em fase de desenvolvimento e consolidação de mercados, como por exemplo, a sua pele, utilizadano tratamento de pessoas queimadas e na fabricação de artefatos pela indústria de couros; o óleo, em aplicações diversas como cosméticos e medicamentos de efeito cicatrizante, o fígado e o ovário em aplicações culinárias (patê de fígado e caviar,respectivamente) (LIMA, 2012).

Praticamente toda a produção brasileira é utilizada pelo mercado interno, mas o Brasil possui condições de conquistar grande espaço no mercado externo. Atualmente o consumo no Brasil situa-se em torno de 400 toneladas/ano. Segundo a Associação Brasileira de Ranicultura o Brasil conta com aproximadamente 600 ranários implantados, quinze indústrias de abate e processamento, seis associações estaduais de ranicultores e quatro cooperativas (BELTRÃO, 2008). Existem dois tipos distintos de mercado para o ranicultor. O mercado de animais vivos para atendimento a outros ranicultores (reprodutores, girinos e imagos), laboratórios e centros universitários de ensino e pesquisa. Outro mercado, bem maior que o primeiro, o de animais abatidos, tem na carne seu maior e mais importante produto. Devido às suas características (classificado como exótico), e principalmente o seu preço, a carne de rã tem seu grande espaço demercado entre as camadas privilegiadas e melhor nível sociocultural (SEBRAE, 2009).

No Brasil, a carne de rã é encontrada nos estabelecimentos comerciais na forma de carcaça ou em coxas. Todavia, no mercado internacional há uma forte preferência pelas coxas, sendo praticamente inexistente a demanda por outro produto (LIMA et al., 1999).

Internacionalmente os maiores consumidores, e também importadores de carne de rã são: Estados Unidos, França, Alemanha, Suíça, Itália e Holanda. Países como o Japão, China, Indonésia, Índia, México e Cuba já foram considerados grandes exportadores, porém o faziam graças a sua produção fruto do extrativismo, fato que vem gerando problemas de ordem econômica e ecológica. A ação predatória de caça coloca em risco a espécie, e o desequilíbrio do ecossistema. Por outro lado, o uso de defensivos e fertilizantes nas plantações, berços para a criação das rãs na natureza,intoxicam os animais, dificultando sua comercialização, devido às barreiras sanitárias. Abre-se desta forma, um grande espaço para a ranicultura brasileira, que vem desenvolvendo tecnologia visando sua produção intensiva, dentro de controles mais rígidos (SEBRAE, 2009).

Os potenciais clientes para a comercialização da carcaça de rãs congeladas são bastante diversificados, entre os quais se podem listar: restaurantes, bares, casas de carnes, peixarias, supermercados, delicatessen e casas de festas, alémda venda direta ao consumidor em lojas da própria empresa, sejam no próprio estabelecimento, ou em grandes cidades. 


\section{METODOLOGIA}

O estudo foi elaborado conforme as etapas definidas pelo Ministério do Desenvolvimento Agrário, observandoas orientações proposta no Roteiro de Elaboração de Projetos Agroindustriais para Territórios Rurais (2007).

Para a realização do projeto foram feitas pesquisas na literatura nacional como internacional sobre o abate de rã e pescado. Foram consultadas as normas e regras para instalação de Abatedouro de Pescado. No Manual de Procedimentos para Implantação de Estabelecimento Industrial de Pescado do MAPA - Ministério da Agricultura, Pecuária e Abastecimento (2007), estabelece regras para a correta instalação de um abatedouro, seguindo as normas sanitárias para que se possa obter um produto final de qualidade, inócuo e com valor nutricional ao consumidor final.

Na previsão de custo foi feita uma pesquisa para avaliar o custo de produção e o preço pago pelo quilo de carne (coxas, carcaça e picado), dos rejeitos e da pele. Utilizou-se como base o abate de 700 animais/dia, da espécie Rana Catesbiana (Rã Touro), com peso aproximado de 350 gramas.

\subsection{Aspectos Técnicos}

Segundo a Associação Brasileira das Indústrias de Alimentos - ABIA (2003), a localização de qualquer fábrica de alimentos (agroindústria) deve ser definida considerando alguns aspectos da infraestrutura do local, como a disponibilidade de água, rede de esgotos, energia, via de transporte e sistemas de comunicação para garantir futuras ampliações na linha de produção. É recomendável uma análise da qualidade da água da região para verificar se está dentro das especificações desejáveis ao processamento. A proximidade com os centros consumidores e com os fornecedores pode significar um grande passo para a conquista do mercado e representa uma economia no transporte dos produtos (CORRÊA, 1999).

O local de implantação da agroindústria possui condições ideais de infraestrutura urbana, principalmente no quediz respeito às instalações elétricas e hidráulicas, rede de esgoto, estações de tratamento, facilidade de comunicações (telefone, internet) e água abundante, explorada através de poços artesianos. Para a escolha do tipo de tratamento utilizado para as águas residuais de abatedouros consideramos: o grau de remoção exigido dos poluentes, 
disponibilidade de área e custos de implantação, operação e manutenção do sistema (KATO, 1982).

O terreno da agroindústria esteve livre de contaminantes de qualquer espécie e com local apropriado para depósito de resíduos; a agroindústria estará, disposta no sentido de garantir aspectos relacionados à segurança, movimentação e supervisão de pessoal, direção dos ventos, posição do sol e inclinação do terreno. A agroindústria de abate de rã e pescado foi implantada, na fazenda experimental Fatec Rio Preto, antigo IPA, no município de São José do Rio PretoSP. Foram abatidas 700 rãs/dia e nas horas ociosas, pescado, conforme a disponibilidade de horário e mão-de-obra. A escolha da região Noroeste Paulista foi devido à falta dessa categoria de agroindústria, visando o aumento da atividade de ranicultura, tendo em vista que a região é uma grande produtora de pescado devido aos grandes rios da região. O local escolhido para a implantação da agroindústria preenche todos os requisitos básicos para implantação de uma agroindústria de abate estabelecido pelo MAPA.

Para as instalações físicas a indústria foi instalada em um terreno com $50 \mathrm{~m} \times 40 \mathrm{~m}$, perfazendo $2000 \mathrm{~m}^{2}$ de área. O prédio da agroindústria terá como dimensões: Prédio do Abate: $19 \mathrm{~m} \times 7.5 \mathrm{~m}$, totalizando $142,5 \mathrm{~m}$ de construção em alvenaria, figura 1 . O bloco administrativo terá um total $68.4 \mathrm{~m}^{2}$, foi construído separadamente do bloco de abate.

Conforme o Roteiro de elaboração de projetos agroindústrias proposto pelo Ministério do Desenvolvimento Agrário (2007) agroindustrializar significa beneficiar os produtos agropecuários e/ou transformar a matéria-prima agropecuária gerando novos produtos, de origem animal e vegetal. A agroindústria proposta - Abatedouro de Rã e Pescados foi construída em uma área total de $2.000 \mathrm{~m}^{2}$. Sua classificação, segundo o MAPA é de um Estabelecimento Industrial de Pescado. A figura 1 apresenta o layout da empresa, criado observando as indicações do MAPA no Manual de Procedimentos para Implantação de Estabelecimento Industrial de Pescado. 


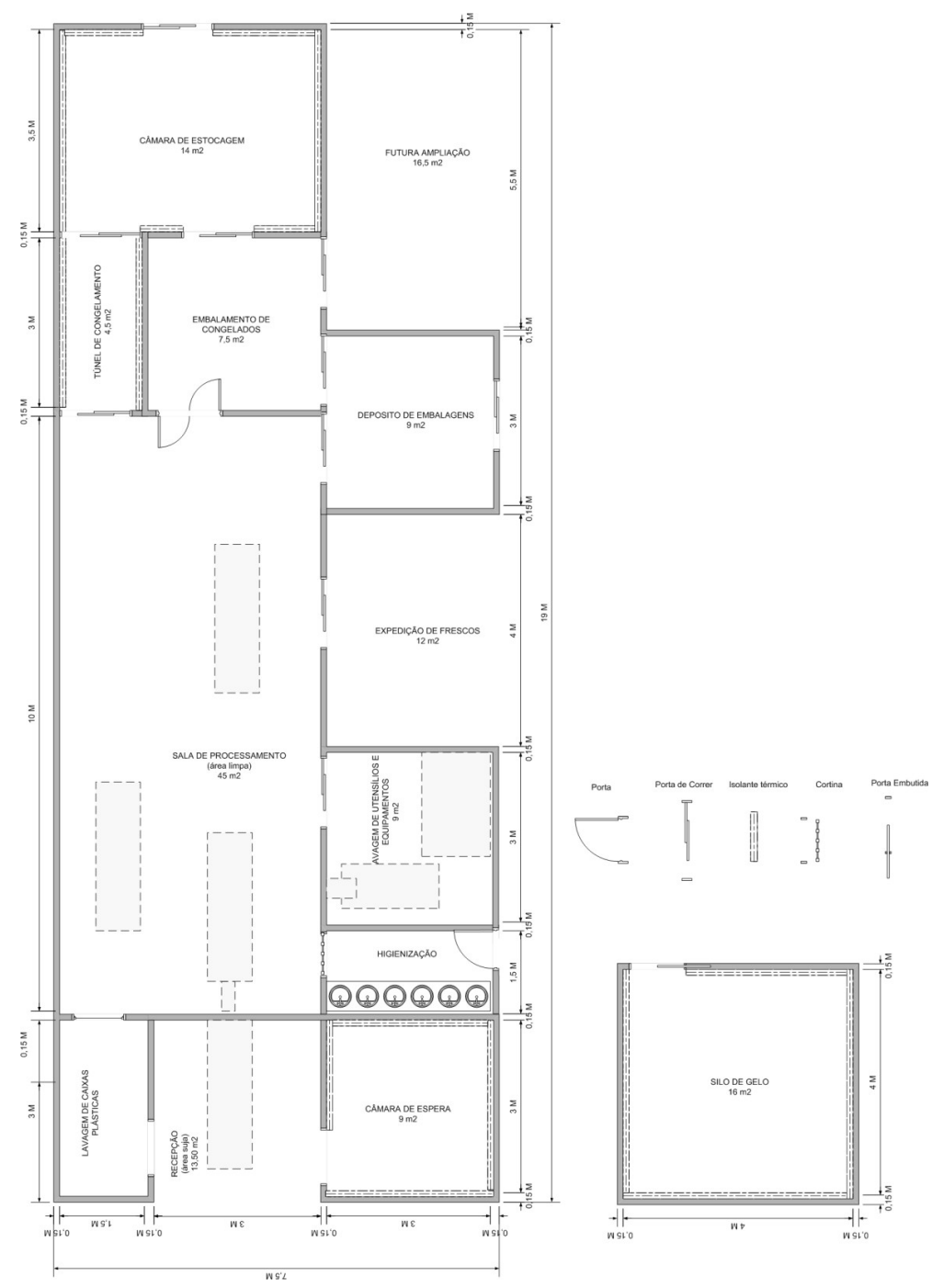

Figura 01: Planta da área de abate e silo de gelo.

Fonte: Elaborado pelos autores adaptado do MAPA- Manual de Procedimentos de abatedouros- 2007

Segundo Sandroni (1985), "matéria-prima é um produto natural ou semimanufaturado (bem intermediário) que deve ser submetido a um processo produtivo até tornar-se um produto acabado". Os fornecedores foram os ranários da região e existe um projeto paralelo para produção consorciada com produtores da região.

$\mathrm{Na}$ última década, a piscicultura vem se desenvolvendo muito na região Noroeste Paulista, principalmente coma criação super intensiva e o uso de tanques-rede. A temperatura, clima, área alagada dos reservatórios e políticas públicas favoreceram tanto essa região, que, atualmente, ela se transformou na maior produtora de pescado originado da piscicultura continental do Estado (CASTELLANI, 2007). As estradas no Noroeste Paulista para recebimento de matéria-prima e escoamento da produção até São Paulo e outras capitais, são de excelente qualidade. 
O artigo 438 do Regulamento da Inspeção Industrial e Sanitárias de Produtos de Origem Animal (RIISPOA) define com a denominação genérica "pescado", os crustáceos, peixes, moluscos, anfíbios, quelônios e mamíferos de água doce ou salgada usados na alimentação humana; incluindo as rãs (BRASIL, 1997).

As instalações e o fluxo de operações foram planejados com rigoroso critério de fluxo linear para evitar as contaminações cruzadas. Cuidados observados para que a planta de fluxo do processamento fosse contínuo, sem que a fase inicial do processo se cruzasse com fases posteriores, evitando possíveis contaminações (RODRIGUES et al, 2010).

Segundo o BRASIL (2006) as instalações apresentaram, de acordo com as normas sanitárias, características quepossibilitaram a limpeza e a higiene, tais como:

-Construído em material impermeável na parte interna;

- Forros e paredes com acabamento liso e de fácil higienização;

-Pisos impermeáveis, antiderrapantes e com pequena inclinação que facilitou o escoamento de águas residuais efacilitando a limpeza;

-Ambiente interno de trabalho deve ser fechado com vedação contra insetos, roedores e outros animais, apresentando boa ventilação e claridade;

- Área limpa da agroindústria familiar deve ser separada da área suja e do banheiro;

-Altura adequada do pé direito, permitindo a ventilação, a claridade e a colocação dos equipamentos;

- Os cantos entre pisos e paredes foram arredondados, evitando acúmulo de sujeiras e facilitando a limpeza;

-Um sistema de escoamento de esgotos, de águas e de resíduos em geral, interligado a um adequado sistema detratamento ou reaproveitamento, de acordo com as normas ambientais.

De acordo com o Manual de Procedimentos para Implantação de Estabelecimento Industrial de Pescado (BRASIL, 2007), devido à importância da unidade de refrigeração no êxito do empreendimento, alguns cuidados foram tomados na aquisição:

- Foram determinadas as reais necessidades em termos de quantidades e tipos de produtos a serem elaborados;

- Consultaram-se fornecedores idôneos para verificar a satisfação dos clientes relacionados nas listas de referência dos mesmos;

- Solicitou-se orçamentos detalhados com descrição completa dos equipamentos, indicando dimensões, capacidades, materiais utilizados, e os orçamentos acompanhados de 
folhetos, diagramas e esquemas e demais dados técnicos necessários à análise e avaliação do oferecido;

- Os fornecedores relacionaram todos os equipamentos complementares necessários ao funcionamento da instalação frigorífica e que não eram de sua responsabilidade de fornecimento;

- Outras necessidades foram indicadas: pontos de água, de esgoto, e de energia elétrica e seus dimensionamentos;

- Foram exigidos dos fornecedores meios eficazes para garantir o funcionamento, principalmente das câmaras dearmazenamento, em caso de pane de equipamento. Verificou-se também a possibilidade de interligação e intercâmbio entre os equipamentos, principalmente compressores frigoríficos, em caso de necessidade.

A aquicultura é mais uma atividade a competir com outras pelo recurso água. Seu desenvolvimento apresenta riscos de deteriorar a qualidade e quantidade da água, podendo afetar a qualidade ambiental, social e econômica. Correntes técnicas, científicas e representativas da aquicultura brasileira têm afirmado que a atividade não consome,mas sim, usa a água, e esta característica de não consultividade poderia mudar enfoques e estratégias relativos à gestão do recurso hídrico voltado às criações aquáticas, distanciando-as, por exemplo, das indústrias (TIAGO \& GIANESELLA, 2003). O efluente deve obedecer aos padrões de lançamentos estabelecidos nesta resolução, de acordo com a qualidade da classe em que o corpo d'água receptor estiver enquadrado - CNRH: Conselho Nacional deRecursos Hídricos, Resolução nº 91/2008 (TIAGO, 2010).

Uma das formas para garantir qualidade e segurança nas agroindústrias é a implantação do programa de Boas Práticas de Fabricação (BPF) que visa o fornecimento de alimentos inócuos a população. As BPF são procedimentos que devem ser adotados pelas agroindústrias com o objetivo de garantir a qualidade higiênico-sanitária dos alimentos de acordo com a legislação vigente. Este programa abrange cinco pontos principais: controle de água, higiene das instalações, higiene pessoal, controle de pragas e higiene dos equipamentos e utensílios. Com a necessidade de assegurar alimentos seguros e de qualidade à população foi instituída pelo Ministério da Saúde (MS) a Portaria no 326, de 30 de julho de 1997 (BRASIL, 1997), juntamente com a Portaria n ${ }^{\circ}$ 368, de 04 de setembro de 1997 (BRASIL, 1997b) do Ministério da Agricultura Pecuária e Abastecimento (MAPA) o Regulamento Técnico sobre as “Condições Higiênico-Sanitárias e de Boas Práticas de Fabricação (BPFs) para Estabelecimentos Produtores/Industrializadores de Alimentos". 
As pessoas que trabalham com manipulação de alimentos devem possuir cuidados com a higiene pessoal, comportamento e aparência. Entre esses cuidados estão: banho diário; uso de roupas limpas; o cabelo deve ser lavado no mínimo duas vezes por semana; escovar dos dentes sempre após as refeições; manter as unhas curtas e limpas (sempre sem esmaltes); cabelos presos; não utilizar acessórios durante a manipulação de alimentos (brincos, pulseiras, anéis, relógios); não comer, mascar chiclete, fumar, tossir, espirrar e evitar falar enquanto estiver manipulando alimentos; lavar as mãos com água e sabão frequentemente. Outro fator importante é a saúde dos trabalhadores, por isso foi fundamental que fossem realizados exames laboratoriais com periodicidade e sempre que o manipulador apresentar problemas de saúde é necessário que ocorra o afastamento da função (BRASIL, 1997b).

Recomenda-se a análise periódica da água, segundo as exigências sanitárias, mantendo os registros das análises em arquivo. Os produtos processados devem ser enviados para analises rotineiras e regulamentares aos laboratórios credenciados. De cada lote uma amostra deverá ser armazenada para exames laboratoriais em caso de problemas sanitários detectados pela vigilância sanitária ou pelo consumidor. O uso da água na agroindústria de alimentos foi intenso, envolvendo desde a limpeza e higienização dos equipamentos, utensílios e ambiente até a etapa do processo final. Segundo o CODEX ALIMENTARIUS (2003) é de fundamental importância o controle total da água de forma que garanta as características físicas, químicas e microbiológicas, para que não haja contaminação dos equipamentos e alimentos.

Preparo da água clorada: segundo Chitarra (1998), o agente sanitizante mais utilizado na indústria é o cloro na forma líquido de hipoclorito de sódio $(\mathrm{NaOCl})$. Do cloro adicionado à água, cerca de $20 \%$ pode combinar com resíduosorgânicos e apenas $80 \%$ permanecem na forma ativa, reduzindo a ação biocida, quando a concentração do cloro é baixa.Portanto, as soluções de cloro foram preparadas de acordo com as recomendações, não esquecendo que o excesso de cloro pode causar descoloração do produto, corrosão nos equipamentos e intoxicação dos consumidores.

A carne de rã é comercializada principalmente como: rã inteira resfriada ou congelada e coxas congeladas. De acordo com o Regulamento Técnico para Rotulagem de Produtos de Origem Animal Embalado do MAPA a rotulagem de alimentos embalados deve apresentar obrigatoriamente: denominação de venda do produto, lista de ingredientes, conteúdos líquidos, identificação de origem, nome ou razão social e endereço do importador (quando houver), carimbo oficial da inspeção, categoria do estabelecimento, CNPJ, conservação do produto, marca comercial do produto, identificação do lote, data de validade e instruções sobre o preparo 
e uso do alimento (BRASIL, 2005).

A carne de rã é vista como alimento saudável, excelente fonte de nutrientes, rica em proteínas, mineral e baixo teor em gordura e calorias. Sua biodisponibilidade de cálcio é elevada, chegando a ser igual à do leite e produtos derivados. Pode ser indicada como complemento alimentar no tratamento de osteoporose e hipertensão arterial. A liofilização dessa carne disponibiliza uma excelente matéria-prima a ser utilizada em produtos diversos e para fins de dietas específicas (FRAGOSO et al., 2012).

Lima e Agostinho (1998 apud CARRARO,K.C., 2008) afirmam que a carne de rã, por sua composição é recomendada por médicos e nutricionistas, pois sua taxa de gordura é de 3\%, sendo a única carne produzida em cativeiro que possui os 10 aminoácidos básicos para o ser humano e com digestibilidade alta, por ser formada por moléculas de cadeias curtas, sendo indicada especialmente para a alimentação de crianças que possuem rejeição à proteína animal.

Para agregar valor ao segmento, várias alternativas estão sendo estudadas, para o melhor aproveitamento da carne desta parte do corpo das rãs, dentre elas a utilização em formulações de alimento infantil, devido ao seu alto valor biológico (CONCEIÇÃO, 2000; MOURA, 1999; NÓBREGA et al., 2007).

Quanto ao desenvolvimento economicamente viável de novos subprodutos da ranicultura, pode-se destacar o aproveitamento do óleo, do fígado e da pele das rãs (FEIX et al., 2006). As propriedades do óleo de rã estão sendo analisadas, existindo resultados favoráveis à sua utilização na produção de cosméticos, enquanto que o fígado é utilizado para a produção de patês. Já a pele das rãs pode ter como destino a indústria farmacêutica ou de vestuário, Velly (2001) destacou o significado econômico do aproveitamento da pele da rã na indústria farmacêutica, enfatizando o desconhecimento do criador quanto às possibilidades de comercialização da mesma. A queratina retirada da pele da rã-touro, por exemplo, pode ser utilizada como tecido regenerativo de proteção para pessoas queimadas.

Uma das idéias para aumento da venda da carne de rã é uma abordagem aos responsáveis pela merenda escolar na tentativa de implantar a mesma na alimentação dos estudantes como fonte de proteína. Outra maneira de aumento de consumo é disponibilizar em quantidade suficiente nos estabelecimentos comerciais, como açougues, mercados e delicatessen.

O levantamento sobre os canais de comercialização feitos por Lima \& Cruz (1999) evidenciou que $16,3 \%$ dos consumidores efetivos da carne de rã o fazem por problemas de saúde (OLIVEIRA et al., 2007). O principal produto da atividade é a carne de rã, que é comercializada fresca, congelada ou processada, cujo excelente sabor e qualidades nutricionais, 
têm propiciado crescimento considerável do seu consumo, não obstante às restrições de preço. A coxa é a parte de maior aceitação, embora no Brasil esta preferência não seja tão acentuada como no mercado internacional, onde praticamente não se consome o restante da carcaça (LIMA; CRUZ 1999). A produção do abatedouro será comercializada entre redes de supermercados, redes de hotéis e restaurantes, através de contratos pré-firmados. Os resíduos serão vendidos para fábricas de ração animal e a pele para curtumes.

Outra medida foi propor aos abatedouros de rã uma ação ao nível nacional para estimular o consumo de carnede rã, baseada na importância nutricional desta carne e estimular pequenos e médios produtores rurais a produzirem rã como uma fonte de renda complementar.

\subsection{Análise econômica}

Para o estudo foi considerado o abate de 700 animais/dia com 26 dias de trabalho mensal, tendo quatro dias de folga para limpeza geral e revisão das máquinas e utensílios de abate. A agroindústria proposta abaterá 700 animais diariamente, durante 26 dias/mês, com peso médio de $350 \mathrm{~g}$ cada animal, totalizando $245 \mathrm{~kg}$ de animal vivo/dia. Durante o processo de abate, aproximadamente $29 \%$ do animal é retirado como rejeitos (cabeça e patas) e vísceras, ou seja, há uma quebra de aproximadamente $73 \mathrm{~kg}$. A tabela 1 mostra o abate diário e mensal.

\begin{tabular}{ccc} 
Tabela 01 - Abate diário/mensal do abatedouro de rã \\
\hline \multicolumn{3}{c}{ ABATE DIÁRIO/MENSAL: 700 ANIMAIS } \\
Riário/Kg & Mensal (26 dias)/Kg \\
Rã Unidade (350 g) & 245 & 6370 \\
Carne (60\%) & 147 & 3822 \\
Pele (11\%) & 26,95 & 700,7 \\
Rejeitos/Vísceras (29\%) & $\underline{71,05}$ & $\underline{1847,3}$
\end{tabular}

Os investimentos para a implantação da agroindústria compreenderam: construção civil, capital de giro,utensílios para abate em geral, veículos para distribuição, equipamentos em geral e outros gastos totalizando $\mathrm{R} \$ 258.265,58$ mais o Capital de Giro no valor de $\mathrm{R} \$ 133.165,71$, totalizando R $\$ 391.431,29$ com horizonte de planejamento de 05 anos, conforme tabela 2.

Tabela 2 - Resumo do Investimento Total $(\mathrm{R} \$)$

\section{Investimento Total (Resumo) (RS)}

$\begin{array}{ccc}\text { Descrição dos Investimentos } & \text { Valor (RS) } & \text { (\%) } \\ \text { 1. Investimentos Fixos } & 258.265,58 & 65,98 \\ \text { 2. Capital de Giro } & 133.165,71 & 34,02\end{array}$

RCMOS - Revista Científica Multidisciplinar O Saber. ISSN: 2675-9128. São Paulo, v. 08, p. 01-22, ago. 2021. 
Total

Fontes de Recursos

1. Recursos próprios

$\underline{\text { Total }}$
391.431,29

Valor (R\$) (\%)

$391.431,29 \quad 100$

$\underline{391.431,29}$

Os custos operacionais compreendem gastos com matérias-primas, mão-de-obra, embalagens, impostos, energia, água, materiais auxiliares e depreciação, totalizando $\mathrm{R} \$ 14.527,64$ mensal. A tabela 3 demonstra a estimativa de custos fixos mensais.

\begin{tabular}{cc} 
Tabela 3 - Estimativa dos custos fixos operacionais mensais (R\$) \\
\cline { 2 - 2 } Estimativa dos custos fixos operacionais mensais (R\$) \\
\hline Descrição & Custo Total Mensal (R\$) \\
Energia elétrica & $2.000,00$ \\
Telefone & 300 \\
Honorários do contador & $1.000,00$ \\
Material de limpeza & 100 \\
Material de escritório & 50 \\
Salários e encargos & $15.512,40$ \\
Combustível & 500 \\
Depreciação & 994,74 \\
Total & $\underline{\mathbf{2 0 . 4 5 7 , 1 4}}$
\end{tabular}

O custo dos materiais diretos ou mercadorias vendidas são os custos com a matériaprima (rã viva). O valor pago pelos abatedouros para os produtores atualmente é aproximadamente $\mathrm{R} \$ 9,24 / \mathrm{Kg}$ animal vivo. Na tabela 4 estão osgastos com matéria-prima/mês, totalizando R\$50.268,97.

Tabela 4 - Custos dos materiais diretos e/ou mercadorias vendidas

\begin{tabular}{cccc}
\hline \multicolumn{4}{c}{ Custo dos materiais diretos CMD e/ou mercadorias vendidas CMV } \\
\hline Produto/ Serviço & $\begin{array}{c}\text { Estimativa de vendas(em } \\
\text { unidades) }\end{array}$ & $\begin{array}{c}\text { Custo unitário de } \\
\text { materiais/Aquisição (R\$) }\end{array}$ & CMD/CMV (R\$) \\
Bandeja Carcaça & 2444 & 4,62 & $11.286,39$ \\
Bandeja Coxa & 3172 & 4,62 & $14.654,64$ \\
Bandeja Picado & 2028 & 4,62 & $9.369,36$ \\
Vísceras & 1859 & 4,62 & $8.588,58$ \\
Pele & 18200 & 0,35 & $6.370,00$ \\
& Total & & $\mathbf{5 0 . 2 6 8 , 9 7}$ \\
\hline
\end{tabular}

As receitas foram obtidas através da venda de três tipos de bandejas de carne de rã: bandeja de carcaça, bandejade coxa e bandeja de picado, além da venda separadamente das vísceras, rejeitos, sangue e pele, totalizando R $\$ 204.163,70$ mensal de Receita Total de vendas, conforme tabela 5:

Tabela 5 - Estimativa do faturamento mensal da empresa (R\$)

RCMOS - Revista Científica Multidisciplinar O Saber. ISSN: 2675-9128. São Paulo, v. 08, p. 01-22, ago. 2021. 


\begin{tabular}{cccc}
\hline \multicolumn{4}{c}{ Estimativa do faturamento mensal da empresa (R\$) } \\
Produto/Serviço & Quantidade & Preço de venda & Faturamento Total \\
Bandeja Carcaça & 2.444 & 18 & $43.992,00$ \\
Bandeja Coxa & 3.172 & 40 & $126.880,00$ \\
Bandeja Picado & 2.028 & 13 & $26.364,00$ \\
Vísceras & 1.859 & 0,3 & 557,7 \\
Pele & 18.200 & 0,35 & $6.370,00$ \\
& Total & & $\mathbf{2 0 4 . 1 6 3 , 7 0}$ \\
\hline
\end{tabular}

O abate de rã foi feito de uma forma simples. Os funcionários de abate (auxiliar de abate) receberam prévio treinamento antes de iniciar as atividades de abate. Um dos auxiliares foi treinado por um Zootecnista para trabalhar na parte de análises. O controle geral do abatedouro foi feito pelo Gerente Geral e pelo Auxiliar Administrativo que ficaram responsável por toda parte Administrativa e de Produção, incluindo a compra de matéria-prima de qualidade. Aempresa contou com um quadro de seis funcionários, com gasto mensal (salários e encargos) de $\mathrm{R} \$ 15.512,40$ como descrito na tabela 6 :

Tabela 6 - Estimativa dos custos com mão-de-obra

\begin{tabular}{|c|c|c|c|c|c|c|}
\hline \multicolumn{7}{|c|}{ Estimativa dos custos com mão-de-obra } \\
\hline Função & $\begin{array}{c}\mathrm{N}^{\circ} \text { de } \\
\text { empregados }\end{array}$ & $\begin{array}{c}\text { Salário Mensal } \\
\text { (R\$) }\end{array}$ & Subtotal (R\$) & $\begin{array}{c}\text { Encargos } \\
\text { sociais (\%) }\end{array}$ & $\begin{array}{c}\text { Encargos } \\
\text { Sociais (R\$) }\end{array}$ & Total (R\$) \\
\hline Gerente Geral & 1 & $1.800,00$ & $1.800,00$ & 25,1 & 451,8 & $2.251,80$ \\
\hline Aux. Administrativo & 1 & $1.200,00$ & $1.200,00$ & 25,1 & 301,2 & $1.501,20$ \\
\hline Auxiliar de Abate & 3 & $1.000,00$ & $3.000,00$ & 25,1 & 753 & $3.753,00$ \\
\hline Cozinheira & 1 & $1.000,00$ & $1.000,00$ & 25,1 & 251 & $1.251,00$ \\
\hline Porteiro & 1 & 900 & 900 & 25,1 & 225,9 & $1.125,90$ \\
\hline Zootecnista & 1 & $4.500,00$ & $4.500,00$ & 25,1 & $1.129,50$ & $5.629,50$ \\
\hline \multirow[t]{2}{*}{ Contador } & 1 & 700 & 700 & 25,1 & 175,7 & 875,7 \\
\hline & & Total & & & & $15.512,40$ \\
\hline
\end{tabular}

Foram calculados o investimento necessário, os custos operacionais, as receitas e o payback.

\section{RESULTADOS E DISCUSSÕES}

\subsection{Resultados técnicos}

O abatedouro seguiu rigorosamente as normas de higiene, controle sanitário e qualidade exigidos pelos órgãos competentes, a fim de proporcionar produtos de mais alta qualidade nutricional e assim conquistar a confiança e satisfação de seus clientes. Todas as normas e exigências dos órgãos ambientais serão observadas para que a empresa não agredisse o meio ambiente local. Na embalagem do produto, consta a importância do consumo de carne de rã e 
seus benefícios para saúde. A empresa foi orientada a utilizar de SAC por telefone e um site onde os consumidores possam tirar possíveis dúvidas de consumo, sugestões de receitas e contatos de compra/venda.

Segundo a Resolução Conama 385, o empreendedor deverá apresentar a seguinte documentação:I - requerimento de licença ambiental;

II - projeto contendo descrição do empreendimento, contemplando sua localização, bem como o detalhamento dosistema de Controle de Poluição e Efluentes, acompanhada da Anotação de Responsabilidade Técnica - ART;

III - certidão de uso do solo expedida pelo município; e

IV - comprovação de origem legal quando a matéria prima for de origem extrativista, quando couber.

Os abatedouros deverão apresentar obrigatoriamente, I - a capacidade máxima diária de abate;

II - o sistema de coleta e destino do sangue, proveniente da sangria; e III - o funcionamento da seção de evisceração.

O órgão ambiental competente, após a análise da documentação emitirá manifestação expressa sobre a viabilidade da localização do empreendimento e, caso haja comprovação de baixo impacto ambiental e de reduzida produção de efluentes e resíduos, concederá as licenças ambientais correspondentes.

O abatedouro proposto seguirá as normas de construção baseadas no Serviço de Inspeção Federal (SIF) e do MAPA Ministério da Agricultura, Pecuária e Abastecimento, o que permitirá a comercialização em todo território nacional e posteriormente exportação.

Os abatedouros e estabelecimentos que processam pescados serão licenciados em duas etapas:I - Licença Prévia e de Instalação - LPI, que autoriza a localização e instalação da atividade; e

II - Licença de Operação - LO, que autoriza a operação da atividade.

No processo de abate de rã, algumas ações foram feitas ainda no Ranário para obtenção de um produto final de qualidade. A padronização do tamanho dos animais enviados para o abate foi uma premissa fundamental para que a matéria-prima (rã viva) gerasse produtos padronizados para o mercado. Os animais foram mantidos em jejum no período que antecede o abate evitando que o tubo digestivo se rompesse durante a evisceração e comprometesse o produto por contaminação, ao entrar em contato com o suco gástrico e as fezes do animal. $\mathrm{O}$ tempo para o jejum foi de 36 a 48 horas. Essas etapas foram feitas no Tanque de Engorda ainda 
no Ranário.

Segundo Beltrão (2008), “A água que abastece a sala de abate deve ser clorada separadamente com hipoclorito de sódio a 10\% (50 ml / 1000L de água) ou água sanitária a 2\% (250 ml / 1000L de água)." Os equipamentos e instrumentos utilizados no abate devem estar em perfeitas condições de uso e limpeza. Foi importante também, que os responsáveis por esta etapa do ciclo de produção, fossem pessoas esclarecidas e conscientes da importância do fator higiene. É importante ressaltar que a desidratação é um problema sério para esses animais, além do estresse físico a que são submetidos quando transportados. $O$ estresse antes do abate compromete a qualidade da carne do animal. A figura2 apresenta o fluxograma de abate.

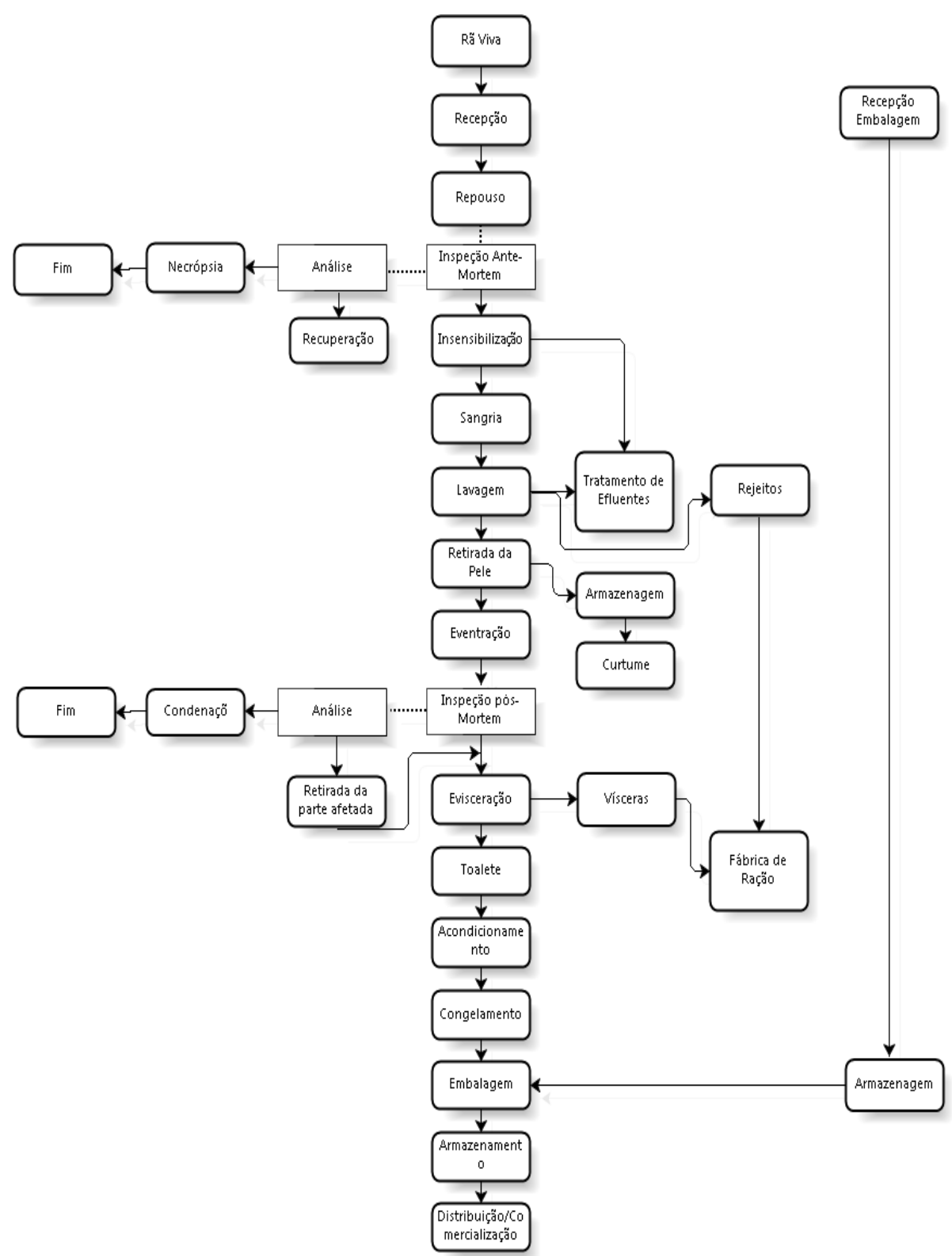

Figura 2: Fluxograma do abate e processamento da rã, elaborado por Donizetti, 1985 e adaptadopelos autores.

RCMOS - Revista Científica Multidisciplinar O Saber. ISSN: 2675-9128. São Paulo, v. 08, p. 01-22, ago. 2021. 
Segundo Donizetti (1985 apud LIMA, 2012) as fases do abate e processamentos da rã são: recepção, repouso, inspeção, insensibilização, sangria, lavagem, retirada da pele, eventração, inspeção pós-mortem, evisceração, toalete, acondicionamento, congelamento, embalagem, armazenamento e distribuição/comercialização.

\subsection{Resultados Financeiros}

Para chegar à viabilidade do Plano foram calculados os itens descritos na tabela 7 :

Tabela 7 - Demonstrativo de resultados

\begin{tabular}{cc}
\hline \multicolumn{2}{c}{ Demonstrativo de resultados } \\
Descrição & Valores (R\$) \\
1. Receita Total com Vendas & $204.163,70$ \\
Custos CMD e/ou CMV & $50.268,97$ \\
Impostos sobre vendas & $12.188,57$ \\
Gastos com vendas & $2.041,64$ \\
Subtotal 2 & $64.499,18$ \\
3. Índice de Margem de contribuição & 0,68 \\
4. Custos Fixos Totais & $20.832,84$ \\
5. CUSTO TOTAL & $\underline{\mathbf{8 4 . 9 5 6 , 3 2}}$
\end{tabular}

A tabela 8 descreve os indicadores de viabilidade (lucro bruto e líquido) ao mês, a lucratividade e rentabilidadeao ano. Além do ponto de equilíbrio e tempo de retorno em anos.

\begin{tabular}{cc} 
Tabela 8 - Indicadores de Viabilidade \\
\hline \multicolumn{2}{c}{ Indicadores de Viabilidade } \\
Descrição & Resultado \\
Lucro Bruto (a.m.) & $\mathrm{R} \$ 133.437,59$ \\
Lucro Líquido (a.m.) & $\mathrm{R} \$ 119.207,38$ \\
Ponto de equilíbrio & $\mathrm{R} \$ 29.904,05$ \\
Lucratividade (a.a.) & $58,39 \%$ \\
Rentabilidade (a.a.) & $30,45 \%$ \\
Tempo de retorno (anos) & $\underline{0,27}$
\end{tabular}

O payback tem como função mostrar o tempo de recuperação do capital investido 
calculado da forma simples, levando em consideração em seu cálculo o valor do dinheiro no tempo. Assim, de acordo com os dados apresentadosna tabela 8, o Tempo de Recuperação do Capital é de 0,27 anos, ou seja, aproximadamente três meses e meio, indicandoo período de tempo que seria necessário para a recuperação do capital investido, o que mostra que o investimento é economicamente viável, com retorno rápido. Na tabela seguinte, observa-se que o projeto se paga no primeiro ano de atividade, com caixa positivo no valor de $\mathrm{R} \$ 1.039 .057,27$ para o próximo ano.

Tabela 9 - Projeção para os próximos anos $(\mathrm{R} \$)$

\begin{tabular}{ccccc}
\hline \multicolumn{5}{c}{ Projeção para os próximos anos (R\$) } \\
\hline Ano & Investimentos & Receita & Despesas & Saldo \\
Ano 0 & $391.431,29$ & $2.449 .964,40$ & $1.019 .475,84$ & $1.039 .057,27$ \\
Ano 1 & - & $2.449 .964,40$ & $1.019 .475,84$ & $1.430 .488,56$ \\
Ano 2 & - & $2.449 .964,40$ & $1.019 .475,84$ & $1.430 .488,56$ \\
Ano 3 & - & $2.449 .964,40$ & $1.019 .475,84$ & $1.430 .488,56$ \\
Ano 4 & - & $2.449 .964,40$ & $1.019 .475,84$ & $1.430 .488,56$ \\
Ano 5 & - & $2.449 .964,40$ & $1.019 .475,84$ & $1.430 .488,56$ \\
& & & & $\mathbf{8 . 1 9 1 . 5 0 0 , 0 7}$
\end{tabular}

Para que o projeto alcance a lucratividade esperada, é preciso que a atividade seja desenvolvida com todo acompanhamento técnico que uma agroindústria exige. Profissionais bem treinados e capacitados a desenvolver a atividade, fornecedores de matéria-prima comprometidos com a qualidade, observando as exigências zootécnicas da produção e manejo do animal são alguns fatores imprescindíveis para o sucesso do empreendimento.

O aproveitamento de 100\% dos animais na atividade de abate é também um dos fatores que elevam a lucratividade. Cuidados especiais ao tirar a pele, condicionamento correto das vísceras, rejeitos e sangue, observando as exigências das indústrias que utilizaram esse material são indispensáveis também, pois desperdícios podem comprometer os lucros.

\section{CONCLUSÕES}

Diante dos resultados obtidos com o estudo, ficou evidenciada a viabilidade econômica do projeto, com retornodo capital investido em, aproximadamente três meses e meio, o que é considerado bastante rápido quando se trata de uma agroindústria.

Observando a grande demanda pela carne de rã, a implantação da agroindústria na região permitiria a expansãoda atividade e conseqüentemente o fortalecimento da cadeia produtiva da carne de rã na região, baseado no fato que muitos produtores afirmaram, em conversa informal 
que não investem na atividade por falta de abatedouro, despontando como mais uma oportunidade de negócio para pequenas e médias propriedades rurais.

Com um investimento relativamente baixo ( $\mathrm{R} \$ 391.431,29)$ e abate de 700 animais/dia é possível a implantação de uma indústria de abate. Além disso, o abatedouro de rã pode ser adaptado para abate de Pescado nas horas ociosas, o que aumentaria ainda mais os lucros da empresa.

\section{BIBLIOGRAFIA}

ASSOCIAÇÃO BRASILEIRA DAS INDÚSTRIAS DA ALIMENTAÇÃO (ABIA). Compêndio de Legislação de Alimentos. Atos do Ministério da Saúde e ANVISA. Revisão no. 9. 3 volumes ou versão eletrônica (CD). São Paulo, ABIA, fevereiro, 2003.

BELTRÃO. K.R.A. Dossiê Técnico - Ranicultura - 2008 - Disponível em http://www.respostatecnica.org.br/dossie- tecnico/downloadsDT/MTA3Ng== Acessado em 13/04/2013.

BRASIL. Ministério da Saúde. Secretaria de Vigilância Sanitária. Portaria no . 326, de 30 de julho de 1997a. Regulamento Técnico sobre as Condições Higiênico-sanitárias e de Boas Práticas de Fabricação para Estabelecimentos produtores/Industrializadores de Alimentos. Diário Oficial União, Brasília, 01 ago. 1997. Seção1.

BRASIL. Ministério da Saúde. Secretaria de Vigilância Sanitária. Portaria no . 368, de 04 de setembro de 1997b. Aprova o regulamento técnico sobre as condições higiênico-sanitárias e de boas práticas de fabricação para estabelecimentos/industrializadores de alimentos. Diário Oficial [da] União, Brasília, 8 set. 1997. Seção 1, p. 19697.

BRASIL. Ministério da Agricultura Pecuária e Abastecimento. Regulamento de Inspeção Industrial e Sanitária de Produtos de Origem Animal (RIISPOA). Diário Oficial da República Federativa do Brasil, Brasília - DF, Decreto no 30.691, de 29 de março de 1952, alterados pelos Decretos $\mathrm{n}^{\mathrm{o}} 1.255$, de 25 de junho de 1962, $\mathrm{n}^{\circ} 1.236$, de 2 de setembro de 1964 e no 1812, de 08 de fevereiro de 1996. p. 11.555, 5 de junho de 1997. Seção 1.

BRASIL 2005 Instrução Normativa 22, de 24 de novembro de 2005, Regulamento Técnico para Rotulagem de Produtos de Origem Animal Embalado. Diário Oficial da República Federativa do Brasil, Brasília - DF - p. 15, 25 de Nov.2005. Seção 1.

BRASIL 2006 Recomendações básicas para a aplicação das boas práticas agropecuárias e de fabricação na agricultura familiar. organizador, Fénelon do Nascimento Neto. - Brasília, DF: Embrapa Informação Tecnológica, 2006. 243 p.

BRASIL 2007 Ministério da Agricultura, Pecuária e Abastecimento. Manual de 
procedimentos para implantação de estabelecimento industrial de pescado: produtos frescos e congelados / Ministério da Agricultura, Pecuária eAbastecimento; Secretaria Especial de Aqüicultura e Pesca - Brasília: MAPA: SEAP/PR, 2007.

CARRARO, K, C. Ranicultura: Um bom negócio que contribui para saúde. Revista da FAE, 2008. Disponível em http://www.unifae.br/publicacoes/pdf/revista_da_fae/fae_v11_n1/10_karen.pdf. Acesso: 26 abr. 2013. 
CASTELLANI D., Situação da Aqüicultura na região do Noroeste do Estado de São Paulo XI Reunião Científica do Instituto de Pesca, abr.2013. São Paulo - Disponível em http://www.pesca.sp.gov.br/11recip2013/resumos/11a_ReCIP_P7_227-229.pdf. Acessado em 25 abr. 2013.

CHITARRA, M.I.F. Processamento mínimo de frutos e hortaliças. Viçosa: CPT, 1998, 88p. (CPT. Agroindústria, manual, 155).

CONCEIÇÃO, C. (2000). Utilização de carne de dorso de rã (Rana catesbeiana, Shaw 1802) no desenvolvimento de um produto alimentício. [Dissertação de Mestrado]. Rio de Janeiro (RJ): Universidade Federal Rural do Rio de Janeiro.

CODEX ALIMENTARIUS 1984 - Recommended International code of hygienic practive for the processing of frong legs. Rome FAO.

CODEX ALIMENTARIUS 2003 - Higiene dos Alimentos - Programa conjunto da FAO/OMS sobre normas Alimentares - 2003. Roma. Disponível em http://www.anvisa.gov.br/divulga/public/alimentos/codex_alimentarius.pdf. Acessado em 3005-2013

CORREAA, C.L. Como montar e operar uma pequena fábrica de chocolate. Viçosa: CPT, 1999. $44 \mathrm{p}$.

FAO Fishery and Aquaculture Statistics. 2008/FAO annuaire. Rome: FAO, 2010.

FEIX, R. D; ABDALLAH, P. R; FIGUEIREDO, M. R. C. 2006 Resultado econômico da criação de rã em regiões declima temperado, Brasil. Informações Econômicas, v.36, n.3, p.70-80.

FERREIRA, C.M. 2002 I Ciclo de Palestras sobre Ranicultura do Instituto de pesca. Boletim Técnico de Pesca, 31, 49p.

FERREIRA. C., F., \& FONTANELlO, D. 2011 Histórico da Ranicultura Nacional Disponível emhttp://www.aquicultura.br/historico.htm. Acessado em 25-03-2013

FRAGOSO, S.P., MOURA; O. M., CASALI; A. P., COSTA, A. R.; PEREIRA, R.F. 2012 Características Físico - químicas da carne de rã Touro (Lithobatescatesbeianus) Liofilizada. 2012 Disponível em http://www.cbcta45.net.br/cd/Resumos/ResumoCBCTA_622.pdf . Acessado em 16-05-2013.

LIMA, S.,L. Criação de Rãs - Novas Tecnologias - CPT- Centro de Produção Técnica Viçosa - p. 198, 188 -2012.

LIMA, S. L. , CRUZ, T. A. 1999 - Canais de Comercialização. Disponível em http://www.ufv.br/dta/ran/mercado.htm . Acessado em 16-04-2013.

LIMA, S.L. e AGOSTINHO, C.A. 1988 Sistema Anfigranja de criação de rãs. In: ENCONTRO NACIONAL DE RANICULTURA, 6, 1988, Rio de Janeiro, RJ. Anais...Rio de Janeiro: Associação de Ranicultores do Estado do Rio de Janeiro (ARERJ): 29-34 
LIMA, S. L. . Manejo de anfigranja. Viçosa (MG): CPT, 2004.

LIMA, S.S.; CRUZ, T.A.; MOURA, 0.M. 1999. Ranicultura: Análise da cadeia produtiva. Ed. Folha de Viçosa, Viçosa, 172 p.

LOPERA-BARRERO, N.M.; RIBEIRO, R.P.; POVH, J.A.; MENDEZ, L.D.V.; POVEDA-PARRA, A.R.; DIGMAYER, M. As principais espécies produzidas no Brasil. In: LOPERA-BARRERO, N.M. RIBEIRO, R.P.; POVH, J.A.; MENDEZ, L.D.V.; POVEDAPARRA, A.R. (Org.). Produção de organismos aquáticos: uma visão no Brasil e no mundo. Guaíba: Agrolivros, 2010. p. 143-203.

KATO, M. T. (1982) Estudo e tratamento de águas residuárias de abatedouros de aves. São Carlos. 262pp.Dissertação (Mestrado) - Escola de Engenharia de São Carlos, Universidade de São Paulo.

KOHLER, A. Criação de rã, 2010. Disponível em http://www.apostilasgratuitas.info/apostilas/criacao-de-aves/395-criacao-de-ras. Acessado em 15-04-2012.

MOURA, O.M. Características físico-químicas da carne de rã-touro, Rana catesbeiana. 1999. 102f. Teses.(Doutorado em Ciência e Tecnologia de Alimentos), Universidade Federal de Viçosa, 102 p. 1999.

NEGRINI, M. Revista Brasileira de Agropecuária. v.1, 2001.

NÓBREGA, I. C. C.; ATAÍDE, C. S.; MOURA, O. M.; LIVERA, A. V.; MENEZES, P. H. Volatile constituents of cooked bullfrog (Rana catesbeiana) legs. Food Chemistry, v.102, p. 186-191, 2007.

OLIVEIRA, T. C.; MEZENCIO, J. M. S.; COSTA, N. M. B.; PELUCIO, M. do C. G.; MATTA, S.L. P.; BRESSAN, J. Influência Do tratamento térmico sobre o perfil eletroforético da carne de rã (RANA CATESBEIANA). Disponível em http://www.revistanutrire.org.br/articles/view/id/4fabc35c1 eflfa074f000006 acessado em 26 abr. 2013.

OSTRENSKY, A.; BORGHETTI, J.R.; SOTO, D. Aqüicultura no Brasil: o desafio é crescer. Brasília, DF: SEAP,2008.

RODRIGUES, E.; GROOTENBOER, C.S.; MELlO, S.C.R.P.; CASTAGNA, A. A. Alimentos - Manual de Boas Práticas de Fabricação. Niterói - p. 7 . Jul. 2010.

SANDRONI, P. Dicionário de Economia. São Paulo: Abril Cultural, 1985.

SEBRAE, 2009 - Série Perfil de projetos para Ranicultura. Disponível em http://201.2.114.147/bds/BDS.nsf/40B4F0F3B9AD7533832574360059981C/\$File/Ranicultur a.pdf . Acessado em 16-05-2013.

TIAGO, G. G; GIANESELLA, S. M. F. Uso da água pela aquicultura: estratégias e ferramentas de implementaçãode gestão. Boletim do Instituto de Pesca, v. 29, n.1, p. 1-7, 2003.

RCMOS - Revista Científica Multidisciplinar O Saber. ISSN: 2675-9128. São Paulo, v. 08, p. 01-22, ago. 2021. 
TIAGO, G. G. Ementário da Legislação de Aquicultura e Pesca do Brasil. 2 ed. São Paulo: Gláucio Gonçalves Tiago (Editor), 2010. 95 p.

VELLY, M. L. M. 2001. A pele animal e os comportamentos mercadológicos para o novo milênio. I Ciclo dePalestras Sobre Ranicultura do Instituto de Pesca. Boletim Técnico do Instituto de Pesca. São Paulo, 2001, 31, 49 p.

VIZOTTO, L.D. Ranicultura brasileira. Boletim da Associação Nacional de Ranicultura, n. 4, 1975. 


\title{
Viabilidade econômica de uma pequena indústria para abate de rãs
}

\author{
SHIDOSHI, Christian José ${ }^{1}$; \\ SANTOS, Claudio Luciano dos ${ }^{2}$
}

\section{Resumo}

O Brasil por possuir condições climáticas ideais para a criação de rã em cativeiro tem visto crescer a atividadenos últimos anos. A ranicultura no país ainda tem muito a se desenvolver, mas já é uma atividade altamente lucrativa, quando executadas por pessoas capacitadas e treinadas para tal. Com o crescimento da busca por alimentos saudáveis, vem crescendo o interesse pela carne de rã por ser importante fonte proteica. A rã possui alta versatilidade no uso culinário, podendo ser usada na elaboração de vários pratos ou até mesmo em simples porções, agradando os mais sofisticados paladares. Quanto à comercialização a carne de rã possui alta aceitabilidade por ser um produto de qualidade e alto poder nutritivo, além de ter mercado para todos os seus rejeitos. A falta de um abatedouro do gênero na região foi um dos motivos que motivou o estudo. Com sua implantação seria possível o fortalecimento da cadeia produtiva na região. Uma grande vantagem da atividade é o aproveitamento total da matériaprima. O projeto permitiu visualizar o retorno rápido que a atividade proporciona quando feita observando as normas de qualidade e de regulamentação do setor e a lucratividade alta, tendo em vista o investimento relativamente baixo.

Palavras-chave: Agroindústria, lucratividade, Processamento, rana catesbeiana.

\begin{abstract}
The Brazil has a climate ideal for frog breeding in captivity has seen growing activity in recent years. The frog culture in the country still has a lot to develop, but it is a highly profitable activity when performed by qualified personnel and trained to do so. With the growth of the search for healthy foods has been growing interest in the frog meat due to be important protein source. The frog has high versatility in culinary use and can be used in the preparation of various dishes or even simple parts, pleasing the most sophisticated palates. As for marketing the frog meat has high acceptability for being a quality product and high nutritional value, in addition to market for all their waste.

The lack of an abattoir of its kind in the region was one of the reasons that motivated the study. With its implementation would be possible to strengthen the supply chain in the region. One of the great advantages of the activity is the total utilization of raw material, its refuse and waste, with a large gap activity. The project enabled to view quick return to activity when done watching provides quality standards and industry regulations and high profitability, given the relatively low investment.
\end{abstract}

Keywords: Agribusiness, profitability, processing, rana catesbeiana

\section{INTRODUÇÃO}

Na busca por uma alimentação mais saudável, a partir da década de 1980, o consumo

\footnotetext{
${ }^{1}$ Graduado em Agronegócio pela Faculdade de Tecnologia de Rio Preto - Fatec. São J.do Rio Preto - SP. Pósgraduado em Engenharia de Produção pela Faculdade Play - Praia Grande - SP.

${ }^{2}$ Graduado em Agronegócio pela Faculdade de Tecnologia de Rio Preto - Fatec. São J.do Rio Preto - SP.
}

RCMOS - Revista Científica Multidisciplinar O Saber. ISSN: 2675-9128. São Paulo, v. 08, p. 01-22, ago. 
de carnes consideradas brancas aumentou consideravelmente. Essa tendência proporcionou um aumento considerável à aqüicultura. Em 2008 a produção mundial atingiu 73 milhões de toneladas (LOPEIRA-BARREIRO et al., 2010).

No período entre 2003 e 2009 a produção aquícola brasileira teve um crescimento de $25 \%$, acima do mundial que foi $10 \%$ no mesmo período (OSTRENKY et al., 2008). Este cenário possibilitou um grande crescimento na criação de rã no Brasil, destacando-se pela qualidade da carne e excelente fonte de proteína.

De acordo com a FAO (2010), a produção mundial da carne de rã, durante o período de 1999-2008, foi em torno de 44.000 toneladas anuais, atingindo em 2008, 85.000 toneladas.

O Brasil produz cerca de 600 toneladas anuais de rã. Os estados com maior produção são: São Paulo, Minas Gerais e Pará (KOHLER, 2010).

Praticamente toda a produção brasileira é absorvida pelo mercado interno, mas o Brasil possui condições de conquistar grande espaço no mercado externo, porém, necessita prepararse para tal. Quanto aos subprodutos podemos dizer que praticamente o ranicultor ganha dinheiro praticamente só com a venda da carne. As vísceras e a pele são quaseque em sua totalidade descartadas. Existe tecnologia para curtimento da pele, mas não há indústria que faça isso em escala comercial (LIMA; CRUZ, 1999).

A implantação de uma indústria de abate e processamento de qualquer animal exige investimentos relativamente elevados, e uma equipe habilitada para seguir as mesmas normas higiênico-sanitárias que são adotadas internacionalmente, com base no código alimentar da Food and Agriculture Organization (FAO) (CODEX ALIMENTARIUS,1984). Para Negrini (2001), a demanda potencial pela carne de rã é três vezes maior do que a oferta, tornando-se, assim, um atrativo para a instalação de novas empresas.

\section{REVISÃO BIBLIOGRÁFICA}

A ranicultura no Brasil teve início na década de 30, quando Tom Cyrril Harrison trouxe do Canadá os primeiros 300 exemplares de Rana catesbeiana, popularmente conhecido como rã-touro americana. Em 1935 foi implantado o primeiro ranário comercial no Brasil, o Ranário Aurora, situado no município de Itaguaí, Estado do Rio de Janeiro, nas proximidades da rodovia Presidente Dutra. A partir de 1975 outros empreendimentos foram construídos, mas geralmente funcionando de forma empírica (FERREIRA, 2002).

Segundo Vizzoto (1975), a ranicultura foi introduzida no Brasil em 1935, importados

RCMOS - Revista Científica Multidisciplinar O Saber. ISSN: 2675-9128. São Paulo, v. 08, p. 01-22, ago. 2021. 
da América do Norte os primeiros casais da espécie rã-touro. Devido sua grande adaptabilidade, a rã-touro tornou-se a espécie cultivada no Brasil, surgindo vários sistemas de cultivo.

É considerado um animal exótico, pois é originária dos EUA (nordeste) e Canadá (sudeste), onde vive em temperaturas muito baixas durante vários meses do ano. Quando foi introduzida no Brasil, adaptou-se perfeitamente às condições climáticas do país, o que favoreceu seu desempenho em relação à reprodução e engorda, passando a atingir rapidamente maturidade sexual e peso de abate (sete meses e um ano em média, respectivamente) (LIMA \& AGOSTINHO, 1988).

O consumo da carne de rã é um hábito tão saudável quanto antigo, já citado por Heródoto (filósofo grego, nos anos de 484-425 a.C.) em seus escritos, como fina iguaria que os gregos serviam aos nobres em comemorações da mais distinta e elevada sociedade (LIMA et al, 2004).

O hábito de consumir rã no Brasil era prática das famílias de baixa renda. Os animais eram capturados na natureza para complementar sua alimentação. Mais tarde, alguns restaurantes passaram a oferecer o produto como aperitivo, o que estimulou a caça com objetivos comerciais. Como a caça proporcionava um fornecimento da carne de maneira irregular, foi preciso esperar pelo desenvolvimento da criação comercial para que o fornecimento se tornasse mais sistemático e alguns restaurantes oferecessem pratos requintados à base de sua carne (LIMA; AGOSTINHO, 1988).

A canalização da produção da carne de rã para comercialização abrirá um grande nicho, uma vez que ela poderáser conhecida e popular, já que, sendo introduzida no mercado, será facilmente encontrada, despertando a curiosidade nos consumidores em experimentá-la ou mesmo consumi-la com certa regularidade (CARRARO, 2008).

O preço dos produtos oriundos da Ranicultura, no mercado internacional, é bastante variável em função de diversos fatores, entre os quais merecem destaque o tamanho do produto, a época do ano e a sua origem. Os originários da criação em cativeiro, geralmente têm preço mais elevado, em razão de seus próprios custos de produção e também por possuírem maior qualidade e regularidade na oferta (BELTRÃO, 2008).

O desenvolvimento da rã-touro no Brasil é superior ao de seu país de origem (EUA). Esta afirmativa apóia-se no desempenho da mesma para as condições brasileiras que, em média, não ultrapassa quatro meses de duração para as fases de girino e engorda (FERREIRA; FONTANELLO, 2011).

A carne de rã in natura (congelada ou fresca) sempre foi o principal produto da 
ranicultura. Os demais produtos ainda se encontram em fase de desenvolvimento e consolidação de mercados, como por exemplo, a sua pele, utilizadano tratamento de pessoas queimadas e na fabricação de artefatos pela indústria de couros; o óleo, em aplicações diversas como cosméticos e medicamentos de efeito cicatrizante, o fígado e o ovário em aplicações culinárias (patê de fígado e caviar,respectivamente) (LIMA, 2012).

Praticamente toda a produção brasileira é utilizada pelo mercado interno, mas o Brasil possui condições de conquistar grande espaço no mercado externo. Atualmente o consumo no Brasil situa-se em torno de 400 toneladas/ano. Segundo a Associação Brasileira de Ranicultura o Brasil conta com aproximadamente 600 ranários implantados, quinze indústrias de abate e processamento, seis associações estaduais de ranicultores e quatro cooperativas (BELTRÃO, 2008). Existem dois tipos distintos de mercado para o ranicultor. O mercado de animais vivos para atendimento a outros ranicultores (reprodutores, girinos e imagos), laboratórios e centros universitários de ensino e pesquisa. Outro mercado, bem maior que o primeiro, o de animais abatidos, tem na carne seu maior e mais importante produto. Devido às suas características (classificado como exótico), e principalmente o seu preço, a carne de rã tem seu grande espaço demercado entre as camadas privilegiadas e melhor nível sociocultural (SEBRAE, 2009).

No Brasil, a carne de rã é encontrada nos estabelecimentos comerciais na forma de carcaça ou em coxas. Todavia, no mercado internacional há uma forte preferência pelas coxas, sendo praticamente inexistente a demanda por outro produto (LIMA et al., 1999).

Internacionalmente os maiores consumidores, e também importadores de carne de rã são: Estados Unidos, França, Alemanha, Suíça, Itália e Holanda. Países como o Japão, China, Indonésia, Índia, México e Cuba já foram considerados grandes exportadores, porém o faziam graças a sua produção fruto do extrativismo, fato que vem gerando problemas de ordem econômica e ecológica. A ação predatória de caça coloca em risco a espécie, e o desequilíbrio do ecossistema. Por outro lado, o uso de defensivos e fertilizantes nas plantações, berços para a criação das rãs na natureza,intoxicam os animais, dificultando sua comercialização, devido às barreiras sanitárias. Abre-se desta forma, um grande espaço para a ranicultura brasileira, que vem desenvolvendo tecnologia visando sua produção intensiva, dentro de controles mais rígidos (SEBRAE, 2009).

Os potenciais clientes para a comercialização da carcaça de rãs congeladas são bastante diversificados, entre os quais se podem listar: restaurantes, bares, casas de carnes, peixarias, supermercados, delicatessen e casas de festas, alémda venda direta ao consumidor em lojas da própria empresa, sejam no próprio estabelecimento, ou em grandes cidades. 


\section{METODOLOGIA}

O estudo foi elaborado conforme as etapas definidas pelo Ministério do Desenvolvimento Agrário, observandoas orientações proposta no Roteiro de Elaboração de Projetos Agroindustriais para Territórios Rurais (2007).

Para a realização do projeto foram feitas pesquisas na literatura nacional como internacional sobre o abate de rã e pescado. Foram consultadas as normas e regras para instalação de Abatedouro de Pescado. No Manual de Procedimentos para Implantação de Estabelecimento Industrial de Pescado do MAPA - Ministério da Agricultura, Pecuária e Abastecimento (2007), estabelece regras para a correta instalação de um abatedouro, seguindo as normas sanitárias para que se possa obter um produto final de qualidade, inócuo e com valor nutricional ao consumidor final.

Na previsão de custo foi feita uma pesquisa para avaliar o custo de produção e o preço pago pelo quilo de carne (coxas, carcaça e picado), dos rejeitos e da pele. Utilizou-se como base o abate de 700 animais/dia, da espécie Rana Catesbiana (Rã Touro), com peso aproximado de 350 gramas.

\subsection{Aspectos Técnicos}

Segundo a Associação Brasileira das Indústrias de Alimentos - ABIA (2003), a localização de qualquer fábrica de alimentos (agroindústria) deve ser definida considerando alguns aspectos da infraestrutura do local, como a disponibilidade de água, rede de esgotos, energia, via de transporte e sistemas de comunicação para garantir futuras ampliações na linha de produção. É recomendável uma análise da qualidade da água da região para verificar se está dentro das especificações desejáveis ao processamento. A proximidade com os centros consumidores e com os fornecedores pode significar um grande passo para a conquista do mercado e representa uma economia no transporte dos produtos (CORRÊA, 1999).

O local de implantação da agroindústria possui condições ideais de infraestrutura urbana, principalmente no quediz respeito às instalações elétricas e hidráulicas, rede de esgoto, estações de tratamento, facilidade de comunicações (telefone, internet) e água abundante, explorada através de poços artesianos. Para a escolha do tipo de tratamento utilizado para as águas residuais de abatedouros consideramos: o grau de remoção exigido dos poluentes, 
disponibilidade de área e custos de implantação, operação e manutenção do sistema (KATO, 1982).

O terreno da agroindústria esteve livre de contaminantes de qualquer espécie e com local apropriado para depósito de resíduos; a agroindústria estará, disposta no sentido de garantir aspectos relacionados à segurança, movimentação e supervisão de pessoal, direção dos ventos, posição do sol e inclinação do terreno. A agroindústria de abate de rã e pescado foi implantada, na fazenda experimental Fatec Rio Preto, antigo IPA, no município de São José do Rio PretoSP. Foram abatidas 700 rãs/dia e nas horas ociosas, pescado, conforme a disponibilidade de horário e mão-de-obra. A escolha da região Noroeste Paulista foi devido à falta dessa categoria de agroindústria, visando o aumento da atividade de ranicultura, tendo em vista que a região é uma grande produtora de pescado devido aos grandes rios da região. O local escolhido para a implantação da agroindústria preenche todos os requisitos básicos para implantação de uma agroindústria de abate estabelecido pelo MAPA.

Para as instalações físicas a indústria foi instalada em um terreno com $50 \mathrm{~m} \times 40 \mathrm{~m}$, perfazendo $2000 \mathrm{~m}^{2}$ de área. O prédio da agroindústria terá como dimensões: Prédio do Abate: $19 \mathrm{~m} \times 7.5 \mathrm{~m}$, totalizando $142,5 \mathrm{~m}$ de construção em alvenaria, figura 1 . O bloco administrativo terá um total $68.4 \mathrm{~m}^{2}$, foi construído separadamente do bloco de abate.

Conforme o Roteiro de elaboração de projetos agroindústrias proposto pelo Ministério do Desenvolvimento Agrário (2007) agroindustrializar significa beneficiar os produtos agropecuários e/ou transformar a matéria-prima agropecuária gerando novos produtos, de origem animal e vegetal. A agroindústria proposta - Abatedouro de Rã e Pescados foi construída em uma área total de $2.000 \mathrm{~m}^{2}$. Sua classificação, segundo o MAPA é de um Estabelecimento Industrial de Pescado. A figura 1 apresenta o layout da empresa, criado observando as indicações do MAPA no Manual de Procedimentos para Implantação de Estabelecimento Industrial de Pescado. 


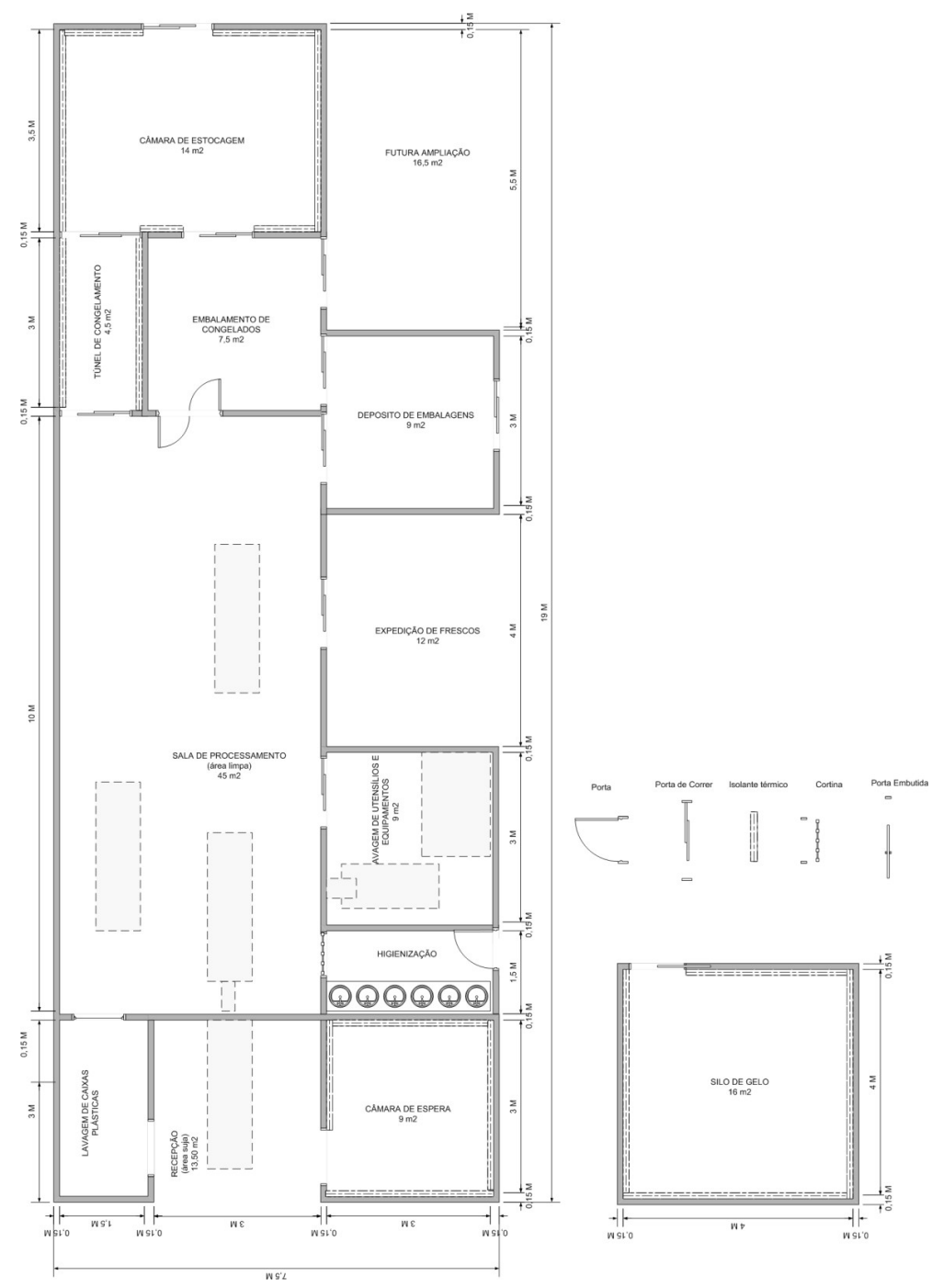

Figura 01: Planta da área de abate e silo de gelo.

Fonte: Elaborado pelos autores adaptado do MAPA- Manual de Procedimentos de abatedouros- 2007

Segundo Sandroni (1985), "matéria-prima é um produto natural ou semimanufaturado (bem intermediário) que deve ser submetido a um processo produtivo até tornar-se um produto acabado". Os fornecedores foram os ranários da região e existe um projeto paralelo para produção consorciada com produtores da região.

$\mathrm{Na}$ última década, a piscicultura vem se desenvolvendo muito na região Noroeste Paulista, principalmente coma criação super intensiva e o uso de tanques-rede. A temperatura, clima, área alagada dos reservatórios e políticas públicas favoreceram tanto essa região, que, atualmente, ela se transformou na maior produtora de pescado originado da piscicultura continental do Estado (CASTELLANI, 2007). As estradas no Noroeste Paulista para recebimento de matéria-prima e escoamento da produção até São Paulo e outras capitais, são de excelente qualidade. 
O artigo 438 do Regulamento da Inspeção Industrial e Sanitárias de Produtos de Origem Animal (RIISPOA) define com a denominação genérica "pescado", os crustáceos, peixes, moluscos, anfíbios, quelônios e mamíferos de água doce ou salgada usados na alimentação humana; incluindo as rãs (BRASIL, 1997).

As instalações e o fluxo de operações foram planejados com rigoroso critério de fluxo linear para evitar as contaminações cruzadas. Cuidados observados para que a planta de fluxo do processamento fosse contínuo, sem que a fase inicial do processo se cruzasse com fases posteriores, evitando possíveis contaminações (RODRIGUES et al, 2010).

Segundo o BRASIL (2006) as instalações apresentaram, de acordo com as normas sanitárias, características quepossibilitaram a limpeza e a higiene, tais como:

-Construído em material impermeável na parte interna;

- Forros e paredes com acabamento liso e de fácil higienização;

-Pisos impermeáveis, antiderrapantes e com pequena inclinação que facilitou o escoamento de águas residuais efacilitando a limpeza;

-Ambiente interno de trabalho deve ser fechado com vedação contra insetos, roedores e outros animais, apresentando boa ventilação e claridade;

- Área limpa da agroindústria familiar deve ser separada da área suja e do banheiro;

-Altura adequada do pé direito, permitindo a ventilação, a claridade e a colocação dos equipamentos;

- Os cantos entre pisos e paredes foram arredondados, evitando acúmulo de sujeiras e facilitando a limpeza;

-Um sistema de escoamento de esgotos, de águas e de resíduos em geral, interligado a um adequado sistema detratamento ou reaproveitamento, de acordo com as normas ambientais.

De acordo com o Manual de Procedimentos para Implantação de Estabelecimento Industrial de Pescado (BRASIL, 2007), devido à importância da unidade de refrigeração no êxito do empreendimento, alguns cuidados foram tomados na aquisição:

- Foram determinadas as reais necessidades em termos de quantidades e tipos de produtos a serem elaborados;

- Consultaram-se fornecedores idôneos para verificar a satisfação dos clientes relacionados nas listas de referência dos mesmos;

- Solicitou-se orçamentos detalhados com descrição completa dos equipamentos, indicando dimensões, capacidades, materiais utilizados, e os orçamentos acompanhados de 
folhetos, diagramas e esquemas e demais dados técnicos necessários à análise e avaliação do oferecido;

- Os fornecedores relacionaram todos os equipamentos complementares necessários ao funcionamento da instalação frigorífica e que não eram de sua responsabilidade de fornecimento;

- Outras necessidades foram indicadas: pontos de água, de esgoto, e de energia elétrica e seus dimensionamentos;

- Foram exigidos dos fornecedores meios eficazes para garantir o funcionamento, principalmente das câmaras dearmazenamento, em caso de pane de equipamento. Verificou-se também a possibilidade de interligação e intercâmbio entre os equipamentos, principalmente compressores frigoríficos, em caso de necessidade.

A aquicultura é mais uma atividade a competir com outras pelo recurso água. Seu desenvolvimento apresenta riscos de deteriorar a qualidade e quantidade da água, podendo afetar a qualidade ambiental, social e econômica. Correntes técnicas, científicas e representativas da aquicultura brasileira têm afirmado que a atividade não consome,mas sim, usa a água, e esta característica de não consultividade poderia mudar enfoques e estratégias relativos à gestão do recurso hídrico voltado às criações aquáticas, distanciando-as, por exemplo, das indústrias (TIAGO \& GIANESELLA, 2003). O efluente deve obedecer aos padrões de lançamentos estabelecidos nesta resolução, de acordo com a qualidade da classe em que o corpo d'água receptor estiver enquadrado - CNRH: Conselho Nacional deRecursos Hídricos, Resolução nº 91/2008 (TIAGO, 2010).

Uma das formas para garantir qualidade e segurança nas agroindústrias é a implantação do programa de Boas Práticas de Fabricação (BPF) que visa o fornecimento de alimentos inócuos a população. As BPF são procedimentos que devem ser adotados pelas agroindústrias com o objetivo de garantir a qualidade higiênico-sanitária dos alimentos de acordo com a legislação vigente. Este programa abrange cinco pontos principais: controle de água, higiene das instalações, higiene pessoal, controle de pragas e higiene dos equipamentos e utensílios. Com a necessidade de assegurar alimentos seguros e de qualidade à população foi instituída pelo Ministério da Saúde (MS) a Portaria no 326, de 30 de julho de 1997 (BRASIL, 1997), juntamente com a Portaria n ${ }^{\circ}$ 368, de 04 de setembro de 1997 (BRASIL, 1997b) do Ministério da Agricultura Pecuária e Abastecimento (MAPA) o Regulamento Técnico sobre as “Condições Higiênico-Sanitárias e de Boas Práticas de Fabricação (BPFs) para Estabelecimentos Produtores/Industrializadores de Alimentos". 
As pessoas que trabalham com manipulação de alimentos devem possuir cuidados com a higiene pessoal, comportamento e aparência. Entre esses cuidados estão: banho diário; uso de roupas limpas; o cabelo deve ser lavado no mínimo duas vezes por semana; escovar dos dentes sempre após as refeições; manter as unhas curtas e limpas (sempre sem esmaltes); cabelos presos; não utilizar acessórios durante a manipulação de alimentos (brincos, pulseiras, anéis, relógios); não comer, mascar chiclete, fumar, tossir, espirrar e evitar falar enquanto estiver manipulando alimentos; lavar as mãos com água e sabão frequentemente. Outro fator importante é a saúde dos trabalhadores, por isso foi fundamental que fossem realizados exames laboratoriais com periodicidade e sempre que o manipulador apresentar problemas de saúde é necessário que ocorra o afastamento da função (BRASIL, 1997b).

Recomenda-se a análise periódica da água, segundo as exigências sanitárias, mantendo os registros das análises em arquivo. Os produtos processados devem ser enviados para analises rotineiras e regulamentares aos laboratórios credenciados. De cada lote uma amostra deverá ser armazenada para exames laboratoriais em caso de problemas sanitários detectados pela vigilância sanitária ou pelo consumidor. O uso da água na agroindústria de alimentos foi intenso, envolvendo desde a limpeza e higienização dos equipamentos, utensílios e ambiente até a etapa do processo final. Segundo o CODEX ALIMENTARIUS (2003) é de fundamental importância o controle total da água de forma que garanta as características físicas, químicas e microbiológicas, para que não haja contaminação dos equipamentos e alimentos.

Preparo da água clorada: segundo Chitarra (1998), o agente sanitizante mais utilizado na indústria é o cloro na forma líquido de hipoclorito de sódio $(\mathrm{NaOCl})$. Do cloro adicionado à água, cerca de $20 \%$ pode combinar com resíduosorgânicos e apenas $80 \%$ permanecem na forma ativa, reduzindo a ação biocida, quando a concentração do cloro é baixa.Portanto, as soluções de cloro foram preparadas de acordo com as recomendações, não esquecendo que o excesso de cloro pode causar descoloração do produto, corrosão nos equipamentos e intoxicação dos consumidores.

A carne de rã é comercializada principalmente como: rã inteira resfriada ou congelada e coxas congeladas. De acordo com o Regulamento Técnico para Rotulagem de Produtos de Origem Animal Embalado do MAPA a rotulagem de alimentos embalados deve apresentar obrigatoriamente: denominação de venda do produto, lista de ingredientes, conteúdos líquidos, identificação de origem, nome ou razão social e endereço do importador (quando houver), carimbo oficial da inspeção, categoria do estabelecimento, CNPJ, conservação do produto, marca comercial do produto, identificação do lote, data de validade e instruções sobre o preparo 
e uso do alimento (BRASIL, 2005).

A carne de rã é vista como alimento saudável, excelente fonte de nutrientes, rica em proteínas, mineral e baixo teor em gordura e calorias. Sua biodisponibilidade de cálcio é elevada, chegando a ser igual à do leite e produtos derivados. Pode ser indicada como complemento alimentar no tratamento de osteoporose e hipertensão arterial. A liofilização dessa carne disponibiliza uma excelente matéria-prima a ser utilizada em produtos diversos e para fins de dietas específicas (FRAGOSO et al., 2012).

Lima e Agostinho (1998 apud CARRARO,K.C., 2008) afirmam que a carne de rã, por sua composição é recomendada por médicos e nutricionistas, pois sua taxa de gordura é de 3\%, sendo a única carne produzida em cativeiro que possui os 10 aminoácidos básicos para o ser humano e com digestibilidade alta, por ser formada por moléculas de cadeias curtas, sendo indicada especialmente para a alimentação de crianças que possuem rejeição à proteína animal.

Para agregar valor ao segmento, várias alternativas estão sendo estudadas, para o melhor aproveitamento da carne desta parte do corpo das rãs, dentre elas a utilização em formulações de alimento infantil, devido ao seu alto valor biológico (CONCEIÇÃO, 2000; MOURA, 1999; NÓBREGA et al., 2007).

Quanto ao desenvolvimento economicamente viável de novos subprodutos da ranicultura, pode-se destacar o aproveitamento do óleo, do fígado e da pele das rãs (FEIX et al., 2006). As propriedades do óleo de rã estão sendo analisadas, existindo resultados favoráveis à sua utilização na produção de cosméticos, enquanto que o fígado é utilizado para a produção de patês. Já a pele das rãs pode ter como destino a indústria farmacêutica ou de vestuário, Velly (2001) destacou o significado econômico do aproveitamento da pele da rã na indústria farmacêutica, enfatizando o desconhecimento do criador quanto às possibilidades de comercialização da mesma. A queratina retirada da pele da rã-touro, por exemplo, pode ser utilizada como tecido regenerativo de proteção para pessoas queimadas.

Uma das idéias para aumento da venda da carne de rã é uma abordagem aos responsáveis pela merenda escolar na tentativa de implantar a mesma na alimentação dos estudantes como fonte de proteína. Outra maneira de aumento de consumo é disponibilizar em quantidade suficiente nos estabelecimentos comerciais, como açougues, mercados e delicatessen.

O levantamento sobre os canais de comercialização feitos por Lima \& Cruz (1999) evidenciou que $16,3 \%$ dos consumidores efetivos da carne de rã o fazem por problemas de saúde (OLIVEIRA et al., 2007). O principal produto da atividade é a carne de rã, que é comercializada fresca, congelada ou processada, cujo excelente sabor e qualidades nutricionais, 
têm propiciado crescimento considerável do seu consumo, não obstante às restrições de preço. A coxa é a parte de maior aceitação, embora no Brasil esta preferência não seja tão acentuada como no mercado internacional, onde praticamente não se consome o restante da carcaça (LIMA; CRUZ 1999). A produção do abatedouro será comercializada entre redes de supermercados, redes de hotéis e restaurantes, através de contratos pré-firmados. Os resíduos serão vendidos para fábricas de ração animal e a pele para curtumes.

Outra medida foi propor aos abatedouros de rã uma ação ao nível nacional para estimular o consumo de carnede rã, baseada na importância nutricional desta carne e estimular pequenos e médios produtores rurais a produzirem rã como uma fonte de renda complementar.

\subsection{Análise econômica}

Para o estudo foi considerado o abate de 700 animais/dia com 26 dias de trabalho mensal, tendo quatro dias de folga para limpeza geral e revisão das máquinas e utensílios de abate. A agroindústria proposta abaterá 700 animais diariamente, durante 26 dias/mês, com peso médio de $350 \mathrm{~g}$ cada animal, totalizando $245 \mathrm{~kg}$ de animal vivo/dia. Durante o processo de abate, aproximadamente $29 \%$ do animal é retirado como rejeitos (cabeça e patas) e vísceras, ou seja, há uma quebra de aproximadamente $73 \mathrm{~kg}$. A tabela 1 mostra o abate diário e mensal.

\begin{tabular}{ccc} 
Tabela 01 - Abate diário/mensal do abatedouro de rã \\
\hline \multicolumn{3}{c}{ ABATE DIÁRIO/MENSAL: 700 ANIMAIS } \\
Riário/Kg & Mensal (26 dias)/Kg \\
Rã Unidade (350 g) & 245 & 6370 \\
Carne (60\%) & 147 & 3822 \\
Pele (11\%) & 26,95 & 700,7 \\
Rejeitos/Vísceras (29\%) & $\underline{71,05}$ & $\underline{1847,3}$
\end{tabular}

Os investimentos para a implantação da agroindústria compreenderam: construção civil, capital de giro,utensílios para abate em geral, veículos para distribuição, equipamentos em geral e outros gastos totalizando $\mathrm{R} \$ 258.265,58$ mais o Capital de Giro no valor de $\mathrm{R} \$ 133.165,71$, totalizando R $\$ 391.431,29$ com horizonte de planejamento de 05 anos, conforme tabela 2.

Tabela 2 - Resumo do Investimento Total $(\mathrm{R} \$)$

\section{Investimento Total (Resumo) (RS)}

$\begin{array}{ccc}\text { Descrição dos Investimentos } & \text { Valor (RS) } & \text { (\%) } \\ \text { 1. Investimentos Fixos } & 258.265,58 & 65,98 \\ \text { 2. Capital de Giro } & 133.165,71 & 34,02\end{array}$

RCMOS - Revista Científica Multidisciplinar O Saber. ISSN: 2675-9128. São Paulo, v. 08, p. 01-22, ago. 2021. 
Total

Fontes de Recursos

1. Recursos próprios

$\underline{\text { Total }}$
391.431,29

Valor (R\$) (\%)

$391.431,29 \quad 100$

$\underline{391.431,29}$

Os custos operacionais compreendem gastos com matérias-primas, mão-de-obra, embalagens, impostos, energia, água, materiais auxiliares e depreciação, totalizando $\mathrm{R} \$ 14.527,64$ mensal. A tabela 3 demonstra a estimativa de custos fixos mensais.

\begin{tabular}{cc} 
Tabela 3 - Estimativa dos custos fixos operacionais mensais (R\$) \\
\cline { 2 - 2 } Estimativa dos custos fixos operacionais mensais (R\$) \\
\hline Descrição & Custo Total Mensal (R\$) \\
Energia elétrica & $2.000,00$ \\
Telefone & 300 \\
Honorários do contador & $1.000,00$ \\
Material de limpeza & 100 \\
Material de escritório & 50 \\
Salários e encargos & $15.512,40$ \\
Combustível & 500 \\
Depreciação & 994,74 \\
Total & $\underline{\mathbf{2 0 . 4 5 7 , 1 4}}$
\end{tabular}

O custo dos materiais diretos ou mercadorias vendidas são os custos com a matériaprima (rã viva). O valor pago pelos abatedouros para os produtores atualmente é aproximadamente $\mathrm{R} \$ 9,24 / \mathrm{Kg}$ animal vivo. Na tabela 4 estão osgastos com matéria-prima/mês, totalizando R\$50.268,97.

Tabela 4 - Custos dos materiais diretos e/ou mercadorias vendidas

\begin{tabular}{cccc}
\hline \multicolumn{4}{c}{ Custo dos materiais diretos CMD e/ou mercadorias vendidas CMV } \\
\hline Produto/ Serviço & $\begin{array}{c}\text { Estimativa de vendas(em } \\
\text { unidades) }\end{array}$ & $\begin{array}{c}\text { Custo unitário de } \\
\text { materiais/Aquisição (R\$) }\end{array}$ & CMD/CMV (R\$) \\
Bandeja Carcaça & 2444 & 4,62 & $11.286,39$ \\
Bandeja Coxa & 3172 & 4,62 & $14.654,64$ \\
Bandeja Picado & 2028 & 4,62 & $9.369,36$ \\
Vísceras & 1859 & 4,62 & $8.588,58$ \\
Pele & 18200 & 0,35 & $6.370,00$ \\
& Total & & $\mathbf{5 0 . 2 6 8 , 9 7}$ \\
\hline
\end{tabular}

As receitas foram obtidas através da venda de três tipos de bandejas de carne de rã: bandeja de carcaça, bandejade coxa e bandeja de picado, além da venda separadamente das vísceras, rejeitos, sangue e pele, totalizando R $\$ 204.163,70$ mensal de Receita Total de vendas, conforme tabela 5:

Tabela 5 - Estimativa do faturamento mensal da empresa (R\$)

RCMOS - Revista Científica Multidisciplinar O Saber. ISSN: 2675-9128. São Paulo, v. 08, p. 01-22, ago. 2021. 


\begin{tabular}{cccc}
\hline \multicolumn{4}{c}{ Estimativa do faturamento mensal da empresa (R\$) } \\
Produto/Serviço & Quantidade & Preço de venda & Faturamento Total \\
Bandeja Carcaça & 2.444 & 18 & $43.992,00$ \\
Bandeja Coxa & 3.172 & 40 & $126.880,00$ \\
Bandeja Picado & 2.028 & 13 & $26.364,00$ \\
Vísceras & 1.859 & 0,3 & 557,7 \\
Pele & 18.200 & 0,35 & $6.370,00$ \\
& Total & & $\mathbf{2 0 4 . 1 6 3 , 7 0}$ \\
\hline
\end{tabular}

O abate de rã foi feito de uma forma simples. Os funcionários de abate (auxiliar de abate) receberam prévio treinamento antes de iniciar as atividades de abate. Um dos auxiliares foi treinado por um Zootecnista para trabalhar na parte de análises. O controle geral do abatedouro foi feito pelo Gerente Geral e pelo Auxiliar Administrativo que ficaram responsável por toda parte Administrativa e de Produção, incluindo a compra de matéria-prima de qualidade. Aempresa contou com um quadro de seis funcionários, com gasto mensal (salários e encargos) de $\mathrm{R} \$ 15.512,40$ como descrito na tabela 6 :

Tabela 6 - Estimativa dos custos com mão-de-obra

\begin{tabular}{|c|c|c|c|c|c|c|}
\hline \multicolumn{7}{|c|}{ Estimativa dos custos com mão-de-obra } \\
\hline Função & $\begin{array}{c}\mathrm{N}^{\circ} \text { de } \\
\text { empregados }\end{array}$ & $\begin{array}{c}\text { Salário Mensal } \\
\text { (R\$) }\end{array}$ & Subtotal (R\$) & $\begin{array}{c}\text { Encargos } \\
\text { sociais (\%) }\end{array}$ & $\begin{array}{c}\text { Encargos } \\
\text { Sociais (R\$) }\end{array}$ & Total (R\$) \\
\hline Gerente Geral & 1 & $1.800,00$ & $1.800,00$ & 25,1 & 451,8 & $2.251,80$ \\
\hline Aux. Administrativo & 1 & $1.200,00$ & $1.200,00$ & 25,1 & 301,2 & $1.501,20$ \\
\hline Auxiliar de Abate & 3 & $1.000,00$ & $3.000,00$ & 25,1 & 753 & $3.753,00$ \\
\hline Cozinheira & 1 & $1.000,00$ & $1.000,00$ & 25,1 & 251 & $1.251,00$ \\
\hline Porteiro & 1 & 900 & 900 & 25,1 & 225,9 & $1.125,90$ \\
\hline Zootecnista & 1 & $4.500,00$ & $4.500,00$ & 25,1 & $1.129,50$ & $5.629,50$ \\
\hline \multirow[t]{2}{*}{ Contador } & 1 & 700 & 700 & 25,1 & 175,7 & 875,7 \\
\hline & & Total & & & & $15.512,40$ \\
\hline
\end{tabular}

Foram calculados o investimento necessário, os custos operacionais, as receitas e o payback.

\section{RESULTADOS E DISCUSSÕES}

\subsection{Resultados técnicos}

O abatedouro seguiu rigorosamente as normas de higiene, controle sanitário e qualidade exigidos pelos órgãos competentes, a fim de proporcionar produtos de mais alta qualidade nutricional e assim conquistar a confiança e satisfação de seus clientes. Todas as normas e exigências dos órgãos ambientais serão observadas para que a empresa não agredisse o meio ambiente local. Na embalagem do produto, consta a importância do consumo de carne de rã e 
seus benefícios para saúde. A empresa foi orientada a utilizar de SAC por telefone e um site onde os consumidores possam tirar possíveis dúvidas de consumo, sugestões de receitas e contatos de compra/venda.

Segundo a Resolução Conama 385, o empreendedor deverá apresentar a seguinte documentação:I - requerimento de licença ambiental;

II - projeto contendo descrição do empreendimento, contemplando sua localização, bem como o detalhamento dosistema de Controle de Poluição e Efluentes, acompanhada da Anotação de Responsabilidade Técnica - ART;

III - certidão de uso do solo expedida pelo município; e

IV - comprovação de origem legal quando a matéria prima for de origem extrativista, quando couber.

Os abatedouros deverão apresentar obrigatoriamente, I - a capacidade máxima diária de abate;

II - o sistema de coleta e destino do sangue, proveniente da sangria; e III - o funcionamento da seção de evisceração.

O órgão ambiental competente, após a análise da documentação emitirá manifestação expressa sobre a viabilidade da localização do empreendimento e, caso haja comprovação de baixo impacto ambiental e de reduzida produção de efluentes e resíduos, concederá as licenças ambientais correspondentes.

O abatedouro proposto seguirá as normas de construção baseadas no Serviço de Inspeção Federal (SIF) e do MAPA Ministério da Agricultura, Pecuária e Abastecimento, o que permitirá a comercialização em todo território nacional e posteriormente exportação.

Os abatedouros e estabelecimentos que processam pescados serão licenciados em duas etapas:I - Licença Prévia e de Instalação - LPI, que autoriza a localização e instalação da atividade; e

II - Licença de Operação - LO, que autoriza a operação da atividade.

No processo de abate de rã, algumas ações foram feitas ainda no Ranário para obtenção de um produto final de qualidade. A padronização do tamanho dos animais enviados para o abate foi uma premissa fundamental para que a matéria-prima (rã viva) gerasse produtos padronizados para o mercado. Os animais foram mantidos em jejum no período que antecede o abate evitando que o tubo digestivo se rompesse durante a evisceração e comprometesse o produto por contaminação, ao entrar em contato com o suco gástrico e as fezes do animal. $\mathrm{O}$ tempo para o jejum foi de 36 a 48 horas. Essas etapas foram feitas no Tanque de Engorda ainda 
no Ranário.

Segundo Beltrão (2008), “A água que abastece a sala de abate deve ser clorada separadamente com hipoclorito de sódio a 10\% (50 ml / 1000L de água) ou água sanitária a 2\% (250 ml / 1000L de água)." Os equipamentos e instrumentos utilizados no abate devem estar em perfeitas condições de uso e limpeza. Foi importante também, que os responsáveis por esta etapa do ciclo de produção, fossem pessoas esclarecidas e conscientes da importância do fator higiene. É importante ressaltar que a desidratação é um problema sério para esses animais, além do estresse físico a que são submetidos quando transportados. $O$ estresse antes do abate compromete a qualidade da carne do animal. A figura2 apresenta o fluxograma de abate.

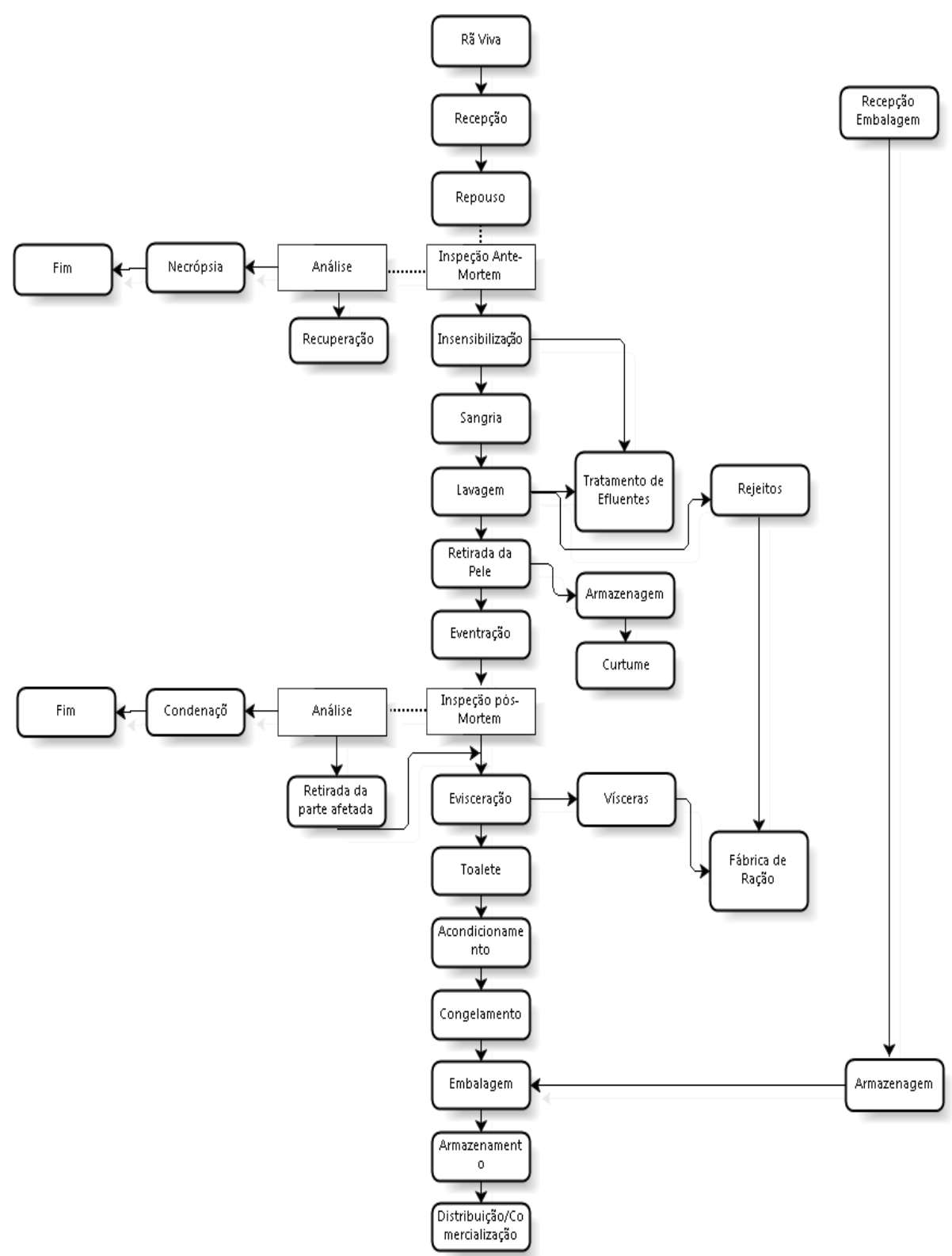

Figura 2: Fluxograma do abate e processamento da rã, elaborado por Donizetti, 1985 e adaptadopelos autores.

RCMOS - Revista Científica Multidisciplinar O Saber. ISSN: 2675-9128. São Paulo, v. 08, p. 01-22, ago. 2021. 
Segundo Donizetti (1985 apud LIMA, 2012) as fases do abate e processamentos da rã são: recepção, repouso, inspeção, insensibilização, sangria, lavagem, retirada da pele, eventração, inspeção pós-mortem, evisceração, toalete, acondicionamento, congelamento, embalagem, armazenamento e distribuição/comercialização.

\subsection{Resultados Financeiros}

Para chegar à viabilidade do Plano foram calculados os itens descritos na tabela 7 :

Tabela 7 - Demonstrativo de resultados

\begin{tabular}{cc}
\hline \multicolumn{2}{c}{ Demonstrativo de resultados } \\
Descrição & Valores (R\$) \\
1. Receita Total com Vendas & $204.163,70$ \\
Custos CMD e/ou CMV & $50.268,97$ \\
Impostos sobre vendas & $12.188,57$ \\
Gastos com vendas & $2.041,64$ \\
Subtotal 2 & $64.499,18$ \\
3. Índice de Margem de contribuição & 0,68 \\
4. Custos Fixos Totais & $20.832,84$ \\
5. CUSTO TOTAL & $\underline{\mathbf{8 4 . 9 5 6 , 3 2}}$
\end{tabular}

A tabela 8 descreve os indicadores de viabilidade (lucro bruto e líquido) ao mês, a lucratividade e rentabilidadeao ano. Além do ponto de equilíbrio e tempo de retorno em anos.

\begin{tabular}{cc} 
Tabela 8 - Indicadores de Viabilidade \\
\hline \multicolumn{2}{c}{ Indicadores de Viabilidade } \\
Descrição & Resultado \\
Lucro Bruto (a.m.) & $\mathrm{R} \$ 133.437,59$ \\
Lucro Líquido (a.m.) & $\mathrm{R} \$ 119.207,38$ \\
Ponto de equilíbrio & $\mathrm{R} \$ 29.904,05$ \\
Lucratividade (a.a.) & $58,39 \%$ \\
Rentabilidade (a.a.) & $30,45 \%$ \\
Tempo de retorno (anos) & $\underline{0,27}$
\end{tabular}

O payback tem como função mostrar o tempo de recuperação do capital investido 
calculado da forma simples, levando em consideração em seu cálculo o valor do dinheiro no tempo. Assim, de acordo com os dados apresentadosna tabela 8, o Tempo de Recuperação do Capital é de 0,27 anos, ou seja, aproximadamente três meses e meio, indicandoo período de tempo que seria necessário para a recuperação do capital investido, o que mostra que o investimento é economicamente viável, com retorno rápido. Na tabela seguinte, observa-se que o projeto se paga no primeiro ano de atividade, com caixa positivo no valor de $\mathrm{R} \$ 1.039 .057,27$ para o próximo ano.

Tabela 9 - Projeção para os próximos anos $(\mathrm{R} \$)$

\begin{tabular}{ccccc}
\hline \multicolumn{5}{c}{ Projeção para os próximos anos (R\$) } \\
\hline Ano & Investimentos & Receita & Despesas & Saldo \\
Ano 0 & $391.431,29$ & $2.449 .964,40$ & $1.019 .475,84$ & $1.039 .057,27$ \\
Ano 1 & - & $2.449 .964,40$ & $1.019 .475,84$ & $1.430 .488,56$ \\
Ano 2 & - & $2.449 .964,40$ & $1.019 .475,84$ & $1.430 .488,56$ \\
Ano 3 & - & $2.449 .964,40$ & $1.019 .475,84$ & $1.430 .488,56$ \\
Ano 4 & - & $2.449 .964,40$ & $1.019 .475,84$ & $1.430 .488,56$ \\
Ano 5 & - & $2.449 .964,40$ & $1.019 .475,84$ & $1.430 .488,56$ \\
& & & & $\mathbf{8 . 1 9 1 . 5 0 0 , 0 7}$
\end{tabular}

Para que o projeto alcance a lucratividade esperada, é preciso que a atividade seja desenvolvida com todo acompanhamento técnico que uma agroindústria exige. Profissionais bem treinados e capacitados a desenvolver a atividade, fornecedores de matéria-prima comprometidos com a qualidade, observando as exigências zootécnicas da produção e manejo do animal são alguns fatores imprescindíveis para o sucesso do empreendimento.

O aproveitamento de 100\% dos animais na atividade de abate é também um dos fatores que elevam a lucratividade. Cuidados especiais ao tirar a pele, condicionamento correto das vísceras, rejeitos e sangue, observando as exigências das indústrias que utilizaram esse material são indispensáveis também, pois desperdícios podem comprometer os lucros.

\section{CONCLUSÕES}

Diante dos resultados obtidos com o estudo, ficou evidenciada a viabilidade econômica do projeto, com retornodo capital investido em, aproximadamente três meses e meio, o que é considerado bastante rápido quando se trata de uma agroindústria.

Observando a grande demanda pela carne de rã, a implantação da agroindústria na região permitiria a expansãoda atividade e conseqüentemente o fortalecimento da cadeia produtiva da carne de rã na região, baseado no fato que muitos produtores afirmaram, em conversa informal 
que não investem na atividade por falta de abatedouro, despontando como mais uma oportunidade de negócio para pequenas e médias propriedades rurais.

Com um investimento relativamente baixo ( $\mathrm{R} \$ 391.431,29)$ e abate de 700 animais/dia é possível a implantação de uma indústria de abate. Além disso, o abatedouro de rã pode ser adaptado para abate de Pescado nas horas ociosas, o que aumentaria ainda mais os lucros da empresa.

\section{BIBLIOGRAFIA}

ASSOCIAÇÃO BRASILEIRA DAS INDÚSTRIAS DA ALIMENTAÇÃO (ABIA). Compêndio de Legislação de Alimentos. Atos do Ministério da Saúde e ANVISA. Revisão no. 9. 3 volumes ou versão eletrônica (CD). São Paulo, ABIA, fevereiro, 2003.

BELTRÃO. K.R.A. Dossiê Técnico - Ranicultura - 2008 - Disponível em http://www.respostatecnica.org.br/dossie- tecnico/downloadsDT/MTA3Ng== Acessado em 13/04/2013.

BRASIL. Ministério da Saúde. Secretaria de Vigilância Sanitária. Portaria no . 326, de 30 de julho de 1997a. Regulamento Técnico sobre as Condições Higiênico-sanitárias e de Boas Práticas de Fabricação para Estabelecimentos produtores/Industrializadores de Alimentos. Diário Oficial União, Brasília, 01 ago. 1997. Seção1.

BRASIL. Ministério da Saúde. Secretaria de Vigilância Sanitária. Portaria no . 368, de 04 de setembro de 1997b. Aprova o regulamento técnico sobre as condições higiênico-sanitárias e de boas práticas de fabricação para estabelecimentos/industrializadores de alimentos. Diário Oficial [da] União, Brasília, 8 set. 1997. Seção 1, p. 19697.

BRASIL. Ministério da Agricultura Pecuária e Abastecimento. Regulamento de Inspeção Industrial e Sanitária de Produtos de Origem Animal (RIISPOA). Diário Oficial da República Federativa do Brasil, Brasília - DF, Decreto no 30.691, de 29 de março de 1952, alterados pelos Decretos $\mathrm{n}^{\mathrm{o}} 1.255$, de 25 de junho de 1962, $\mathrm{n}^{\circ} 1.236$, de 2 de setembro de 1964 e no 1812, de 08 de fevereiro de 1996. p. 11.555, 5 de junho de 1997. Seção 1.

BRASIL 2005 Instrução Normativa 22, de 24 de novembro de 2005, Regulamento Técnico para Rotulagem de Produtos de Origem Animal Embalado. Diário Oficial da República Federativa do Brasil, Brasília - DF - p. 15, 25 de Nov.2005. Seção 1.

BRASIL 2006 Recomendações básicas para a aplicação das boas práticas agropecuárias e de fabricação na agricultura familiar. organizador, Fénelon do Nascimento Neto. - Brasília, DF: Embrapa Informação Tecnológica, 2006. 243 p.

BRASIL 2007 Ministério da Agricultura, Pecuária e Abastecimento. Manual de 
procedimentos para implantação de estabelecimento industrial de pescado: produtos frescos e congelados / Ministério da Agricultura, Pecuária eAbastecimento; Secretaria Especial de Aqüicultura e Pesca - Brasília: MAPA: SEAP/PR, 2007.

CARRARO, K, C. Ranicultura: Um bom negócio que contribui para saúde. Revista da FAE, 2008. Disponível em http://www.unifae.br/publicacoes/pdf/revista_da_fae/fae_v11_n1/10_karen.pdf. Acesso: 26 abr. 2013. 
CASTELLANI D., Situação da Aqüicultura na região do Noroeste do Estado de São Paulo XI Reunião Científica do Instituto de Pesca, abr.2013. São Paulo - Disponível em http://www.pesca.sp.gov.br/11recip2013/resumos/11a_ReCIP_P7_227-229.pdf. Acessado em 25 abr. 2013.

CHITARRA, M.I.F. Processamento mínimo de frutos e hortaliças. Viçosa: CPT, 1998, 88p. (CPT. Agroindústria, manual, 155).

CONCEIÇÃO, C. (2000). Utilização de carne de dorso de rã (Rana catesbeiana, Shaw 1802) no desenvolvimento de um produto alimentício. [Dissertação de Mestrado]. Rio de Janeiro (RJ): Universidade Federal Rural do Rio de Janeiro.

CODEX ALIMENTARIUS 1984 - Recommended International code of hygienic practive for the processing of frong legs. Rome FAO.

CODEX ALIMENTARIUS 2003 - Higiene dos Alimentos - Programa conjunto da FAO/OMS sobre normas Alimentares - 2003. Roma. Disponível em http://www.anvisa.gov.br/divulga/public/alimentos/codex_alimentarius.pdf. Acessado em 3005-2013

CORREAA, C.L. Como montar e operar uma pequena fábrica de chocolate. Viçosa: CPT, 1999. $44 \mathrm{p}$.

FAO Fishery and Aquaculture Statistics. 2008/FAO annuaire. Rome: FAO, 2010.

FEIX, R. D; ABDALLAH, P. R; FIGUEIREDO, M. R. C. 2006 Resultado econômico da criação de rã em regiões declima temperado, Brasil. Informações Econômicas, v.36, n.3, p.70-80.

FERREIRA, C.M. 2002 I Ciclo de Palestras sobre Ranicultura do Instituto de pesca. Boletim Técnico de Pesca, 31, 49p.

FERREIRA. C., F., \& FONTANELlO, D. 2011 Histórico da Ranicultura Nacional Disponível emhttp://www.aquicultura.br/historico.htm. Acessado em 25-03-2013

FRAGOSO, S.P., MOURA; O. M., CASALI; A. P., COSTA, A. R.; PEREIRA, R.F. 2012 Características Físico - químicas da carne de rã Touro (Lithobatescatesbeianus) Liofilizada. 2012 Disponível em http://www.cbcta45.net.br/cd/Resumos/ResumoCBCTA_622.pdf . Acessado em 16-05-2013.

LIMA, S.,L. Criação de Rãs - Novas Tecnologias - CPT- Centro de Produção Técnica Viçosa - p. 198, 188 -2012.

LIMA, S. L. , CRUZ, T. A. 1999 - Canais de Comercialização. Disponível em http://www.ufv.br/dta/ran/mercado.htm . Acessado em 16-04-2013.

LIMA, S.L. e AGOSTINHO, C.A. 1988 Sistema Anfigranja de criação de rãs. In: ENCONTRO NACIONAL DE RANICULTURA, 6, 1988, Rio de Janeiro, RJ. Anais...Rio de Janeiro: Associação de Ranicultores do Estado do Rio de Janeiro (ARERJ): 29-34 
LIMA, S. L. . Manejo de anfigranja. Viçosa (MG): CPT, 2004.

LIMA, S.S.; CRUZ, T.A.; MOURA, 0.M. 1999. Ranicultura: Análise da cadeia produtiva. Ed. Folha de Viçosa, Viçosa, 172 p.

LOPERA-BARRERO, N.M.; RIBEIRO, R.P.; POVH, J.A.; MENDEZ, L.D.V.; POVEDA-PARRA, A.R.; DIGMAYER, M. As principais espécies produzidas no Brasil. In: LOPERA-BARRERO, N.M. RIBEIRO, R.P.; POVH, J.A.; MENDEZ, L.D.V.; POVEDAPARRA, A.R. (Org.). Produção de organismos aquáticos: uma visão no Brasil e no mundo. Guaíba: Agrolivros, 2010. p. 143-203.

KATO, M. T. (1982) Estudo e tratamento de águas residuárias de abatedouros de aves. São Carlos. 262pp.Dissertação (Mestrado) - Escola de Engenharia de São Carlos, Universidade de São Paulo.

KOHLER, A. Criação de rã, 2010. Disponível em http://www.apostilasgratuitas.info/apostilas/criacao-de-aves/395-criacao-de-ras. Acessado em 15-04-2012.

MOURA, O.M. Características físico-químicas da carne de rã-touro, Rana catesbeiana. 1999. 102f. Teses.(Doutorado em Ciência e Tecnologia de Alimentos), Universidade Federal de Viçosa, 102 p. 1999.

NEGRINI, M. Revista Brasileira de Agropecuária. v.1, 2001.

NÓBREGA, I. C. C.; ATAÍDE, C. S.; MOURA, O. M.; LIVERA, A. V.; MENEZES, P. H. Volatile constituents of cooked bullfrog (Rana catesbeiana) legs. Food Chemistry, v.102, p. 186-191, 2007.

OLIVEIRA, T. C.; MEZENCIO, J. M. S.; COSTA, N. M. B.; PELUCIO, M. do C. G.; MATTA, S.L. P.; BRESSAN, J. Influência Do tratamento térmico sobre o perfil eletroforético da carne de rã (RANA CATESBEIANA). Disponível em http://www.revistanutrire.org.br/articles/view/id/4fabc35c1 eflfa074f000006 acessado em 26 abr. 2013.

OSTRENSKY, A.; BORGHETTI, J.R.; SOTO, D. Aqüicultura no Brasil: o desafio é crescer. Brasília, DF: SEAP,2008.

RODRIGUES, E.; GROOTENBOER, C.S.; MELlO, S.C.R.P.; CASTAGNA, A. A. Alimentos - Manual de Boas Práticas de Fabricação. Niterói - p. 7 . Jul. 2010.

SANDRONI, P. Dicionário de Economia. São Paulo: Abril Cultural, 1985.

SEBRAE, 2009 - Série Perfil de projetos para Ranicultura. Disponível em http://201.2.114.147/bds/BDS.nsf/40B4F0F3B9AD7533832574360059981C/\$File/Ranicultur a.pdf . Acessado em 16-05-2013.

TIAGO, G. G; GIANESELLA, S. M. F. Uso da água pela aquicultura: estratégias e ferramentas de implementaçãode gestão. Boletim do Instituto de Pesca, v. 29, n.1, p. 1-7, 2003.

RCMOS - Revista Científica Multidisciplinar O Saber. ISSN: 2675-9128. São Paulo, v. 08, p. 01-22, ago. 2021. 
TIAGO, G. G. Ementário da Legislação de Aquicultura e Pesca do Brasil. 2 ed. São Paulo: Gláucio Gonçalves Tiago (Editor), 2010. 95 p.

VELLY, M. L. M. 2001. A pele animal e os comportamentos mercadológicos para o novo milênio. I Ciclo dePalestras Sobre Ranicultura do Instituto de Pesca. Boletim Técnico do Instituto de Pesca. São Paulo, 2001, 31, 49 p.

VIZOTTO, L.D. Ranicultura brasileira. Boletim da Associação Nacional de Ranicultura, n. 4, 1975. 